Mineração de estruturas musicais e composição automática utilizando redes complexas

\author{
Andrés Eduardo Coca Salazar
}





\title{
Mineração de estruturas musicais e composição automática utilizando redes complexas
}

\author{
Andrés Eduardo Coca Salazar
}

Orientador: Prof. Dr. Zhao Liang

Tese apresentada ao Instituto de Ciências Matemáticas e de Computação - ICMC-USP, como parte dos requisitos para obtenção do título de Doutor em Ciências - Ciências de Computação e Matemática Computacional. VERSÃO REVISADA

USP - São Carlos

Maio de 2015 
Ficha catalográfica elaborada pela Biblioteca Prof. Achille Bassi e Seção Técnica de Informática, ICMC/USP, com os dados fornecidos pelo(a) autor(a)

Coca Salazar, Andrés Eduardo
Mineraça de estruturas musicais e composição
automática utilizando redes complexas / Andrés
Eduardo Coca Salazar; orientador Zhao Liang. -- São
Carlos, 2015.
171 p.
Tese (Doutorado - Programa de Pós-Graduação em
Ciências de Computação e Matemática Computacional) --
Instituto de Ciências Matemáticas e de Computação,
Universidade de São Paulo, 2015.
1. redes neurais artificiais. 2. detecção de
comunidades. 3. mineração de dados. 4. gêneros
musicais. 5. sistemas dinâmicos caóticos. I. Liang,
Zhao, orient. II. Título.


A meus pais,

Luis Fernando e Deyanid. 


\section{Agradecimentos}

Meu profundo agradecimento ao meu orientador o Prof. Dr. Zhao Liang pelas recomendações, paciência e ajudas prestadas durante o desenvolvimento da tese; à agência de fomento $\mathrm{CAPES}^{1}$ pelo apoio financeiro recebido e a Daiana Ellen Canato por todo o amor, carinho, apoio e compreensão.

Um especial agradecimento ao Prof. Dr. Emmanuel Vincent e Prof. Dr. Frédéric Bimbot do grupo de pesquisa METISS do INRIA da Universidade de Rennes 1 na França, pelo convite, parceria, e colaboração durante o meu estágio de pesquisa nessa universidade; e à Sra. Mariannick D. Laurent, pelo recebimento, atenção, orientação e amizade durante minha estadia em Rennes.

Agradeço também ao pessoal do laboratório de Computação Bioinspirada (BioCom), especialmente a Bilzã Araújo, Filipi Neto Verri, Paulo Andretta Jaskowiak, Danilo Horta, Thiago Cupertino e Lilian Berton, pela resolução de dúvidas e colaborações eventuais; e à Prof. ${ }^{a}$ Dr. ${ }^{a}$ Roseli A. Francelin Romero, que me motivou a publicar os primeiros resultados desta tese e à minha colega Dr. ${ }^{a}$ Débora Cristina Corrêa por alguns dos tópicos que inspiraram esta pesquisa e pelo trabalho em coautoria; por fim, também agradeço a Julio César Herrera (Don Julio), César Vera Casañas, José Valencia Alvites, Patricia Moreira, Josiane Silva, Maria Gonçalves, Vilma Santos, Elaine Cristina Santos, Luz Adriana Muñoz, Lina Johana Palermo, Jessica Bueso, Li Weiwei, Yorladis Castillo, Deyanira Montes, Ana Tereza Costa, Nayara Cavalcante, María Elvira Prieto, Liliana Maria Gonzales, Yorladys Palermo Neira, Marlene Zanfirow, Rita Castro, Paul Bustios e Luis Alberto Rosero, pela amizade, a companhia e os momentos vividos.

\footnotetext{
${ }^{1}$ O presente trabalho foi realizado com apoio do Programa Estudantes-Convênio de PósGraduação - PEC-PG, da CAPES/CNPq - Brasil
} 


\section{Resumo}

teoria das redes complexas tem se tornado cada vez mais em uma
poderosa teoria computacional capaz de representar, caracterizar e
examinar sistemas com estrutura não trivial, revelando características intrínsecas locais e globais que facilitam a compreensão do comportamento e da dinâmica de tais sistemas. Nesta tese são exploradas as vantagens das redes complexas na resolução de problemas relacionados com tarefas do âmbito musical, especificamente, são estudadas três abordagens: reconhecimento de padrões, mineração e síntese de músicas. A primeira abordagem é desempenhada através do desenvolvimento de um método para a extração do padrão rítmico de uma peça musical de caráter popular. Nesse tipo de peças coexistem diferentes espécies de padrões rítmicos, os quais configuram uma hierarquia que é determinada por aspectos funcionais dentro da base rítmica. Os padrões rítmicos principais são caracterizados por sua maior incidência dentro do discurso musical, propriedade que é refletida na formação de comunidades dentro da rede. Técnicas de detecção de comunidades são aplicadas na extração dos padrões rítmicos, e uma medida para diferenciar os padrões principais dos secundários é proposta. Os resultados mostram que a qualidade da extração é sensivel ao algoritmo de detecção, ao modo de representação do ritmo e ao tratamento dado às linhas de percussão na hora de gerar a rede. Uma fase de mineração foi desempenhada usando medidas topológicas sobre a rede obtida após a remoção dos padrões secundários. Técnicas de aprendizado supervisionado e não-supervisionado foram aplicadas para discriminar o gênero musical segundo os atributos calculados na fase de mineração. Os resultados revelam a eficiência da metodologia proposta, a qual foi constatada através de um teste de significância estatística. A última abordagem foi tratada mediante o desenvolvimento de modelos para a composição de melodias através de duas perspectivas, na primeira perspectiva é usada uma caminhada controlada por critérios sobre redes complexas predefinidas e na segunda redes neurais recorrentes e sistemas dinâmicos caóticos. 
Nesta última perspectiva, o modelo é treinado para compor uma melodia com um valor preestabelecido de alguma característica tonal subjetiva através de uma estratégia de controle proporcional que modifica a complexidade de uma melodia caótica, melodia que atua como entrada de inspiração da rede. 


\section{Abstract}

$\mathrm{T}$ he theory of complex networks has become increasingly a powerful computational tool capable of representing, characterizing and examining systems with non-trivial structure, revealing both local and global intrinsic structures that facilitate the understanding of the behavior and dynamics of such systems. In this thesis, the virtues of complex networks in solving problems related to tasks within the musical scope are explored. Specifically, three approaches are studied: pattern recognition, data mining, and synthesis. The first perspective is addressed by developing a method for extracting the rhythmic pattern of a piece of popular music. In that type of musical pieces, there coexist different types of rhythm patterns which constitute a hierarchy determined by functional aspects within the basic rhythm. The main rhythmic patterns are characterized by a higher incidence within the musical discourse and this factor is reflected in the formation of communities within the network constructed from the music piece. Community detection techniques are applied in the extraction of rhythmic patterns, and a measure to distinguish the main patterns of the secondary is proposed. The results showed that the quality of extraction is sensitive to the detection algorithm, the method of representing rhythm, and treatment of percussion lines when generating the network. Data mining is performed using topological measures over the network obtained after the removal of secondary patterns. Techniques of supervised and unsupervised learning are applied to discriminate the musical genre according to the attributes calculated in the data mining phase. The quantitative results show the efficiency of the proposed methodology, which is confirmed by a test of statistical significance. Regarding the melody generation, an algorithm using a walk controlled by criteria on predefined complex networks has been developed, as well as the development of melody composition models using recurrent neural networks and chaotic dynamical systems. In the last approach, the model is trained to compose a melody with a subjective characteristic melodic value pre-established by a proportional control 
strategy that acts on the parameters of a chaotic melody as input inspiration. 


\section{Sumário}

Resumo

ix

Abstract $\quad$ xi

Sumário $\quad$ xiii

Lista de Figuras . . . . . . . . . . . . . . . . xv

Lista de Tabelas . . . . . . . . . . . . . . . . . . . xxi

Lista de Algoritmos . . . . . . . . . . . . . . . xxv

1 Introdução 1

1.1 Motivações ....................... 4

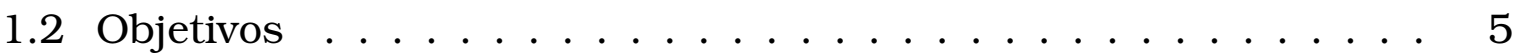

1.3 Organização do Documento ............... 6

2 Fundamentos Teóricos $\quad 9$

2.1 Redes Complexas . . . . . . . . . . . . . . . . . . . . 9

2.1.1 Medidas Topológicas de Redes Complexas . . . . . . . . . 10

2.1.2 Tipos de Redes . . . . . . . . . . . . . . 18

2.1.3 Detecção de Comunidades . . . . . . . . . . . . . . 19

2.2 Sistemas Dinâmicos Caóticos e Redes Neurais Recorrentes . . . . 24

2.2.1 Sistemas Dinâmicos Caóticos . . . . . . . . . . . 24

2.2.2 Redes Neurais Recorrentes . . . . . . . . . . . . 26

2.3 Aprendizado Supervisionado e Não-Supervisionado . . . . . . . . 33

2.3.1 Técnicas de Reamostragem . . . . . . . . . . . . . . . . . . 39

2.3.2 Medidas de Desempenho . . . . . . . . . . . . . . . . 40

2.3.3 Métricas para Comparação de Agrupamentos . . . . . . . . 44

2.4 Medidas Musicais . . . . . . . . . . . . . . . . 46

2.4.1 Medidas para Quantificar Escalas Musicais . . . . . . . 46

2.4.2 Medidas para Quantificar Melodias . . . . . . . . . . . 47

2.5 Considerações Finais . . . . . . . . . . . . . . . . . 49 
3 Composição Automática de Estruturas Musicais Usando Redes Complexas e Redes Neurais Recorrentes $\quad \mathbf{5 1}$

3.1 Modelo Baseado em Redes Complexas Predefinidas . . . . . . . . 52

3.1 .1 Descrição do Modelo . . . . . . . . . . . . . . . 52

3.1.2 Simulações Computacionais . . . . . . . . . . . 58

3.2 Metodologia Baseada em Redes Neurais Recorrentes e Inspiração

Caótica ......................... 63

3.2.1 Descrição do Modelo . . . . . . . . . . . . . . . 65

3.2.2 Simulações Computacionais . . . . . . . . . . . 70

3.3 Considerações Finais . . . . . . . . . . . . . . . 78

4 Extração do Padrão Rítmico e Identificação de Gêneros Musicais 81

4.1 Sumarização e Extração do Padrão Rítmico . . . . . . . . . . . . . 82

4.1 .1 Descrição do Modelo . . . . . . . . . . . . . . 82

4.1.2 Simulações Computacionais . . . . . . . . . . . . . . 92

4.2 Identificação do Gênero Musical . . . . . . . . . . . . . . . . . 104

4.2.1 Descrição do Modelo . . . . . . . . . . . . . . . 104

4.2.2 Simulações Computacionais . . . . . . . . . . . 111

4.3 Considerações Finais . . . . . . . . . . . . . . . . 127

5 Conclusões $\quad 131$

5.1 Principais Contribuições . . . . . . . . . . . . . . 132

5.2 Trabalhos Futuros . . . . . . . . . . . . . 133

A Algoritmos de Codificação e Decodificação de Objetos Musicais 135

A. 1 Células Rítmicas . . . . . . . . . . . . . . . . . . . 135

A.1.1 Algoritmo Codificador . . . . . . . . . . . . . . 136

A.1.2 Algoritmo Decodificador . . . . . . . . . . . . . . . 140

A.2 Escalas Musicais . . . . . . . . . . . . . . . . . . 142

A.2.1 Algoritmo Codificador . . . . . . . . . . . . . . . . . 142

A.2.2 Algoritmo Decodificador . . . . . . . . . . . . . . 145

B Notação Musical $\quad \mathbf{1 5 1}$

B. 1 Notação de Altura . . . . . . . . . . . . . . . . . . 151

B.2 Notação de Duração . . . . . . . . . . . . . . . . . 155

B.3 Notação de Bateria . . . . . . . . . . . . . . . 157

C Lista de Amostras do Banco de Dados de Músicas Folclóricas $\quad 159$

$\begin{array}{ll}\text { Referências Bibliográficas } & 171\end{array}$ 


\section{Lista de Figuras}

2.1 Tipos de triângulos em redes direcionadas: (a) Ciclo; (b) Intermediário; (c) Entrada; (d) Saída. . . . . . . . . . . . . . . . . . . 15

2.2 Modelos de redes complexas. (a) Regular; (b) Pequeno mundo; (c) Aleatória; (d) Livre de escala. . . . . . . . . . . . . . . . . 20

2.3 Rede complexa com estrutura de comunidade. . . . . . . . . 21

2.4 Comunidades detectadas pelo algoritmo de otimização de modularidade. (a) Rede com 3 comunidades; (b) Dendrograma. . . . . . 22

2.5 Diagrama de bifurcação do mapa logístico. . . . . . . . . . . 25

2.6 Rede neural recorrente com uma entrada, uma saída e dois neurônios na única camada oculta. Adaptado de (Haykin, 1999). . . . . 26

2.7 Desdobramento temporal da rede RNN da Fig. 2.6 no decorrer de três épocas. Adaptado de (Haykin, 1999). . . . . . . . . . . . . . 28

2.8 Arquiterura de RNNs. (a) RNN com uma camada oculta; (b) Rede LSTM como blocos de memória na camada oculta (somente um bloco de memória é mostrado). Adaptado de (Gers, 2001). . . . . . 29

2.9 Bloco de memória com uma célula de memória. Adaptado de (Gers, 2001). . . . . . . . . . . . . . 30

2.10 Problema de agrupamento com 5 amostras. (a) Pontos no espaço bidimensional; (b) Dendrograma. . . . . . . . . . . . 36

3.1 Valor da média da porcentagem de similaridade harmônica (MPHS) de cada uma das 927 escalas secundárias. A linha sólida é o valor de MPHS da escala maior igual a 39.45 . . . . . . . . . . . . . 59

3.2 Valor do grau de uniformidade (DEV) de cada uma das 123 escalas primárias. A linha sólida é o valor de DEV da escala maior igual

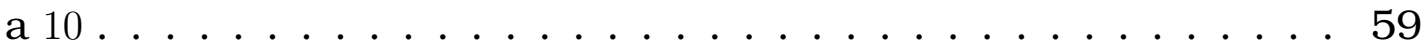


3.3 Média normalizada do grau de uniformidade e da média da porcentagem de similaridade harmônica $(\Phi)$ de cada uma das 927 escalas secundárias. A linha sólida é o valor de $\Phi$ da escala maior igual a 0.873 . . . . . . . . . . . . . . . . . . . . 60

3.4 Melodia composta usando caminhada aleatória na rede regular. . 62

3.5 Melodia composta usando caminhada aleatória na rede de pequeno mundo. . . . . . . . . . . . . . . . 62

3.6 Melodia composta usando caminhada aleatória na rede aleatória de Erdős-Rényi. . . . . . . . . . . . . . . . . . 63

3.7 Rede complexa livre de escala escolhida para composição musical e a sua distribuição de grau. . . . . . . . . . . . . . . . . . 63

3.8 Resultado usando a rede livre de escala e caminhada regida pela força máxima.

3.9 Interface do modelo de composição de melodias com redes complexas predefinidas e sistema de decodificação de escalas. . . . .

3.10 Rede neural recorrente com entrada de inspiração caótica (Coca et al., 2011). . . . . . . . . . . . . . . . . . 67

3.11 Rede LSTM com inspiração caótica (Coca et al., 2013). . . . . . . . 69

3.12 Diagrama do sistema de composição de melodias com valor predefinido de subjetividade melódica (Coca et al., 2013). . . . . . . .

3.13 Compassos do segundo movimento das quatro estações de Vivaldi. 71

3.14 Melodia composta pela RNN sem notas de inspiração caótica. . 71

3.15 Melodia composta pela RNN com 4 notas de inspiração caótica. . 71

3.16Complexidade da melodia de treino e das melodias compostas pela RNN sem notas de inspiração e com $j(1 \leq j \leq 20)$ notas de inspiração caótica. . . . . . . . . . . . . . . 73

3.17 Originalidade melódica da melodia de treino e das melodias compostas pela RNN sem notas de inspiração e com $j(1 \leq j \leq 20)$ notas de inspiração caótica. . . . . . . . . . . . . . 73

3.18Similaridade tonal entre a melodia de treino e a melodia composta pela RNN sem notas de inspiração caótica. . . . . . . . . . . 74

3.19Similaridade rítmica entre a melodia de treino e a melodia composta pela RNN sem notas de inspiração caótica. . . . . . . . . . . 74

3.20 Originalidade melódica vs. taxa de aprendizado. . . . . . . . . 75

3.21 Diagrama de bifurcação do mapa de Hénon. . . . . . . . . . . . . 76

3.22 Complexidade tonal das melodias geradas como o mapa de Hénon. 76

3.23Região ascendente da complexidade tonal das melodias geradas como o mapa de Hénon. . . . . . . . . . . . . . . 76

3.24 Compassos da sonata para piano No. 16 em C maior K. 545 de W.A. Mozart (pentagrama superior da partitura para piano). . . . 
3.25 Grau de melodiosidade da melodia composta pela rede LSTM variando o parâmetro $a$ do mapa de Hénon. . . . . . . . . . . . . . . 77

3.26 Evolução do parâmetro $a$ do mapa de Hénon até atingir o valor predefinido de melodiosidade igual a 5. . . . . . . . . . . . 78

3.27 Melodia com grau de melodiosidade igual a 5 composta pelo modelo de composição baseado na rede LSTM com entrada de inspiração caótica.

4.1 Diagrama de blocos do método proposto para a extração do padrão rítmico.

4.2 Vetor de representação de (a) uma Célula Rítmica Primária (CRP) e (b) as suas Células Rítmicas Secundárias (CRSs) com $n=4$. . . 84

4.3 Fragmento rítmico com repetição de frases e uma ponte. . . . . . 88

4.4 Dígrafos do fragmento rítmico da Fig. 4.3. (a) Usando Figuras Rítmicas Individuais (FRIs); (b) Usando CRs. As comunidades estão destacadas. . . . . . . . . . . . . . . . . . 89

4.5 Partitura de bateria de From me to you de The Beatles. . . . . . . . 92

4.6 Dígrafo da percussão de From me to you usando FRIs e concatenação horizontal $\left(\mathbf{R}_{0}\right)$.

4.7 Dígrafos das linhas de percussão de From me to you. (a) Linha superior $\left(\mathbf{R}_{1}\right)$; (b) Linha intermediária $\left(\mathbf{R}_{2}\right)$; (c) Linha inferior $\left(\mathbf{R}_{3}\right)$.

4.8 Dígrafo das três linhas de percussão de From me to you concatenadas horizontalmente $\left(\mathbf{R}_{4}\right)$.

4.9 Dígrafo das três linhas de percussão de From me to you concatenadas verticalmente $\left(\mathbf{R}_{5}\right) \ldots \ldots . \ldots 96$

4.10 Comunidades detectadas com o algoritmo de Louvain para o dígrafo $R_{5} \ldots \ldots \ldots$. . . . . . . . . . . . . 96

4.11 Métricas índice corrigido de Rand (ARI) e informação mútua normalizada (NMI) das comunidades detectadas pelo algoritmo de Otimização de Modularidade (OM) e de Louvain para $\mathbf{R}_{5}$. . . . . . 99

4.12 Partitura do padrão rítmico extraído do dígrafo $R_{5}$. . . . . . . . . . 99

4.13Valor de pertinência dos nós das comunidades detectadas pelo algoritmo BNMF. . . . . . . . . . . . . . . 100

4.14 Valor de pertinência dos nós comuns entre as comunidades detectadas pelo algoritmo BNMF. . . . . . . . . . . . 101

4.15Índice ômega e informação mútua normalizada generalizada (GNMI) das comunidades detectadas para $\mathbf{R}_{5}$ com o algoritmo BNMF. . . 101

4.16 Comunidades detectadas com o algoritmo de Louvain para a rede formada pelas 20 canções da Tabela 4.12. . . . . . . . . . . 103

4.17 Padrão rítmico que sumariza o gênero musical do conjunto de canções de The Beatles listadas na Tabela 4.12. . . . . . . . . . . 104 
4.18Diagrama de blocos da metodologia para a identificação de gêneros musicais baseada em redes complexas. . . . . . . . . . 106

4.19Reduções realizadas na extração da estrutura rítmica. (a) Redução de acordes; (b) Redução de retardos; (c) Redução de ornamentos. . . . . . . . . . . . . . . . . . . . . . 109

4.20 Exemplos de dígrafos da base de dados de três gêneros do folclore andino colombiano. (a) Pasillo - Hacia el calvario de Carlos Vieco; (b) Bambuco - Cuatro preguntas de Pedro Morales Pino; (c) Danza - Malvaloca de Luis A. Calvo. . . . . . . . . . . . . . . . . . . . . . 109

4.21 Partitura de bateria da canção Is This Love de Bob Marley. . . . . 111

4.22 Dígrafos de exemplos do banco de dados de quatro gêneros populares. (a) Blues - The Thrill Is Gone de BB King; (b) Bossa Nova Fotografia de Tom Jobim; (c) Reggae - Is This Love de Bob Marley; (d) Rock - From Me to You de The Beatles. . . . . . . . . . . . . . 112

4.23 Máximo valor de relevância das amostras do banco de dados de músicas folclóricas. . . . . . . . . . . . . . . . . . . . . 114

4.24 As novas três características obtidas com PCA para a metodologia C8. (a) primeira vs. segunda componente; (b) primeira vs. terceira componente; (c) porcentagem de variância acumulada e explicada. . . . . . . . . . . . . . . . . 116

4.25Evolução da rede e da acurácia quando variado o limiar de relevância na metodologia C8 usando o banco de dados de músicas folclóricas. (a) Número de CRs; (b) Número de nós; (c) Evolução da acurácia média usando o conjunto DGO; (d) Evolução da acurácia média usando o conjunto DGCO . . . . . . . . . . . 117

4.26Resultado obtido com o algoritmo de seleção sequencial de características (SFS). (a) Porcentagem de seleção de cada medida; (b) Média e desvio do critério de seleção; (c) Evolução da acurácia média usando as características encontradas. . . . . . . . . . . . . 119

4.27 Dendrograma obtido com o agrupamento hierárquico aglomerativo usando a metodologia $\mathrm{C} 8$ e o banco de dados de músicas folclóricas. (a) Dendrograma completo; (b) Dendrograma do agrupamento 1; (c) Dendrograma do agrupamento 2; (d) Dendrograma do agrupamento $3 \ldots \ldots$. . . . . . . . . . . . . . 123

4.28 Acurácia total e ARI usando aprendizado não-supervisionado. . 124

4.29 Máximo valor de relevância das amostras do banco de dados de músicas populares. . . . . . . . . . . . . . . 125 
4.30 Evolução da rede e da acurácia quando variado o limiar de relevância na metodologia $\mathrm{C} 8$ usando o banco de dados de músicas populares. (a) Número de CRs; (b) Número de nós; (c) Evolução da acurácia média usando o conjunto DGCO . . . . . . . . . 126

4.31 Dendrograma obtido com o agrupamento hierárquico aglomerativo usando a metodologia $\mathrm{C} 8$ e o banco de dados de músicas populares. . . . . . . . . . . . . . . . . 127

A. 1 Diagrama de blocos do codificador de células rítmicas. . . . . . 140

A.2 Diagrama de blocos do decodificador de células rítmicas. . . . . . 142

A.3 Diagrama de blocos do algoritmo (a) codificador e (b) decodificador de células rítmicas. . . . . . . . . . . . . . . . . . . . . 149

A.4 Diagrama de blocos do algoritmo de validação da estrutura da escala. . . . . . . . . . . . . . . . . 150

B.1 Pentagrama musical incluindo (a) linhas, espaços, linhas suplementares, claves e as notas musicais com os seus respectivos intervalos e nomes; (b) Armaduras com sustenidos e bemóis. . . . 155

B.2 Série dos harmônicos. . . . . . . . . . . . . . . . . . . . . . 155

B.3 Nomes, símbolos e valores das figuras rítmicas e das pausas. . . 157

B.4 Instrumentos musicais que compõem a bateria. O identificador (Id.) relaciona o instrumento com o nome e o número MIDI da

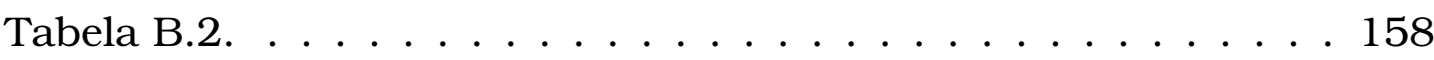

B.5 Notação musical dos instrumentos que compõem a bateria. $\mathrm{O}$ identificador (Id.) relaciona a notação do instrumento com o nome e o número MIDI da Tabela B.2 . . . . . . . . . . . . . 158 


\section{Lista de Tabelas}

2.1 Matriz de confusão multiclasse. . . . . . . . . . . . . . . . 40

2.2 Taxas de desempenho para avaliar a performance de um classificador. . . . . . . . . . . . . . . . . . 42

2.3 Interpretação subjetiva do coeficiente $\kappa$ (Landis \& Koch, 1977). . 43

3.1 Critérios para a seleção do próximo nó (nota da melodia) do algoritmo de composição baseado em redes complexas predefinidas. . 53

3.2 Total de escalas do sistema $N$-TET para diferentes valores de $N$ (valores apróximados en notação científica). . . . . . . . . . . 55

3.3 Código de algumas escalas selecionadas e o seu número de Forte ( $x$ significa qualquer valor de tônica entre 0 e 11 ). . . . . . . 57

3.4 Códigos e medidas das 21 escalas com melhores valores da média normalizada entre o grau de uniformidade e a média da porcentagem de similaridade harmônica $(\Phi) \ldots \ldots \ldots$. . . . . . . 60

3.5 Escala usada na composição com redes complexas predefinidas. 61

3.6 Melodiosidade das melodias geradas usando todas as opções possíveis de executar o modelo de composição baseado em redes complexas predefinidas, a escala maior e a nova escala com có-

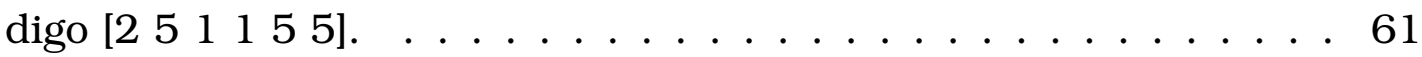

3.7 Complexidade (CMe) e originalidade (OMe) das melodias compostas pela RNN com $j(0 \leq j \leq 10)$ notas de inspiração caótica. . . . 72

3.8 Similaridade tonal e rítmica entre a melodia de treino e a melodia composta pela RNN com $j(0 \leq j \leq 10)$ notas de inspiração caótica. 72

4.1 Notação Binária (NB) de todas as Células Rítmicas Primárias (CRPs) e o seu equivalente decimal $\Delta_{p}$, Combinatória das Ligaduras Possiveis (CLPs), Notação de Durações Ponderadas (NDP) e ordem lexicográfica $\left(\Delta_{s}\right)$ de todas as Células Rítmicas Secundárias (CRSs) $\operatorname{com} n=4 \ldots \ldots \ldots \ldots \ldots \ldots$ 
4.2 Vetor de código das CRPs e CRSs da quarta divisão da figura de mínima (d).

4.3 Diferenças entre os dígrafos criados com Figuras Rítmicas Individuais (FRIs) e com Células Rítmicas (CRs). . . . . . . . . . . . . . 88

4.4 Partes e pontes rítmicas da canção From me to you e algumas características básicas: Extensão em Batidas (EB), Quantidade de CRs (QCRs) e ranking de relevância estimado $(\hat{\Lambda})$. . . . . . . . . 93

4.5 Comunidades detectadas com o algoritmo de otimicação de modularidade para os dígrafos $R_{0}$ a $R_{5}$. . . . . . . . . . . . . 95

4.6 Comunidades detectadas com o algoritmo de Louvain para os dígrafos $\mathbf{R}_{0}$ a $\mathbf{R}_{5} \ldots \ldots \ldots \ldots 6$

4.7 Relevância das comunidades detectadas com o algoritmo de otimização de modularidade para os dígrafos $R_{0}$ a $R_{5}$. . . . . . . . 97

4.8 Relevância das comunidades detectadas com o algoritmo Louvain

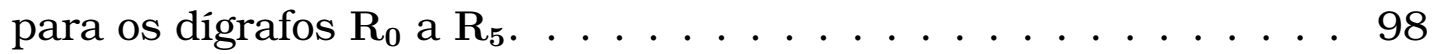

4.9 Nós do dígrafo $R_{5}$ que formam cada parte da canção From me to

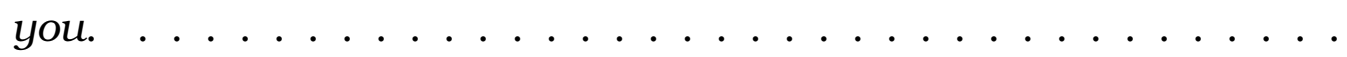

4.10Valores de relevância e comunidades detectadas com o algoritmo BNMF para o dígrafo $R_{5} \ldots \ldots \ldots 100$

4.11 Nós das Comunidade Mais Relevantes (NCMR), valor de relevância e partitura do Padrão Rítmico de Bateria Extraído (PRBE) para as músicas da Tabela 4.12. . . . . . . . . . . . . . . . . . . . . . 102

4.12 Conjunto de canções de The Beatles usadas para extração do padrão rítmico e sumarização rítmica.

4.13 Padrões rítmicos e variações dos gêneros pasillo, bambuco e danza. 108

4.14 Metodologias para a identificação de gêneros musicais resultantes da ausência (0) ou presença (1) de CRs, relevância de comunidades e medidas topológicas de redes complexas. . . . . . . . . 113

4.15 Porcentagem de acurácia inicial, máxima, diferença de acurácia (Dif.) e número de nós usando a metodologia $\mathrm{C} 8$, todas as combinações de conjuntos de características e o banco de dados de músicas folclóricas. . . . . . . . . . . . . . . . . . . 118

4.16 Coeficiente kappa $(\kappa)$, variância de kappa (var $(\kappa))$ e porcentagem de acurácia (Ac.) usando resubstituição e validação cruzada 10fold.

4.17 Coeficiente kappa ( $\kappa)$, variância de kappa (var $(\kappa)$ ) e porcentagem de acurácia (Ac.) usando hold-out e variando a porcentagem de amostras do conjunto de treino entre $30 \%$ e $90 \%$. . . . . . . . . 120

4.18 Matriz de confusão das metodologias C6 e C8 usando resubstituição. 
4.19Taxas de desempenho das duas metodologias de análise usando

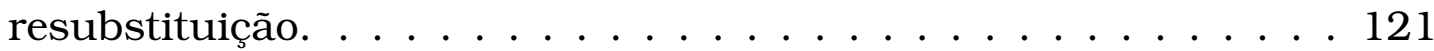

4.20Tabela de contingência obtida com o agrupamento hierárquico aglomerativo e as duas metodologias de análise. . . . . . . . . . 122

4.21 Tabela de contingência com os índices das amostras dentro de cada agrupamento obtida com o algoritmo de agrupamento hierárquico aglomerativo, o banco de dados de músicas folclóricas e a metodologia C8. . . . . . . . . . . . . . . . . . . . . 124

4.22 Porcentagem de acurácia inicial e máxima, e diferença de acurácia absoluta (Dif.) e em porcentagem (Dif.(\%)) usando a metodologia C8, a combinação DCGO e o banco de dados de músicas populares. . . . . . . . . . . . . . . . . . . 125

4.23Tabela de contingência obtida com o algoritmo de agrupamento hierárquico aglomerativo, o banco de dados de músicas populares e a metodologia $\mathrm{C} 8 . \ldots \ldots \ldots \ldots \ldots$

A. 1 Valores de algumas variáveis usadas pelo codificador de escalas quando aplicado a escalas com estrutura $u=\{s, t, 0\}$. Número de notas $(n)$, número de tons $(t)$, número de semitons $(s)$, grupo $(g)$, vetor com o total de escalas primárias E, vetor com o total de escalas secundárias $\mathrm{M}$ e total de escalas secundárias $(P R) \ldots$. . 146

A.2 Valores de algumas variáveis usadas pelo codificador de escalas quando aplicado a escalas com estrutura $u=\left\{s, t, t_{m}\right\}$. Número de notas $(n)$, número de tons e meio $\left(t_{m}\right)$, número de tons $(t)$, número de semitons $(s)$, grupo $(g)$, vetor com o total de escalas primárias $\mathrm{E}$, vetor com o total de escalas secundárias $\mathrm{M}$ e total de escalas secundárias $(P R) . \ldots \ldots$. . . . . . . . . . . . . . 146

B.1 Razões de frequência (R. freq.) dos intervalos da serie harmônica. 156

B.2 Instrumentos musicais que compõem a bateria e os seus respectivos nomes e números MIDI.

C.1 Lista de amostras do banco de dados de três gêneros da região andina colombiana: Pasillo, Bambuco e Danza. . . . . . . . . . . . 159 


\section{Lista de Algoritmos}

1 Pseudocódigo para calcular de um vetor binário o tamanho dos blocos de 1's consecutivos e o seu índice inicial e final . . . . . . . 139 
xxvi 


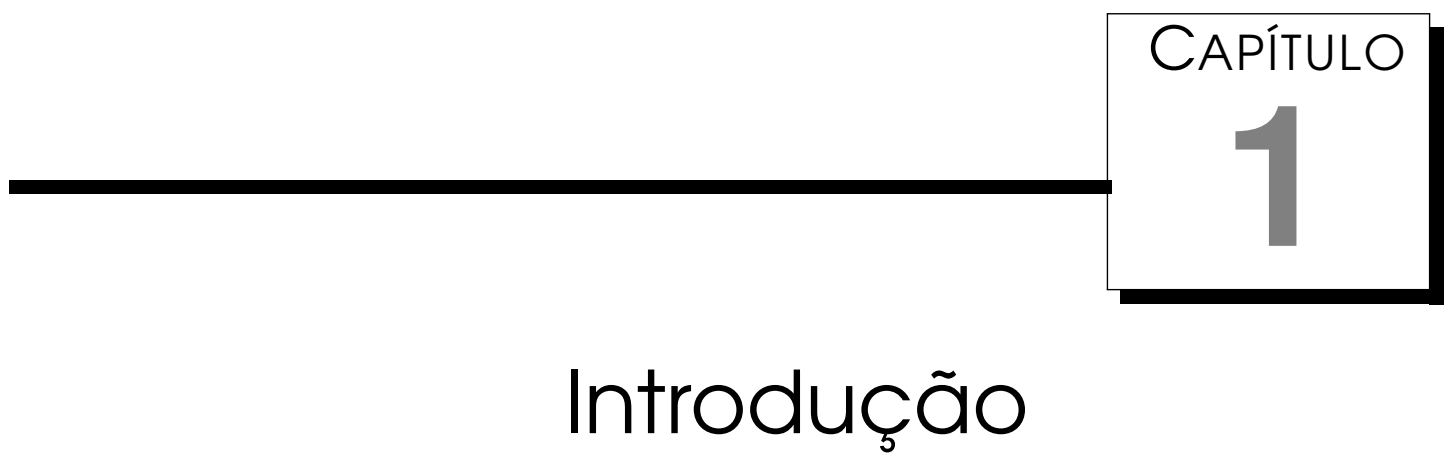

rápida evolução das técnicas de processamento e aquisição de dados 1 digitais tem incrementado enormemente o tamanho das bases de da1 dos e diversificado o seu conteúdo. A divulgação de amostras digitais em sites especializados e em redes sociais de Internet favoreceu a expansão destas, fazendo com que a organização e classificação de grandes volumes de informação se torna-se iminente. Para extrair, analisar e organizar de maneira eficiente e automática a informação contida nos bancos de dados, técnicas de aprendizado de máquina e reconhecimento de padrões têm sido aplicadas para extrair conhecimento em diversas áreas, dentro das quais podem ser citadas: telecomunicações (Hatonen et al., 1996), medicina (Roddick \& Fule, 2003), biologia (Brusic \& Zeleznikow, 1999) e música (Eck, 2012).

No contexto musical, uma nova área de pesquisa, chamada Recuperação de Informação Musical (MIR ${ }^{1}$ ), estuda o desenvolvimento de técnicas para analisar, organizar, sintetizar ou extrair informação musical (Rás \& Wieczorkowska, 2010). Um tópico específico estudado via MIR é a classificação de gêneros musicais, para o qual muitos métodos têm sido propostos na literatura (Sturm, 2012). Segundo o tipo de dados usado para representar uma música, os métodos de classificação de gêneros podem ser divididos nas seguintes categorias: (1) métodos baseados no sinal acústico de áudio (Tzanetakis \& Cook, 2002), (2) métodos baseados na informação contida na partitura (Kotsifakos et al., 2013), a qual é representada por dados simbólicos como arquivos MIDI; (3) métodos que usam informação tanto acústica quanto simbólica (McKay et al., 2010) e (4) métodos que usam outro tipo de dados, por exemplo, informação sobre a lírica (McKay et al., 2010) ou o âmbito cultural (Abeßer et al.,

\footnotetext{
${ }^{1}$ Sigla de Music Information Retrieval
} 
2010). A exploração em dados simbólicos é uma característica saliente, já que permite realizar análises nas peças musicais antes de serem gravadas, ocupa um tamanho digital bem menor e, por estar relacionada diretamente com a partitura, indica os valores de todos os eventos que descrevem as peças. No entanto, apesar da exploração em dados simbólicos ser promissora, a maior parte das pesquisas sobre classificação de gêneros musicais realizadas até a presente data encontra-se na primeira categoria e, consequentemente, a maioria dos bancos de dados públicos contém amostras de áudio ou características acústicas (Sturm, 2012). Além disso, a maioria dos métodos propostos na literatura considera toda a informação musical com igual relevância para classificação, fato que contrasta com a teoria musical, já que nem toda a informação musical contida nas amostras é relevante para discriminar o gênero musical.

Da mesma forma, a tarefa de extração de conhecimento musical também é um importante objetivo que tem sido estudado em diversas tarefas de MIR, sendo um componente importante e de grande interesse em muitos tópicos o ritmo musical, uma vez que este participa na descrição do caráter e na transmissão de emoção de uma peça. Devido a sua importância, muitos pesquisadores têm concentrado seus esforços na extração do ritmo, pois é útil em tarefas como análise (Akhtaruzzaman et al., 2008), caracterização (Qian et al., 2010) e classificação de gêneros musicais (Peeters, 2005). Para esta última, vários autores têm focalizado seu estudo na extração de padrões rítmicos, já que os gêneros musicais, principalmente os gêneros populares, apoiam as características próprias do gênero em padrões rítmicos repetitivos e predefinidos. De fato, algumas pesquisas relacionadas com a identificação do gênero musical usam sequências rítmicas executadas por instrumentos de percussão (Völkel et al., 2010), padrões melódicos (Conklin, 2009)(Karydis et al., 2006), caracterização de padrões repetitivos significativos (Lin et al., 2004) ou padrões de linhas de contrabaixo (Abeßer et al., 2012)(Simsekli, 2010). Cabe ressaltar que uma etapa fundamental para atingir bons resultados em aplicações baseadas no ritmo é a sua notação e representação, devido ao fato de que a correta representação do ritmo define a qualidade do resultado final da tarefa principal. Portanto, considerar um sistema de representação adequado para o ritmo, que seja fiel à teoria musical e que facilite o manuseio computacional, se mostra promissor.

Uma proeminente área de pesquisa conhecida como teoria de redes comple$\mathrm{xas}^{2}$, a qual estuda as redes que modelam sistemas complexos e que possuem uma topologia não trivial (Brandes \& Erlebach, 2005), vem sendo aplicada com sucesso em tarefas de aprendizado de máquina como extração de conhe-

\footnotetext{
${ }^{2}$ Nesta tese os termos rede e grafo são considerados intercambiáveis
} 
cimento (Zanin et al., 2013), mineração (Deyi et al., 2005) e classificação de dados (Backesa et al., 2013). O fato da teoria de redes complexas envolverem vários ramos da ciência levou à consolidação da mesma e a tornou uma técnica multidisciplinar de alta abrangência (Bornholdt \& Schuster, 2003). Alguns dos estudos sobre redes incluem a Internet (Faloutsos et al., 1999), redes organizacionais ou de negócios entre companhias (Ritter et al., 2004), relações sociais (Scott, 2000) e de gêneros humanos (Ibarra, 2001), redes étnicas transnacionais (Hsu, 2009) e redes de conhecimento (Schuller \& Theisens, 2010), dentre outros. A teoria de redes complexas é vista hoje como uma poderosa técnica de computação pelo fato de facilitar o estudo de sistemas complexos a partir da análise local e global de suas interconexões (Bornholdt \& Schuster, 2003). Este fato explica o surgimento de muitas aplicações em diversas áreas, dentro das quais podem ser encontradas: ciência da computação, matemática, física, biologia, sociologia (Brandes \& Erlebach, 2005) e música (Liu et al., 2010). Alguns exemplos de aplicação em música são a análise de estruturas musicais contidas nas obras de compositores clássicos e populares (Liu et al., 2010), a composição de novas estruturas (Yang et al., 2009) e a classificação de gêneros musicais (Corrêa et al., 2010). Um problema comum nos trabalhos anteriores é que os silêncios são desconsiderados e que o ritmo é representado usando figuras rítmicas individuais, pois tradicionalmente o ritmo tem sido representado assim, até mesmo usando outras técnicas, por exemplo, o gerador de melodias caóticas de Coca et al. (2010) e o algoritmo de composição probabilístico de Kim \& Yeo (2013). Este fato leva consigo uma perda de informação relevante e desperdiça a função hierárquica das figuras musicais. Portanto, uma representação do ritmo mais fiel aos dados musicais, diferente da simples figuração das durações de maneira individual, proporcionaria melhores resultados e seria mais adequada em tarefas de extração de conhecimento, classificação e composição.

No que diz respeito à composição automática de música usando redes complexas (Liu et al., 2009), esta pode ser considerada como uma abordagem interessante que consegue conservar a assinatura do compositor e a essência original da música. No entanto, esta vantagem se torna uma limitante à hora de gerar melodias inovadoras, já que as conexões são fixas e carecem de elementos de memória, características fundamentais para uma estratégia de inovação. Portanto, métodos baseados em redes neurais com elementos de recorrência e memória, como redes de Elman e LSTM ${ }^{3}$, têm se mostrado atrativos para tal fim (Eck \& Schmidhuber, 2002).

Nesta pesquisa são estudadas três abordagens das redes complexas na solução de tarefas do âmbito musical, sendo estas: mineração, reconhecimento

\footnotetext{
${ }^{3}$ Sigla de Long-Short Term Memory
} 
de padrões e síntese de estruturas musicais. Os problemas descritos acima são tratados através do estudo e desenvolvimento de métodos mais apropriados para a representação do ritmo e de técnicas para a depuração de dados, visando o aprimoramento de técnicas de identificação de gêneros musicais, extração de padrões rítmicos e composição musical.

\subsection{Motivações}

A teoria de redes complexas tem demonstrado ser uma teoria versátil que permite uma representação consistente e rápida de sistemas complexos através da interconexão dos seus elementos. Esta representação revela informação relacional que seria difícil de extrair por outro meio. O fato da teoria de redes ter se tornado multidisciplinar fez com que o leque de medidas topológicas fosse enriquecido com medidas de diferentes tipos e inspiradas em problemas de diferentes áreas. As vantagens da teoria das redes fazem com que seja um mecanismo atraente e motivador para abordar problemas de pesquisa relacionados com música. Como consequência, pesquisas relacionadas com informação musical usando redes complexas têm emergido na última década, por exemplo, um sistema de recomendação automática de música e de predição de gostos musicais (Buldúl et al., 2007), comunidades de redes de colaboração entre artistas musicais (Teitelbaum et al., 2008), análises de redes de canções da Música Popular Brasileira (MPB) (Lima et al., 2004), detecção de padrões dinâmicos repetidos em enlaces harmônicos (Itzkovitz et al., 2006), sintese musical (McCormack et al., 2007)(Liu et al., 2010), classificação de gêneros (Corrêa et al., 2010, 2011) e análises de melodias (Wang \& Wei, 2014). Uma característica comum destas últimas pesquisas é a geração das redes usando figuras rítmicas individuais, que embora eficiente em alguns casos, tem várias lacunas que afetam a qualidade da representação dos dados, limitação que é refletida no resultado do objetivo final.

Um método de classificação de gêneros musicais baseado em redes complexas foi proposto em (Corrêa et al., 2010). Este método usa uma taxonomia de quatro gêneros musicais, cujas instâncias são descritas através da base rítmica percussiva da bateria. Cada amostra é representada mediante um dígrafo, onde um nó é uma figura rítmica e uma aresta representa a conexão entre duas figuras rítmicas consecutivas, desconsiderando os silêncios e a hierarquia das figuras dentro de cada batida. Devido ao fato da bateria ser composta por vários instrumentos, além de instrumentos de percussão adicionais, várias linhas rítmicas podem ser encontradas em uma amostra. Portanto, a fim de obter um único vetor rítmico, nessa pesquisa as durações

de todas as linhas foram misturadas, desconsiderando as diferenças entre os 
instrumentos que conformam a bateria e a informação de início dos eventos. Além disso, essa mistura elimina a informação de simultaneidade temporal das linhas percussivas, considerando os diferentes instrumentos que conformam a percussão como um único instrumento. A partir desse vetor rítmico é gerado o dígrafo para cada instância, o qual é usado como vetor de atributos do sistema de reconhecimento de gêneros. À vista do anterior, o método para a geração desse dígrafo apresenta vários problemas que terminam afetando o desempenho do classificador. Não obstante, algumas vantagens dessa metodologia podem ser apontadas. De acordo com os resultados, essa metodologia tem um desempenho aceitável segundo o coeficiente kappa ${ }^{4}$, permite a extensão a tarefas de classificação multiclasse e facilita a identificação das sequências de pares de notas que mais contribuem para a representação e separação das classes. As particularidades promissoras dessa proposta e as suas desvantagens solúveis motivaram a presente pesquisa, de tal forma que fosse possível aprimorá-la conservando as vantagens e restringindo as desvantagens. Portanto, nesta tese essa abordagem foi estudada com o intuito de aperfeiçoá-la e estendê-la a outras aplicações musicais.

\subsection{Objetivos}

O objetivo principal desta pesquisa é desenvolver novas metodologias para a composição, extração e identificação de estruturas musicais usando redes complexas.

Para tanto, dentro da perspectiva de síntese de dados musicais com redes complexas, primeiro foram estudados e adaptados algoritmos de composição automática de melodias baseados em redes complexas, especificamente, o método proposto por Liu et al. (2009), o qual gera novas melodias a partir de uma melodia conhecida usando uma caminhada controlada sobre os nós da rede. Porém, nesta tese, para não ficar confinado na essência da melodia original, foram explorados algoritmos de composição usando redes complexas predefinidas e foram estendidos os critérios para controlar a caminhada. Além disso, visando obter maior controle sobre a variabilidade melódica, também foram exploradas as redes neurais recorrentes em combinação com sistemas caóticos e foi estendido o leque de escalas de maneira sistemática.

$\mathrm{Na}$ aproximação de reconhecimento de padrões com redes complexas, inicialmente foram estudados métodos para a notação matemática do ritmo musical, onde foram escolhidos os métodos de representação que cumpriam com as especificações do problema e foi desenvolvido um algoritmo para codificar o vetor de notação a fim de lidar com a variabilidade dimensional. Este avanço

\footnotetext{
${ }^{4}$ Medida estatística de associação usada para descrever o grau de concordância entre dois agrupamentos
} 
permitiu representar bem o ritmo musical e facilitou o desenvolvimento de um modelo para extrair todos os padrões rítmicos de uma música, tanto principais quanto secundários, com alta precisão. Em vista do alto desempenho obtido com o modelo de extração, este foi aplicado no desenvolvimento de uma nova metodologia de reconhecimento de gêneros musicais. A metodologia desenvolvida tem como novidade que ao poderem ser extraídos todos os padrões rítmicos, somente os principais são usados na etapa de mineração, já que são os mais discriminativos do gênero musical. A etapa de mineração foi desempenhada através de medidas topológicas de redes complexas, concretizando desta forma a última abordagem das redes complexas na solução de tarefas do âmbito musical.

\subsection{Organização do Documento}

A organização da presente tese é a seguinte:

- Capítulo 2: Apresenta de forma concisa os principais fundamentos teóricos necessários para o desenvolvimento desta pesquisa. A primeira seção descreve tópicos relacionados com a teoria de redes complexas, tais como medidas topológicas, tipos de redes e técnicas de detecção de comunidades. Na seção seguinte é descrita a fundamentação teórica das redes neurais recorrentes, bem como uma breve descrição sobre sistemas dinâmicos caóticos. O capítulo finaliza com uma revisão sobre técnicas de aprendizado supervisionado e não-supervisionado e medidas de desempenho, assim como com os conceitos básicos das medidas musicais usadas para avaliar as melodias compostas pelos modelos de composição propostos;

- Capítulo 3: Apresenta o desenvolvimento e os resultados de simulação de três modelos para a composição automática de melodias, dois modelos baseados em redes neurais recorrentes e um baseado em caminhada controlada por critérios sobre redes complexas predefinidas;

- Capítulo 4: Apresenta o método proposto para extração do padrão rítmico usando detecção de comunidades em redes complexas e a sua aplicação no desenvolvimento de uma metodologia para a identificação de gêneros musicais;

- Capítulo 5: Discute as principais conclusões desta pesquisa e são sugeridas atividades para trabalhos futuros;

- Apêndices: Como elementos adicionais da tese, na parte final são apresentados três apêndices. O primeiro apresenta os algoritmos desenvolvi- 
dos para codificar e decodificar objetos musicais, especificamente, células rítmicas e escalas musicais. O segundo descreve brevemente os conceitos sobre teoria e notação musical necessários para o entendimento dos tópicos tratados na presente pesquisa. Por fim, o terceiro contém uma tabela com a lista das amostras do banco de dados de músicas folclóricas que foi criado para testar a metodologia de identificação de gêneros musicais proposta nesta tese. 


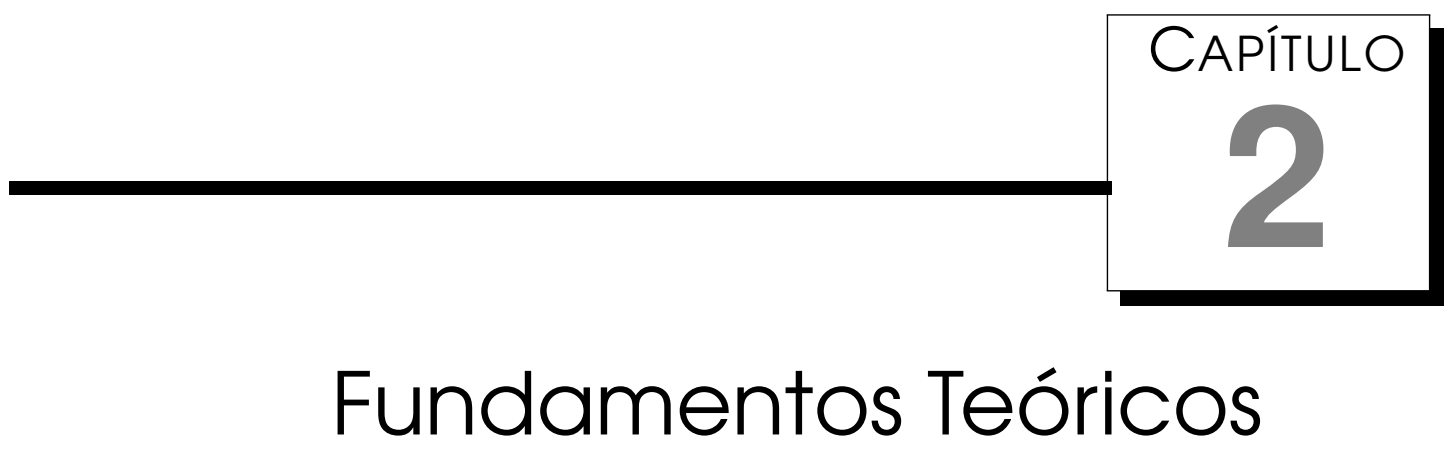

$\mathrm{N}$ este capítulo são descritos os conceitos e as técnicas mais relevantes que dão suporte ao desenvolvimento desta tese. A Seção 2.1 contém uma revisão sobre a teoria de redes complexas, incluindo medidas topológicas, tipos de redes e detecção de comunidades. Na Seção 2.2, alguns conceitos sobre sistemas dinâmicos caóticos e redes neurais recorrentes são apresentados. A Seção 2.3 faz uma revisão sobre aprendizado supervisionado e não-supervisionado. Por fim, na Seção 2.4, as medidas musicais usadas para avaliar as características das melodias compostas pelos modelos desenvolvidos são descritas.

\subsection{Redes Complexas}

Inúmeros fenômenos com estrutura de rede podem ser encontrados na natureza, sendo uma característica comum dessas redes a sua complexidade estrutural, característica que tem despertado um grande interesse pelo estudo, a compreensão e a modelagem de tais fenômenos. Com o avanço da matemática, especificamente, a teoria de grafos, e com a evolução da tecnologia, estas estruturas foram melhor compreendidas e a teoria de redes complexas cimentou-se como uma teoria vasta e abrangente, abrangência que abarca vários campos da ciência (Bornholdt \& Schuster, 2003). Dentro das muitas áreas de atuação da teoria de redes podem ser citadas: biologia (Montoya \& Solé, 2002; Sporns, 2002), administração (Ritter et al., 2004), ciência sociais (Hsu, 2009; Schuller \& Theisens, 2010; Ibarra, 2001) e computação (Faloutsos et al., 1999; Albert et al., 1999). Esta característica multidisciplinar justifica-se pela facilidade que proveem as redes na compreensão de sistemas 
complexos através das interconexões locais e globais dos elementos de uma maneira independente dos dados (Albert \& Barabási, 2002).

\subsubsection{Medidas Topológicas de Redes Complexas}

Uma rede $G$ é um par de conjuntos $N$ e $M$, denotada como $G(N, M)$, onde $N$ é um conjunto de nós (vértices) e $M$ é um conjunto de arestas (enlaces) que conectam dois elementos de $N$. O número total de nós é denotado como $n \mathrm{e}$ o número total de arestas como $m$. Os valores $n$ e $m$ são características globais da rede (Brandes \& Erlebach, 2005). Uma rede pode ser completamente descrita mediante a matriz de adjacência $\mathbf{A}_{n \times n}$, cuja entrada $a_{i j}(i, j=1, \ldots, n)$ é igual a 1 se existir uma aresta entre os nós $i$ e $j$, e zero no caso contrário. Este valor define dois tipos de redes, as redes binárias ou não ponderadas e as redes ponderadas. O primeiro caso corresponde às redes que têm somente conexões com valores de 0 ou 1. Em uma rede ponderada, na matriz de adjacência $\mathbf{W}$, o elemento $w_{i j}$, chamado peso da aresta, pode ter um valor diferente de 1 ou 0 . Ademais, as redes podem ser direcionadas e não direcionadas. Em uma rede direcionada (dígrafo) cada aresta tem um sentido (direção) que conecta um vértice origem a um vértice destino. Neste caso, a matriz de adjacência não é simétrica dado que um peso da conexão do nó $i$ ao nó $j$ pode não existir na direção contrária. Além disso, um dígrafo pode ser cíclico se houver um caminho de um nó para ele mesmo, ou acíclico quando não existir tal caminho (Metz et al., 2007).

Após ter a rede construída, a qual é uma abstração dos dados obtidos para um problema em particular, é de grande interesse extrair informação a partir desta para posteriormente realizar análises ou inferir conclusões relacionadas com o problema de estudo. Para isso, são calculadas diversas medidas que quantificam a estrutura da rede e que ajudam a compreender melhor o comportamento dos dados (Bornholdt \& Schuster, 2003; Albert \& Barabási, 2002; Newman, 2003b; Rubinov \& Sporns, 2010). No que segue são apresentadas as medidas topológicas que foram usadas na etapa de mineração ${ }^{1}$ da metodologia de identificação de gêneros musicais proposta na presente tese. As medidas são agrupadas de acordo com a classificação usada por Rubinov \& Sporns (2010), a qual compreende medidas básicas, de integração, segregação, resiliência e centralidade.

\section{Medidas Básicas}

Fazendo uso das características globais $n$ e $m$, pode ser quantificada a densidade da rede (Wasserman \& Katherine, 1994), que indica quão conectada

\footnotetext{
${ }^{1}$ Processo que consiste em extrair características de um conjunto de dados visando a procura de padrões (Deyi et al., 2005)
} 
a rede está, permitindo classificar as redes em densas e esparsas. A densidade é definida como a fração de conexões presentes com relação ao total de conexões possíveis. Para uma rede não direcionada, a densidade é dada por: $2 m /\left(n^{2}-n\right)$; e para uma rede direcionada é calculada como: $m /\left(n^{2}-n\right)$. A densidade cai na faixa de 0 a 1 , sendo 1 a densidade máxima, correspondendo à densidade de uma rede totalmente conectada.

A mais importante quantidade local da rede é o grau do nó $\left(k_{i}\right)$, o qual define o número de enlaces conectados ao nó $i$, que para uma rede binária não direcionada é calculado como (Costa et al., 2005):

$$
k_{i}=\sum_{j} a_{i j}=\sum_{j} a_{j i}
$$

Vale ressaltar que o grau do nó é uma medida local, para quantificar a rede toda em termos do grau é usado o grau médio da rede, que é a média de todos os graus da rede, e a qual é calculada como:

$$
\bar{k}=\frac{1}{n} \sum_{i} k_{i}=\frac{1}{n} \sum_{i j} a_{i j} .
$$

Para uma rede direcionada, três casos são possíveis quando considerado o sentido das arestas, podendo ser estes: grau de entrada, grau de saída e grau total. O grau de entrada $k_{i}^{i n}$ contabiliza unicamente as arestas que entram ao

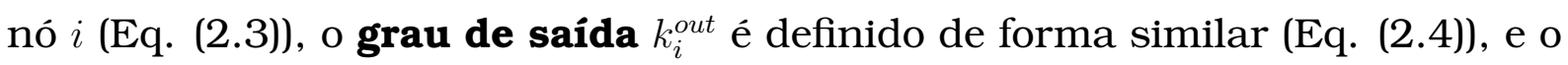
grau total de um nó é a soma dos graus de entrada e saída (Eq. (2.5)).

$$
\begin{aligned}
k_{i}^{\text {in }} & =\sum_{j} a_{j i}, \\
k_{i}^{\text {out }} & =\sum_{j} a_{i j}, \\
k_{i}=k_{i}^{\text {out }}+k_{i}^{\text {in }} & =\sum_{j} a_{i j}+\sum_{j} a_{j i} .
\end{aligned}
$$

O grau médio de uma rede direcionada é definido de maneira semelhante, no entanto, neste caso o grau médio de entrada e de saída são iguais, isto é:

$$
\bar{k}^{\text {in }}=\bar{k}^{\text {out }}=\frac{1}{n} \sum_{i j} a_{i j} .
$$

A definição equivalente a grau em redes ponderadas é a força do nó $\left(s_{i}\right)$, que é a soma dos pesos das arestas conectadas ao nó $i$ (Brandes \& Erlebach, 2005). O conceito de força para redes ponderadas e direcionadas é semelhante ao de redes direcionadas binárias, porém, neste caso, deve-se considerar no 
cálculo a direção e o peso da aresta, por exemplo, a força total do nó $i$ é:

$$
s_{i}=s_{i}^{o u t}+s_{i}^{i n}=\sum_{j} w_{i j}+\sum_{j} w_{j i}
$$

Medidas de Integração

A medida de distância é uma importante característica que depende da estrutura da rede. A distância geodésica entre os nós $i$ e $j$, denotada como $d_{i j}$, é igual ao número de arestas do menor caminho existente entre esses nós. Para uma rede ponderada será necessário incluir os pesos dentro dos cálculos (Costa et al., 2005). Existem diversas medidas que utilizam a distância para quantificar características específicas da rede, a mais básica delas é o Índice de Wiener (IW), que é definido como a somatória das distâncias de todos os caminhos mínimos (Brandes \& Erlebach, 2005). Outra medida desta categoria é a distância média ( $\lambda$ ), que é o valor médio das distâncias geodésicas e é calculada da seguinte forma:

$$
\lambda=\frac{1}{n(n-1)} \sum_{i \neq j \in N} d_{i j} .
$$

Um problema desta medida é sua divergência para redes desconexas, dado que nesse caso a distância geodésica é infinita. Este problema pode ser evitado computando só os pares de nós conectados, porém é introduzida uma distorção se a rede tiver muitos pares de nós desconexos, obtendo assim, um valor pequeno de distância média, que é o valor esperado para redes com um número grande de enlaces (Costa et al., 2005). A eficiência global $(E)$ quantifica a eficiência da rede para enviar informação entre nós, considerando que enviar informação entre dois nós $i$ e $j$ é inversamente proporcional à distância (Albert et al., 1999). A equação para o cálculo de $E$ é similar à Eq. (2.8), mas substituindo $d_{i j}$ por $d_{i j}^{-1}$. A média harmônica (h), que é o recíproco da eficiência global, isto é, $h=\frac{1}{E}$, não apresenta o problema de divergência que apresenta $\lambda$, sendo assim, mais apropriada para redes com mais de um nó desconexo (Costa et al., 2005). Outra medida baseada na distância é a excentricidade, a qual determina uma localização que minimiza a distância máxima com relação a outras localizações. A excentricidade do nó $i(e(i))$ é o maior caminho mínimo entre qualquer nó e o nó $i$, isto é: $e(i)=\max \left\{d_{i j}: i \in N\right\}$. O mínimo de todos os valores de $e(i)$ é conhecido como raio $(r)$ e o maior caminho mínimo de todos os nós da rede, isto é, o máximo valor de excentricidade, é o diâmetro $(\Delta)$ (Albert et al., 1999). 
Maior informação sobre o comportamento dos graus é capturada mediante a distribuição probabilistica de graus, $P(k)$, a qual indica a probabilidade de um nó escolhido aleatoriamente ter grau $k$ (Strogatz, 2001). Para uma rede aleatória a distribuição de graus tem uma distribuição de Poisson (Erdős \& Rényi, 1959). A distribuição de graus de redes ponderadas segue uma definição semelhante, porém usando a força do nó em vez do grau e tomando neste caso o nome de distribuição de forças. Esta distribuição compreende a probabilidade $P(s)$ de escolher aleatoriamente um nó com força $s$. Nas redes direcionadas três tipos de distribuição diferentes podem ser calculadas, sendo estas: distribuição de grau de entrada $P\left(k^{i n}\right)$, de saída $P\left(k^{\text {out }}\right)$ e total $P(k)$. Todas estas distribuições podem ser representada em coordenadas logarítmicas, e para quantificar o nível de aproximação dos dados no plano é usado o coeficiente de Pearson. O coeficiente de correlação de Pearson $(\rho)$ quantifica a tendência na rede de nós de um dado grau conectarem nós de grau semelhante e é calculado da seguinte maneira (Costa et al., 2005):

$$
\rho=\frac{(1 / m) \sum_{j>i} k_{i} k_{j} a_{i j}-\left[(1 / m) \sum_{j>i}(1 / 2)\left(k_{i}+k_{j}\right) a_{i j}\right]^{2}}{(1 / m) \sum_{j>i}(1 / 2)\left(k_{i}^{2}+k_{j}^{2}\right) a_{i j}-\left[(1 / m) \sum_{j>i}(1 / 2)\left(k_{i}+k_{j}\right) a_{i j}\right]^{2}} .
$$

O coeficiente de Pearson é interpretado assim: $\rho>0$ indica maior tendência de conexão entre nós como alto grau (rede assortativa), $\rho<0$ indica que nós com alto grau tendem a conectar nós com baixo grau (rede dissortativa) e $\rho=0$ indica inexistência de correlação entre os graus.

Outra distribuição probabilística relacionada com os graus é a distribuição conjunta de graus, a qual relaciona o grau de dois nós diretamente conectados, ao contrário da anterior distribuição que só considera um único nó. A probabilidade de grau de dois nós vizinhos diretos é expressa mediante a probabilidade $P\left(k, k^{\prime}\right)$, a qual proporciona a probabilidade de escolher aleatoriamente uma aresta ligando dois nós com grau $k$ e $k^{\prime}$ cada um. Para redes ponderadas e/ou direcionadas são aplicáveis as mesmas observações da distribuição conjunta de graus, mas ao se considerar o sentido da aresta quatro casos são possíveis, sendo estes: distribuição conjunta de entrada-entrada $P\left(k^{i n}, k^{i n}\right)$, entrada-saída $P\left(k^{\text {in }}, k^{\text {out }}\right)$, saída-entrada $P\left(k^{\text {out }}, k^{\text {in }}\right)$ e saída-saída $P\left(k^{\text {out }}, k^{\text {out }}\right)$. Por outro lado, pelo fato da distribuição de graus ser difícil de avaliar experimentalmente, consequência do tamanho finito da rede e de ser o resultado de pequenas amostras de nós com alto grau, prefere-se computar a média dos graus dos vizinhos mais próximos a um dado nó com grau $k$, a 
qual é dada por (Costa et al., 2005):

$$
\bar{k}_{n n}(k)=\sum_{k^{\prime}} k^{\prime} P\left(k^{\prime} \mid k\right)
$$

Esta distribuição pode ser interpretada de forma semelhante à distribuição de graus, onde uma rede assortativa terá uma função crescente de $\bar{k}_{n n}(k) \mathrm{e}$ uma dissortativa uma função decrescente.

\section{Medidas de Segregação}

Dentro da estrutura da rede podem ser encontrados agrupamentos intrínsecos triplos, os quais ocorrem quando um nó $A$ está conectado com um nó $B$ e este, por sua vez, está conectado com um nó $C$. Então é muito provável que o nó $A$ esteja conectado também com o nó $C$, criando assim um triângulo (Brandes \& Erlebach, 2005). Esse tipo de conexão é conhecido como transitividade e é quantificado pelo coeficiente de aglomeração ou coeficiente de clustering. O coeficiente de aglomeração global é definido como a fração entre todos os triângulos da rede e o número total de possiveis triângulos que poderiam ser formados, e é obtido a partir da seguinte equação:

$$
C=\frac{3 \cdot N_{\Delta}}{N_{3}}
$$

onde $N_{\Delta}$ refere-se ao número de triângulos na rede, dado por $\sum_{k>j>i} a_{i j} a_{i k} a_{j k}$, e $N_{3}$ representa o número de conexões triplas, calculado como: $\sum_{k>j>i}^{k>j>i}\left(a_{i j} a_{i k}+a_{j i} a_{j k}+\right.$ $\left.a_{k i} a_{k j}\right)$. A diferença entre um triângulo e uma conexão tripla é que um triângulo é uma conexão entre três nós com arestas entre cada par de nós, enquanto a conexão tripla só tem arestas entre dois pares de nós com um nó comum ou central. O coeficiente de aglomeração da rede também pode ser representado da seguinte maneira:

$$
C=\frac{1}{n} \sum_{i \in N} C_{i}=\frac{1}{n} \sum_{i \in N} \frac{2 t_{i}}{k_{i}\left(k_{i}-1\right)},
$$

em que $C_{i}$ é o coeficiente de aglomeração do nó $i$ escrito em termos de $t_{i}$, que é igual a (1/2) $\sum_{j, k \in N} a_{i j} a_{i k} a_{j k}$ (Costa et al., 2005). A expressão do coeficiente de aglomeração local para redes ponderadas é dada pela seguinte equação:

$$
C_{i}^{w}=\frac{1}{s_{i}\left(k_{i}-1\right)} \sum_{k>j} \frac{w_{i j}+w_{i k}}{2} \cdot a_{i j} a_{i k} a_{j k},
$$

onde $s_{i}$ é a força do nó e $w_{i j}$ são as entradas da matriz de adjacência ponderada $\left(\mathbf{W}_{n \times n}\right)$. O coeficiente de aglomeração local para redes direcionadas e ponderadas é definido de forma semelhante, mas considerando o sentido e o 
peso das arestas (Fagiolo, 2007). A equação para o cálculo deste coeficiente é:

$$
\tilde{C}_{i}^{D}(\mathbf{W})=\frac{\left[\hat{\mathbf{W}}+\hat{\mathbf{W}}^{T}\right]_{i i}^{3}}{2\left[k_{i}\left(k_{i}-1\right)-2 d_{i}^{\leftrightarrow}\right]},
$$

onde $d^{\leftrightarrow}=\sum_{j \neq i} a_{i j} a_{j i}=A_{i i}^{2}$ e $\hat{\mathbf{W}}$ é a matriz resultante de $\mathbf{W}^{1 / 3}=\left[w_{i j}^{1 / 3}\right]$. No entanto, a definição do coeficiente de aglomeração da Eq. (2.14) não diferencia o tipo de triângulo conectado ao nó $i$ segundo a direção das arestas, uma vez que dentro de uma rede direcionada podem ser encontrados 8 tipos de triângulos diferentes dependendo da direção das arestas ligadas ao nó $i$ e da direção da aresta entre os nós que formam triângulo com o nó $i$, conforme mostrado na Fig. 2.1.

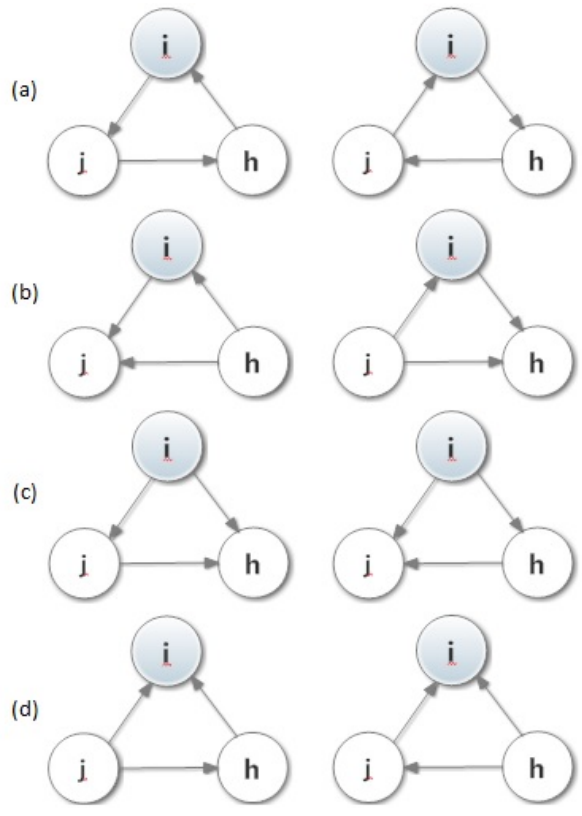

Figura 2.1: Tipos de triângulos em redes direcionadas: (a) Ciclo; (b) Intermediário; (c) Entrada; (d) Saída.

A definição dos quatro tipos de triângulos mostrados na figura anterior são (Tabak et al., 2011):

- Aglomeração de ciclos: Na qual o nó $i$ forma uma relação cíclica com os seus vizinhos seguindo um sentido horário ou anti-horário (Fig. 2.1(a)), sendo esta calculada como:

$$
\tilde{C}_{i}^{c y c}=\frac{[\hat{\mathbf{W}}]_{i i}^{3}}{k_{i}^{\text {in }} k_{i}^{\text {out }}-d_{i}^{\leftrightarrow}} .
$$

- Aglomeração intermediária: Considera o caso quando os vizinhos que formam triângulo com o nó $i$ têm grau 2, uma conexão de entrada e outra 
de saîda (Fig. 2.1(b)), e é calculada como:

$$
\tilde{C}_{i}^{\text {mid }}=\frac{\left[\hat{\mathbf{W}} \hat{\mathbf{W}}^{T} \hat{\mathbf{W}}\right]_{i i}}{k_{i}^{\text {in }} k_{i}^{\text {out }}-d_{i}^{\leftrightarrow}} .
$$

- Aglomeração de entrada: Quantifica a proporção de triângulos onde o nó $i$ tem grau 2 de entrada (Fig. 2.1(c)), e é dado por:

$$
\tilde{C}_{i}^{i n}=\frac{\left[\hat{\mathbf{W}}^{T} \hat{\mathbf{W}}^{2}\right]_{i i}}{k_{i}^{i n}\left(k_{i}^{i n}-1\right)} .
$$

- Aglomeração de saída: Quantifica a proporção de triângulos onde o nó $i$ tem grau 2 de saída (Fig. 2.1(d)), e é calculado da seguinte maneira:

$$
\tilde{C}_{i}^{\text {out }}=\frac{\left[\hat{\mathbf{W}}^{2} \hat{\mathbf{W}}^{T}\right]_{i i}}{k_{i}^{\text {out }}\left(k_{i}^{\text {out }}-1\right)} .
$$

O coeficiente de aglomeração para redes binárias direcionadas é calculado substituindo, em qualquer uma das equações anteriores, a matriz de adjacência direcionada e ponderada $(W)$ pela correspondente matriz de adjacência direcionada binária (A) (Fagiolo, 2007).

Coeficiente Cíclico: Este coeficiente quantifica a propriedade cíclica de uma rede (Kim \& Kim, 2005). O coeficiente cíclico $\theta_{i}$ do nó $i$ é definido como a média dos inversos das distâncias geodésicas dos caminhos fechados partindo e voltando do nó $i$ através dos seus vizinhos diretos (Kim \& Kim, 2005), e é calculado da seguinte maneira:

$$
\theta_{i}=\frac{2}{k_{i}\left(k_{i}-1\right)} \sum_{(i, j)} \frac{1}{S_{i j k}} a_{i j} a_{i k},
$$

em que $S_{i j k}$ é o tamanho do caminho mínimo que contém o nó $i$ e os seus dois vizinhos $j$ e $k$, e $(j, k)$ indica que a somatória deve ser realizada para todos os pares de vizinhos ( $j$ e $k$ ) do nó $i$. O coeficiente cíclico global $(\theta)$ é igual à média dos coeficientes cíclicos de todos os nós, como segue:

$$
\theta=\frac{1}{n} \sum_{i} \theta_{i}
$$

O coeficiente cíclico global tem um valor entre 0 e $1 / 3$, onde 0 significa que a rede tem uma estrutura de árvore na qual nenhum ciclo pode ser encontrado, e o caso oposto, isto é, $\theta=1 / 3$, indica que existe conexão entre todos os pares de nós. Note-se que no último caso o coeficiente de aglomeração é 1.

Para o cálculo da medida anterior é necessário determinar primeiro os caminhos que são ciclos e os seus tamanhos. Fazendo uso desta informação, 
duas medidas podem ser derivadas: (1) proporção de caminhos de tamanho $q$ que são ciclos; (2) probabilidade de um caminho de tamanho $q-1$ se tornar um ciclo de tamanho $q$, que é igual ao total de ciclos de tamanho $q$ sobre o total de caminhos de tamanho $q-1$ sem considerar aqueles que são ciclos (Rubinov \& Sporns, 2010). Note-se que a proporção de caminhos de tamanho 0 corresponde à fração de autoconexão $\left(p_{a}\right)$ em redes cíclicas.

Coeficiente de Reciprocidade: Para uma rede direcionada, a reciprocidade refere-se às arestas que saem de um nó para outro e retornam imediatamente ao mesmo nó de partida. Uma forma simples de quantificar a reciprocidade é calcular a fração de arestas bilaterais da rede da seguinte forma (Garlaschelli \& Loffredo, 2004):

$$
\hat{r}_{e}=\frac{\sum_{i j} a_{i j} a_{j i}}{m}
$$

Uma rede totalmente unidirecional terá um valor de $\hat{r}_{e}$ igual a 0 e uma totalmente bidirecional igual a 1 . No entanto, a taxa de reciprocidade anterior não permite realizar uma comparação real entre a rede de análise e uma versão aleatória dela, dado que em uma rede aleatória com igual número de nós e arestas, a tendência de arestas mútuas é alta e governada tão somente pelo acaso. Em consequência, determinou-se uma medida de reciprocidade $\left(r_{e}\right)$ que levasse em conta a tendência da ocorrência das arestas bilaterais comparada com o valor esperado pelo acaso, a qual é definida como o coeficiente de correlação das entradas da matriz de adjacência e é calculada da seguinte forma (Garlaschelli \& Loffredo, 2004):

$$
r_{e}=\frac{\sum_{i \neq j}\left(a_{i j}-\bar{a}\right)\left(a_{j i}-\bar{a}\right)}{\sum_{i \neq j}\left(a_{i j}-\bar{a}\right)^{2}},
$$

onde $\bar{a}$ é o valor médio dos elementos da matriz de adjacência, calculado como: $m /\left(n^{2}-n\right)$. Uma versão compacta da Eq. (2.22) usando a Eq. (2.21) é: $\left(\hat{r}_{e}-\bar{a}\right) /(1-\bar{a})$. O valor $r_{e}$ é um valor absoluto, em que valores positivos indicam maior reciprocidade (rede reciproca) e valores negativos significam menor reciprocidade (rede anti-recíproca), ambos comparados com uma rede aleatória. Para uma rede ponderada a reciprocidade é calculada substituindo nas equações mostradas acima o valor $a_{i j}$ por $w_{i j}$ (Squartini et al., 2012).

\section{Medidas de Centralidade}

As medidas de centralidade compreendem a centralidade de proximidade ${ }^{2}$, centralidade de intermediação ${ }^{3}, z$-score e o coeficiente de participação, dentre outras. Nesta seção são apresentadas as duas últimas.

\footnotetext{
${ }^{2}$ Do inglês: Closeness centrality

3 Do inglês: Betweenness centrality
} 
Coeficiente de Participação: Em uma divisão em comunidades, os nós de cada comunidade cumprem um papel diferente segundo as conexões que tiverem dentro da sua comunidade e segundo as conexões ligando nós de outras comunidades. Esta propriedade é mensurada por duas medidas, o $z$-score e o coeficiente de participação, sendo a primeira uma medida intra-comunidade e a segunda uma medida inter-comunidades. O z-score quantifica o quão bem conectado é o nó $i$ da comunidade $s$ com relação aos nós da sua própria comunidade, e é calculado como: $z_{i}=\left(k_{s_{i}}-\bar{k}_{s_{i}}\right) / \sigma_{k_{s_{i}}}$, onde $k_{s_{i}}$ é o grau do nó $i$ dentro da comunidade $s$, e $\bar{k}_{s_{i}}$ e $\sigma_{k_{s_{i}}}$ são a média e o desvio padrão dos graus da comunidade $s$, respectivamente (Guimerà \& Amaral, 2005). O coeficiente de participação $\left(P_{i}\right)$ mensura o quão bem distribuídas estão as arestas de um dado nó que conectam nós de outras comunidades, e é calculado como:

$$
P_{i}=1-\sum_{s=1}^{n_{M}}\left(\frac{k_{i s}}{k_{i}}\right)^{2},
$$

em que $k_{i}$ é o grau do nó $i$ dentro da rede toda, $k_{i s}$ é o número de arestas do nó $i$ que conectam nós da comunidade $s$, e $n_{M}$ é o número total de comunidades. O coeficiente de participação cai na faixa de $[0,1]$, onde um valor mínimo indica que para um dado nó todas as suas arestas estão dentro da sua comunidade e um valor próximo a 1 indica que suas arestas estão uniformemente distribuídas entre todas as outras comunidades (Guimerà \& Amaral, 2005). A versão para redes ponderadas e direcionadas é facilmente obtida substituindo o grau pela força e calculando o coeficiente segundo a força de entrada, saída ou total (Costa et al., 2005).

\subsubsection{Tipos de Redes}

Uma análise comparativa entre a distribuição de grau de diferentes redes deu lugar a uma categorização que discrimina as redes segundo a topologia e a forma da distribuição. A primeira categoria compreende a rede regular, a qual tem uma distribuição de grau uniforme que estipula que todos os nós da rede têm o mesmo valor de grau. Os amplos estudos realizados por Erdős-Rényi deram lugar à segunda categoria, que enquadra as redes aleatórias, nas quais a distribuição de grau corresponde à distribuição de probabilidade de Poisson. Devido aos autores que estudaram este tipo de redes, estas também são conhecidas como modelos de Erdős-Rényi (Erdős \& Rényi, 1959). Recentemente, foram estudadas redes nas quais pode ser drasticamente reduzida a média de caminhos mínimos mediante a alteração aleatória de algumas poucas conexões de uma rede regular, dando lugar à terceira categoria de redes, a qual abrange as redes denominadas redes de pequeno mundo ${ }^{4}$ (Watts \& Strogatz,

\footnotetext{
${ }^{4}$ Do inglês: Small-World Network
} 
1998). Posteriormente, com o estudo realizado sobre redes que representam sistemas complexos encontrados na natureza, surgiu uma nova categoria que descreve as redes cuja distribuição de grau obedece à lei de potência ${ }^{5}$. A lei de potência é uma função que relaciona o grau $k$ com uma forma linear decrescente, descrita matematicamente como: $P(k) \sim k^{\gamma}$, em que $\gamma$ é o expoente de escala (Barabási \& Albert, 1999). Esta distribuição heterogênea significa que a probabilidade de selecionar aleatoriamente um nó com grau baixo é maior que a de escolher um nó com alto grau, devido ao fato de que nestas redes existe um grande conjunto de nós que têm poucas conexões, enquanto o número de nós com alto grau é bem menor. Em razão disso, as redes que apresentam esta característica na sua distribuição de grau são denominadas redes livre de escala ${ }^{6}$. O algoritmo para gerar redes de pequeno mundo é conhecido como modelo de Watts-Strogatz e o algoritmo para gerar uma rede livre de escala como modelo de Barabási-Albert (Barabási \& Albert, 1999), o nome de ambos os algoritmos está relacionado com o nome dos autores. Para gerar uma rede aleatória vários algoritmos têm sido propostos, por exemplo, o algoritmo de Bender-Canfield, de Jerrum-Sinclair e de Steger-Wormald, entretanto o mais conhecido é o algoritmo de Erdös-Rényi (Wormald, 1999). Na Fig. 2.2 são mostrados os quatro modelos de redes descritos acima.

\subsubsection{Detecção de Comunidades}

Uma estrutura de comunidade é definida pela tendência de alguns nós da rede a estarem organizados em módulos com alta densidade de conexão entre eles e baixa densidade de conexão entre os nós pertencentes a outros módulos (Newman, 2003a). Existem muitos exemplos de comunidades que podem ser encontradas na natureza e na vida cotidiana, algumas destas são: comunidades sociais, científicas, tecnológicas e biológicas, dentre outras (Boccaletti et al., 2006). Usualmente, as comunidades são formadas por nós que compartilham algumas propriedades semelhantes. Várias técnicas têm sido desenvolvidas para detectar comunidades em redes complexas, essas técnicas aproveitam as propriedades existentes entre os nós internos das comunidades ou entre nós de comunidades diferentes. O estudo de comunidades em redes complexas é importante, pois ajuda a compreender melhor as relações existentes entre os diferentes elementos que formam a rede, permitindo identificar a função que cumpre cada elemento dentro da comunidade. No entanto, a detecção de comunidades não é uma tarefa fácil, por conseguinte, vários métodos aproximados para a identificação de comunidades têm sido desenvolvidos, mas cada um apresentando limitações de precisão e de custo computacional

\footnotetext{
${ }^{5}$ Do inglês: Power-law

${ }^{6}$ Do inglês: Scale-free Networks
} 


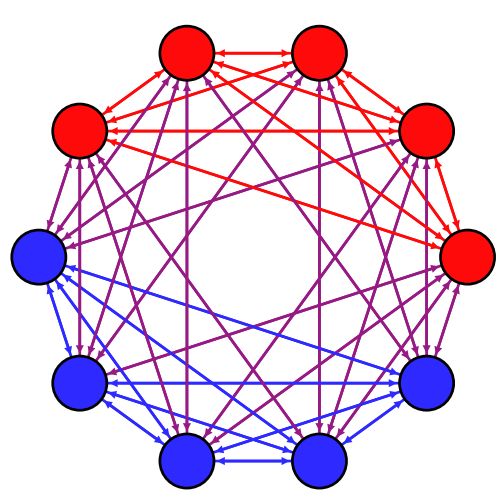

(a)

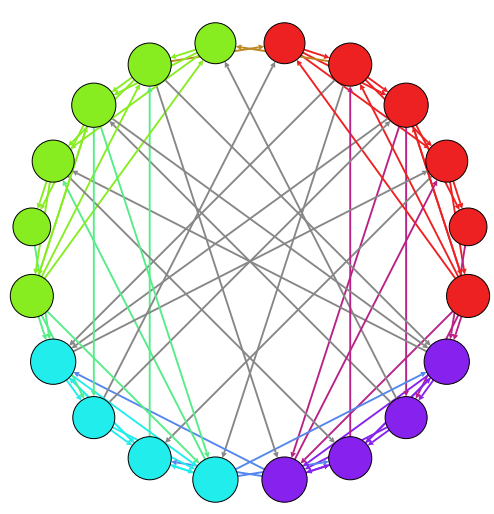

(c)

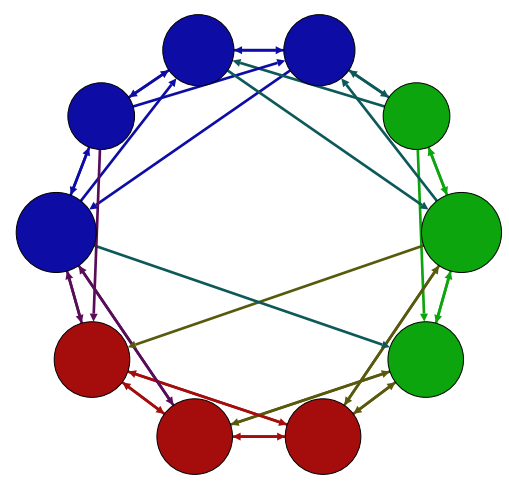

(b)

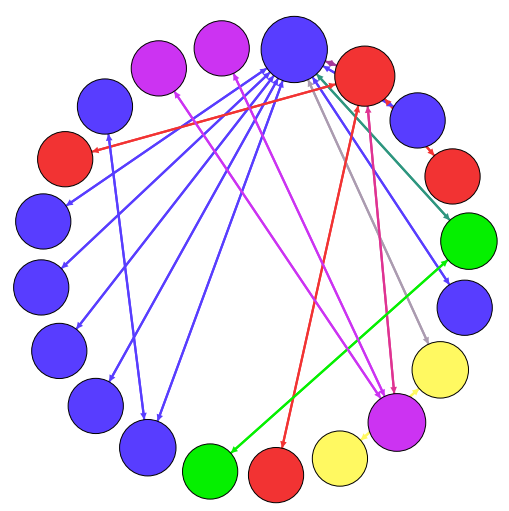

(d)

Figura 2.2: Modelos de redes complexas. (a) Regular; (b) Pequeno mundo; (c) Aleatória; (d) Livre de escala.

(Fortunato, 2010).

Considerando uma rede com $n$ nós, para a qual foram detectadas $k$ comunidades, a saída do algoritmo de detecção pode ser representada com uma matriz $\mathbf{C}$ (matriz de comunidades) de dimensão $n \times k$, onde o elemento $C_{i, j}$ é 1 se o nó $i$ pertence à comunidade $j$, e zero no caso contrário. Algumas comunidades têm sobreposição de nós, neste caso, a matriz de comunidades terá valores na faixa $[0,1]$, indicando o grau de pertinência de cada nó dentro de cada comunidade. Este caso é conhecido como comunidades sobrepostas, enquanto o caso binário é conhecido como comunidades disjuntas. Na Fig. 2.3 é mostrada uma rede complexas com 6 comunidades disjuntas, cada uma com 20 nós. A seguir, é realizada uma breve descrição dos algoritmos de detecção de comunidades usados nesta tese.

\section{Algoritmo de Otimização de Modularidade}

O algoritmo de Otimização de Modularidade ${ }^{7}(\mathrm{OM})$ baseia-se no cálculo de uma medida que quantifica a viabilidade de particionar uma rede em comunidades. Esta medida foi proposta em (Newman \& Girvan, 2004) e é conhe-

\footnotetext{
${ }^{7}$ Do inglês: Modularity Optimization
} 


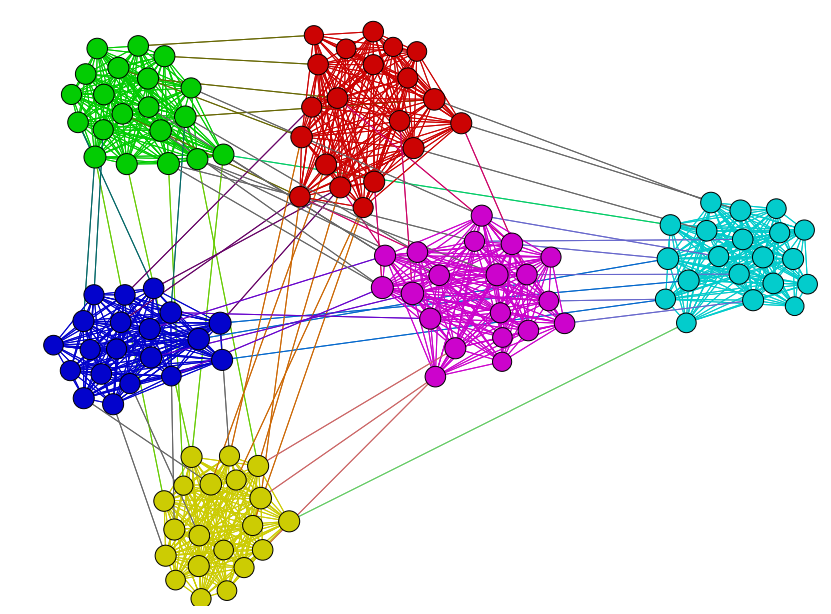

Figura 2.3: Rede complexa com estrutura de comunidade.

cida como o fator de modularidade $Q$. Este fator é definido como a fração de arestas intra-comunidades menos o valor esperado da mesma fração. Porém, considerando que as arestas são inseridas aleatoriamente e independente da estrutura da comunidade. A expressão matemática do fator $Q$ é dada por:

$$
Q=\sum_{i}\left(e_{i i}-a_{i}^{2}\right)=\operatorname{tr}(\mathbf{E})-\left\|\mathbf{E}^{2}\right\|,
$$

em que $e_{i j}$ denota a fração de arestas entre a comunidade $i$ e a comunidade $j$, as quais são dispostas na matriz simétrica E, $a_{i}$ é a soma através das colunas da matriz $\mathbf{E}\left(a_{i}=\sum_{j} e_{i j}\right)$ e representa a fração de todos os enlaces que conectam os nós da comunidade $i$, e $\operatorname{tr}(\cdot)$ denota o traço de uma matriz (somatória dos elementos da diagonal principal) e $\|\cdot\|$ a soma dos seus elementos. Um valor de $Q$ igual a zero corresponde ao valor esperado para uma divisão aleatória, enquanto valores positivos indicam uma divisão em comunidades, isto é, um desvio da aleatoriedade. Na prática uma boa divisão em comunidade é indicada por valores maiores a 0.3 (Newman, 2006).

O algoritmo clássico de modularidade proposto por Newman e Girvan em (Newman \& Girvan, 2004) faz uma remoção iterativa de arestas, calculando em cada passo o valor de $Q$. A divisão da rede que obtiver o máximo resultado de $Q$ será considerada a melhor divisão possível da rede em comunidades. Evidentemente essa divisão iterativa da rede tem um alto custo computacional, portanto, em (Newman, 2003a) Newman propôs um algoritmo aglomerativo hierárquico baseado na otimização do fator de modularidade $Q$. O algoritmo inicia considerando cada nó como uma comunidade, em seguida, as comunidades são agrupadas em pares, e o par que produzir o maior incremento ou o menor decremento no valor $Q$ é selecionado para formar uma comunidade. O processo é terminado se o ganho for negativo ou se um ponto de parada for atingido. A variação de $Q$ da junção das comunidades $i$ e $j$ é dada por: 
$\Delta Q=2\left(e_{i j}-a_{i} a_{j}\right)$. O resultado da união progressiva de nós formando comunidades pode ser visualizado em um dendrograma, por exemplo, na Fig. 2.4 (b) é mostrado o dendrograma obtido de aplicar o algoritmo OM à rede da Fig. $2.4(\mathrm{a})$.

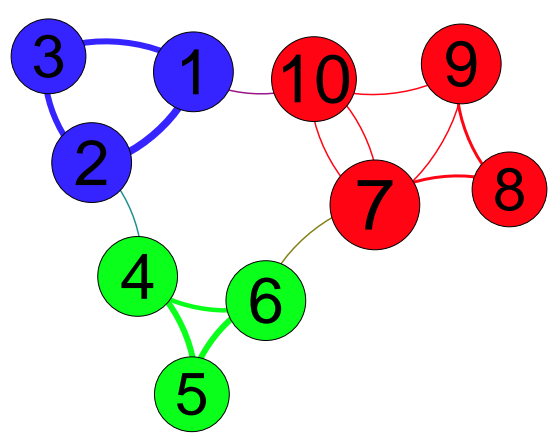

(a)

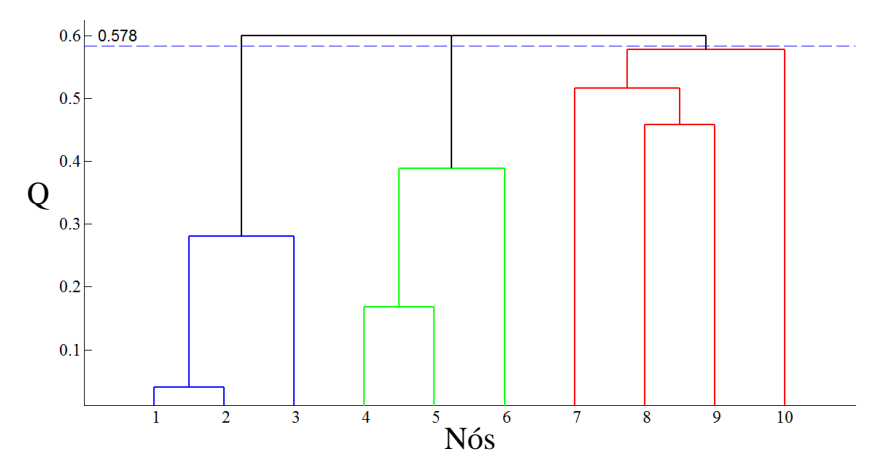

(b)

Figura 2.4: Comunidades detectadas pelo algoritmo de otimização de modularidade. (a) Rede com 3 comunidades; (b) Dendrograma.

A procura do máximo valor de $Q$ neste dendrograma indica o nível de corte onde é produzida a melhor divisão em comunidades. Para o anterior exemplo, o valor ótimo de $Q$ é 0.578 e um corte nesse nível resulta em 3 comunidades. A complexidade de tempo do algoritmo no pior caso é da ordem de $O((m+n) n)$.

\section{Algoritmo de Louvain}

Um método popular para a otimização da modularidade, conhecido como método de Louvain, foi proposto em (Blondel et al., 2008). Este método é fácil de implementar e extremamente rápido. A velocidade é explicada principalmente ao fato de que o ganho de modularidade pode ser calculado. $\mathrm{O}$ algoritmo é composto por duas fases que são repetidas iterativamente. Na primeira fase cada nó conforma uma comunidade, e para cada nó $i$ é calculado o ganho de modularidade obtido ao transferir esse nó à comunidade do seu nó vizinho $j$. Dessa forma, o nó $i$ será movido à comunidade que produzir o máximo ganho positivo. O processo é repetido para todos os nós até atingir uma estabilidade em $Q$. O ganho de modularidade $\Delta Q$ obtido ao mover o nó $i$ à comunidade de destino $C$ é calculado pela seguinte equação:

$$
\Delta Q=\left[\frac{\Sigma_{i n}+s_{i, i n}}{2 s}-\left(\frac{\Sigma_{t o t}+s_{i}}{2 s}\right)^{2}\right]-\left[\frac{\Sigma_{i n}}{2 s}-\left(\frac{\Sigma_{t o t}}{2 s}\right)^{2}-\left(\frac{s_{i}}{2 s}\right)^{2}\right]
$$

em que $\Sigma_{i n}$ é a somatória das forças da comunidade de destino $C, \Sigma_{\text {tot }}$ é a somatória das forças incidentes à comunidade de destino $C, s_{i}$ é a força do nó $i$ na rede toda, $s_{i, i n}$ é a somatória das forças das arestas do nó $i$ que conectam 
os nós da comunidade de destino $C$ e $s$ é a força total da rede. A segunda fase consiste em criar uma nova rede cujos nós são as comunidades detectadas na primeira fase, e onde a força das arestas entre os novos nós é dada pela somatória das forças entre os nós de duas comunidades correspondentes. Para essa nova rede a primeira fase é aplicada novamente e o processo é repetido até não conseguir mais mudanças, ponto no qual o máximo valor de modularidade é atingido. Este método é implementado pelo software Gephi (Bastian et al., 2009), que é um software especializado na exploração e manuseio de redes e foi usado em algumas simulações computacionais desta tese.

\section{Fatoração de Matriz Não-Negativa Bayesiana}

O método fatoração de matriz não-negativa Bayesiana $\left(\mathrm{BNMF}^{8}\right)$ é um eficiente algoritmo para a detecção de comunidades sobrepostas (Psorakis et al., 2011). O algoritmo BNMF é uma adaptação da técnica fatoração de matriz não-negativa (NMF) usada em aprendizado de máquina para redução de dimensionalidade e extração de atributos (Xie et al., 2013). Esta técnica fatoriza a matriz $\mathbf{V} \in \mathbb{R}_{+}^{n \times n}$ em duas matrizes $\mathbf{W} \in \mathbb{R}_{+}^{n \times k}$ e $\mathbf{H} \in \mathbb{R}_{+}^{k \times n}$, cujos elementos são não negativos, tal que $\mathrm{V} \approx \mathrm{WH}$. Dentro do contexto de detecção de comunidades, $\mathrm{V}$ é a matriz de adjacência da rede, $n$ é o número de nós e $k$ é o número de comunidades predefinidas. Cada elemento da linha $i$ ou da coluna $j$ da matriz $\mathbf{W}$ representa a dependência existente entre uma comunidade e o nó $i$. Devido à multiplicação de matrizes, o tradicional NMF é ineficiente em relação ao tempo e restrição de memória. Portanto, Psorakis et al. (2011) propuseram um algoritmo híbrido baseado em otimização Bayesiana (Psorakis et al., 2011). Este algoritmo otimiza uma função objetivo expressa em função das matrizes antes mencionadas e de hiperparâmetros $\beta \in \mathbb{R}^{k}=\left[\beta_{1}, \ldots \beta_{k}\right]$ que representam a importância das comunidades sobre as interações da matriz de adjacência. O algoritmo envolve consecutivas atualizações de $\mathbf{W}, \mathbf{H}$ e $\beta$ até atingir uma medida de convergência ou um número máximo de iterações. As matrizes W, H e os hiperparâmetros $\beta$ são calculados da seguinte maneira:

$$
\begin{gathered}
\mathbf{H}=\left(\frac{\mathbf{H}}{\mathbf{W}^{\mathrm{T}} \mathbf{1}+\mathbf{B H}}\right) \cdot\left[\mathbf{W}^{\mathrm{T}}\left(\frac{\mathbf{V}}{\mathbf{W H}}\right)\right], \\
\mathbf{W}=\left(\frac{\mathbf{W}}{\mathbf{1} \mathbf{H}^{\mathrm{T}}+\mathbf{W B}}\right) \cdot\left[\left(\frac{\mathbf{V}}{\mathbf{W H}}\right) \mathbf{H}^{\mathrm{T}}\right], \\
\beta_{k}=\frac{n+a-1}{\frac{1}{2}\left(\sum_{i} w_{i k}^{2}+\sum_{j} w_{i j}^{2}\right)+b},
\end{gathered}
$$

em que $a$ e $b$ são parâmetros fixos de uma distribuição gamma (Hogg \& Craig,

\footnotetext{
${ }^{8}$ Sigla de Bayesian Nonnegative Matrix Factorization
} 
1978) e as matrizes W, H são inicializadas com valores aleatórios. Por fim, as colunas de W (ou linhas de $\mathbf{H}$ ) que contêm todos os elementos iguais a zero são removidas, e o número de comunidades é dado pelo número de colunas de $\mathbf{W}$ (ou linhas de $\mathbf{H}$ ) obtidas após a remoção.

\subsection{Sistemas Dinâmicos Caóticos e Redes Neurais Re- correntes}

Nesta seção são descritas algumas noções básicas sobre sistemas dinâmicos não-lineares com comportamento caótico e bifurcação, bem como uma revisão dos conceitos básicos de redes neurais recorrentes e do algoritmo usado para o treinamento das mesmas. Também é apresentada uma rede recorrente especial conhecida como rede LSTM e o seu respectivo algoritmo de treinamento.

\subsubsection{Sistemas Dinâmicos Caóticos}

Um sistema não-linear é um sistema dinâmico que não atende ao princípio de superposição, isto é, não responde de forma semelhante tanto para entradas individuais quanto para combinações de diferentes entradas externas (Angulo, 2004). Esta característica leva o sistema a ter um comportamento bem mais complexo e vasto que não é encontrado na sua contraparte não-linear. Alguns destes comportamentos são: ciclos limite ou oscilações, bifurcações e dependência crítica aos parâmetros e às condições iniciais, dentre outros. As bifurcações referem-se às mudanças qualitativas no comportamento do sistema quando algum dos seus parâmetros é alterado, por exemplo, duplicação de período no retrato de fase. Os sistemas não lineares que apresentam dependência crítica às condições iniciais ou aos parâmetros são conhecidos como sistemas caóticos, sendo esta uma definição superficial. Contudo, uma definição mais aprofundada é possível ao descrever com detalhe e rigor matemático as características de sensibilidade, transitividade topológica e pontos periódicos densos (Strogatz, 1994). Uma das primeiras definições de caos foi sugerida na conferência internacional sobre caos, patrocinada pela Royal Society de Londres em 1986, onde o caos foi definido como "comportamento estocástico que ocorre em um sistema determinista”. Esta definição provém do fato de que os sistemas caóticos apresentam um comportamento aparentemente irregular, instável ou aleatório apesar de serem, ao mesmo tempo, sistemas deterministas, o que dificulta a predição exata de valores futuros a partir de valores históricos.

Nesta tese é aproveitada a propriedade caótica dos sistemas não lineares no 


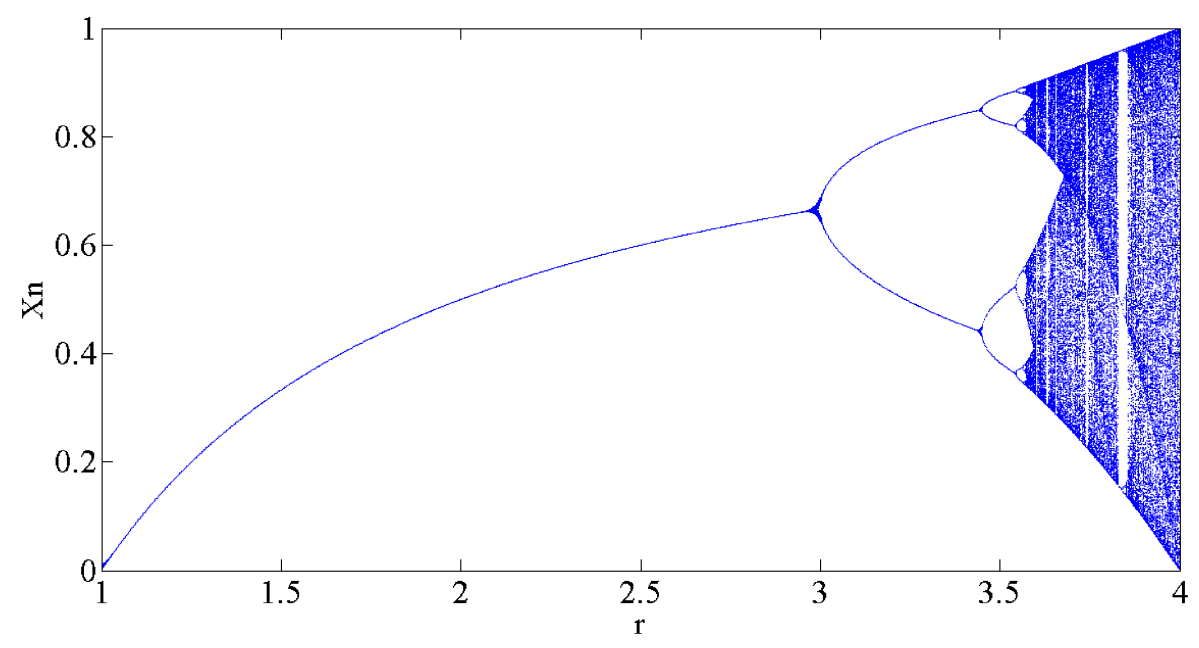

Figura 2.5: Diagrama de bifurcação do mapa logístico.

desenvolvimento de modelos de composição de melodias (Coca, 2009). Especificamente, são usados dois sistemas, um sistema unidimensional conhecido como equação logística discreta ou mapa logístico, o qual é o mais simples sistema que tem comportamento caótico e de bifurcação, e um sistema bidimensional discreto conhecido como mapa de Hénon. O mapa logístico foi proposto em 1845 por Verhulst para modelar as variações anuais de crescimento de uma população confinada. Este mapa apresenta um grande espectro de comportamento dinâmico, sendo, portanto, fundamental no estudo da teoria do caos (Wiggins, 2003). O mapa logístico é dado por:

$$
x_{n+1}=r x_{n}\left(1-x_{n}\right)
$$

onde $x_{n}$ é uma variável discreta que representa o tamanho da população no $n$-ésimo momento e $r$ é a taxa de crescimento populacional. Na Fig. 2.5 é mostrado o valor de $x_{n}$ resultante ao variar o parâmetro $r$ entre 1 e 4 . Esta figura é chamada diagrama de bifurcação e ilustra a aproximação do caos através da duplicação de período, em outras palavras, ilustra o processo de bifurcação que leva ao caos. É possível enxergar que entre 1 e 3 o sistema apresenta um valor fixo e crescente, e que, quando alcança o valor 3, começa a oscilar entre dois valores, isto é, o sistema entra na primeira bifurcação. Próximo de 3.44 o sistema passa a oscilar entre 4 valores, e um pouco mais para adiante entre 8 valores, e assim por diante até que depois de um determinado valor (aprox. 3.9) começa a se observar que o sistema passa por qualquer valor sem haver um padrão de repetição, momento no qual se diz que o sistema entrou no estado caótico (Wiggins, 2003). 


\subsubsection{Redes Neurais Recorrentes}

Uma rede neural recorrente $\left(\mathrm{RNN}^{9}\right)$ é um perceptron de múltiplas camadas $\left(\mathrm{MLP}^{10}\right)$ no qual existe pelo menos uma saída de um neurônio da camada oculta que é enviada para todos os neurônios da camada de entrada, configurando o que se conhece como laço de realimentação. Existem vários tipos de RNNs, sendo a mais popular a rede de Elman (Haykin, 1999). Na Fig. 2.6 é mostrada uma RNN no instante $n$ com uma entrada $(u(n))$, dois neurônios na única camada oculta (neurônio 1 e 2) e um neurônio na camada de saída (neurônio 3). Nessa rede, os pesos sinápticos são denotados como $w_{i j}$, o bias (limiar que controla a função de ativação de cada neurônio) como $b_{i}$, a saída como $y(n+1)$ e as saídas dos neurônios das camadas ocultas que são realimentadas na entrada, as quais simulam a memória da rede e cujo conjunto é conhecido como camada de contexto, são denotadas como $x(n+1)$.

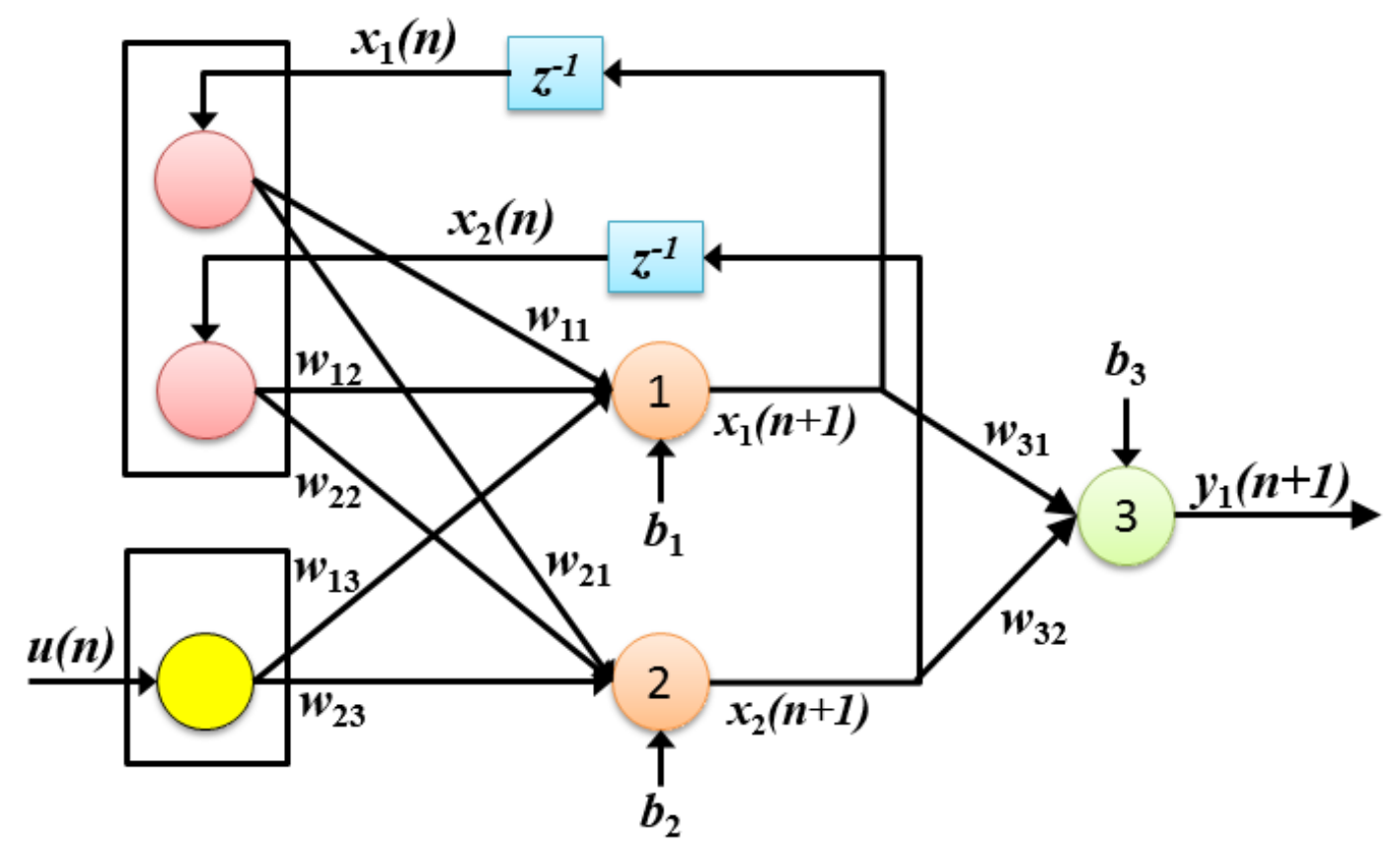

Figura 2.6: Rede neural recorrente com uma entrada, uma saída e dois neurônios na única camada oculta. Adaptado de (Haykin, 1999).

Algoritmo de Retropropagação através do Tempo (BPT)

As tradicionais redes neurais recorrentes são treinadas com o algoritmo de retropropagação através do tempo (BPTT ${ }^{11}$ ), o qual é uma uma adaptação do algoritmo de retropropagação (BP) padrão que é usado para treinar redes alimentadas à frente $\left(\mathrm{FF}^{12}\right)$, nas quais cada camada é conectada à próxima,

\footnotetext{
${ }^{9}$ Sigla de Recurrent Neural Network

${ }^{10}$ Sigla de Multi-Layer Pereceptron

${ }^{11}$ Sigla de BackproPagation Through Time

${ }^{12}$ Sigla de FeedForward
} 
porém sem um caminho de volta, isto é, uma FF é uma MLP sem realimentação (Haykin, 1999).

O modo de operação temporal de uma rede recorrente pode se desdobrado em uma rede $\mathrm{FF}$ que adiciona a cada passo de tempo uma nova camada. Duas formas de implementar o algoritmo BPTT são possíveis: contínuo e por época. No contínuo os pesos são atualizados logo após cada aplicação do par entrada-saída à rede. Na implementação por época o conjunto de dados de treinamento é particionado em subconjuntos (lotes) para serem treinados em épocas independentes, as atualizações são feitas após a submissão de cada subconjunto de pares entrada-saída. Neste caso é calculado o erro total para cada lote e após isso são realizadas as correções dos pesos (Galván, 2004). O passo de propagação é semelhante ao do algoritmo BP na fase de propagação da rede $\mathrm{FF}$, onde, primeiramente, os pesos sinápticos são inicializados aleatoriamente com valores pequenos e, logo após submeter a rede ao estímulo de entrada, para cada neurônio $j$ é calculado, de maneira individual, o seu potencial de ativação $v_{j}(n)$ e seu sinal funcional $y_{j}(n)$, assim:

$$
\begin{gathered}
v_{j}(n)=\sum_{i=0}^{m} w_{i j}(n) y_{i}(n), \\
y_{j}(n)=\varphi\left(v_{j}(n)\right),
\end{gathered}
$$

em que $m$ é o número total de entradas (sem o bias), $w_{i j}(n)$ é o peso sináptico que conecta os neurônios $i$ e $j, \varphi(\cdot)$ é a função de ativação dos neurônios e $y_{i}(n)$ é a saída do neurônio predecessor (o neurônio $i$ ), que para neurônios da primeira camada oculta, os quais têm conexão direta com o $i$-ésimo valor de entrada $x_{i}(n)$, tem-se que $y_{i}(n)=x_{i}(n)$, porém se estiver na camada de saída, então $y_{j}(n)$ corresponde ao $j$-ésimo elemento do vetor de saída $o_{j}(n)$. Após percorrer todas as camadas e obtida a saída de cada neurônio e é calculado o sinal de erro, assim: $e_{j}(n)=d_{j}(n)-y_{j}(n)$, onde $d_{j}(n)$ é a saída desejada. Neste ponto termina a fase de propagação e começa a de retropropagação que vai no sentido inverso, da camada de saída até a camada oculta, mas já não passando o sinal funcional, e sim o sinal de erro, que é obtido calculando recursivamente o gradiente local de cada neurônio $\left(\delta_{j}(n)\right)$. O gradiente local é a derivada parcial do erro com respeito aos pesos sinápticos. No algoritmo BP os gradientes da camada de saída e das camadas ocultas são calculados como $\delta_{j}(n)=\varphi_{j}^{\prime}\left(v_{j}(n)\right) e_{j}(n)$ e $\delta_{j}(n)=\varphi_{j}^{\prime}\left(v_{j}(n)\right) \sum_{k} \varphi_{k}(n) w_{k j}(n)$, respectivamente, e os pesos são atualizados com a regra delta $\Delta w_{j i}(n)=\eta \delta_{j}(n) y_{i}(n)$, onde $\eta$ é a taxa de aprendizagem. O algoritmo BPTT segue um processo semelhante, porém considerando os desdobramentos sucessivos da rede através do tempo, já que a cada passo é acrescida uma camada à topologia da rede (Galván, 2004). Na 
Fig. 2.7 é ilustrado o desdobramento no tempo da rede da Fig. 2.6 para três iterações de treino.

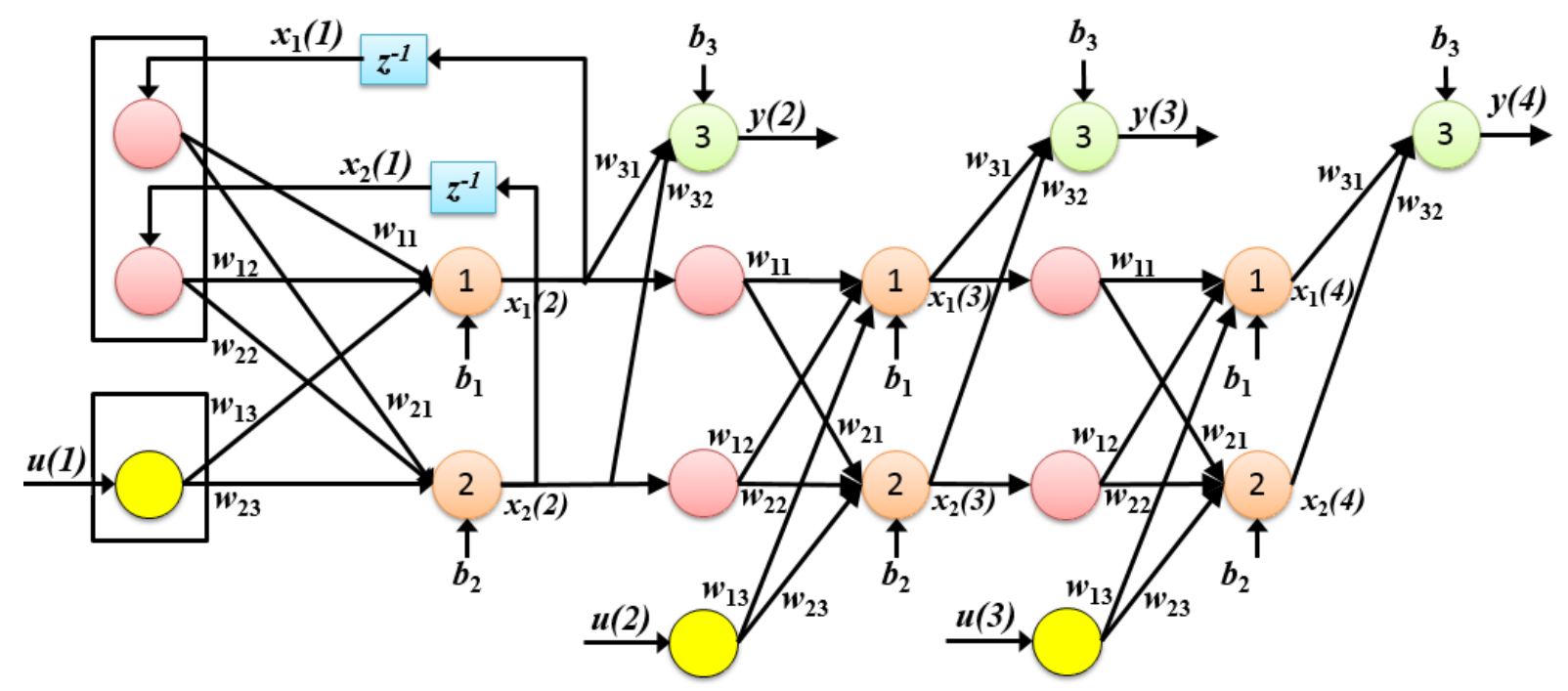

Figura 2.7: Desdobramento temporal da rede RNN da Fig. 2.6 no decorrer de três épocas. Adaptado de (Haykin, 1999).

No algoritmo BPTT por época com tempo inicial e final de $n_{0}$ e $n_{1}$, respectivamente, o erro total após calcular todas as saídas é dado por:

$$
E_{\text {total }}\left(n_{0}, n_{1}\right)=\frac{1}{2} \sum_{n}^{n 1} \sum_{j \in A} e_{j}^{2}(n)
$$

em que $A$ é o conjunto de índices $j$ dos neurônios cujas respostas foram especificadas e $n$ é uma variável que indica a iteração atual $\left(n_{o}<n \leq n_{1}\right)$. Em seguida, é calculado o gradiente local dos neurônios da camada de saída, como segue:

$$
\delta_{j}(n)=-\frac{\partial E_{t o t a l}\left(n_{0}, n_{1}\right)}{\partial v_{j}(n)} .
$$

O cálculo dos gradientes das camadas ocultas, para todo $j \in A$, durante o decorrer da época $n_{0}<n \leq n_{1}$, é dado por:

$$
\delta_{j}(n)=\left\{\begin{array}{cc}
\varphi^{\prime}\left(v_{j}(n)\right) e_{j}(n) & n=n_{1} \\
\varphi^{\prime}\left(v_{j}(n)\right)\left[e_{j}(n)+\sum_{k \in A} w_{j k} \delta_{k}(n+1)\right] & n_{0}<n<n_{1}
\end{array} .\right.
$$

Por fim, ao término do processo de retropropagação, são ajustados os pesos sinápticos, assim:

$$
\Delta w_{j i}=-\eta \frac{\partial E_{t o t a l}\left(n_{0}, n_{1}\right)}{\partial w_{j i}}=\eta \sum_{n=n_{0}+1}^{n_{1}} \delta_{j}(n) x_{i}(n-1) .
$$


Conforme supracitado, as RNNs são usualmente treinadas com o algoritmo BPTT, o qual implementa um método de aprendizado baseado no gradiente descendente. No entanto, os métodos baseados no cálculo do gradiente compartilham um problema, o qual acontece quando ao longo do tempo, conforme a informação do gradiente é passada para atrás visando atualizar os pesos cujos valores afetarão as posteriores saídas, a informação do erro/gradiente é continuamente aumentada ou diminuída pela atualização dos pesos em valores escalares (Pearlmutter, 1995). Isso significa que a evolução temporal do caminho integral sobre todo o sinal de erro fluindo de volta no tempo exponencialmente depende da magnitude dos pesos. Por esse motivo, as tradicionais RNN não conseguem aprender ao longo do tempo defasagens entre as entradas relevantes e os eventos objetivo (Hochreiter et al., 2001).

A rede LSTM foi desenvolvida para minimizar a desvantagem do desvanecimento do gradiente ${ }^{13}$ com a inclusão de blocos de memória: a unidade básica da camada oculta. Na Fig. 2.8 é contrastada a arquitetura da RNN (Fig. 2.8(a)) com a arquitetura da rede LSTM (Fig. 2.8(b)) usando uma camada oculta. Os dois neurônios da primeira arquitetura são substituídos por blocos de memória na segunda, porém por questões de espaço somente um bloco de memória é mostrado.

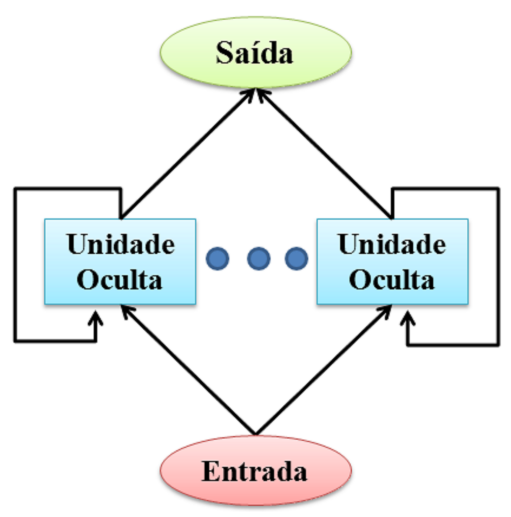

(a)

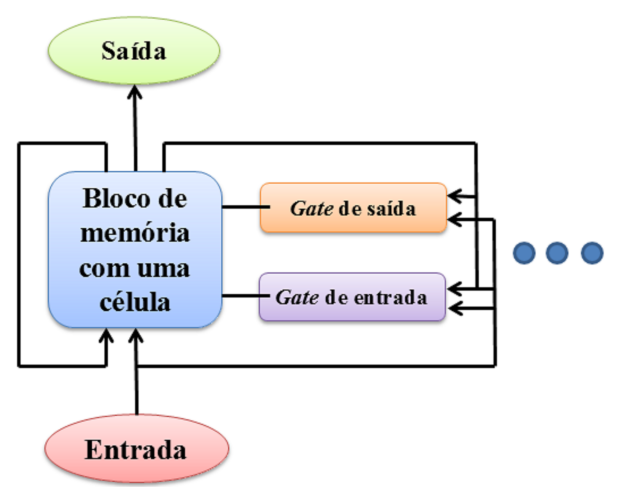

(b)

Figura 2.8: Arquiterura de RNNs. (a) RNN com uma camada oculta; (b) Rede LSTM como blocos de memória na camada oculta (somente um bloco de memória é mostrado). Adaptado de (Gers, 2001).

A rede LSTM é uma arquitetura alternativa para RNNs inspiradas no sistema de memória humano. A rede LSTM minimiza o problema de desvanecimento do gradiente forçando um fluxo de erro constante através de unidades responsáveis por conservar o sinal de erro, chamadas $\mathrm{CECs}^{14}$, que são localizadas dentro dos blocos de memória e que evitam o decaimento do fluxo do

\footnotetext{
${ }^{13}$ Do inglês: Vanishing gradient

${ }^{14}$ Sigla de Constant Error Carousels
} 


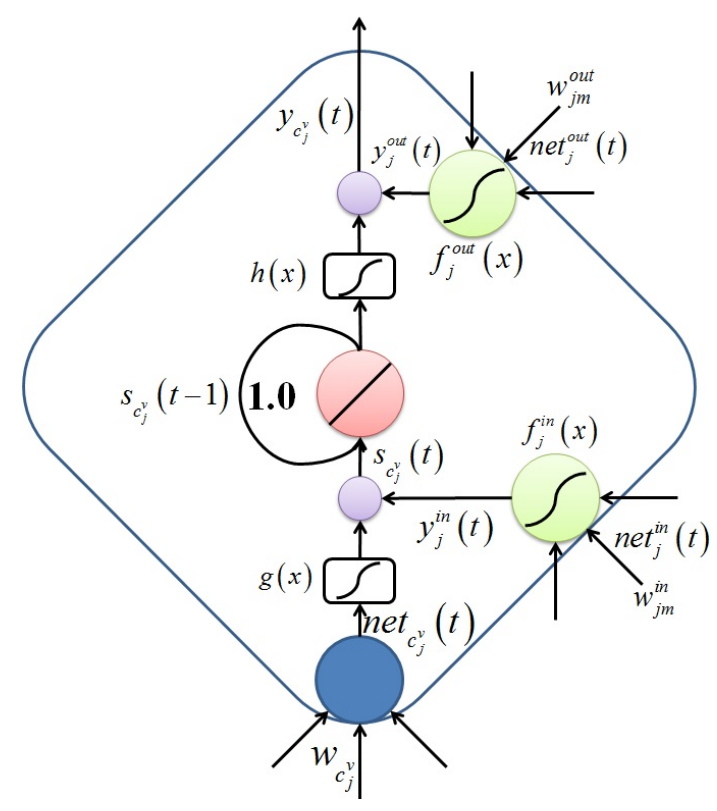

Figura 2.9: Bloco de memória com uma célula de memória. Adaptado de (Gers, 2001).

erro quando este é retropropagado (Gers, 2001). As CECs ativam a rede para aprender importantes dados e armazená-los sem degradação ao longo de um período de tempo.

Um bloco de memória inclui uma ou várias células de memória, um par de gates multiplicativos e unidades de saída (segundo a quantidade de células de memória), a Fig. 2.9 mostra os detalhes de um bloco de memória com uma célula. Nessa figura pode ser enxergada uma unidade linear auto-conectada que está presente em cada célula de memória, esta unidade corresponde à CEC e é fundamental para passar o sinal de erro através da rede, minimizando o problema de desvanecimento do gradiente. Mais detalhes sobre a relação entre as CECs e os sinais erro/gradiente podem ser encontrados em (Gers, 2001). A seguir são descritos os passos de propagação e retropropagação para o treino de redes LSTM.

Passo de Propagação: O passo de propagação da rede LSTM é semelhante ao passo equivalente nas tradicionais RNNs, exceto que as unidades ocultas compreendem subunidades nas quais o sinal é propagado. Considere-se novamente a Fig. 2.9, basicamente, o estado da célula $s_{c}$ é atualizado segundo o seu estado atual e o estado das seguintes três conexões: a conexão net ${ }_{c}$, que reflete o sinal da camada de entrada; e as duas conexões net ${ }^{\text {in }}$, net ${ }^{\text {out }}$, que representam as conexões de entrada e saída dos gates, respectivamente. Usualmente, um passo $t$ envolve a atualização de todas as unidades e o cálculo dos sinais de erro para ajustar os pesos. A ativação do gate de entrada $y_{j}^{i n}(t) \mathrm{e}$ de saída $y_{j}^{\text {out }}(t)$ é geralmente definida como uma função sigmoide sobre a soma 
ponderada das entradas net $t^{o u t}(t)$ e $n e t_{j}^{i n}(t)$, ambas recebidas via enlaces recorrentes dos blocos de memória e das entradas externas da rede, assim (Gers, 2001):

$$
n e t_{j}^{i n}(t)=\sum_{m} w_{j m}^{i n} y_{m}(t-1)+b_{j}^{i n}
$$

e

$$
y_{j}^{i n}(t)=f_{j}^{i n}\left(n e t_{j}^{i n}(t)\right) .
$$

Portanto,

$$
\operatorname{net}_{j}^{\text {out }}(t)=\sum_{m} w_{j m}^{\text {out }} y_{m}(t-1)+b_{j}^{\text {out }},
$$

e

$$
y_{j}^{\text {out }}(t)=f_{j}^{\text {out }}\left(\text { net }_{j}^{\text {out }}(t)\right) \text {, }
$$

em que $b_{j}^{\text {in }}$ e $b_{j}^{\text {out }}$ são os pesos dos gates de entrada e saída, respectivamente. Os blocos de memória são indexados com $j$ e as células de memória em cada bloco $j \operatorname{com} c_{j}^{v}$; e $w_{l m}$ é o peso da conexão da unidade $m$ à unidade $l$. Os gates usam a função sigmoide logística (geralmente na faixa $[0,1]$ ) dada por:

$$
f(x)=\frac{1}{1+e^{-x}} .
$$

As entradas de $c_{j}^{v}$ são multiplicadas pelos pesos $w_{c_{j}^{v} m}$, desde a entrada $m$ até a célula $c_{j}^{v}$, da seguinte maneira:

$$
\operatorname{net}_{c_{j}^{v}}(t)=\sum_{m} w_{c_{j}^{v} m} y_{m}(t-1) \text {. }
$$

Seguindo a sequência, a função sigmoide $g(x)$ (Eq. 2.42) variando de -2 a 2 é aplicada a $\operatorname{net}_{c_{j}^{v}}(t)$.

$$
g(x)=\frac{4}{1+e^{-x}}-2 .
$$

Consequentemente, o estado interno da célula de memória $c_{j}^{v}$ para $t>0$ é:

$$
\begin{aligned}
& s_{c_{j}^{v}}(0)=0, \\
& s_{c_{j}^{v}}(t)=s_{c_{j}^{v}}(t-1)+y_{j}^{i n}(t) g\left(\text { net }_{c_{j}^{v}}(t)\right) .
\end{aligned}
$$

Por fim, a saída da célula é dada por:

$$
y_{c_{j}^{v}}=y_{j}^{o u t}(t) h\left(s_{c_{j}^{v}}(t)\right),
$$

em que $h(x)$ é usualmente uma função sigmoide que varia na faixa $[-1,1]$, e a 
qual é definida como:

$$
h(x)=\frac{2}{1+e^{-x}}-1 .
$$

Considerando uma rede com uma camada de entrada padrão, uma camada oculta composta de vários blocos de memória e uma camada de saída padrão, a saída típica da rede $y_{k}(t)$ é a soma ponderada de $\operatorname{net}_{k}(t)$ que é propagada através da função sigmoide $f(x)$ (Eq. (2.40)), da seguinte maneira:

$$
\begin{gathered}
\operatorname{net}_{k}(t)=\sum_{m} w_{k m} y_{m}(t-1), \\
y_{k}(t)=f_{k}\left(\operatorname{net}_{k}(t)\right),
\end{gathered}
$$

em que $m$ representa todas a unidades que alimentam as unidades de saída.

Passo de Retropropagação: O passo de retropropagação busca minimizar o erro quadrático através das alterações dos pesos usando o gradiente descendente (Gers, 2001). O erro quadrático é dado por:

$$
E(t)=\frac{1}{2} \sum_{k} e_{k}(t)^{2}
$$

em que $e_{k}(t)$ é o erro do $k$-ésimo neurônio de saída, dado por $t^{k}(t)-y^{k}(t)$. De forma semelhante aos algoritmos anteriores, os pesos são alterados usando a regra delta, que do neurônio $l$ para o neurônio $m$ é definida como $\Delta w_{l m}(t)=$ $\eta \delta_{l}(t) y^{m}(t-1)$, onde $\eta$ é a taxa de aprendizado e $\delta_{l}(t)$ o delta de Kronecker, que para o neurônio $l=k$, tem-se que: $\delta_{k}(t)=f_{k}^{\prime}\left(\right.$ net $\left._{k}(t)\right) e_{k}(t)$, e para os gates de saída é dado por:

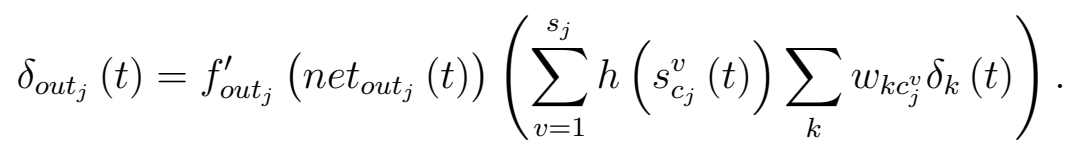

Os pesos que alimentam as células de memória são atualizados assim:

$$
\Delta w_{c_{j}^{v} m}(t)=\alpha e_{s_{c_{j}^{v}}}(t) \frac{\partial s_{c_{j}^{v}}(t)}{\partial w_{c_{j}^{v} m}}
$$

em que $e_{s_{c_{j}^{v}}}(t)$ é o erro interno, dado por: $e_{s_{c_{j}^{v}}}(t)=y^{o u t_{j}}(t) h^{\prime}\left(s_{c_{j}^{v}}(t)\right)\left(\sum_{k} w_{k c_{j}^{v}} \delta_{k}(t)\right)$. A derivada parcial no estado inicial é igual a 0 , isto é, $\frac{\partial s_{c_{j}^{v}}(t=0)}{\partial w_{l m}}=0$ para $l \in\left\{i n, c_{j}^{v}\right\}$, porém para $l=c_{j}^{v}$ e $l=i n$ é dada por:

$$
\frac{\partial s_{c_{j}^{v}}(t)}{\partial w_{c_{j}^{v} m}}=\frac{\partial s_{c_{j}^{v}}(t-1)}{\partial w_{c_{j}^{v} m}}+g^{\prime}\left(\operatorname{net}_{c_{j}^{v}}(t)\right) y^{i n_{j}}(t) y^{m}(t-1),
$$




$$
\frac{\partial s_{c_{j}^{v}}(t)}{\partial w_{i n_{j} m}}=\frac{\partial s_{c_{j}^{v}}(t-1)}{\partial w_{i n_{j} m}}+g\left(\text { net }_{c_{j}^{v}}(t)\right) f_{i n_{j}}^{\prime}\left(\text { net }_{i n_{j}}\right) y^{m}(t-1) .
$$

Por fim, os pesos do gate de entrada são atualizados mediante a somatória das contribuições de todas as células do bloco, assim:

$$
\Delta w_{l m}(t)=\alpha \sum_{v=1}^{s_{j}} e_{s_{c_{j}^{v}}}(t) \frac{\partial s_{c_{j}^{v}}(t)}{\partial w_{l m}}, \quad \text { para } l=i n
$$

\subsection{Aprendizado Supervisionado e Não-Supervisionado}

O aprendizado de máquina é uma área da inteligência artificial que tem como objetivo desenvolver métodos computacionais capazes de inferir conhecimento de forma automática a partir do processamento de conhecimento prévio. Este conhecimento prévio refere-se às observações obtidas para um problema de estudo que, geralmente, são medições feitas para um conjunto de amostras, conhecido como conjunto de treino. As técnicas de aprendizado de máquina são divididas em três categorias: supervisionadas, nãosupervisionadas e semi-supervisionadas (Mitchell, 1997). Nesta seção são apresentadas as duas primeiras, as quais estão relacionadas com os tópicos abordados nesta tese.

O aprendizado supervisionado abrange todos os métodos de aprendizado de máquina que têm a capacidade de inferir uma relação entre pares de exemplos de entrada e saída desejada. O conjunto de pares de exemplo é conhecido como dados de treinamento, em que as entradas são os atributos ou as características mensuradas para as amostras de estudo, e as saídas correspondem a uma categoria ou classe conhecida de maneira natural. Considerando-se um problema com $p$ variáveis extraídas para $n$ amostras, os vetores de atributos de cada amostra são armazenados na matriz de atributos $\mathbf{X}_{n \times p}$, onde cada amostra pode pertencer a uma das classes $c$ de um conjunto de $k$ classes $C=\left\{c_{1}, c_{2}, \ldots, c_{k}\right\}$. Se a saída for um valor contínuo trata-se de um problema de regressão e se for um valor discreto de um problema de classificação. Após a fase de treinamento o objetivo é que o sistema seja capaz de predizer a saída correta para uma nova entrada válida e desconhecida pelo sistema, provando assim que o sistema conseguiu aprimorar a sua capacidade de generalização. As características devem ser adequadamente selecionadas de tal forma que consigam refletir a maior quantidade de informação possível relacionada à tarefa de interesse. Além disso, os dados devem corresponder a características tão diferentes quanto possível, ou seja, não devem ser redundantes ou pelo menos ter uma redundância mínima (Mitchell, 1997). Geralmente esta informação não é conhecida, portanto, é recomendado usar uma técnica de 
redução de dimensionalidade.

A redução da dimensionalidade facilita a visualização dos dados, possibilita um melhor entendimento destes e reduz o custo computacional. Uma técnica clássica para detectar possíveis redundâncias é a análise de componentes principais $\left(\mathrm{PCA}^{15}\right)$. A técnica PCA aplica um processo de transformação ortogonal sobre os dados para obter um conjunto menor de variáveis linearmente não correlacionadas chamadas componentes principais. A obtenção das componentes principais pode ser realizada de duas formas, mediante a decomposição em autovalores da matriz de covariância ou através da decomposição em valores singulares da matriz de dados, em ambos os casos, a matriz de atributos deve ser previamente normalizada. No primeiro método, são calculados os autovalores da matriz de covariância e ordenados ascendentemente e, pelo fato dos autovalores estarem relacionados com as variâncias das novas variáveis, a seleção dos primeiros $p$ autovalores que atingirem uma porcentagem de variância acumulada desejada indicará o número de auto vetores necessários para formar as novas variáveis, geralmente, a quantidade que explica o $75 \%$ da variação total (Alpaydin, 2004).

Um interessante método alternativo de redução da dimensionalidade é a técnica de seleção de atributos mediante busca heurística. Esta técnica além de auxiliar na redução da dimensionalidade, simplifica o modelo de predição, diminui o custo computacional e fornece uma relação sobre os atributos que facilita o melhor entendimento dos dados. Um conhecido algoritmo desta categoria é o algoritmo de seleção sequencial para frente (SFS ${ }^{16}$ ), o qual seleciona o subconjunto de atributos que melhor representa o conjunto total de atributos originais mediante uma busca sequencial, a qual começa com um conjunto vazio e iterativamente vai testando cada atributo candidato ainda não selecionado, um de cada vez, que produzir o máximo (ou o mínimo segundo a função de critério usada) valor de uma função critério quando combinado com os atributos que foram selecionados até a iteração anterior. Uma função critério comumente usada é o erro de classificação, portanto o algoritmo seleciona o atributo que produzir o menor erro (Jain \& Zongker, 1997). Uma desvantagem deste algoritmo é que um atributo selecionado não pode ser descartado em iterações posteriores.

Após ter considerados os passos anteriores, o passo seguinte é treinar um classificador. Um dos classificadores mais amplamente usados em aprendizado de máquina é o classificador Naive Bayes. Sua popularidade se justifica em virtude do bom desempenho em várias tarefas de classificação apesar da sua simplicidade. Este classificador baseia-se no teorema de Bayes, o qual define a probabilidade condicional a posteriori de uma amostra $a$ per-

\footnotetext{
${ }^{15}$ Sigla de Principal Components Analysis

${ }^{16}$ Sigla de Sequential Forward Selection
} 
tencer à classe $c$, denotada como $P(c \mid a)$, dada a probabilidade a priori da classe $c(P(c))$ e a probabilidade condicional $P(a \mid c)$, e cujo cálculo é dado por: $[P(a \mid c) \cdot P(c)] / P(a)$. O objetivo do algoritmo é determinar a melhor classe $c_{M A P}{ }^{17}$ que maximiza a probabilidade a posteriori, isto é: $c_{M A P}=\underset{c \in C}{\arg \max } P(a \mid c)$ $P(c)$. Porém, como uma amostra está definida em termos de $p$ atributos, temse que $c_{M A P}=\underset{c \in C}{\arg \max } P\left(x_{1}, x_{2}, \ldots, x_{p} \mid c\right) P(c)$. Dado que o classificador assume que as probabilidades dos atributos são independentes ${ }^{18}$, isto é, $P\left(x_{1}, x_{2}, \ldots, x_{p} \mid c\right)$ $=\prod_{i} P\left(x_{i} \mid c\right)$, então o algoritmo designa a classe $c_{M A P}$ à amostra $x$ da seguinte forma (Hand \& Yu, 2001):

$$
c_{M A P}=\underset{c \in C}{\arg \max } P\left(c_{j}\right) \prod_{x \in X} P(x \mid c) .
$$

Contrário ao aprendizado supervisionado, no não-supervisionado as amostras de treinamento não estão rotuladas, contando somente com o vetor de atributos calculado para cada amostra. Ao não ter uma categoria conhecida, o objetivo é agrupar as amostras de acordo com similaridades ou dissimilaridade entre os padrões existentes, para posteriormente derivar conclusões úteis sobre o resultado. Este processo é chamado de agrupamento (clusterização) e os conjuntos obtidos de grupos (clusters). Uma característica fundamental é que os elementos dentro dos grupos devem ser tão similares quanto possível, e tão dissimilares quanto possível com os elementos de outros grupos. Para tal, um critério de similaridade deve ser estabelecido. Este critério permite quantificar quão similar são dois vetores de atributos, os quais devem ser previamente normalizados para evitar a influência dos valores de um atributo sobre o outro, de tal forma que a contribuição à média seja equitativa. Baseando-se nos valores de similaridade determinados, as amostras são agrupadas segundo um critério previamente definido e adequado às características dos atributos. Tendo definido a medida de similaridade e o critério de agrupamento, um algoritmo de agrupamento é executado (Jain et al., 1999).

Quanto aos algoritmos de agrupamento, estes são divididos em duas categorias: hierárquicos e particionais. Os algoritmos hierárquicos, por sua vez, são divididos em aglomerativos e divisivos, e os particionais em exclusivos e não-exclusivos. Nos métodos particionais uma amostra é aderida a um grupo se a adesão dela a esse grupo minimizar uma função de custo. Nesta abordagem o número de agrupamentos deve ser escolhido a priori, e uma amostra pode mudar de agrupamento em qualquer iteração do algoritmo (Jain et al., 1999). Apesar do inconveniente que pode trazer a seleção prévia do número de agrupamentos, este método é mais rápido que o método hierárquico, per-

\footnotetext{
${ }^{17}$ Sigla de Maximum A Posteriori

${ }^{18}$ Isso explica o nome de ingênuo (naives)
} 
mitindo operar com bases de dados maiores. Um popular algoritmo desta categoria é o $k$-médias.

Nos algoritmos de agrupamento hierárquico o conjunto de amostras é dividido em partições aninhadas de acordo com uma hierarquia entre elas. No estado inicial do algoritmo hierárquico aglomerativo cada elemento começa formando um grupo, isto é, são formados tantos grupos quanto amostras houverem. Em seguida, o algoritmo iterativamente vai juntando os pares de grupos que tiverem a maior similaridade de acordo com uma métrica, criando assim um novo grupo. A cada passo o número de grupos é reduzido em uma unidade. O processo é repetido até obter um único grupo de dados ou até atingir um limiar especificado com anterioridade. Esta estratégia é conhecida como bottom-up. Os algoritmos hierárquicos divisivos seguem o processo contrário dos algoritmos aglomerativos. Nessa abordagem todos os elementos pertencem a um único agrupamento que vai sucessivamente se dividindo em grupos menores, formando um novo agrupamento com a divisão dos pares de grupos que tiverem o menor valor de similaridade. Computacionalmente, este método é considerado menos eficiente que o caso aglomerativo. Esta estratégia é conhecida como top-down. O resultado de um algoritmo hierárquico pode ser representado mediante um diagrama em árvore chamado dendrograma. A Fig. 2.10(b) ilustra o exemplo de um dendrograma para um problema de agrupamento de 5 amostras (Fig. 2.10(a)). Nesse diagrama, os agrupamentos são formados mediante um corte transversal em algum nível desejado do dendrograma, não havendo um corte recomendado pelo algoritmo, portanto, este deve ser definido segundo as especificações do problema ou a critério do pesquisador.

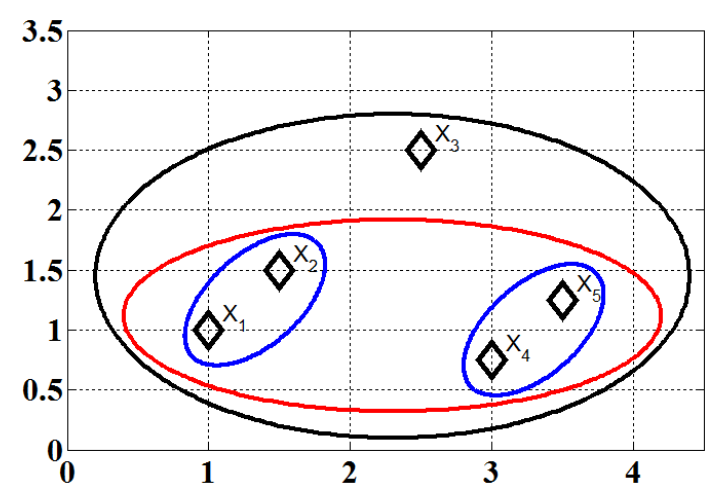

(a)

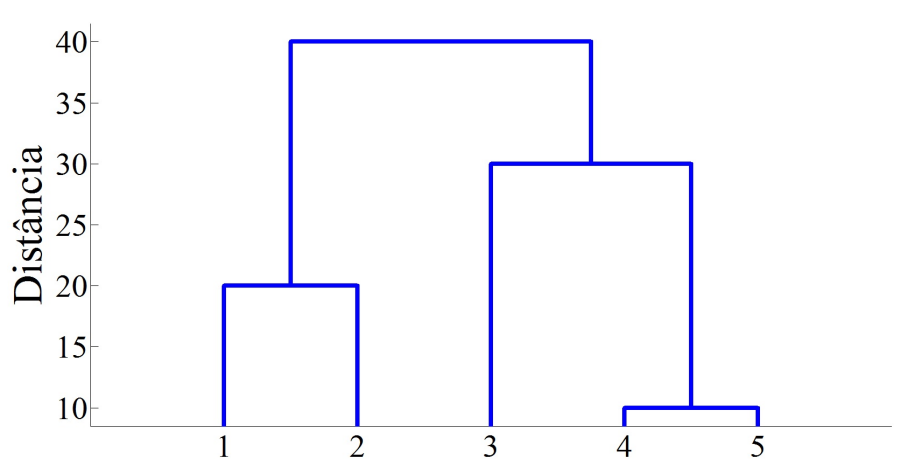

(b)

Figura 2.10: Problema de agrupamento com 5 amostras. (a) Pontos no espaço bidimensional; (b) Dendrograma.

Algumas das medidas de distância usadas pelos algoritmos e agrupamento são descritas a seguir. A distância entre os valores $i$ e $j$ de $\mathbf{X}$, denotada como $d_{i j}$, pode ser calculada usando alguma das seguintes métricas de semelhança (Jain et al., 1999): 
- Minkowski: Corresponde a uma métrica generalizada para o cálculo da distância entre dois pontos no plano $p$-dimensional e é calculada com a Eq. (2.55). Segundo o valor de $\lambda \geq 1$ podem ser obtidas distâncias particulares, com $\lambda=1$ tem-se a métrica Euclidiana (distância $\ell_{1}$ ), com $\lambda=2$ designa-se a métrica de Manhattan ${ }^{19}$ (distância $\ell_{2}$ ) e com $\lambda=\infty$ é obtida a métrica do máximo (distância $\ell_{\infty}$ ), igual a $d_{i j}=\max _{k}\left|x_{i k}-x_{j k}\right|$.

$$
d_{i j}=\left(\sum_{k=1}^{p}\left|x_{i k}-x_{j k}\right|^{\lambda}\right)^{1 / \lambda} .
$$

- Mahalanobis: Esta métrica tem a particularidade de ser baseada nas correlações das variáveis e ser invariante a mudanças de escala, e é calculada como:

$$
d_{i j}=\sqrt{\left(\mathbf{x}_{i}-\mathbf{x}_{j}\right)^{\mathbf{T}} \Sigma^{-1}\left(\mathbf{x}_{i}-\mathbf{x}_{j}\right)},
$$

em que $\Sigma$ é a matriz de covariâncias das variáveis.

- Camberra: Métrica exclusiva para variáveis com valores não negativos. Também é uma medida invariante a transformações de escala e é dada por:

$$
d_{i j}=\sum_{k=1}^{p} \frac{\left|x_{i k}-x_{j k}\right|}{\left(x_{i k}+x_{j k}\right)} .
$$

- Cosseno: Esta métrica relaciona a semelhança entre dois vetores de acordo como o ângulo de separação entre eles, e é dada por:

$$
d_{i j}=1-\frac{\sum_{k=1}^{p} x_{i k} x_{j k}}{\sqrt{\sum_{i=1}^{p} x_{i}^{2}} \sqrt{\sum_{j=1}^{p} x_{j}^{2}}} .
$$

Conforme supracitado, o algoritmo aglomerativo começa com um agrupamento para cada amostra, e iterativamente agrupa pares de grupos segundo a similaridade/dissimilaridade, porém somente na primeira iteração é calculada a distância entre pares de amostras, dado que nas próximas iterações a similaridade é calculada entre grupos visando formar um novo agrupamento com os grupos que tiverem as amostras mais similares. Por conseguinte, já não deverá ser mais calculada a distância entre pares de amostra, e sim entre agrupamentos de acordo com a semelhança das suas amostras. Os diferentes critérios de agrupamento descritos abaixo são os mais destacados. Para todos os métodos apresentados, considere dois conjuntos $U=\left\{u_{1}, u_{2}, \ldots, u_{r}\right\} \mathrm{e}$

\footnotetext{
${ }^{19}$ Também conhecida como city-block metric
} 
$V=\left\{v_{1}, v_{2}, \ldots, v_{s}\right\}$ de tamanhos $r$ e $s$, respectivamente, e $d_{i j}$ denota a distância entre os elementos $u_{i} \in U$ e $v_{j} \in V$, e $D(U, V)$ a distância entre os grupos $U$ e $V$.

- Ligação simples: A distância de dois grupos é definida de acordo com a menor distância entre os seus elementos, assim:

$$
D(U, V)=\min _{u_{i} \in U, v_{j} \in V}\left\{d_{i j}\right\} .
$$

- Ligação completa: A distância de dois grupos é definida de acordo com a maior distância entre os seus elementos, isto é:

$$
D(U, V)=\max _{u_{i} \in U, v_{j} \in V}\left\{d_{i j}\right\} .
$$

- Ligação média: A distância de dois grupos é definida de acordo com a distância média entre os seus elementos, e é calculada da seguinte forma:

$$
D(U, V)=\frac{1}{r s} \sum_{u_{i} \in U, v_{j} \in V} d_{i j} .
$$

- Centroide: A distância de dois grupos é definida de acordo com a distância entre os seus centroides (média das distâncias), e é calculada da seguinte forma:

$$
D(U, V)=\left\|\frac{1}{r} \sum_{1<i \leq r} U_{i}-\frac{1}{s} \sum_{1<i \leq s} V_{j}\right\|^{2} .
$$

- Ward: Este método de ligação, contrário aos anteriores, não usa uma medida de distância, mas procura entre todos as partições possíveis as duas que minimizam a perda de informação ao serem juntadas. A cada passo, os elementos do novo agrupamento terão a maior homogeneidade entre eles (menor dispersão intraclasse) e a maior heterogeneidade com os elementos dos outros grupos. Para tal, é calculada a soma dos erros quadráticos para cada agrupamento, assim:

$$
D=\sum_{i=1}^{K} \sum_{j=1}^{n_{i}}\left(x_{i j}-\overline{\mathbf{x}}_{i}\right)^{2},
$$

em que $x_{i j}$ é o $j$-ésimo elemento do $i$-ésimo agrupamento, $n_{i}$ é o número de elementos desse grupo e $K$ o número de agrupamentos na iteração atual. Este método também é conhecido como o método da mínima variância. 


\subsubsection{Técnicas de Reamostragem}

O modelo de classificação é construído usando um conjunto de instâncias ou amostras. Após construído o modelo, o mais natural é poder determinar a sua capacidade de generalização em termos de taxas de erro, por exemplo, a acurácia. Para tal fim, o modelo deverá ser executado usando instâncias novas e o resultado avaliado mediante alguma medida de desempenho. Para tanto, o conjunto de amostras deverá ser particionado em dois conjuntos, um conjunto para construir o modelo, chamado conjunto de treino, e um conjunto para realizar o teste, chamado conjunto de teste (Good, 2006). Alguns métodos para realizar tal partição são descritos a seguir:

- Resubstituição: Nesta técnica o conjunto de teste é igual ao conjunto de treino, isto é, a taxa de erro é calculada usando o conjunto de treinamento. Evidentemente o resultado será otimista.

- Retenção ${ }^{20}$ : Este método reserva aleatoriamente uma pequena quantidade de amostras para realizar o teste, geralmente $30 \%$, tendo o risco de uma ou mais amostras selecionadas não serem representativas, por exemplo, porque alguma classe está ausente. Para evitar isso é usada uma versão estratificada que garante que todas as classes estarão presentes no conjunto de teste e em aproximadamente igual proporção, reduzindo assim a variância da estimativa. Outra aproximação consiste em calcular a taxa média de repetições sucessivas de retenção, usando diferentes amostras em cada etapa.

- Validação cruzada $^{21}$ : Nesta técnica o conjunto de amostras é dividido em $k$ subconjuntos de teste de igual tamanho, e o modelo é executado $k$ vezes, sendo usado como conjunto de treino o conjunto formado pelos $k-1$ conjuntos de teste restante. A taxa de erro total é igual à média das taxas de erros calculadas em cada etapa. Este processo também é conhecido como validação cruzada $k$-fold. Uma forma particular de validação cruzada é a validação cruzada deixando um fora ${ }^{22}$, na qual o número de folds é igual a $n$, onde $n$ é o número de amostras, e o classificador é construído $n$ vezes. O alto custo computacional é evidente, ademais, esta técnica não permite formar o conjunto de treino com amostras selecionadas aleatoriamente nem a estratificação. Note-se que na validação cruzada $k$-fold uma amostra, uma vez selecionada, não pode ser selecionada novamente para um conjunto de treino ou de teste, dado que a amostragem foi realizada sem reposição. Isso diminui a variância que pode

\footnotetext{
20 Do inglês: Hold-out

21 Do inglês: Cross-validation

22 Do inglês: Leave-one-out
} 
Tabela 2.1: Matriz de confusão multiclasse.

\begin{tabular}{c|cccccccc|c}
\hline \multirow{2}{*}{ Classe de saída } & \multicolumn{7}{|c|}{ Classe de entrada } & \multirow{2}{*}{ Total } \\
\cline { 2 - 8 } & 1 & $\ldots$ & $i-1$ & $i$ & $i+1$ & $\ldots$ & $k$ & $M_{1+}$ \\
$\vdots$ & $M_{11}$ & $\ldots$ & $M_{1 i-1}$ & $M_{1 i}$ & $M_{1 i+1}$ & $\ldots$ & $M_{1 k}$ & $M_{2+}$ \\
$i-1$ & $\vdots$ & $\ddots$ & $\vdots$ & $\vdots$ & $\vdots$ & $\ddots$ & $\vdots$ & $M_{2+}$ \\
$i$ & $M_{i-11}$ & $\ldots$ & $M_{i-1 i-1}$ & $M_{i-1 i}$ & $M_{i-1 i+1}$ & $\ldots$ & $M_{i-1 k}$ & $M_{i-1+}$ \\
$i+1$ & $M_{i 1}$ & $\ldots$ & $M_{i i-1}$ & $M_{i i}$ & $M_{i i+1}$ & $\ldots$ & $M_{i k}$ & $M_{i+}$ \\
$\vdots$ & $M_{i+11}$ & $\ldots$ & $M_{i+1 i-1}$ & $M_{i+1 i}$ & $M_{i+1 i+1}$ & $\ldots$ & $M_{i+1 k}$ & $M_{i+1+}$ \\
$k$ & $\vdots$ & $\ddots$ & $\vdots$ & $\vdots$ & $\vdots$ & $\ddots$ & $\vdots$ & $\vdots$ \\
\hline Total & $M_{k 1}$ & $\ldots$ & $M_{k i-1}$ & $M_{k i}$ & $M_{k i+1}$ & $\ldots$ & $M_{k k}$ & $M_{k+}$ \\
\hline & $M_{+1}$ & $\ldots$ & $M_{+i-1}$ & $M_{+i}$ & $M_{+i+1}$ & $\ldots$ & $M_{+k}$ & $n$ \\
\hline
\end{tabular}

ocorrer em cada fold. Para evitar isso, é usada a técnica bootstrap, que consistem em selecionar aleatoriamente $n$ elementos do conjunto usando reposição, para com estes formar o conjunto de treino. Pelo fato de ter sido usada a reposição, o conjunto de treino terá amostras repetidas e, então, o conjunto de teste é formado com o conjunto de amostras que não foram selecionadas para treino. O processo é repetido $k$ vezes e o conjunto de teste terá diferente tamanho em cada etapa (Good, 2006). O bootstrap é recomendado para conjuntos pequenos.

\subsubsection{Medidas de Desempenho}

Após terminado o aprendizado, o resultado obtido deve ser contrastado com o resultado esperado usando medidas e/ou testes apropriados para tal fim, para posteriormente interpretar os valores obtidos. As medidas de desempenho permitem avaliar quantitativamente o resultado devolvido por uma técnica de classificação ou comparar o resultado obtido com duas ou mais técnicas de classificação diferentes.

O resultado do classificador supervisionado pode ser sumarizado em uma matriz chamada matriz de confusão. Para um problema de classificação multiclasse com $k$ classes, o resultado pode ser condensado na matriz de confusão da Tabela 2.1. Na matriz de confusão $\mathrm{M}$ de $k \times k$, o elemento $M_{i j}$ indica a quantidade total de amostras da classe conhecida $j$ (classe de entrada) que foi designada pelo classificador na classe $i$ (classe de saída), com $i, j=1, \ldots, k$. Dessa forma, a somatória dos elementos da diagonal principal $\left(M_{i i}\right)$ é o total de elementos corretamente classificados, o total de cada linha $\left(M_{i+}\right)$ é o total marginal de amostras designadas pelo classificador em uma dada classe de saída, entretanto, o total de cada coluna $\left(M_{+i}\right)$ indica o número total de amostras de cada classe, e $n$ é o número total de amostras do conjunto de teste (Makhtar et al., 2011). Da matriz de confusão podem ser calculadas diversas medidas estatísticas de desempenho, algumas dessas são descritas a seguir. 
A partir da matriz de confusão podem ser calculadas diversas medidas estatísticas para avaliar a qualidade da performance do classificador. Inicialmente estas medidas foram definidas para duas classes, no entanto, é possível fazer uma generalização ao problema multiclasse. Em uma matriz de confusão binária a quantidade de amostras corretamente classificadas na classe $i$ é chamada verdadeiro positivo $\left(\mathrm{TP}^{23}\right)$, o total de amostras corretamente excluídas da classe $i$ é conhecido como verdadeiro negativo $\left(\mathrm{TN}^{24}\right)$, a quantidade de amostras da classe $i$ que foram classificadas erroneamente na outra classe é o falso negativo $\left(\mathrm{FN}^{25}\right)$ e o total de amostras erroneamente classificadas na classe $i$ se conhece como falso positivo $\left(\mathrm{FP}^{26}\right)$ (Fawcett, 2006). Estes valores servem para calcular as taxas de desempenho.

A taxas de desempenho mais importantes são: sensibilidade (revocação ou taxa de verdadeiros positivos $\left(\mathrm{TPR}^{27}\right)$ ), especificidade (taxa de verdadeiros negativos $\left(\mathrm{TNR}^{28}\right)$ ), precisão (valor preditivo positivo $\left(\mathrm{PPV}^{29}\right)$ ) e valor preditivo negativo $\left(\mathrm{VPN}^{30}\right)$. Outras taxas básicas também são possíveis, porém resultam ser as complementares das anteriores, por exemplo, FNR é o complementar de TPR (TPR + FNR = 1) e FPR o complementar de TNR,...etc. É importante ressaltar que em um problema multiclasse existem tantas taxas de um tipo quanto número de classes. Basicamente, as taxas de desempenho, tanto binárias quanto multiclasse, seguem a definição matemática dada pela Eq. (2.64), em que $T_{i}$ é a taxa de desempenho a ser calculada para a classe $i$ e os valores $a_{i}$ e $b_{i}$ definem o tipo de taxa, podendo ser $T P_{i}, T N_{i}, F P_{i}$ ou $F N_{i}$, conforme a relação apresentada na Tabela 2.2. Na última coluna dessa tabela é descrito o significado de cada taxa.

$$
T_{i}=\frac{a_{i}}{a_{i}+b_{i}}
$$

Na generalização ao problema multiclasse, que abrange o contexto deste trabalho, os valores necessários para o cálculo das taxas descritas anterior-

\footnotetext{
23 Sigla de True Positive

24 Sigla de True Negative

25 Sigla de False Negative

26 Sigla de False Positive

27 Sigla de True Positive Rate

28 Sigla de True Negative Rate

29 Sigla de Positive Predictive Value

30 Sigla de Negative Predictive Value
} 
Tabela 2.2: Taxas de desempenho para avaliar a performance de um classificador.

\begin{tabular}{|c|c|c|c|}
\hline Medida $\left(T_{i}\right)$ & $a_{i}$ & $b_{i}$ & Descrição \\
\hline Sensibilidade $(S)$ & $T P_{i}$ & $F N_{i}$ & Fração de classi \\
\hline Precisão $(P)$ & $T P_{i}$ & $F P_{i}$ & $\begin{array}{l}\text { Probabilidade de uma amostra classi- } \\
\text { ficada na classe } i \text { realmente ser dessa }\end{array}$ \\
\hline Especificidade $(E)$ & $T N_{i}$ & $F P_{i}$ & Fração de exclusão correta de amos- \\
\hline Valor Preditivo Negativo $(V P N)$ & $T N_{i}$ & $F N_{i}$ & $\begin{array}{l}\text { Probabilidade de uma amostra ex- } \\
\text { cluída da classe } i \text { realmente não ser } \\
\text { dessa classe }\end{array}$ \\
\hline
\end{tabular}

mente e sumarizadas na Tabela 2.2 são calculados assim:

$$
\begin{aligned}
& T P_{i}=M_{i i}, \\
& F P_{i}=\sum_{j} M_{i j}-M_{i i}, \\
& F N_{i}=\sum_{j} M_{j i}-M_{i i}, \\
& T N_{i}=\sum \sum[\mathbf{M}(i, i)],
\end{aligned}
$$

em que $\mathbf{M}(i, i)$ é a submatriz resultante de retirar a linha $i$ e a coluna $i$ da matriz de confusão M. Por facilidade os valores necessários para o cálculo das taxas são relacionados dentro da matriz de confusão da Tabela $2.1 \mathrm{com}$ uma cor, sendo $T P_{i}$ em vermelho, $F N_{i}$ em azul, $F P_{i}$ em verde e $T N_{i}$ em cinza. Uma importante medida global é a acurácia (taxa de classificação correta), que é a proporção total de amostras corretamente classificadas sobre o total de amostras do conjunto de teste, e é calculada a partir da matriz de confusão como $\operatorname{tr}(\mathbf{M}) / n$, onde $\operatorname{tr}(\cdot)$ é o traço da matriz. Outra importante medida local é o F-score, que relaciona a sensibilidade $(S)$ com a precisão $(P)$ através da média harmônica balanceada entre $S$ e $P$, igual a $2(S \cdot P) /(S+P)$, e resume a compensação entre essas duas taxas. Todas as medidas descritas acima tomam valores no intervalo $[0,1]$.

Coeficiente kappa ( $\kappa$ ): Esta métrica é uma medida estatística de associação para descrever o grau de concordância entre o resultado de classificação (concordância observada) e o resultado esperado tão somente pelo acaso (concordância esperada). Contrário às taxas de desempenho, o coeficiente $\kappa$ toma valores no intervalo $[-1,1]$, em que 1 é a concordância máxima, 0 a concordância esperada pelo acaso e valores negativos sugerem discordância menor daquela esperada pelo acaso. A definição matemática de $\kappa$ é $\left(p_{o}-p_{e}\right) /\left(1-p_{e}\right)$, onde $p_{o}$ é a concordância observada e $p_{e}$ a concordância esperada (Landis \& Koch, 1977). Usando os valores da matriz de confusão, o coeficiente $\kappa$ é cal- 
Tabela 2.3: Interpretação subjetiva do coeficiente $\kappa$ (Landis \& Koch, 1977).

\begin{tabular}{r|l}
\hline$\kappa$ & Conceito \\
\hline \hline$\kappa \leq 0.0$ & Péssimo \\
$0<\kappa \leq 0.2$ & Ruim \\
$0.2<\kappa \leq 0.4$ & Razoável \\
$0.4<\kappa \leq 0.6$ & Bom \\
$0.6<\kappa \leq 0.8$ & Muito bom \\
$0.8<\kappa \leq 1.0$ & Excelente \\
\hline
\end{tabular}

culado como:

$$
\kappa=\frac{n \sum_{1}^{k} M_{i i}-\sum_{1}^{k} M_{i+} M_{+i}}{n^{2}-\sum_{1}^{k} M_{i+} M_{+i}}
$$

em que $n$ é o total de amostras do conjunto de teste, $M_{i+}$ é o total de amostras associadas à classe correta e $M_{i+}=\sum_{j=1}^{k} M_{i j}$ e $M_{+i}=\sum_{j=1}^{k} M_{j i}$ são os totais marginais de linha e coluna, respectivamente. Duas características estatísticas importante de $\kappa$ são sua normalidade assintótica e o fato de possuir uma variância plenamente definida, a qual é calculada como:

$$
\operatorname{var}(\kappa)=\frac{1}{n}\left[\frac{\theta_{1}\left(1-\theta_{1}\right)}{\left(1-\theta_{2}\right)^{2}}+\frac{2\left(1-\theta_{1}\right)\left(2 \theta_{1} \theta_{2}-\theta_{3}\right)}{\left(1-\theta_{2}\right)^{3}}+\frac{\left(1-\theta_{1}\right)^{2}\left(\theta_{4}-4 \theta_{2}^{2}\right)}{\left(1-\theta_{2}\right)^{4}}\right]
$$

em que

$$
\begin{aligned}
& \theta_{1}=\frac{1}{n} \sum_{i=1}^{k} M_{i i}, \\
& \theta_{2}=\frac{1}{n^{2}} \sum_{i=1}^{k} M_{i+} M_{+i}, \\
& \theta_{3}=\frac{1}{n^{2}} \sum_{i=1}^{k} M_{i i}\left(M_{i+} M_{+i}\right), \\
& \theta_{4}=\frac{1}{n^{3}} \sum_{i=1}^{k} \sum_{j=1}^{k} M_{i j}\left(M_{j+} M_{+i}\right)^{2} .
\end{aligned}
$$

Uma interpretação subjetiva do coeficiente $\kappa$ foi definida por Landis \& Koch (1977) e é apresentada na Tabela 2.3.

Teste de significância: O fato de $\kappa$ ser normalmente distribuído facilita a aplicação de testes de hipóteses paramétricos e o cálculo de intervalos de confiança. Com o intuito de testar objetivamente a existência de uma diferença significativa entre dois resultados de classificação, pode ser aplicado um teste de significância estatística sob a hipótese da diferença de médias, as quais são calculadas através de dados de $\kappa$ obtidos por dois classificadores executados para diferentes tamanhos de amostras de um mesmo conjunto de teste 
(Fawcett, 2006). A hipótese deste teste é dada por:

$$
\begin{aligned}
& H_{0}: \bar{\kappa}=0 \\
& H_{1}: \bar{\kappa}<0
\end{aligned},
$$

em que $\bar{\kappa}$ é diferença das médias calculadas para cada um dos dois conjuntos de valores de $\kappa$ obtidos para os experimentos de classificação a comparar, isto é, $\bar{\kappa}=\bar{\kappa}_{1}-\bar{\kappa}_{2}$, onde $\bar{\kappa}_{1}$ é a média do conjunto de kappas do primeiro classificador e $\bar{\kappa}_{2}$ do segundo. Esta hipótese é verificada usando a estatística $T$, dada por:

$$
T=\frac{\bar{\kappa}}{\left(\sigma_{d} / \sqrt{n}\right)},
$$

em que $n$ é o total de coeficientes de kappa calculados no experimento e $\sigma_{d}$ é o desvio padrão da diferença entre os dois conjuntos de amostras de $\kappa$. Como resultado é confirmada que a diferença de médias entre os dois experimentos é significativa, isto é, $H_{0}$ é rejeitada, se o valor de $T$ for menor que $-T_{\alpha, n-1}$, que é o valor teórico de $T$ dado pela distribuição $t$-student com nível de significância $\alpha$ e $n-1$ graus de liberdade.

\subsubsection{Métricas para Comparação de Agrupamentos}

Nesta seção são descritas algumas medidas para comparar a similaridade entre dois agrupamentos resultantes da aplicação de um método de aprendizado não-supervisionado. Diferentes medidas têm sido propostas para a comparação de resultados em tarefas de agrupamento de dados, as quais também podem ser usadas para comparar as comunidades identificadas por um algoritmo de detecção com o resultado ideal ou esperado (Mitchell, 1997). Duas medidas popularmente usadas para mensurar a semelhança entre agrupamentos disjuntos são: índice corrigido de Rand ( $\left.\mathrm{ARI}^{31}\right)$ e informação mútua normalizada $\left(\mathrm{NMI}^{32}\right)$.

A métrica ARI é uma adaptação do índice de Rand (RI), que é uma medida de similaridade entre dois agrupamentos $U=\left\{u_{1}, \ldots, u_{r}\right\}$ e $V=\left\{v_{1}, \ldots, v_{c}\right\}$ do conjunto $S=\left\{O_{1}, \ldots, O_{n}\right\}$ de $n$ elementos, tal que $\bigcup_{i=1}^{r} u_{i}=S$, e $u_{i} \bigcap u_{j}=\emptyset$, para todo $i \neq j$. Uma definição semelhante é feita para $V$. Este índice mensura a dissimilaridade entre uma partição a priori definida por um critério externo $(V)$ e outra obtida através de um processo de agrupamento $(U)$ (Santos \& Embrechts, 2009). A informação sobre a distribuição de objetos entre pares de grupos das duas partições $U$ e $V$, que é sintetizada em uma tabela de contingência (similar à matriz de confusão), é usada para o cálculo deste índice. Por fim, RI tem valores na faixa de $[0,1]$, onde um valor alto indica maior seme-

\footnotetext{
31 Sigla de Adjusted Rand Index

32 Sigla de Normalized Mutual Information
} 
lhança entre as duas partições, e é calculado com: $\frac{a+d}{a+b+c+d}$, em que $a$ é o total de pares de objetos que estão no mesmo grupo em $U$ e em $V, d$ é o total de pares de objetos em diferente grupo em $U$ e em $V, b$ total de pares de objetos no mesmo grupo em $U$, mas não em $V$; e $c$ total de pares de objetos no mesmo grupo em $V$, mas não em $U$. Para evitar que o índice tenda a valores altos conforme o número de grupos aumenta e que a tendência de um valor esperado seja diferente de zero quando aplicado a duas partições aleatórias, RI foi corrigido, criando o índice ARI (Santos \& Embrechts, 2009), que é calculado como:

$$
\mathrm{ARI}=\frac{{ }_{n} C_{2} \cdot(a+d)-A}{\left({ }_{n} C_{2}\right)^{2}-A},
$$

em que $A=[(a+b)(a+c)+(c+d)(b+d)]$ e ${ }_{n} C_{2}$ significa $n$ combinado 2. ARI tem valores na faixa $[-1,1]$, onde o valor 0 é o valor esperado para uma partição aleatória, um valor positivo indica maior similaridade e um valor negativo indica maior grau de divergência com relação ao valor esperado. A definição original de ARI foi feita para duas partições de diferentes tamanhos, $1 \leq r \neq c \leq n$, gerando uma matriz de contingência de $r \times c$. No entanto, ARI pode ser facilmente adaptado para ser calculado a partir da matriz de confusão $\mathbf{M}$ da Tabela 2.1, sendo $r=k=c$, e calculando os valores $a, b, c$ e $d$ assim:

$$
\begin{aligned}
& a=\frac{1}{2}\left(\sum_{i=1}^{k} \sum_{j=1}^{k} M_{i j}^{2}-n\right), \\
& b=\frac{1}{2}\left(\sum_{i=1}^{k} M_{i+}^{2}-\sum_{i=1}^{k} \sum_{j=1}^{k} M_{i j}^{2}\right), \\
& c=\frac{1}{2}\left(\sum_{j=1}^{k} M_{+j}^{2}-\sum_{i=1}^{k} \sum_{j=1}^{k} M_{i j}^{2}\right), \\
& d=\frac{1}{2}\left(\sum_{i=1}^{k} \sum_{j=1}^{k} M_{i j}^{2}+n^{2}-\sum_{i=1}^{k} M_{i+}^{2}-\sum_{j=1}^{k} M_{+j}^{2}\right) .
\end{aligned}
$$

A medida NMI é uma correção da medida de Informação Mútua ( $\left.\mathrm{MI}^{33}\right)$, que é baseada na teoria da informação e mensura a dependência estatística entre dois agrupamentos, um agrupamento conhecido e outro calculado, por exemplo, uma comunidade detectada com algum algoritmo de detecção de comunidades. NMI cai na faixa de $[0,1]$. Para os dois agrupamentos $U$ e $V$ descritos acima, NMI é calculada como (Vinh et al., 2010):

$$
\operatorname{NMI}(U, V)=\frac{\mathrm{MI}(U, V)-\mathrm{E}\{\mathrm{MI}(U, V)\}}{\max \{\mathrm{H}(U), \mathrm{H}(V)\}-\mathrm{E}\{\mathrm{MI}(U, V)\}},
$$

em que $\mathrm{MI}(U, V)=\sum_{u \in U} \sum_{v \in V} p_{u, v} \log \left(p_{u, v} /\left(p_{u} p_{v}\right)\right)$ é a informação mútua não nor-

${ }^{33}$ Sigla de Mutual Information 
malizada dos conjuntos $U$ e $V$, onde $p_{u}$ é a probabilidade de um elemento pertencer ao conjunto $U$ e $p_{u, v}$ a probabilidade de pertencer aos dois conjuntos simultaneamente; $\mathrm{E}\{\mathrm{MI}(U, V)\}$ é o respectivo valor esperado de $\mathrm{MI}(U, V)$; e $\mathrm{H}(U)=-\sum_{u \in U} p_{u} \log p_{u}$ é a entropia do agrupamento $U$, que é uma medida da quantidade de incerteza sobre o conjunto; consequentemente, $\mathrm{H}(V)$ é a entropia do agrupamento $V$. Um valor alto indica que os dois agrupamentos são idênticos, e 0 que a informação mútua entre os dois agrupamentos são iguais ao seu valor esperado.

Tanto ARI quanto NMI corrigem o efeito de concordância devido à aleatoriedade entre agrupamentos que não é considerado por RI nem MI, respectivamente. A versão original de ARI e AMI foi planejada para comparar partições disjuntas, porém uma generalização para partições sobrepostas também foi desenvolvida. A versão para partições sobrepostas de ARI é conhecida como índice Omega (Murray et al., 2012) e a de NMI como informação mútua normalizada generalizada (GNMI ${ }^{34}$ ) (McDaid et al., 2011).

\subsection{Medidas Musicais}

As medidas usadas para avaliar a saída dos modelos de composição de melodias propostos, descritos no capítulo 3, são apresentadas a seguir. Primeiro são descritas duas medidas usadas para mensurar a qualidade de uma escala musical $^{35}$ e depois as medidas usadas para quantificar algumas propriedades da melodia, a saber: melodiosidade, originalidade, complexidade rítmica e tonal, e similaridade melódica.

\subsubsection{Medidas para Quantificar Escalas Musicais}

Nesta seção são apresentadas duas medidas usadas para quantificar escalas musicais, o grau de uniformidade $\left(\mathrm{DEV}^{36}\right)$ e a média da porcentagem de similaridade harmônica $\left(\mathrm{MPHS}^{37}\right)$.

\section{Grau de Uniformidade (DEV)}

O grau de uniformidade de uma escala parte do conceito de que para o ouvido humano é mais agradável uma escala balanceada ou uniforme, na qual os intervalos entre as notas sucessivas são tão similares quanto possível (Keith, 1991). Para uma escala do sistema igualmente temperado de $N$ notas

\footnotetext{
${ }^{34}$ Sigla de Generalized Normalized Mutual Information

${ }^{35}$ Ver definição de termos musicais no Apêndice B

${ }^{36}$ Sigla de Degree of EVenness

37 Sigla de Mean Percentage of Harmonic Similarity
} 
$\left(N-\right.$ TET $\left.^{38}\right)$, a uniformidade é definida como a distância entre cada um dos intervalos da escala e o conjunto de intervalos formados por $\{N / n, N / n, \ldots, N / n\}$, e é calculada como:

$$
D E V=\frac{1}{n} \sum_{1 \leq i \leq n}\left(I_{i}-\frac{N}{n}\right)^{2}=n \sum_{1 \leq i \leq n} I_{i}^{2}-N^{2},
$$

em que $I_{i}$ são os elementos do vetor de intervalos da escala e $n$ o número de notas da escala. Um valor pequeno indica maior uniformidade, sendo 0 a uniformidade perfeita. A escala diatônica maior, e todos os seus modos, tem DEV igual a 10. É importante ressaltar que esta medida é independente do modo da escala.

\section{Média da Porcentagem de Similaridade Harmônica (MPHS)}

Segundo Gill \& Purves (2009) a preferência por uma pequena quantidade de escalas ao longo da história evolutiva da música e em diferentes culturas, tanto ocidentais quanto orientais, é devido à alta similaridade entre os intervalos da escala e as caraterísticas espectrais do conjunto de intervalos da série harmônica. A porcentagem de similaridade harmônica de um intervalo $i$ é dada por:

$$
\operatorname{phs}(i)=\frac{x_{i}+y_{i}-1}{x_{i} \cdot y_{i}} \cdot 100 \%,
$$

em que $x_{i}$ e $y_{i}$ são o numerador e o denominador da razão de frequência ${ }^{39}$ do intervalo $i\left(\frac{x_{i}}{y_{i}}\right)$ na série harmônica. As razões de frequência são conhecidas, por exemplo, a razão de frequência do intervalo de $4^{a}$ justa, $5^{a}$ justa e oitava é $(4: 3)$, (3:2) e (2:1), respectivamente. Por fim, a média da porcentagem de similaridade harmônica de todos os pares de intervalos da escala corresponde ao valor de MPHS. Note-se que o número total de pares de intervalos do conjunto é igual a $\left(n^{2}+n\right) / 2$. As escalas (ou modos) mais usadas são aquelas que contêm alto valor de MPHS (Gill \& Purves, 2009). A escala diatônica maior tem MPHS igual a 39.61. É importante realçar que MPHS é dependente do modo da escala.

\subsubsection{Medidas para Quantificar Melodias}

Nesta seção são descritas as medidas que foram adotadas para quantificar objetivamente algumas características subjetivas das melodias compostas pelos modelos de composição propostos.

\footnotetext{
38 Sigla de Tone Equal Temperament

39 Ver Tabela B.1 no Apêndice B
} 


\section{Grau de Melodiosidade}

O grau de melodiosidade ${ }^{40}$ sugere que a experiência de ouvir uma melodia é mais prazerosa quanto menor for a complexidade do cálculo mental efetuado pelo ouvinte (Euler, 1739). Considere-se uma melodia com $m$ intervalos, então para cada intervalo $i$ é calculado um novo valor $a_{i}$ usando o numerador $\left(x_{i}\right) \mathrm{e}$ o denominador $\left(y_{i}\right)$ da razão de frequência desse intervalo na série harmônica, assim: $a_{i}=x_{i} \times y_{i}$. Em seguida, o valor $a_{i}$ é decomposto em produtos de potências de diferentes números primos, obtendo: $a_{i}=p_{1}^{k_{1}} \cdot p_{2}^{k_{2}} \cdot \ldots \cdot p_{n}^{k_{n}}$, onde $p_{j}$ representa o $j$-ésimo número primo, $k_{j}$ é o número de ocorrência desse primo e $n$ é o maior número primo na decomposição de $a_{i}$. Em seguida, o grau de melodiosidade $G$ do intervalo $i$ é calculado como:

$$
G\left(a_{i}\right)=\sum_{j=1}^{n}\left(k_{j} p_{j}-k_{j}\right)+1 .
$$

O grau de melodiosidade de uma melodia é a média dos graus de melodiosidade dos seus intervalos, e tem valores altos se tiver números primos com valor alto ou uma grande quantidade de números primos, indicando assim que se trata de uma melodia mais melodiosa.

\section{Originalidade Melódica}

A relação entre originalidade e complexidade define uma função curvilínea com forma de U invertido, indicando que as melodias mais e menos complexas são menos originais, e que as melodias com complexidade média têm a maior originalidade (Simonton, 1984). Estudos realizados por Simonton (1984) sobre uma grande quantidade de obras clássicas revelaram que a popularidade é diretamente proporcional a sua originalidade, ou seja, as peças musicais mais populares têm originalidade média, enquanto as mais e as menos complexas não são consideradas populares. A saída do modelo é o inverso da probabilidade média de transição de tons, escalada na faixa de 0 a 10 , onde um valor alto indica maior originalidade.

\section{Modelo de Complexidade Melódica Baseado na Expectativa}

O modelo de complexidade melódica baseado na expectativa ${ }^{41}$ fundamentase na teoria da expectativa melódica de Eerola (2000), e mensura a complexidade de uma melodia tendo como referência a coleção de Essen (Schaffrath, 1995), a qual tem complexidade média igual a 5 e desvio padrão de 1 . Dependendo do domínio musical requerido a complexidade pode ser tonal se for

\footnotetext{
40 Do latim: Gradus suavitatis

41 Do inglês: Expectancy-based model of melodic complexity
} 
calculada apenas para as alturas, rítmica se for calculada somente para as durações ou conjunta se for calculada tanto para as alturas quanto para as durações. Para todos os casos um valor alto indica maior complexidade (Eerola, 2000).

\section{Similaridade Melódica}

A similaridade melódica é usada para quantificar o nível de semelhança entre dois motivos, frases ou melodias de acordo com alguma característica musical (Hofmann-Engl, 2005). Para tanto, é preciso uma medida de distância e uma representação da característica alvo (Eerola \& Toiviainen, 2004), por exemplo, a distribuição de alturas da melodia. A similaridade entre as propriedades de duas melodias não necessariamente correlaciona, deste modo, duas melodias podem ser melodicamente muito semelhantes segundo as alturas, porém com baixa semelhança rítmica. As medidas de similaridade adotadas nesta pesquisa são:

1. Similaridade melódica segundo a distribuição de pitch class $^{42}$ : Mensura a similaridade entre as notas que conformam o conjunto de alturas e o número de vezes que cada nota acontece nesse conjunto.

2. Similaridade melódica segundo a distribuição de durações: Mensura a similaridade da frequência de ocorrência das durações que compõem a frase musical.

\subsection{Considerações Finais}

Neste capítulo foi apresentada uma revisão sobre redes complexas, destacando algumas medidas topológicas e alguns algoritmos para a detecção de comunidades disjuntas e sobrepostas. Também foi feita uma pequena descrição sobre aprendizado supervisionado e não-supervisionado, redes neurais recorrentes e sistemas dinâmicos caóticos, bem como uma breve apresentação de algumas medidas musicais.

${ }^{42}$ Conjunto de alturas que conformam uma frase musical 
CAPÍTULO 3

\section{Composição Automática de}

\section{Estruturas Musicais Usando Redes Complexas e Redes Neurais Recorrentes}

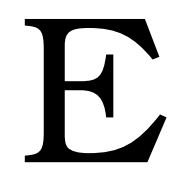

este capítulo apresenta o desenvolvimento de três modelos para a composição automática de melodias. Os modelos propostos são abordados a partir de duas perspectivas diferentes, a primeira usa redes complexas predefinidas, enquanto a segunda usa redes neurais recorrentes. Especificamente, na Seção 3.1 é descrito um modelo que gera material musical fazendo uma caminhada controlada por critérios sobre os nós de uma rede complexa predefinida (Coca \& Zhao, 2014a), abordando desta forma o tópico de síntese de dados musicais com redes complexas. Na Seção 3.2 são descritos os dois modelos da segunda perspectiva, um modelo baseado em RNN treinada com o algoritmo BPTT e entrada adicional de inspiração caótica (Coca et al., 2011) e um sistema de controle baseado em redes LSTM que compõe melodias com um valor preestabelecido em alguma característica melódica subjetiva (Coca et al., 2013). A descrição de cada modelo composicional e as simulações computacionais realizadas são apresentadas a seguir. 


\section{1 Modelo Baseado em Redes Complexas Predefini- das}

O modelo de composição automática apresentado nesta seção usa uma rede complexa predefinida para compor novas melodias através de uma caminhada regida por critérios. As redes predefinidas usadas são: regular, de pequeno mundo, aleatória de Erdős-Rényi e livre de escala. A rede é gerada usando as notas de uma escala escolhida previamente, onde as notas são os nós e as arestas são criadas aleatoriamente conservando as propriedades topológicas da rede escolhida. A novidade principal do modelo é a incorporação de um sistema para a geração automática de escalas musicais que permite fazer uso de um grande leque de escalas do sistema igualmente temperado de 12 notas (12-TET). Diferentes regras para efetuar a caminhada sobre os nós da rede são estudadas. Também é demonstrado como a lei de potência é conservada na melodia gerada pela rede livre de escala, a qual é uma característica presente em estudos de modelos da natureza (Markovica \& Grosa, 2014). As melodias compostas são avaliadas de acordo com o grau de melodiosidade.

\subsubsection{Descrição do Modelo}

As características particulares dos modelos de redes complexas descritos na Seção 2.1.2 são aproveitadas para compor novo material musical que reflete as características intrínsecas da rede. Pesquisas precedentes sobre esta abordagem usam caminhada controlada por critérios sobre redes criadas a partir das notas de uma melodia de entrada (Liu et al., 2009, 2010; Yang et al., 2009). O efeito resultante disso é que a nova melodia conservará a essência da melodia de entrada, algo que é bastante lógico, já que os intervalos da melodia de origem não são modificados no processo de geração da rede. Portanto, poderia se considerar a nova melodia como uma versão desordenada das notas da melodia original. Contudo, essa abordagem motivou o desenvolvimento do primeiro modelo de composição proposto nesta tese.

No modelo proposto já não é mais usada uma melodia conhecida para gerar a rede, e sim uma rede com propriedades previamente conhecidas, visando explorar como essas propriedades são transformadas em características musicalmente interessantes. O processo usado para criar uma rede predefinida pode ser simples, como é o caso das redes regulares, nas quais apenas é necessário especificar o número de nós e o grau que será usado para todos os nós, ou um processo mais elaborado, como é o caso do algoritmo de BarabásiAlbert proposto para gerar redes livre de escala (Barabási \& Albert, 1999) ou o algoritmo de Watts-Strogatz para a geração de redes de pequeno mundo (Watts 
Tabela 3.1: Critérios para a seleção do próximo nó (nota da melodia) do algoritmo de composição baseado em redes complexas predefinidas.

\begin{tabular}{r|c}
\hline Critério para a seleção do próximo nó \\
\hline \hline Grau do nó & Mínimo \\
Força do nó & ou \\
Peso da aresta & Máximo \\
\hline \multicolumn{2}{c}{ Aleatório }
\end{tabular}

\& Strogatz, 1998). Para gerar uma rede aleatória foi adotado o algoritmo de Erdős-Rényi (Erdős \& Rényi, 1959). O parâmetro de entrada comum para gerar qualquer uma das redes usadas pelo modelo de composição é o número de nós. Ademais, exceto para a rede regular, também é necessário um valor de probabilidade de conexão que define quão provável será a adição de uma nova aresta. As redes geradas são ponderadas e direcionadas, onde o sentido das arestas e os pesos são de igual forma gerados aleatoriamente. Outros parâmetros também são possíveis, como o coeficiente de correlação de Pearson e o coeficiente de aglomeração, mas estes serão explorados em trabalhos futuros.

O número de nós da rede corresponde ao número de notas de uma escala musical previamente escolhida e, após criada a rede, cada nó terá uma relação direta com uma única nota da escala. O algoritmo de composição gera uma nova melodia fazendo uma caminhada especial sobre os nós da rede. A caminhada pode ser totalmente aleatória, na qual a escolha do próximo nó é feita livremente ou restringida por algum critério estabelecido sobre um valor mensurado para os nós ou para as arestas, podendo ser esses: grau do nó $\left(k_{i}\right)$, força do nó $\left(s_{i}\right)$ ou peso da aresta $\left(w_{i}\right)$ (Liu et al., 2010). O algoritmo pode usar o valor mínimo ou máximo da respectiva medida para selecionar o próximo nó, como mostrado na Tabela 3.1. Neste caso o algoritmo escolherá, entre os nós que têm conexão direta com o nó atual, o nó que tiver o maior ou menor grau/força, ou o nó que estiver conectado com o nó atual através da aresta com o maior ou menor peso. Ao todo são 26 opções diferentes de executar o modelo de composição, isto é, é possivel escolher 1 entre 4 redes, 1 entre 3 formas de caminhada, e 1 entre 2 critérios para a seleção do próximo nó, resultando em um total de $24(4 \times 3 \times 2)$ opções, mais o critério aleatório que pode ser aplicado nas quatro redes, aumentando o resultado a 28 , porém quando escolhida a rede regular e o critério do grau, escolher o grau mínimo ou máximo não influência a seleção do próximo nó porque todos os nós têm igual grau, sendo este caso igual à caminhada totalmente aleatória. Isto posto, das 28 opções iniciais 2 não são aplicadas, obtendo então 26 opções.

As propriedades estruturais da rede e as propriedades musicais da escala são refletidas na melodia gerada. Portanto, nesta pesquisa também foi explorado e disponibilizado o uso de escalas musicais de uma maneira abrangente. 
Visando estender o leque de escalas, um sistema para a codificação de escalas e os algoritmos necessários para a codificação e decodificação das mesmas são propostos. Estes algoritmos são descritos no Apêndice A, Seção A.2. O algoritmo codificador gera o código da escala de um conjunto de alturas, e o decodificador gera uma escala a partir do seu código. O decodificador pode gerar automaticamente até 11124 escalas diferentes do sistema 12-TET. Em vista disso, o algoritmo decodificador foi adaptado ao presente modelo de composição para gerar a escala de entrada que serve de semente no processo de criação da rede, desempenhando assim uma função de abrangência do material musical. Ademais, tendo em vista a premissa de que uma melodia exibe as propriedades da escala que a originou, premissa amplamente conhecida na teoria musical (Lacerda, 1966), e aproveitando que o decodificador de escalas disponibiliza uma enorme quantidade de escalas de diversos tipos e com uma vasta gama de propriedades, nesta tese também é proposto procurar sistematicamente uma escala pouco conhecida, mas com características adequadas para composição musical segundo as duas medidas estudadas na Seção 2.4.1, o grau de uniformidade (DEV) (Keith, 1991) e média da porcentagem de similaridade harmônica (MPHS) (Gill \& Purves, 2009).

\section{Sistema para a Codificação de Escalas Musicais}

Devido à alta importância que têm as escalas musicais dentro da música, diferentes estudos dentro da área MIR têm sido desenvolvidos, por exemplo, caracterização de escalas da música tradicional Thai (Attakitmongcol et al., 2004), avaliação de felicidade e constrangimento do modo maior e menor (Collier \& Hubbard, 1994) e enumeração de escalas (Duncan, 1991), dentre outros. Os estudos sobre enumeração de escalas têm demonstrado que o número total de escalas é grande, embora na música ocidental apenas seja usada uma pequena parte desse total (Keith, 1991). Desta forma, alguns pesquisadores decidiram realizar um inventário ou uma catalogação das escalas, uma vez que o conhecimento e a ordenação destas facilita o seu manuseio dentro de alguma tarefa especifica. Em (Lucy, 1994) foi proposto um método para a codificação de escalas que é usado na análise de uma coleção de notas, e na teoria musical é usada a nomenclatura numérica chamada número de Forte (Forte, 1997), o qual é usado para designar diferentes tipos de conjuntos como acordes, escalas ou intervalos simples. O número de Forte é um código único que marca a forma prima ${ }^{1}$ de um conjunto de classes de tons ${ }^{2}$, e o qual consiste de dois números, o primeiro especifica o número de classes de tons e o segundo é um número único que foi dado à forma prima e o qual foi sequenci-

\footnotetext{
${ }^{1}$ A forma mais compacta usada para representar um conjunto de alturas (Forte, 1997)

${ }^{2}$ Do inglês: Pitch class set
} 
Tabela 3.2: Total de escalas do sistema $N$-TET para diferentes valores de $N$ (valores apróximados en notação científica).

\begin{tabular}{c|c|c|c}
\hline$N$ & $T_{E}$ & $T_{M}$ & $T_{E T}$ \\
\hline \hline 12 & 351 & 2048 & 24576 \\
24 & 699251 & $8,3 \times 10^{6}$ & $201,3 \times 10^{6}$ \\
36 & $1,9 \times 10^{9}$ & $34,3 \times 10^{9}$ & $1,2 \times 10^{12}$ \\
48 & $5,8 \times 10^{12}$ & $140,7 \times 10^{12}$ & $6,7 \times 10^{15}$ \\
\hline
\end{tabular}

almente designado por Forte. Contudo, o número de Forte é igual para todos os modos da escala, já que indica a forma prima dos conjuntos de todas as classes, e os modos e as suas inversões fazem parte deste conjunto.

$\mathrm{Na}$ teoria musical as escalas são identificadas com um nome textual que, devido a sua dependência idiomática e regional, dificulta a padronização. Ademais, o nome textual é apenas definido para as escalas mais frequentes. Também, do ponto de vista computacional, o uso de um nome textual para se referir a uma escala traz consigo diversas desvantagens, principalmente porque não fornece toda a informação necessária para a sua construção. No contexto de composição musical automática, geralmente, as escalas são previamente representadas e armazenadas em uma tabela com duas entradas para posteriormente serem chamadas via um identificador, onde a primeira entrada é o nome da escala e a segunda é algum tipo de representação que indica como deve ser construída (Coca et al., 2010). A criação de uma tabela padronizada é árdua e até impossível em alguns casos, por exemplo, se for requerida a disponibilização da totalidade de escalas do sistema $N$-TET para ser usada como entrada de um algoritmo de composição, a criação de uma tabela e dos identificadores seria inviável devido ao fato do número de escalas diferentes ser grande e crescer exponencialmente conforme $N$ (Keith, 1991), por exemplo, para $N=12$ o número total de escalas com estrutura de intervalos diferente $\left(T_{E}\right)$ é 351 (Fripertinger, 1999)(Read, 1997), que ao todo somam 2048 modos $\left(T_{M}\right)$, que sendo transportados às 12 notas da escala cromática geram 24576 escalas $\left(T_{E T}\right)$ (Keith, 1991). Para o caso de $N=12$, criar uma tabela com 351 entradas é um tamanho aceitável, e portanto viável, porém para sistemas microtonais $(N>12)$ se torna inalcançável. Na Tabela 3.2 são mostrados os valores de $T_{E}, T_{M}$ e $T_{E T}$ para diferentes valores de $N$. Nesta seção é proposto um código numérico para a identificação, construção, ordenamento e discriminação de escalas.

Uma escala pode ser representada mediante um vetor de intervalos ${ }^{3}$, cujos elementos indicam o intervalo em semitons entre as notas sucessivas que conformam a escala, por exemplo, o vetor de intervalos da escala maior é [2 $\left.\begin{array}{llllll}2 & 1 & 2 & 2 & 2 & 1\end{array}\right]$. Com o vetor de intervalos, junto com o modo e a tônica, pode

\footnotetext{
${ }^{3}$ Ver definição de termos musicais no Apêndice B
} 
ser gerada completamente a escala. Portanto, para gerar todas as escalas para um dado valor de $N$ é necessário gerar todos os vetores de intervalos possíveis. Isto pode ser realizado usando um algoritmo combinatório especial, especificamente um algoritmo para a geração de Permutações Circulares com elementos Repetidos ${ }^{4}$ (PCR) (Keith, 1991). Uma condição comum dos algoritmos combinatórios é a preservação da ordem lexicográfica na organização dos objetos gerados. A ordem lexicográfica para um conjunto finito é uma organização dos elementos do conjunto similar à ordem alfabética das palavras em um dicionário (Ruskey, 2003). Devido ao fato da ordem lexicográfica ser um padrão nos algoritmos combinatórios, esta é conservada dentro do código proposto.

Primeiramente, nesta tese as escalas são classificadas em três classes, a saber: primária (também chamada como tipo de escala (Keith, 1991), escala não equivalente (Vasco, 2007) ou megamodo (Lucy, 1994)), secundária e terciária. A escala primária é a escala criada a partir de uma permutação circular na ordem lexicográfica. As escalas secundárias são obtidas a partir da rotação circular de uma escala primária, ou seja, a escala secundária é um modo de uma escala primária ${ }^{5}$. A escala terciária vem da transposição de uma escala primária ou de uma escala secundária.

Para o sistema 12-TET foram codificadas escalas com intervalos de 1, 2 e 3 semitons ${ }^{6}$, conhecidos como semitom, tom e tom e meio, e denotados com $S, T$ e $T_{m}$, respectivamente. Porém, escalas com estrutura formada por intervalos entre 4 e 6 semitons também são possíveis (Keith, 1991). Ao todo o sistema permite codificar 132 escalas primárias, 927 escala secundárias e 11124 escalas terciárias, conforme mostrado na Tabela A.1 e A.2 da Seção A.2 do Apêndice A. O número total de intervalos de cada tipo $\left(S, T\right.$ ou $T_{m}$ ) que formam a arquitetura da escala musical é armazenado no conjunto $u=\left\{s, t, t_{m}\right\}$, chamado estrutura da escala (Coca et al., 2010). Note-se que $S$ representa o intervalo de semitom e $s$ indica o número total de semitons da escala. Os pares $T$ e $t$, e $T_{m}$ e $t_{m}$ são definidos de maneira similar.

A escala pode ser completamente codificada usando 6 valores, que são dispostos em um vetor c, chamado vetor de código da escala, assim: c = $\left[\begin{array}{llllll}t_{m} & n & g & \eta & m & \tau\end{array}\right]$. Cada um destes elementos são descritos a seguir ${ }^{7}$ :

1. $t_{m}$ : O primeiro valor do vetor de código indica o número de tons e meio $T_{m}$ que tem a estrutura da escala, e pode ter valores no intervalo $0 \leq t_{m} \leq$ 4. Este valor é uma característica importante porque dele dependem o número de notas da escala e o número de tons e semitons.

\footnotetext{
${ }^{4}$ Também conhecido como necklace

${ }^{5}$ Chamado nesta tese modo lexicográfico por conservar tal ordem

${ }^{6}$ Por facilidade notacional

${ }^{7}$ Ver apêndice B para uma explicação detalhada destas variáveis
} 
Tabela 3.3: Código de algumas escalas selecionadas e o seu número de Forte ( $x$ significa qualquer valor de tônica entre 0 e 11 ).

\begin{tabular}{|c|c|c|}
\hline Escala & Código & $\mathrm{N}^{o}$ Forte \\
\hline Cromática & {$\left[\begin{array}{llllllll}0 & 12 & 1 & 1 & 1 & 1 & \mathrm{x}\end{array}\right]$} & $12-1$ \\
\hline C Maior & {$\left[\begin{array}{llllll}0 & 7 & 1 & 3 & 2 & 0\end{array}\right]$} & $7-35$ \\
\hline A menor natural & {$\left[\begin{array}{llllll}0 & 7 & 1 & 3 & 7 & 10\end{array}\right]$} & $7-35$ \\
\hline A menor harmônica & {$\left[\begin{array}{llllll}1 & 7 & 1 & 19 & 2 & 10\end{array}\right]$} & $7-32$ \\
\hline A menor melodica asc. & {$\left[\begin{array}{llllll}0 & 7 & 1 & 2 & 2 & 10\end{array}\right]$} & $7-32$ \\
\hline Hexatônica & {$\left[\begin{array}{llllll}0 & 6 & 1 & 1 & 1 & \mathrm{x}\end{array}\right]$} & $6-35$ \\
\hline Octatônica & {$\left[\begin{array}{llllll}0 & 8 & 1 & 4 & 7 & \mathrm{x}\end{array}\right]$} & $8-28$ \\
\hline
\end{tabular}

2. $n$ : Indica o número de notas da escala e pode ter valores no intervalo $4 \leq n \leq 12$. É importante porque caracteriza globalmente a escala, e ocupa a segunda posição dentro do código porque está compreendido entre os limites inferior $\left(n_{\min }\right)$ e superior $\left(n_{\max }\right)$, os quais são calculados $\operatorname{com} t_{m}$.

3. $g$ : Em alguns casos uma estrutura de intervalos pode ter escalas primárias com diferente quantidade de modos. As escalas primárias são agrupadas segundo o número total de modos possíveis (ver Tabela A.1 e A.2). Portanto, o terceiro valor $g$ representa o grupo da escala primária, e pode ter valores no intervalo $1 \leq g \leq 3$, onde o primeiro grupo tem o maior número de modos.

4. $\eta$ : Para cada grupo $g$ as escalas primárias são numeradas ascendentemente segundo a sua posição lexicográfica dentro do grupo. A sua posição dentro do grupo é representada $\operatorname{com} \eta$, e pode ter valores no intervalo $1 \leq \eta \leq 21$.

5. $m$ : Indica o modo lexicográfico da escala, pode ter valores no intervalo $1 \leq m \leq 11$. O primeiro modo lexicográfico é igual à escala primária, e os seguintes são as suas respectivas escalas secundárias.

6. $\tau$ : O último valor indica a tônica da escala. Este pode ser um valor MIDI e, portanto, ter valores no intervalo $0 \leq \tau \leq 127$, ou também um valor inteiro indicando o número da tônica dentro da escala e, nesse caso, ter valores no intervalo $0 \leq \tau_{o} \leq 11$, sendo necessário um valor adicional para indicar a oitava inicial $o$, que tem valores no intervalo $0 \leq o \leq 7$.

A Tabela 3.3 mostra o sistema de codificação proposto para umas poucas escalas. Na última coluna pode ser visto como o número de Forte é igual para vários modos da mesma escala. Os algoritmos necessários para codificar e decodificar escalas são descritos detalhadamente na Seção A.2 do Apêndice A. Algumas equações e valores desse apêndice são utilizados nesta seção. 
O algoritmo decodificador é aplicado na busca do código de uma escala raramente usada, mas com caraterísticas apropriadas para composição. Posteriormente, o código da escala encontrada será decodificado para servir de material composicional na rede complexa. Este problema equivale a gerar o código para cada uma das 927 escalas secundárias e, mediante o decodificador, criar a correspondente escala e calcular as duas medidas estudadas (DEV e MPSH). Em seguida, são selecionadas as escalas com o maior valor nas duas medidas simultaneamente. Cada elemento do vetor de código é percorrido em toda sua extensão, exceto o grupo $g$ e a tônica $\tau$ porque neste caso são desnecessários. O primeiro elemento do vetor de código $\left(t_{m}\right)$ é percorrido com o índice $j$, assim: $0 \leq j \leq 4$. Para cada valor de $j$ é calculado $n_{\min }$ e $n_{\max }$ com a Eq. (A.10) e (A.11), respectivamente. O segundo elemento ( $n$ ) é percorrido com o índice $i$ da seguinte maneira: $n_{\min } \leq i \leq n_{\max }$. Com estes índices $(j$ e $i$ ) o número de semitons e tons são calculados assim: $s=2 i-12+j$ e $t=12-2 j-i$. Com isso, a estrutura da escala é preenchida e o vetor de intervalos para todas as escalas primárias é gerado usando o algoritmo combinatório descrito em (Ruskey \& Sawada, 1999), o qual é referenciado como $\mathbf{N}^{i}(s, t, j)$, e, portanto, obtendo $\mathbf{H}=\mathbf{N}^{i}(s, t, j)$. Por fim, o vetor de intervalos da $\eta$-ésima linha de $\mathbf{H}$ é separado, isto é, $\mathbf{I}=H_{\eta}, 1 \leq \eta \leq P C R$, onde $P C R$ é o total de escalas primárias, que é calculado com a Eq. (A.20). Em seguida, as duas medidas são calculadas, DEV para cada vetor I e MPHS para cada um dos modos de I.

\subsubsection{Simulações Computacionais}

O algoritmo decodificador de escalas foi usado para procurar uma escala com valores ótimos nas medidas DEV e MPHS. A escala encontrada foi selecionada para testar o modelo de composição com redes complexas predefinidas. A Fig. 3.1 mostra o valor de MPHS de cada uma das 927 escalas secundárias e a Fig. 3.2 o valor de DEV das 132 escalas primárias. A linha vermelha sólida nas duas figuras indica o valor calculado para a escala maior, a qual tem MPHS igual a 39.45 e DEV igual a 10. Usando esses valores como referência, uma escala será considerada com bons valores nas duas medidas se tiver MPHS $\geq 39.4473$ e DEV $\leq 10$. Há 31 escalas que cumprem com a primeira condição e 5 que cumprem com a segunda.

Por facilidade notacional, para uma escala $i$ o valor de MPHS será denotado como $\beta_{i}$ e o valor de DEV como $\omega_{i}$. As duas medidas foram normalizadas para terem valores entre 0 e 1 , MPHS foi normalizado como: $\beta_{i} / \max \{\beta\}$, e DEV como: $\left(100-\omega_{i}\right) /(\max \{100-\omega\})$. Além disso, visando fazer mais rápida a comparação, foi calculada a média das duas medidas normalizadas, obtendo 


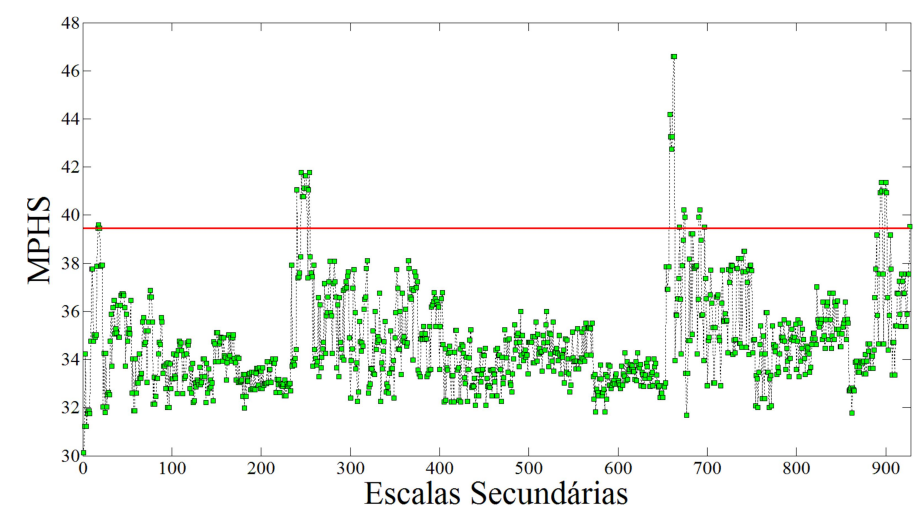

Figura 3.1: Valor da média da porcentagem de similaridade harmônica (MPHS) de cada uma das 927 escalas secundárias. A linha sólida é o valor de MPHS da escala maior igual a 39.45

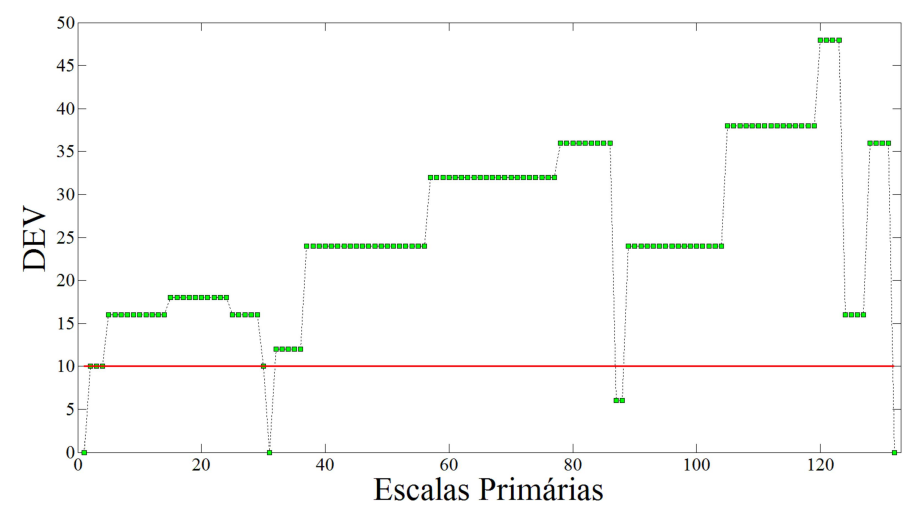

Figura 3.2: Valor do grau de uniformidade (DEV) de cada uma das 123 escalas primárias. A linha sólida é o valor de DEV da escala maior igual a 10

um único valor denotado como $\Phi$. A Fig. 3.3 mostra o valor de $\Phi$ de cada uma das 927 escalas secundárias. A linha sólida vermelha é o valor de $\Phi$ da escala maior igual a 0.873 . Existem 21 escalas que superam esse valor, algumas dessas escalas são conhecidas, como: o modo dórico e frígio, todos os modos da escala pentatônica maior e o acorde de sétima diminuta. Entre as escalas desconhecidas estão as escalas com os seguintes códigos (o valor da tônica foi omitido): os modos 1 e 6 de $\left[\begin{array}{llll}1 & 6 & 1 & 2\end{array}\right]$, os seis modos de $\left[\begin{array}{llll}1 & 6 & 1 & 3\end{array}\right]$, os modos 2 e 3 de [ $\left[\begin{array}{llll}1 & 6 & 1 & 4\end{array}\right]$ e os modos 1,4 e 5 de [ [ $\left.\begin{array}{llll}2 & 5 & 1 & 1\end{array}\right]$. Para as 21 escalas encontradas, na Tabela 3.4 são mostrados os códigos, os valores das medidas e, se tiver, o nome, caso contrário o vetor de intervalos.

Examinando os valores da Tabela 3.4 foi selecionada a escala musical com código [2 $\left.5 \begin{array}{llll}1 & 1 & 5 & 0\end{array}\right]$, a qual tem $\Phi=0.944$, para servir de material composicional no modelo de composição automática proposto nesta seção. A descrição da escala selecionada é mostrada na Tabela 3.5.

Conforme os dados da tabela, a escala selecionada é uma escala pentatônica (escala com 5 notas). Como são usadas 5 oitavas então o número total 


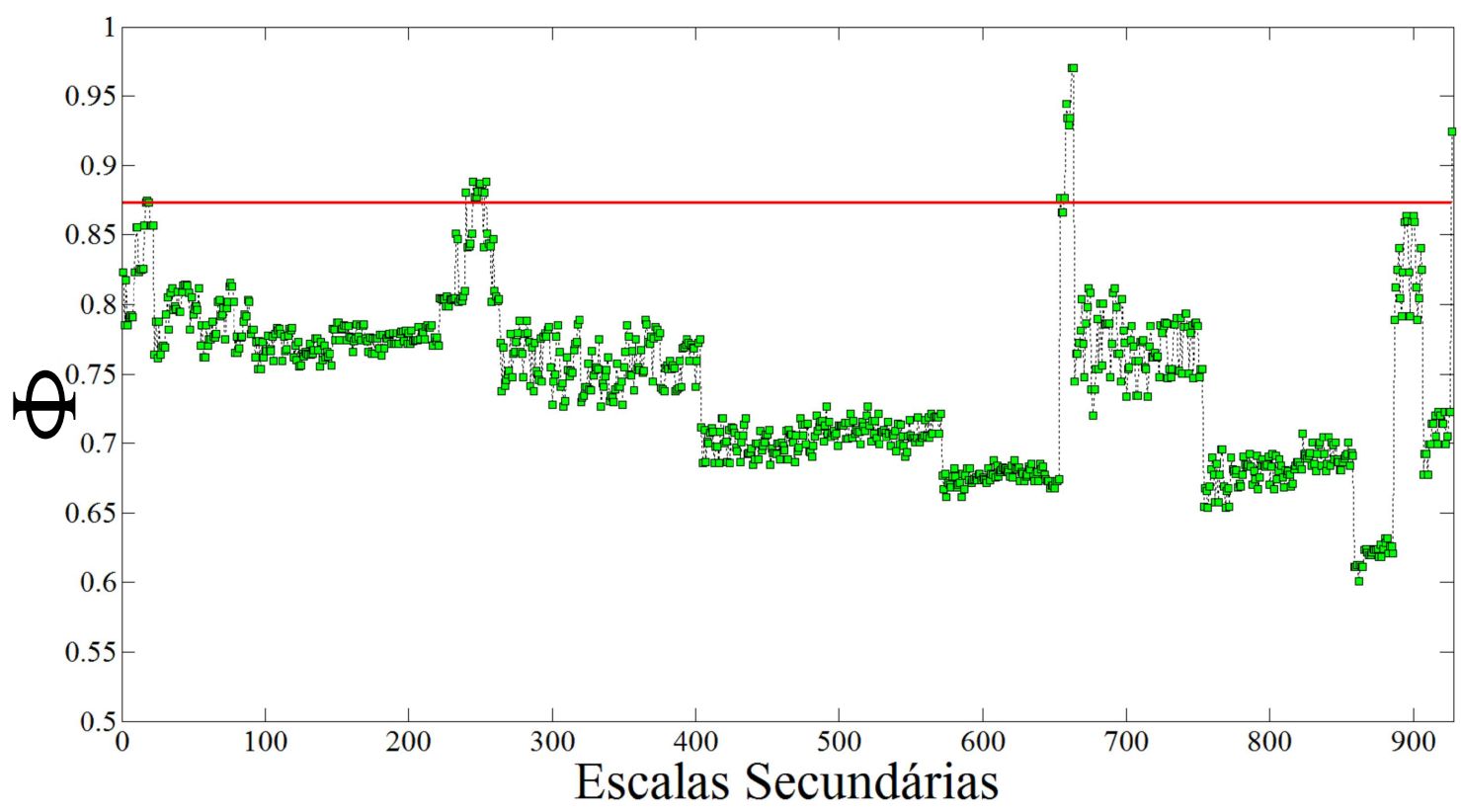

Figura 3.3: Média normalizada do grau de uniformidade e da média da porcentagem de similaridade harmônica ( $\Phi$ ) de cada uma das 927 escalas secundárias. A linha sólida é o valor de $\Phi$ da escala maior igual a 0.873

Tabela 3.4: Códigos e medidas das 21 escalas com melhores valores da média normalizada entre o grau de uniformidade e a média da porcentagem de similaridade harmônica $(\Phi)$.

\begin{tabular}{|c|c|c|c|c|c|}
\hline No. & Código & \multicolumn{2}{|c|}{ MPHS DEV } & $\Phi$ & Nome \\
\hline 1 & {$\left[\begin{array}{llllll}0 & 7 & 1 & 3 & 3\end{array}\right]$} & 39.59 & 10 & 0.87 & Modo dórico \\
\hline 2 & {$\left[\begin{array}{lllll}0 & 7 & 1 & 3 & 4\end{array}\right]$} & 39.45 & 10 & 0.87 & Modo frígio \\
\hline 3 & {$\left[\begin{array}{llllllll}1 & 6 & 1 & 2 & 1\end{array}\right]$} & $.0 \overline{6}$ & 12 & $0 . \overline{8} 8$ & Modo $1: \mathrm{STTT} \mathrm{T}_{\mathrm{m}} \mathrm{T}$ \\
\hline 4 & {$\left[\begin{array}{lllll}1 & 6 & 1 & 2 & 6\end{array}\right]$} & 41.78 & 12 & 0.8 & Modo 6: TS T T T T \\
\hline $5^{-1}$ & 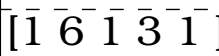 & $\overline{4} \overline{0} . \overline{7} \overline{7}$ & $\overline{12}-$ & $0 . \overline{8} \overline{8}$ & Modo $1: \mathrm{S} T \mathrm{~T}_{\mathrm{m}} \mathrm{T}$ \\
\hline 6 & {$\left[\begin{array}{lllll}1 & 6 & 1 & 3 & 2\end{array}\right]$} & 40.77 & 12 & 0.88 & Modo 2: $\mathrm{T} \mathrm{T} \mathrm{T}_{\mathrm{m}} \mathrm{TTS}$ \\
\hline 7 & {$\left[\begin{array}{lllll}1 & 6 & 1 & 3 & 3\end{array}\right]$} & 41.11 & 12 & 0.88 & Modo 3: $\mathrm{T}_{\mathrm{m}} \mathrm{T}$ \\
\hline 8 & {$\left[\begin{array}{lllll}1 & 6 & 1 & 3 & 4\end{array}\right]$} & 41.64 & 12 & 0.89 & Modo 4: $\mathrm{T}_{\mathrm{m}}$ T TS T T \\
\hline 9 & {$\left[\begin{array}{lllll}1 & 6 & 1 & 3 & 5\end{array}\right]$} & 41.64 & 12 & 0.89 & Modo 5: T TST T $\mathrm{T}_{\mathrm{m}}$ \\
\hline 10 & {$\left[\begin{array}{lllll}1 & 6 & 1 & 3 & 6\end{array}\right]$} & 41.11 & 12 & 0.88 & Modo 6: $\mathrm{TSTT} \mathrm{T}_{\mathrm{m}} \mathrm{T}$ \\
\hline$\overline{1} \overline{1}$ & {$\left[\begin{array}{llllll}1 & 6 & 1 & 4 & 2\end{array}\right]$} & $\overline{4} \overline{1} . \overline{0}$ & 12 & $0 . \overline{88}$ & Modo 2: $\mathrm{ST} \mathrm{T}_{\mathrm{m}} \mathrm{T}$ \\
\hline 12 & {$\left[\begin{array}{llllll}1 & 6 & 1 & 4 & 3\end{array}\right]$} & 41.78 & 12 & 0.89 & Modo 3: $\mathrm{TT}_{\mathrm{m}} \mathrm{TTTS}$ \\
\hline$\overline{1} \overline{3}$ & 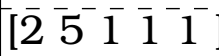 & $\overline{3} \overline{7} . \overline{8} \overline{6}$ & $\overline{6}$ & $0 . \overline{8}$ & Modo $1: \mathrm{T}$ T T ${ }_{\mathrm{m}}^{-}$ \\
\hline 14 & {$\left[\begin{array}{lllll}2 & 5 & 1 & 1 & 4\end{array}\right]$} & 37.86 & 6 & 0.88 & Modo 4: $\mathrm{T}_{\mathrm{m}} \mathrm{T}_{\mathrm{m}} \mathrm{TT} \mathrm{T}$ \\
\hline 15 & {$\left[\begin{array}{lllll}2 & 5 & 1 & 1 & 5\end{array}\right]$} & 44.19 & 6 & 0.94 & Modo 5: $\mathrm{T}_{\mathrm{m}} \mathrm{TT} \mathrm{T} \mathrm{T}_{\mathrm{m}}$ \\
\hline$\overline{1} \overline{6}$ & {$\left[\overline{2} \overline{5}^{1} \overline{2} 1\right.$} & $\overline{4} \overline{3} . \overline{2} \overline{6}$ & $\overline{6}$ & $0 . \overline{9}$ & Modo 1: Pentatônica Maror \\
\hline 17 & {$\left[\begin{array}{lllll}2 & 5 & 1 & 2 & 2\end{array}\right]$} & 42.74 & 6 & 0.9 & Modo 2: Egípcia \\
\hline 18 & {$\left[\begin{array}{lllll}2 & 5 & 1 & 2 & 3\end{array}\right]$} & 43.26 & 6 & 0.93 & Modo 3: Man gong \\
\hline 19 & {$\left[\begin{array}{lllll}2 & 5 & 1 & 2 & 4\end{array}\right]$} & 46.59 & 6 & 0.97 & Modo 4: Ritusen \\
\hline 20 & 25125 & 46.59 & 6 & 0.97 & Modo 5: Pentatônica men \\
\hline$\overline{2} \overline{1}$ & & & $\overline{0}$ & & Acorde diminuto \\
\hline
\end{tabular}


Tabela 3.5: Escala usada na composição com redes complexas predefinidas.

\begin{tabular}{|c|c|}
\hline Especificações & Valor \\
\hline Nome & Indeterminado \\
\hline Código & {$\left[\begin{array}{llllll}2 & 5 & 1 & 1 & 5 & 5\end{array}\right]$} \\
\hline Intervalos & {$\left[\mathrm{T}_{\mathrm{m}} \mathrm{TTT} \mathrm{T}_{\mathrm{m}}\right]$} \\
\hline Tônica & $\mathrm{F}$ \\
\hline Modo & 5 \\
\hline Oitava inicial & 3 \\
\hline No. oitavas & 5 \\
\hline Notas & $\mathrm{F} \mathrm{A} b \mathrm{~B} b \mathrm{C} \mathrm{D} \mathrm{F}$ \\
\hline MPHS & 44.19 \\
\hline DEV & 6 \\
\hline$\Phi$ & 0.94 \\
\hline
\end{tabular}

Tabela 3.6: Melodiosidade das melodias geradas usando todas as opções possíveis de executar o modelo de composição baseado em redes complexas predefinidas, a escala maior e a nova escala com código [2 $\left.5 \begin{array}{lllll}2 & 1 & 1 & 5 & 5\end{array}\right]$.

\begin{tabular}{c|c|c|c|c|c|c|c|c}
\hline \multirow{2}{*}{ Rede $\backslash$ Critério } & \multirow{2}{*}{ Escala } & \multicolumn{3}{|c|}{ Mínimo } & \multicolumn{3}{c|}{ Máximo } & \\
\cline { 3 - 9 } & $k_{i}$ & $s_{i}$ & $w_{i j}$ & $k_{i}$ & $s_{i}$ & $w_{i j}$ & Aleatório \\
\hline \hline Regular & Maior & - & 8.00 & 7.99 & - & 8.13 & 8.01 & 8.00 \\
Pequeno mundo & Nova & - & 8.00 & 7.67 & - & 7.64 & 8.06 & 7.07 \\
Aleatória & Maior & 8.05 & 7.00 & 8.51 & 10.73 & 9.93 & 10.97 & 8.00 \\
& Nova & 7.90 & 8.00 & 7.66 & 7.72 & 7.52 & 5.03 & 6.98 \\
Livre de escala & Maior & 6.28 & 8.00 & 4.34 & 8.00 & 4.04 & 4.98 & 8.00 \\
& Nova & 6.93 & 7.00 & 8.31 & 1.00 & 5.03 & 5.02 & 7.93 \\
& Maior & 6.97 & 4.00 & 4.76 & 7.00 & 8.00 & 4.00 & 7.99 \\
& Nova & 6.71 & 7.00 & 5.53 & 7.00 & 7.93 & 7.88 & 7.99 \\
\hline
\end{tabular}

notas é 26 (5 notas em cada oitava mais 1 nota que fecha o ciclo), correspondendo este número ao número de nós que terão as redes complexas predefinidas. Usando este valor como parâmetro de entrada foram geradas as 4 redes predefinidas e foi composta uma melodia usando cada um dos critérios possiveis. A extensão de todas as melodias foi fixada em 100 notas, os valores rítmicos foram mantidos em semicolcheia, e para cada uma destas foi calculado o grau de melodiosidade (descrito na Seção 2.4.2). Para propósitos de comparação, também foram compostas melodias usando a escala de C maior, e conservando a mesma estrutura da rede. Os resultados são apresentados na Tabela 3.6. Os valores obtidos sugerem que a melodiosidade é sensivel não apenas ao critério de caminhada usado, mas também ao tipo de escala escolhida. Quando comparados os graus de melodiosidade das melodias compostas com diferentes escalas, estes sugerem que a escala nova tem propriedades similares às da escala maior. No entanto, estes resultados não são conclusivos dada a ampla aleatoriedade envolvida na geração dos dados.

As redes complexas regular, de pequeno mundo e aleatória que foram ge- 
radas para serem usadas no modelo proposto são ilustradas na Fig. 3.4(a), 3.5(a) e 3.6(a), respectivamente, já as melodias compostas usando caminhada aleatória sobre essas redes são mostradas na Fig. 3.4(b), 3.5(b) e 3.6(b), respectivamente.

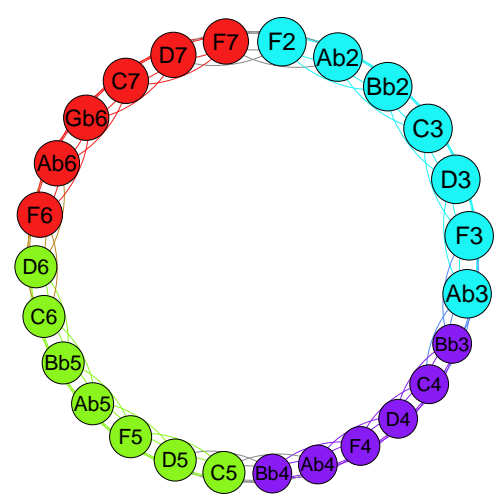

(a) Rede regular

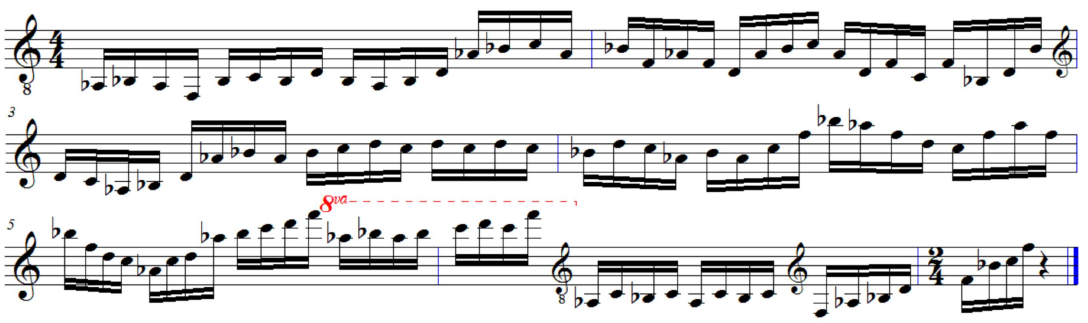

(b) Melodia

Figura 3.4: Melodia composta usando caminhada aleatória na rede regular.

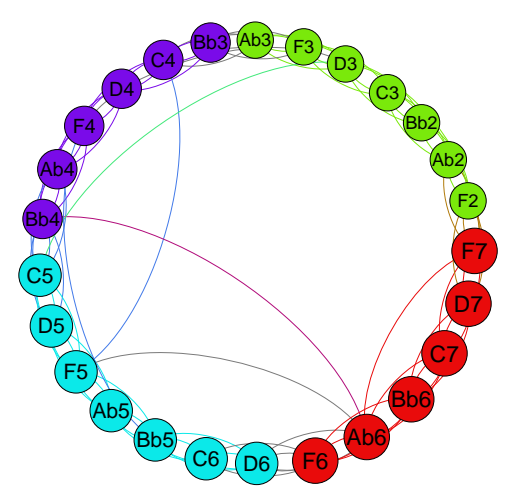

(a) Rede de pequeno mundo

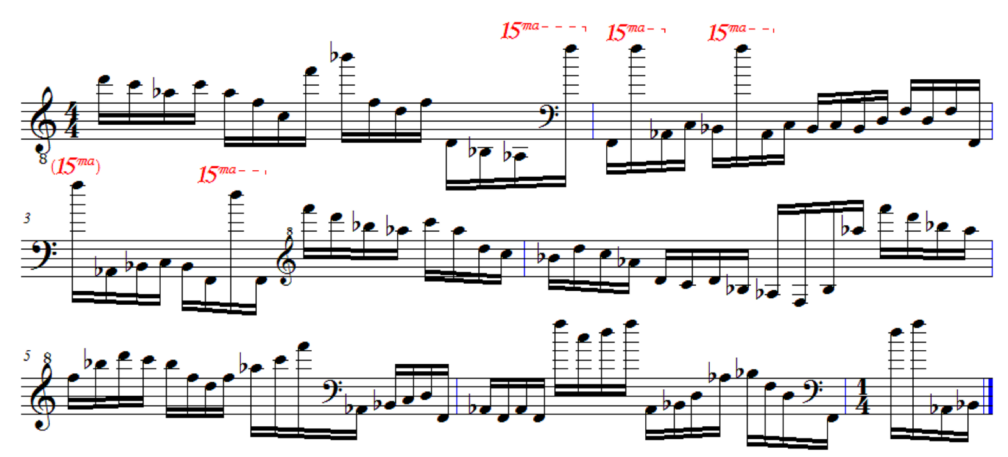

(b) Melodia

Figura 3.5: Melodia composta usando caminhada aleatória na rede de pequeno mundo.

A rede complexa livre de escala gerada é ilustrada na Fig. 3.7(a) e a sua distribuição de grau na Fig. 3.7(b). Esta distribuição tem uma lei de potência igual a $P(k)=13.93 \cdot k^{-2.37}$. A melodia composta pela rede livre de escala usando caminhada regida pela força máxima do nó é mostrada na Fig. 3.8(a). Com as notas da melodia composta foi criada uma nova rede, obtida a sua distribuição de grau e calculada a função de lei de potência. A distribuição de grau da rede da nova melodia é mostrada na Fig. 3.8(b), esta distribuição tem uma lei de potência igual a $P(k)=9.08 \cdot k^{-1.46}$. Nas duas funções calculadas o expoente de escala tem valor negativo, o que confirma que a lei de potência foi conservada. Além disso, os valores da Tabela 3.6 sugerem que a melodiosidade das melodias compostas com a rede livre de escala e de pequeno mundo sobressaem na maioria dos critérios, revelando uma possível influência da lei de potência 


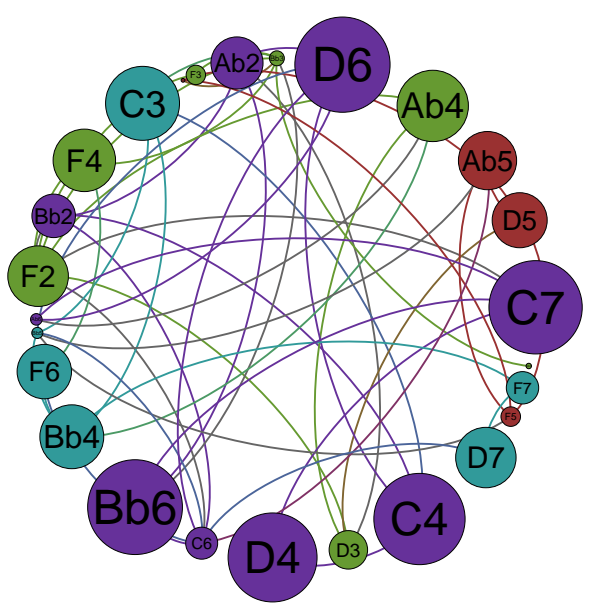

(a) Rede aleatória de Erdős-Rényi

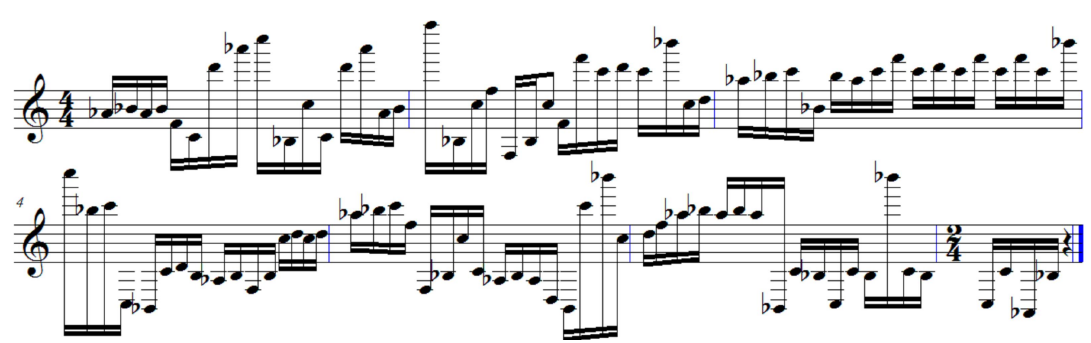

(b) Melodia

Figura 3.6: Melodia composta usando caminhada aleatória na rede aleatória de Erdős-Rényi.

no grau de melodiosidade. Estudos realizados sobre obras musicais de diferentes gêneros e estilos têm concluído que a estética musical obedece à lei de potência (Levitin et al., 2012).

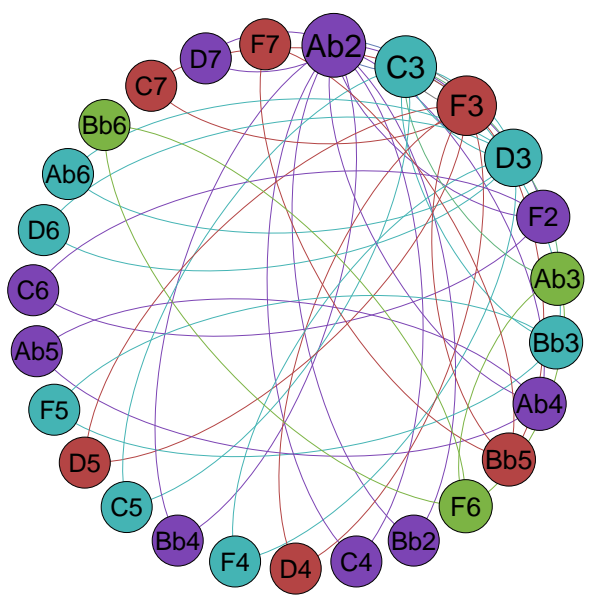

(a) Rede livre de escala

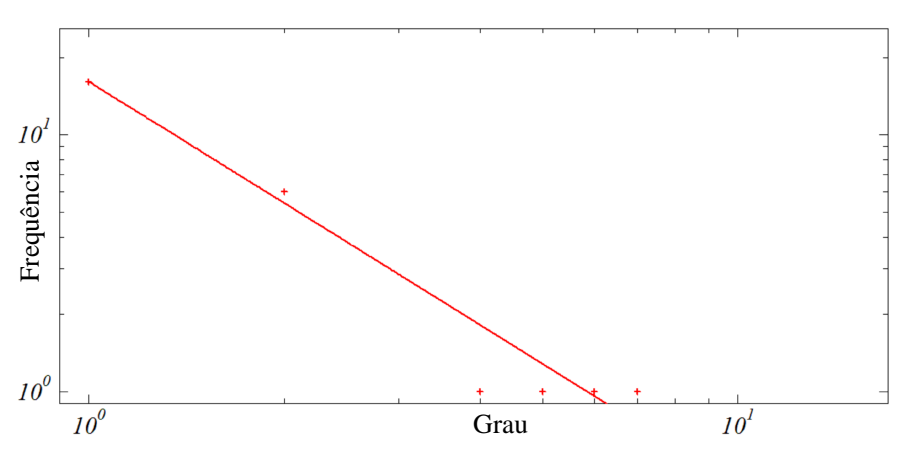

(b) Distribuição de grau

Figura 3.7: Rede complexa livre de escala escolhida para composição musical e a sua distribuição de grau.

Por último, para facilitar o manuseio das entradas e saídas do modelo de composição foi projetada uma interface de usuário, a qual é mostrada na Fig. 3.9 .

\subsection{Metodologia Baseada em Redes Neurais Recor- rentes e Inspiração Caótica}

Os modelos de composição automática apresentados nesta seção baseiamse na adaptação de RNNs através da incorporação de uma entrada adicional, 


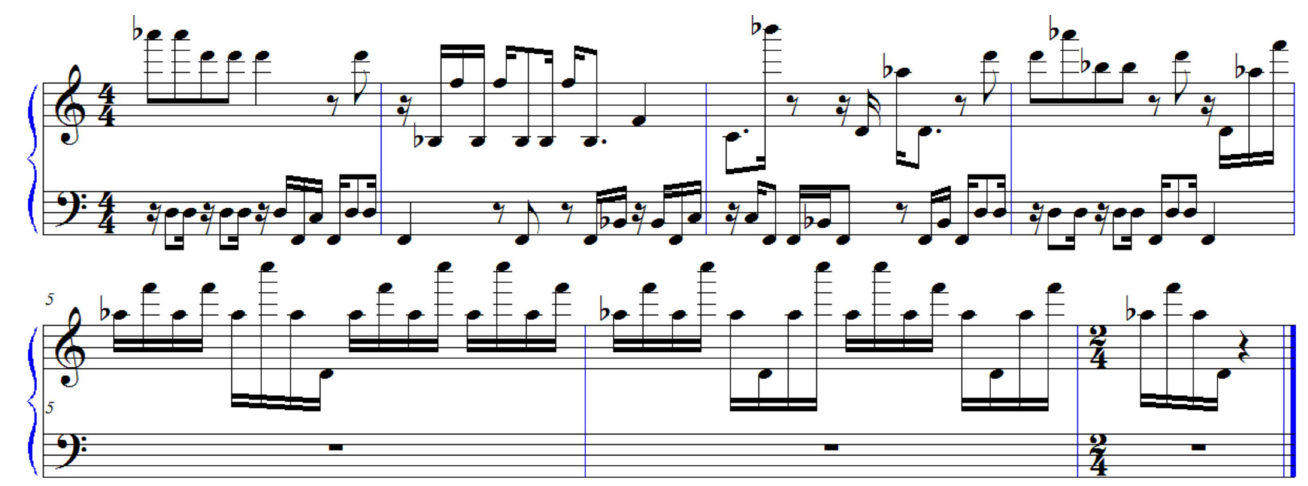

(a) Melodia

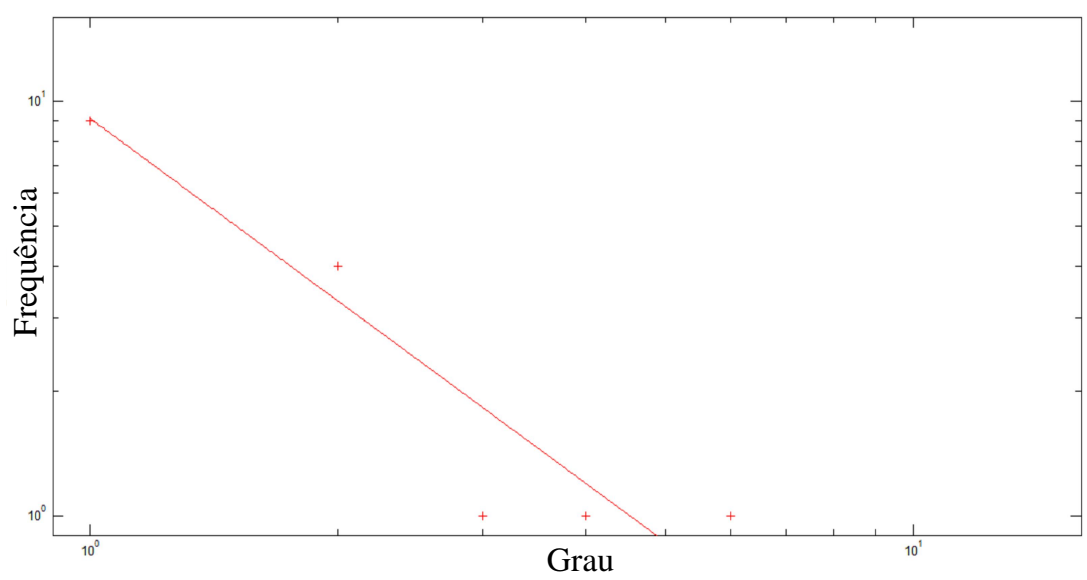

(b) Distribuição de grau

Figura 3.8: Resultado usando a rede livre de escala e caminhada regida pela força máxima.

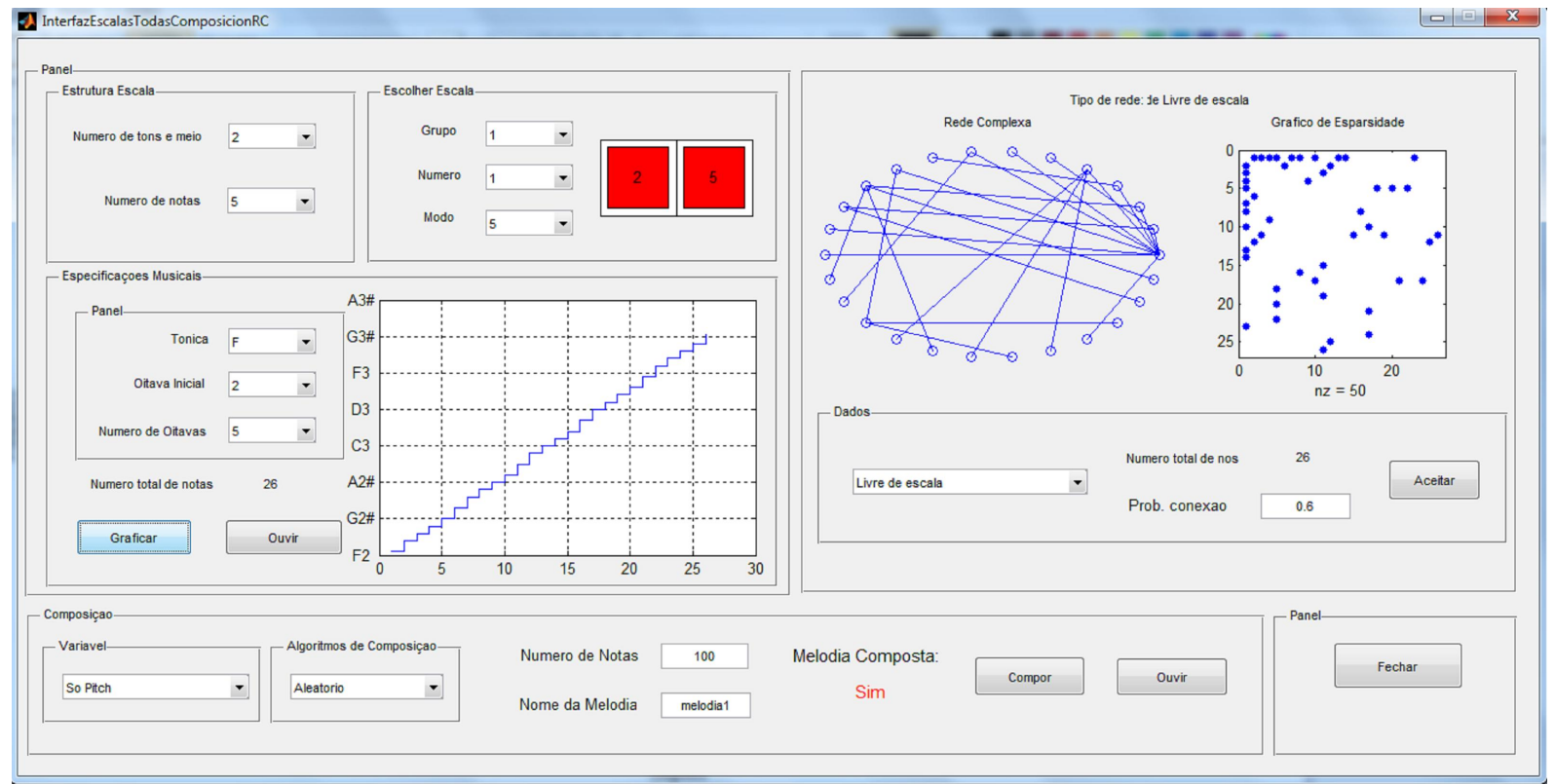

Figura 3.9: Interface do modelo de composição de melodias com redes complexas predefinidas e sistema de decodificação de escalas. 
chamada fonte de inspiração, proveniente da saída de um algoritmo de composição de melodias caóticas. O primeiro modelo usa a rede de Elman treinada com o algoritmo BPTT, enquanto o segundo usa uma rede LSTM integrada a um sistema de controle. A seguir são descritos estes modelos, bem como as respectivas simulações computacionais.

\subsection{Descrição do Modelo}

As RNNs são muito úteis na análise e modelamento de séries de tempo, devido ao fato de integrar laços de realimentação e operadores de retardo, os quais permitem modelar a não-linearidade dos componentes dinâmicos de um sistema. Portanto, diferentes aplicações em composição automática podem ser encontradas. Em 1989 foi utilizada uma RNN treinada com o algoritmo BPTT para compor melodias monofônicas, na qual uma nota ocorre após a outra como um fenômeno sequencial (Todd, 1989), e em (Lewis, 1991) foi desenvolvido um paradigma que utiliza RNNs para a geração de melodias através de uma técnica chama criação por refinamento $\left(\mathrm{CBR}^{8}\right)$, na qual a rede simula um crítico musical que julga exemplos musicais segundo uma diretriz específica. Outro interessante sistema é CONCERT proposto por Mozer (1994), onde a rede foi treinada usando informação psicológica, e as notas geradas são candidatas a pertencer à melodia segundo uma distribuição de probabilidade.

Recentemente, métodos híbridos têm sido propostos, por exemplo, em (Chen \& Miikkulainen, 2001) foi usada uma rede recorrente simples, na qual os pesos são adaptados usando um algoritmo genético; em (Verbeurgt et al., 2004) RNNs e Cadeias de Markov são usadas para compor música através de exemplos; em (Oliwa \& Wagner, 2008) foi usada uma RNN com tempo de retardo e máquinas probabilísticas de estado finito para adquirir conhecimento sobre múltiplos instrumentos musicais através de aprendizado por indução; em (Hoover \& Stanley, 2009) uma RNN foi proposta para modelar múltiplos segmentos funcionalmente relacionados de uma canção, bem como a relação funcional entre os instrumentos não-percussivos e a bateria; em (Bickerman et al., 2010) uma rede neural probabilística baseada em máquinas de Boltzmann foi proposta para improvisação de sequências de acordes de jazz.

Em (Corrêa \& Saito, 2007) foi demonstrado que uma RNN pode aprender as características ou o estilo de uma melodia de treino, adquirindo a capacidade de compor novas melodias similares à melodia de entrada. Com o intuito de controlar esta similaridade foi proposto considerar uma melodia adicional e independente chamada fonte de inspiração, que provém do contorno de uma paisagem geográfica. Contudo, este método tem duas desvantagens, a saber: a primeira é a necessidade de criar e armazenar uma imagem em uma base

\footnotetext{
${ }^{8}$ Sigla de Creation By Refinement
} 
de dados, a qual ocupa espaço de memória; e a segunda está relacionada com a necessidade de pré-processar cada imagem, o qual tem um custo computacional considerável e requer de mais tempo.

Conforme apresentado na Seção 2.2.2, a alta sensibilidade às condições iniciais que têm os sistemas caóticos lhes permite evoluir a uma diferente e até mesmo totalmente inesperada forma devido a pequenas mudanças nas condições iniciais do sistema. Durante as últimas décadas, esta propriedade despertou um grande interesse em diferentes áreas de pesquisa, incluindo a composição musical (Dabby, 1995; Coca et al., 2010, 2009).

Nesta seção é proposto aprimorar o modelo de (Corrêa \& Saito, 2007) usando como fonte de inspiração melodias geradas pelo algoritmo de composição caótico de Coca et al. (2010). Usando esta técnica, não é mais necessário ter uma grande base de dados para ter um grande número de melodias de inspiração, já que é possível obter infinitas variações, e de uma maneira muito rápida, através de uma pequena mudança nos parâmetros do sistema caótico. No contexto desta perspectiva foram explorados dois modelos. No primeiro, uma RNN modificada e treinada com o algoritmo BPTT é usada para compor novas melodias semelhantes à melodia de treino, porém a saída é afetada de maneira controlada mediante a variação do número de notas da melodia de inspiração (Coca et al., 2011). O segundo modelo usa uma rede LSTM integrada a um sistema de controle, o qual mantendo o número de notas de inspiração fixo e variando um parâmetro do sistema dinâmico através de uma estratégia de controle, consegue compor uma melodia com um valor predefinido de melodiosidade (Coca et al., 2013). Estes dois modelos são descritos a seguir.

\section{RNN com Inspiração Caótica}

Neste modelo, uma RNN de Elman modificada é usada para compor automaticamente estruturas musicais baseadas no estilo de uma peça previamente aprendida durante a fase de treino. Visando abranger uma grande variedade de melodias na saída, um pequeno fragmento proveniente de uma melodia caótica (fonte de inspiração) é aderido à entrada da RNN, o qual em combinação com a melodia principal age sobre a melodia de saída. A melodia principal é fixa e conhecida, enquanto a melodia caótica é gerada pelo algoritmo de composição e pode ser modificada através de um parâmetro do sistema caótico. São usadas duas redes, uma para treinar as alturas e outra para treinar o ritmo (Coca et al., 2011). A Fig. 3.10 mostra a RNN de Elman modificada mediante a adição da fonte de inspiração.

O processo de treinamento da rede com o algoritmo BPTT consiste dos seguintes eventos: primeiro, visando não influenciar a saída da rede no primeiro 


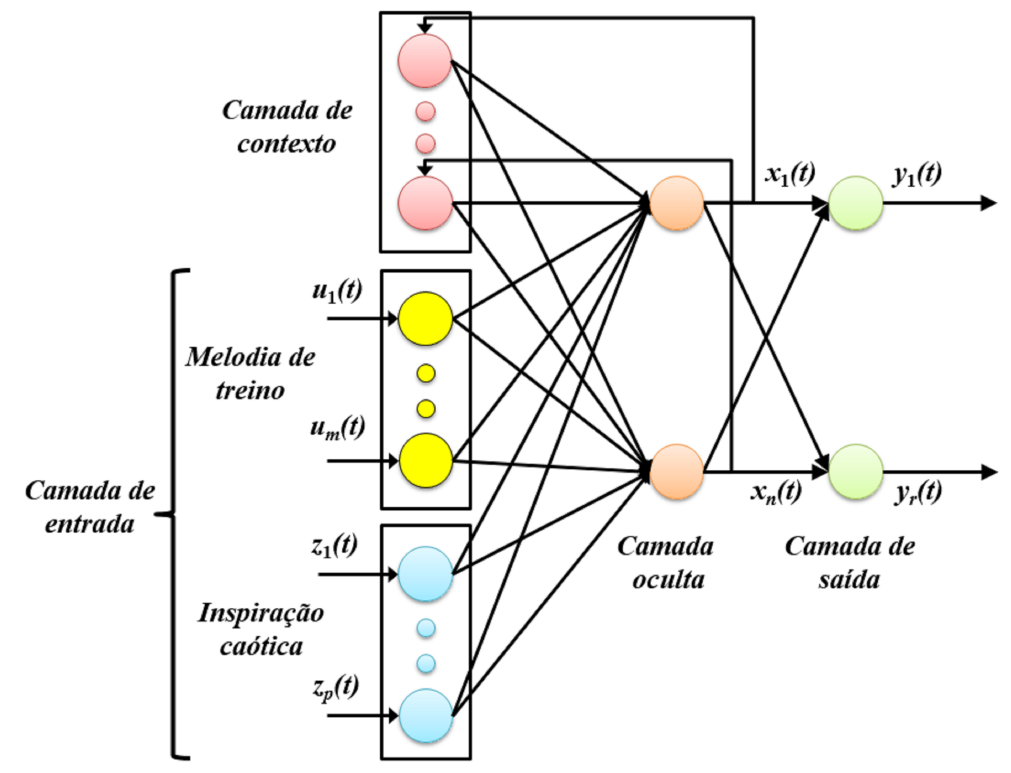

Figura 3.10: Rede neural recorrente com entrada de inspiração caótica (Coca et al., 2011).

estado, as unidades de contexto provenientes da saída da camada oculta são inicializadas com 0 , logo após, na iteração 0 (estado inicial), o sinal é propagado pela rede, isto é, na primeira iteração, a rede se comportará como uma rede $\mathrm{FF}$. $\mathrm{Na}$ iteração $t$ os neurônios ocultos ativarão os neurônios da camada de contexto que armazenarão a saída dessa iteração, a qual será usada no próximo ciclo. Neste ponto, o algoritmo BPTT é aplicado para corrigir os pesos sinápticos $\mathbf{W}$, exceto as sinapses de recorrência que têm valor fixo de 1 . Nas próximas iterações o processo é repetido. A partir deste ponto há uma diferença, pois os neurônios ocultos são ativados não apenas pelas unidades de entrada (melodia de treino + melodia de inspiração), mas também pelas unidades de saída, as quais têm o valor de saída do instante anterior dos neurônios ocultos, isto é, o momento $t-1$. A saída da rede é dada por:

$$
\begin{aligned}
& \mathbf{x}(t)=\mathbf{W}_{x x} \mathbf{x}(t-1)+\mathbf{W}_{x u} \mathbf{u}(t)+\mathbf{W}_{x u} \mathbf{z}(t) \\
& \mathbf{y}(t)=\mathbf{W}_{y x} \mathbf{x}(t)
\end{aligned}
$$

em que $\mathbf{x}(t)$ é a saída dos neurônios da camada oculta no instante $t, \mathbf{W}_{x x}$ são os pesos sinápticos associados, $\mathbf{u}(t)$ a entrada (melodia de treino), $\mathbf{z}(t)$ a entrada de inspiração caótica e y $(t)$ a saída da rede.

Para representar a entrada da rede em bits foi adotada a representação por ciclos de terças (Franklin, 2006). Esta representação usa sete bits, na qual os primeiros quatro indicam em qual ciclo de terça maior a nota é localizada, para um total de quatro ciclos. Os últimos três bits indicam a localização da nota dentro de três ciclos de terça menor. A informação da oitava é dada separadamente com dois bits adicionais, um para indicar se a nota pertence 
à terceira oitava (notas C3 a B3), e outro para indicar se a nota pertence à quinta oitava (notas C5 a B5). Se os dois bits tiverem valor igual à zero, tratase da oitava central, isto é, a quarta oitava (notas C4 a B4). Para representar o ritmo foi usada a notação absoluta, na qual são usados sete niveis de duração diferentes, onde um bit em 1 indica a pertinência de uma figura dentro de algum destes níveis.

\section{Rede LSTM com Inspiração Caótica}

Para este modelo a rede LSTM foi adotada devido a sua capacidade de memória de longo e curto prazo (Gers, 2001). De forma semelhante ao modelo anterior, uma melodia independente provida pela fonte de inspiração foi incluída na entrada. Este modelo é um sistema de controle de composição musical que tem a flexibilidade de ajustar uma característica subjetiva da melodia de saída segundo um valor de referência predefinido. Portanto, a rede LSTM faz parte do sistema, mas não é o sistema composicional em si mesmo. Em outras palavras, a rede LSTM cumpre só uma função específica dentro do sistema todo, que é compor uma nova melodia segundo a combinação de entradas: melodia de treino e melodia de inspiração, sendo esta última alterada em um ciclo de retroalimentação através dos outros elementos do sistema (Coca et al., 2013).

A entrada da rede LSTM foi adaptada dividindo as unidades de entrada em dois grupos: unidades melódicas e unidades caóticas. As unidades melódicas representam a melodia a ser aprendida pela rede e as unidades caóticas a fonte de inspiração. A Fig. 3.11 mostra a rede LSTM adaptada com dois blocos de memória. A n-ésima unidade de entrada melódica, caótica e de saída é representada com $x_{n}(t), y_{n}(t)$ e $z_{n}(t)$, respectivamente. Cada unidade oculta representa um bloco de memória com uma célula de memória, conforme ilustrado na Fig. 2.9.

O funcionamento do sistema composicional completo é o seguinte: no estado inicial a rede LSTM é treinada tendo como entradas uma melodia conhecida e uma melodia caótica. A rede compõe uma nova melodia, para a qual é mensurada uma característica subjetiva, cujo valor obtido é levado à entrada do sistema para ser comparado com um valor de referência. Com a diferença entre estes dois valores, uma estratégia de controle proporcional é ativada, que, segundo o erro, fornece uma ação de controle que age sobre um parâmetro específico do sistema caótico, fazendo que a complexidade do sistema dinâmico seja variável dentro de uma porção da região caótica. Em consequência, o algoritmo de composição gerará uma melodia com complexidade diferente de cada vez. A rede LSTM ao ter uma melodia de inspiração com complexidade variável mudará o valor da característica subjetiva alvo em cada ciclo. O sistema é executado até a característica subjetiva atingir o valor 


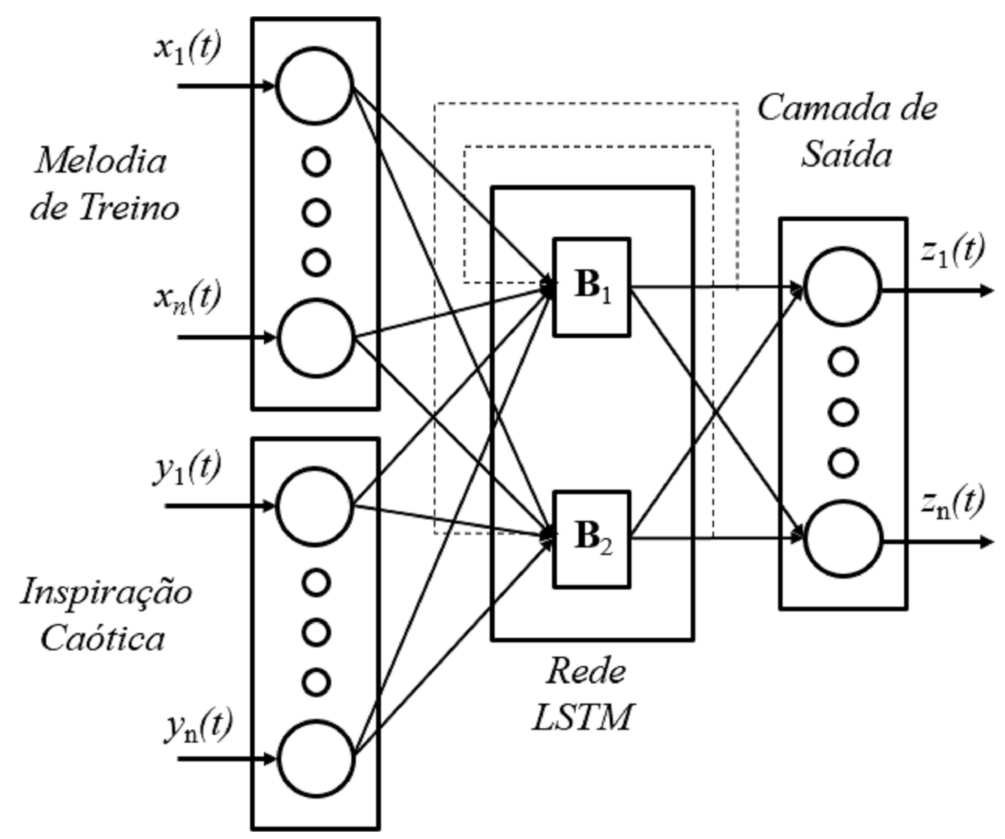

Figura 3.11: Rede LSTM com inspiração caótica (Coca et al., 2013).

de referência.

A Fig. 3.12 mostra o diagrama de blocos do sistema composicional completo, em que $r$ é o valor de referência da característica subjetiva, $m$ é o valor mensurado para a melodia de saída; $u$ é a saída do controlador proporcional, o qual ajusta o parâmetro $p$ do sistema caótico; C é a matriz de solução das variáveis do atrator caótico, $\mathbf{M}^{(1)}$ é a matriz de notas da melodia de inspiração composta pelo algoritmo compositor de melodias caóticas, $\mathbf{M}^{(2)}$ é a matriz de notas da melodia de entrada e $\mathbf{M}^{(3)}$ é a matriz de notas da melodia composta pela rede LSTM.

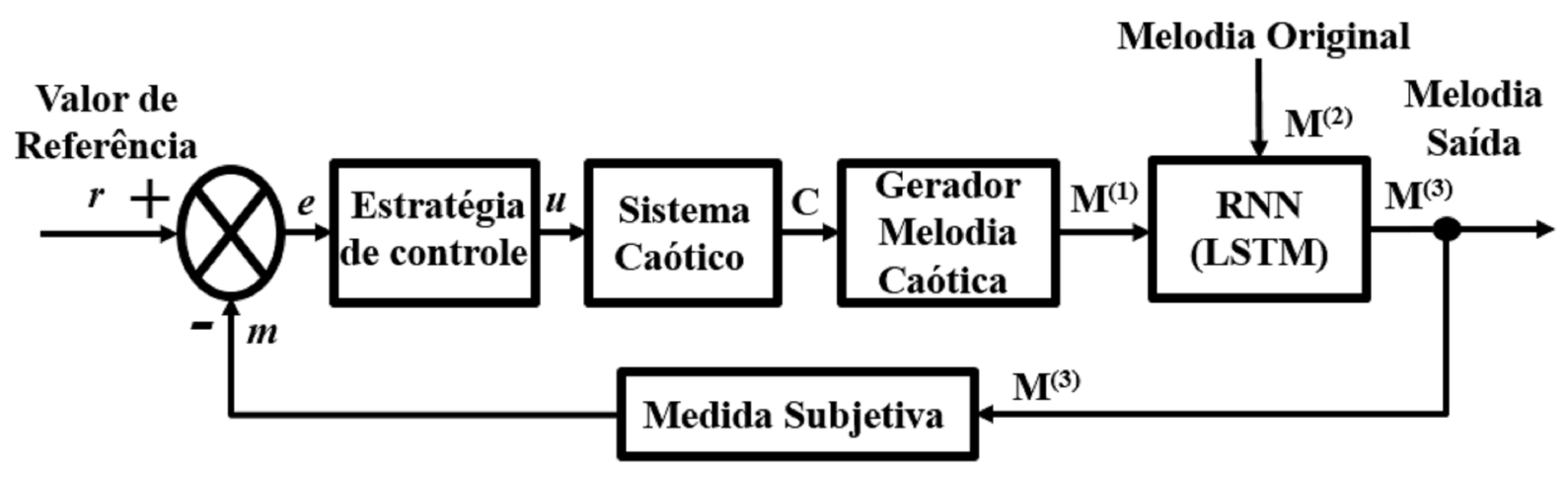

Figura 3.12: Diagrama do sistema de composição de melodias com valor predefinido de subjetividade melódica (Coca et al., 2013).

A variável de erro é igual a $e=r-m$. Esta diferença é usada pelo controlador proporcional para obter uma ação $u$, tal que $u=q \cdot e=q \cdot(r-m)$, a qual muda 
o parâmetro $p$ do sistema caótico. Portanto, a saída do sistema caótico é:

$$
\mathbf{C}=f\left(x_{0}, y_{0}, p+u\right)
$$

em que $x_{0}$ e $y_{0}$ são as condições iniciais do sistema caótico. A solução do sistema é armazenada na matriz $\mathbf{C}_{n \times 2}$ ( $n$ é o número de iterações). As variáveis de solução são separadas, i.e., $x(t)=\mathbf{C}_{1}$ e $y(t)=\mathbf{C}_{2}$. Cada variável de solução é mapeada a um domínio musical. Neste caso, com $x(t)$ são geradas as alturas e com $y(t)$ os valores rítmicos. Seja $\Gamma(\cdot)$ o algoritmo de composição caótico. Então, usando como entrada os vetores caóticos $x(t)$ e $y(t)$, e um conjunto de especificações musicais (como escala, número de oitavas, oitava inicial e outras) denotado como $S$, a saída do bloco de composição caótico é a matriz de notas $\mathbf{M}^{(1)}$, assim:

$$
\mathbf{M}^{(1)}=\Gamma(x(t), y(t), S) .
$$

Com a matriz de notas da melodia caótica $\mathrm{M}^{(1)}$ são obtidos o vetor de alturas $\mathbf{x}^{(1)}=\mathbf{M}_{1}^{(1)}$ e de durações $\mathbf{y}^{(1)}=\mathbf{M}_{2}^{(1)}$, os quais são usados como entradas de inspiração caótica, que conjuntamente com o vetor de alturas $\mathrm{x}^{(2)}$ e o vetor do ritmo $\mathbf{y}^{(2)}$ da melodia de entrada, são aplicados na entrada da rede LSTM, obtendo a matriz de notas da melodia de saída $\mathbf{M}^{(3)}$, da seguinte maneira:

$$
\mathbf{M}^{(3)}=\Omega\left(\mathbf{x}^{(1)}, \mathbf{y}^{(1)}, \mathbf{x}^{(2)}, \mathbf{y}^{(2)}, Q\right),
$$

em que $\Omega(\cdot)$ representa a rede LSTM e $Q$ representa o conjunto de parâmetros de entrada da rede. Por fim, seja $\theta(\cdot)$ uma função que retorna o valor da característica subjetiva alvo da melodia de saída, então $m=\theta\left(\mathbf{M}^{(3)}\right)$ é o valor que é levado à entrada, fechando assim o laço de realimentação.

Nesta tese foi adotada como característica subjetiva alvo o grau de meliodosidade descrito na Seção 2.4.2.

\subsubsection{Simulações Computacionais}

A seguir são apresentados os experimentos e os resultados obtidos com os dois modelos de composição propostos nesta seção.

\section{Modelo 1: RNN Treinada como BPTT}

As simulações computacionais realizadas para este modelo têm como objetivo analisar o efeito de aderir notas de inspiração caótica na fase de treinamento sobre as características da melodia gerada na fase de aplicação. A RNN usada é composta por uma camada oculta com 20 neurônios, e a taxa de aprendizagem é fixada em 0.1. Na fase de treinamento são usadas quatro 
notas de entrada e a rede deve compor as quatro notas seguintes. Para gerar a melodia de inspiração caótica foi usada a equação logística (Eq. (2.29)) no regime caótico $(k=3.9)$. O número de notas de inspiração é variado de 0 a 20 na fase de treinamento. A melodia de treino escolhida é um fragmento (primeiros 4 compassos) do segundo movimento das quatro estações de Vivaldi mostrado na Fig. 3.13.

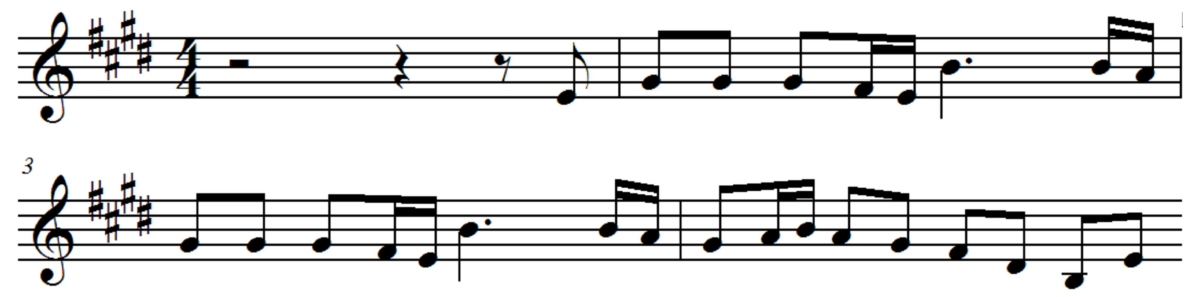

Figura 3.13: Compassos do segundo movimento das quatro estações de Vivaldi.

A melodia mostrada na Fig. 3.14 foi composta usando a rede treinada sem notas de inspiração caótica, enquanto a melodia da Fig. 3.15 usando a rede treinada com quatro notas de inspiração caótica.

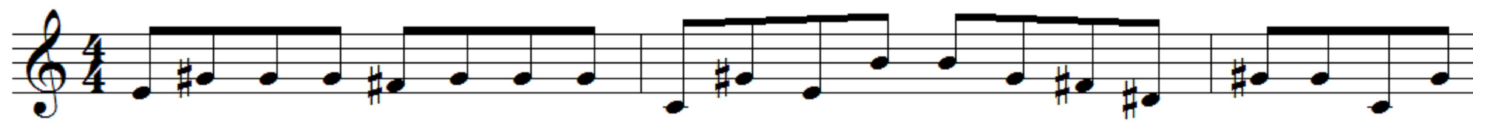

Figura 3.14: Melodia composta pela RNN sem notas de inspiração caótica.

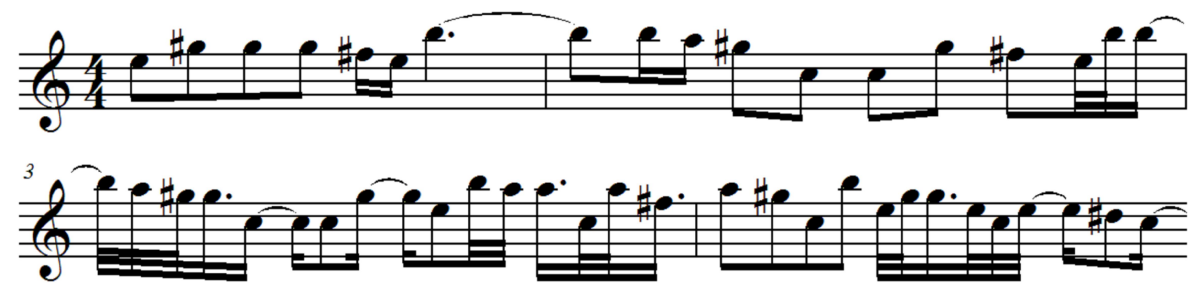

Figura 3.15: Melodia composta pela RNN com 4 notas de inspiração caótica.

A Tabela 3.7 mostra os valores de Complexidade Melódica (CMe) e Originalidade Melódica (OMe) calculados para a melodia de treino (Melodia T.), para a melodia composta sem inspiração caótica (Melodia (0)) e para a melodia usando $j$ nota de inspiração caótica $(\operatorname{Melodia}(j))$, com $1 \leq j \leq 10$. Também é mostrada a média e o desvio padrão.

A Tabela 3.8 mostra os valores de similaridade entre a melodia de treino e a melodia composta com $j$ notas de inspiração, com $0 \leq j \leq 10$, segundo a distribuição de alturas (similaridade tonal) e a distribuição de durações (similaridade rítmica). Também é mostrada a média e o desvio padrão. 
Tabela 3.7: Complexidade (CMe) e originalidade (OMe) das melodias compostas pela RNN com $j(0 \leq j \leq 10)$ notas de inspiração caótica.

\begin{tabular}{r|cc}
\hline \multirow{2}{*}{ Melodias } & \multicolumn{2}{|c}{ Medidas } \\
\cline { 2 - 3 } & CMe & OMe \\
\hline \hline Melodia T. & 5.53 & 9.17 \\
Melodia (0) & 3.873 & 7.895 \\
Melodia (1) & 4.098 & 9.772 \\
Melodia (2) & 4.354 & 8.947 \\
Melodia (3) & 4.577 & 9.384 \\
Melodia (4) & 3.953 & 10.00 \\
Melodia (5) & 4.489 & 9.355 \\
Melodia (6) & 4.431 & 9.235 \\
Melodia (7) & 4.496 & 9.374 \\
Melodia (8) & 4.473 & 9.126 \\
Melodia (9) & 4.625 & 9.255 \\
Melodia (10) & 5.154 & 9.633 \\
\hline \hline Média & 4.59 & 9.278 \\
Desvio padrão & 0.387 & 0.480 \\
\hline
\end{tabular}

Tabela 3.8: Similaridade tonal e rítmica entre a melodia de treino e a melodia composta pela RNN com $j(0 \leq j \leq 10)$ notas de inspiração caótica.

\begin{tabular}{c|c|c}
\hline \multirow{2}{*}{ Melodias } & Distribuição de alturas & Distribuição de durações \\
\cline { 2 - 3 } & Melodia T. & Melodia T. \\
\hline \hline Melodia T. & 1 & 1 \\
Melodia (0) & 0.74 & 0.92 \\
Melodia (1) & 0.75 & 0.78 \\
Melodia (2) & 0.60 & 0.49 \\
Melodia (3) & 0.52 & 0.78 \\
Melodia (4) & 0.75 & 0.80 \\
Melodia (5) & 0.63 & 0.78 \\
\hline \hline Média & 0.598 & 0.696 \\
Desvio padrão & 0.09 & 0.179 \\
\hline
\end{tabular}

A Fig. 3.16 ilustra a complexidade da melodia composta com diferente quantidade de notas de inspiração, a linha pontilhada é a complexidade da melodia sem notas de inspiração, a linha tracejada é a complexidade da melodia de entrada e a curva sólida é a complexidade da melodia de saída (Fig. 3.14). Pode-se perceber que a complexidade da melodia de saída incrementa proporcionalmente com o número de notas de inspiração e que se aproxima do valor de complexidade da melodia de entrada. No entanto, o tempo de treino incrementa com o número de notas de inspiração, o qual é um ponto importante a ser considerado na hora de selecionar o número apropriado de notas de treino.

Para o caso da originalidade melódica, pode-se enxergar que a originalidade da melodia composta pela rede usando notas de inspiração oscila em 


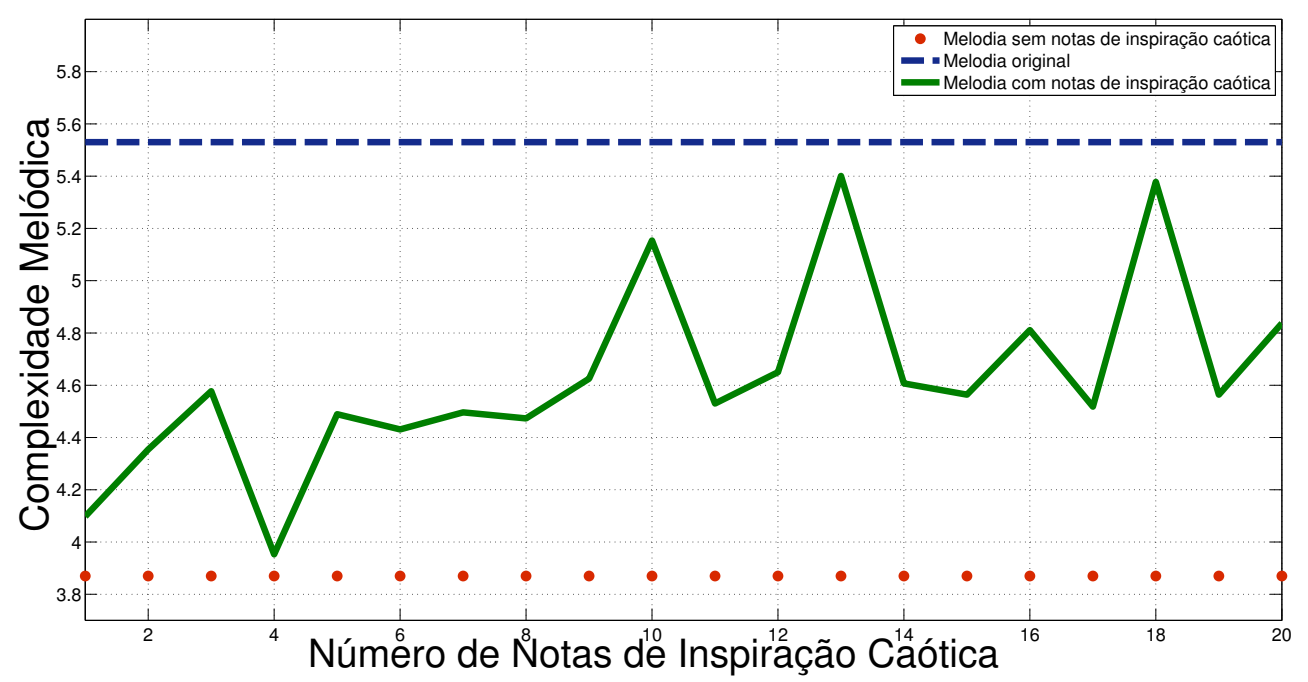

Figura 3.16: Complexidade da melodia de treino e das melodias compostas pela RNN sem notas de inspiração e com $j(1 \leq j \leq 20)$ notas de inspiração caótica.

torno do valor de originalidade da melodia de treino, o que significa que o número de notas de inspiração afeta a originalidade da melodia de saída, porém mantendo uma distância com a originalidade da melodia de treino, conforme mostrado na Fig. 3.17.

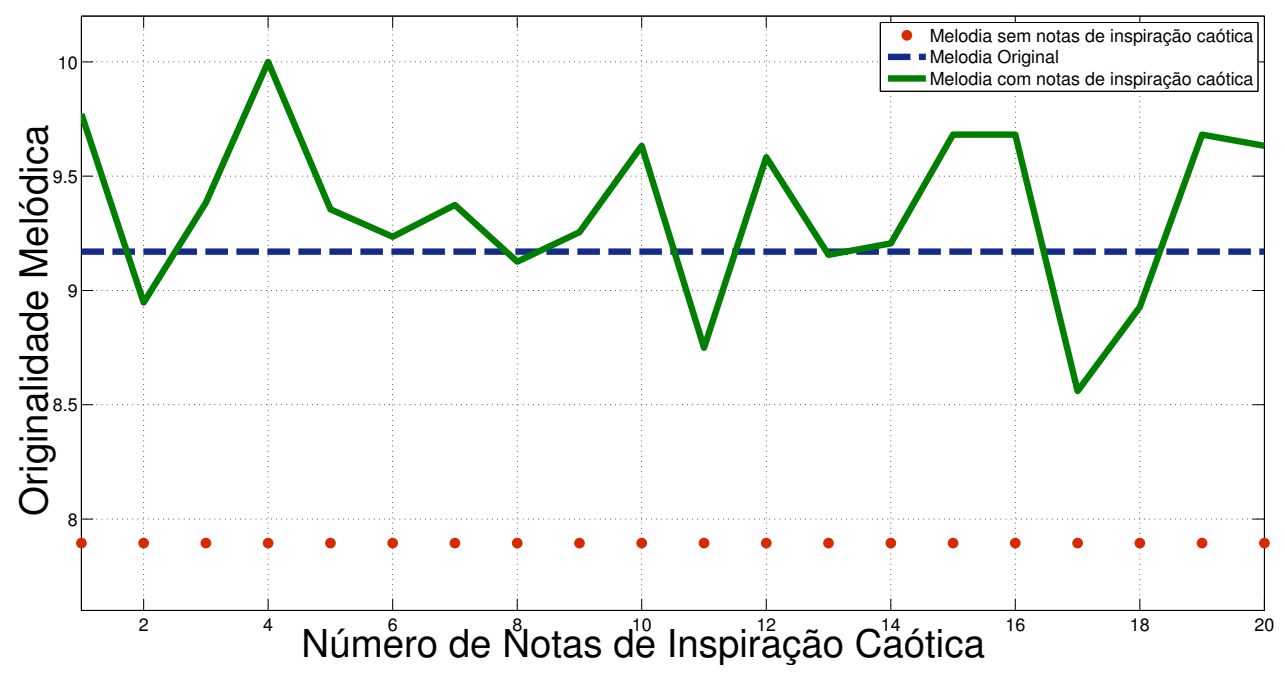

Figura 3.17: Originalidade melódica da melodia de treino e das melodias compostas pela RNN sem notas de inspiração e com $j(1 \leq j \leq 20)$ notas de inspiração caótica.

Na Fig. 3.18 é mostrada a similaridade tonal entre a melodia de treino e cada uma das melodias compostas pela rede variando o número de notas de inspiração de 0 a 20, a linha tracejada é a similaridade entre a melodia de treino e a melodia sem notas de inspiração caótica, e a linha sólida é a evolução da similaridade tonal entre a melodia de treino e cada uma das melodias 
compostas pela rede usando diferente número de notas de inspiração. Variando o número de notas de inspiração é possível ver que a melodia composta se torna um pouco mais diferente que a melodia de treino, isto é, a melodia composta pela rede se parece menos à melodia de entrada se mais notas de inspiração caótica forem usadas.

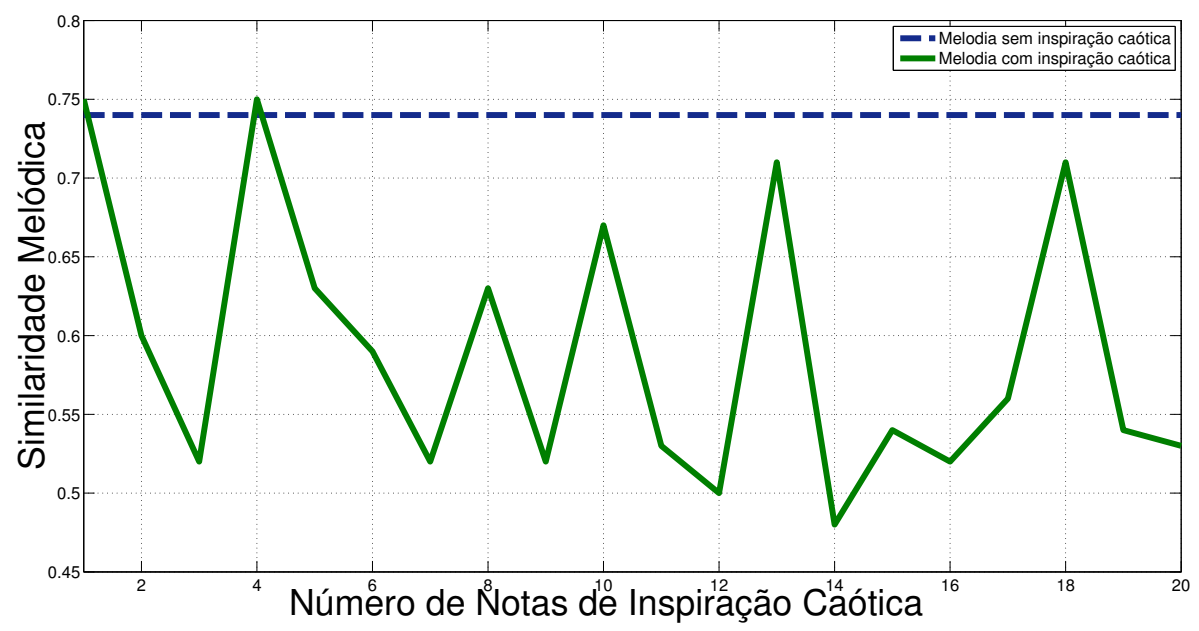

Figura 3.18: Similaridade tonal entre a melodia de treino e a melodia composta pela RNN sem notas de inspiração caótica.

A Fig. 3.19 mostra que a similaridade rítmica entre a melodia de treino e a melodia sem notas de inspiração é alta, porém a similaridade rítmica entre a melodia de treino e a melodia composta usando notas de inspiração diminui conforme o número de notas aumenta.

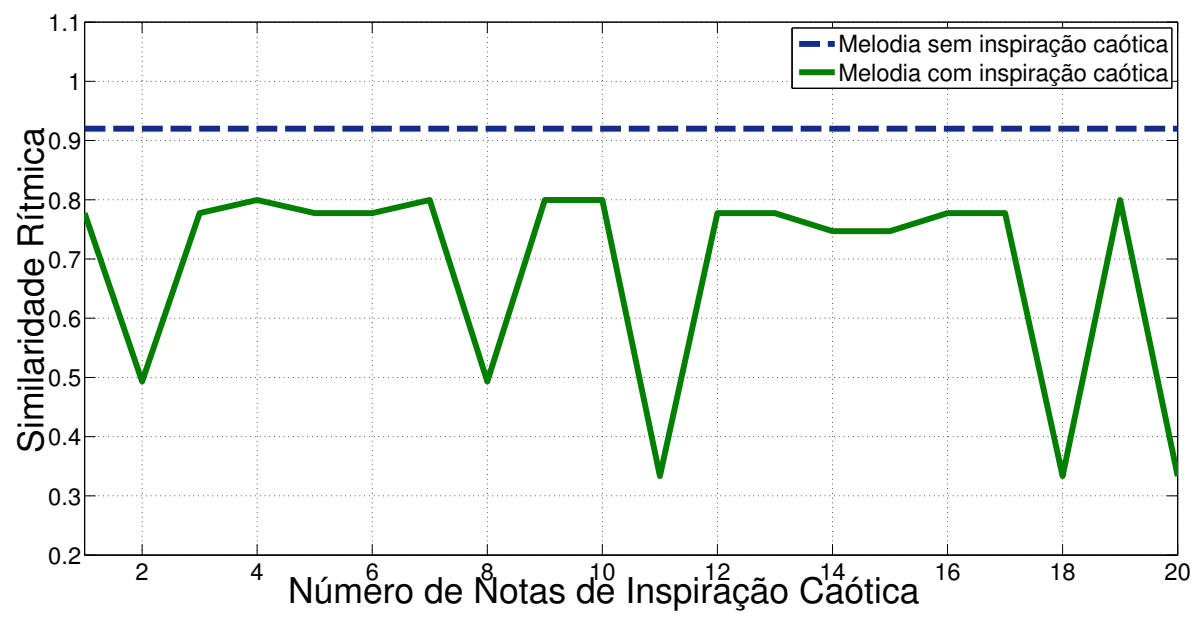

Figura 3.19: Similaridade rítmica entre a melodia de treino e a melodia composta pela RNN sem notas de inspiração caótica.

A Fig. 3.20 mostra a originalidade melódica resultante de variar a taxa de aprendizado. Pode-se enxergar que a originalidade melódica tem poucas mudanças para diferentes valores da taxa de aprendizado. 


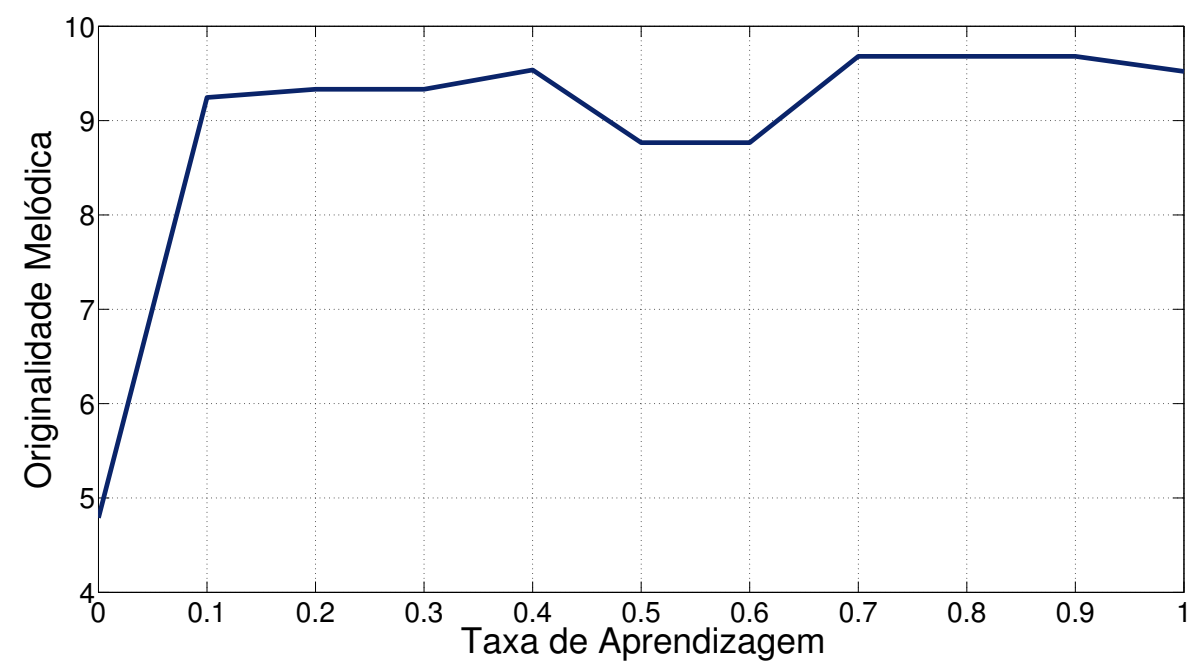

Figura 3.20: Originalidade melódica vs. taxa de aprendizado.

\section{Rede LSTM com Entrada de Inspiração Caótica}

O objetivo principal deste modelo é compor automaticamente uma melodia com um valor predefinido de grau de melodiosidade. Duas redes LSTM, cada uma contendo dois blocos de memória e uma célula de memória, são usadas para treinar as alturas e o ritmo separadamente. A rede para treinar as alturas tem 16 entradas e 9 saídas, as primeiras nove entradas correspondem às notas da melodia de treino, a qual é representada com 7 bits para as alturas e 2 bits para as oitavas; as outras 7 unidades de entrada correspondem às notas da melodia de inspiração caótica. A rede para treinar o ritmo tem 14 entradas, sendo 7 para a melodia de treino e 7 para a melodia de inspiração, onde cada entrada é um bit que representa um nível de duração. Ambas as redes foram treinadas com taxa de aprendizado igual a 0.1. Foi usado um sistema caótico discreto com duas variáveis, chamado mapa de Hénon, que é descrito pelo seguinte sistema de equações:

$$
\begin{aligned}
& x_{n+1}=y_{n+1}-a x_{n}^{2} \\
& y_{n+1}=b x_{n}
\end{aligned},
$$

em que $x_{n}$ e $y_{n}$ são as variáveis do sistema, $a$ e $b$ são os parâmetros e $n$ representa a iteração atual. A Fig. 3.21 ilustra o diagrama de bifurcação do mapa de Hénon variando o parâmetro $a$ entre 0 e 1.4 e mantendo $b$ fixo em 0.3 .

Inicialmente é necessário determinar a região onde a complexidade melódica das melodias geradas pelo mapa de Hénon é ascendente. A Fig. 3.22 mostra a complexidade melódica das melodias geradas com o mapa de Hénon variando o parâmetro $a$ entre 0 e 1.4 e mantendo o parâmetro $b$ fixo em 0.3 . A Fig. 3.23 apresenta a região ascendente (entre 0 e 0.34 ) que será usada no sistema completo. 


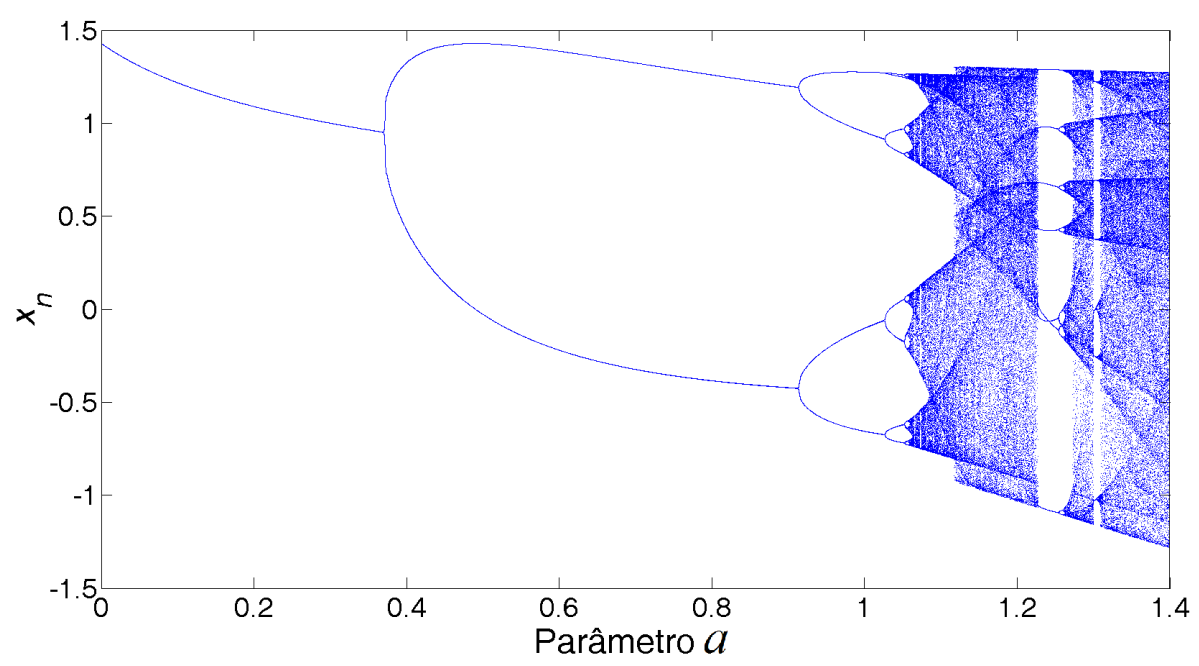

Figura 3.21: Diagrama de bifurcação do mapa de Hénon.

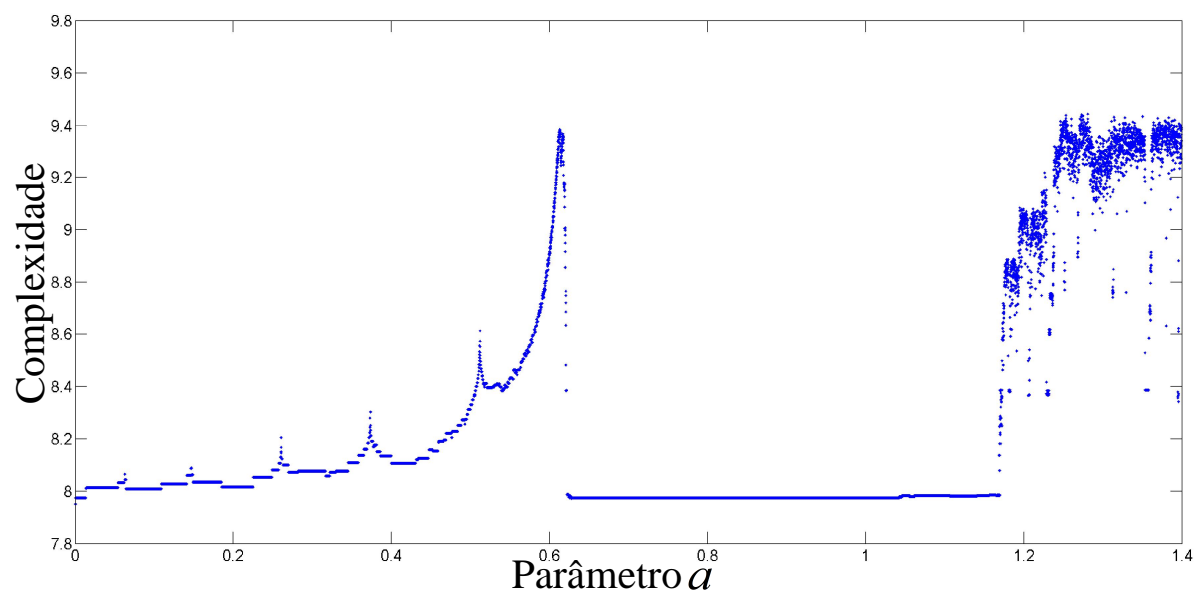

Figura 3.22: Complexidade tonal das melodias geradas como o mapa de Hénon.

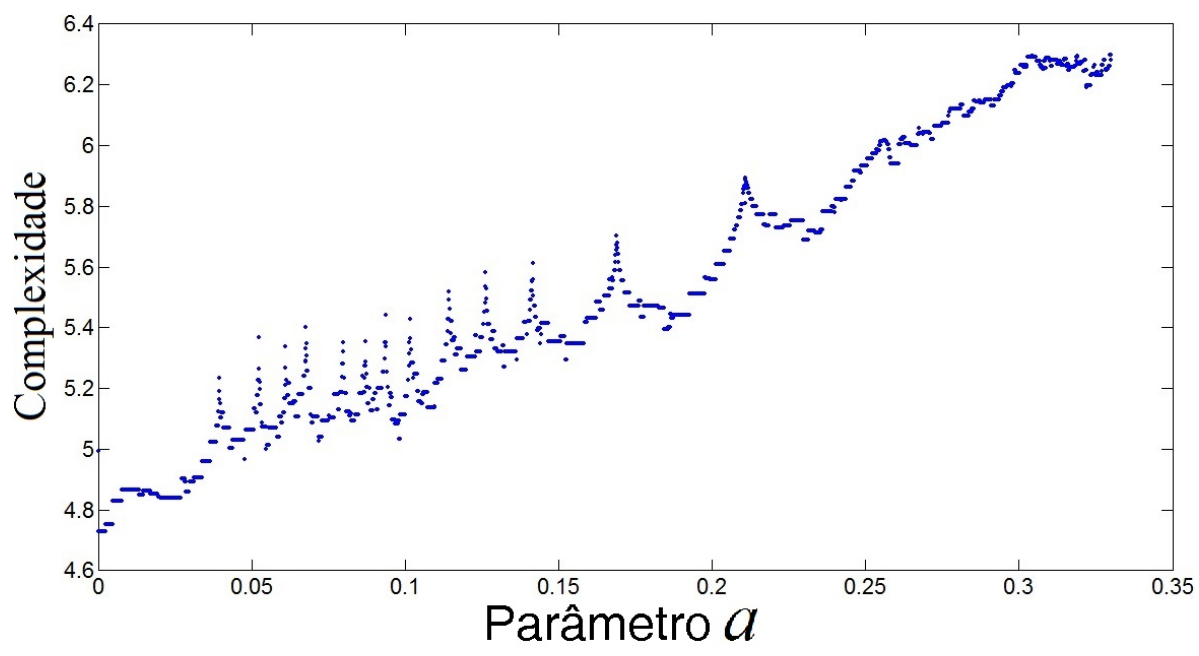

Figura 3.23: Região ascendente da complexidade tonal das melodias geradas como o mapa de Hénon. 
Em seguida, a melodia de entrada é selecionada. A Fig. 3.24 mostra os primeiros compassos da sonata para piano No. 16 em C maior de Mozart.

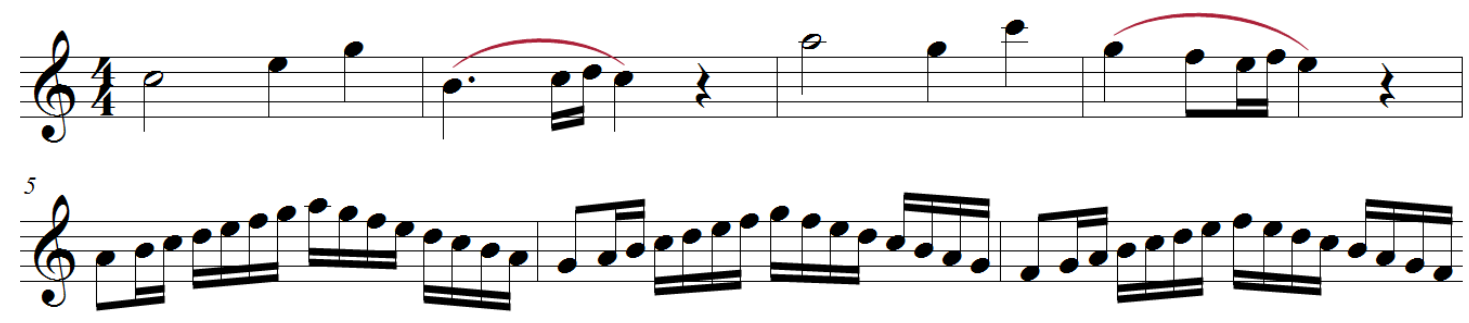

Figura 3.24: Compassos da sonata para piano No. 16 em C maior K. 545 de W.A. Mozart (pentagrama superior da partitura para piano).

A Fig. 3.25 mostra o grau de melodiosidade da melodia composta pela rede LSTM variando o parâmetro $a$ do mapa de Hénon entre 0 e 0.4 e fixando o parâmetro $b$ em 0.3 , a linha pontilhada é o grau de melodiosidade da melodia de entrada e a linha sólida é o grau de melodiosidade das melodias compostas usando diferentes valores do parâmetro $a$. Pode-se enxergar que há pequenas regiões onde o parâmetro $a$ é proporcional ao grau de melodiosidade.

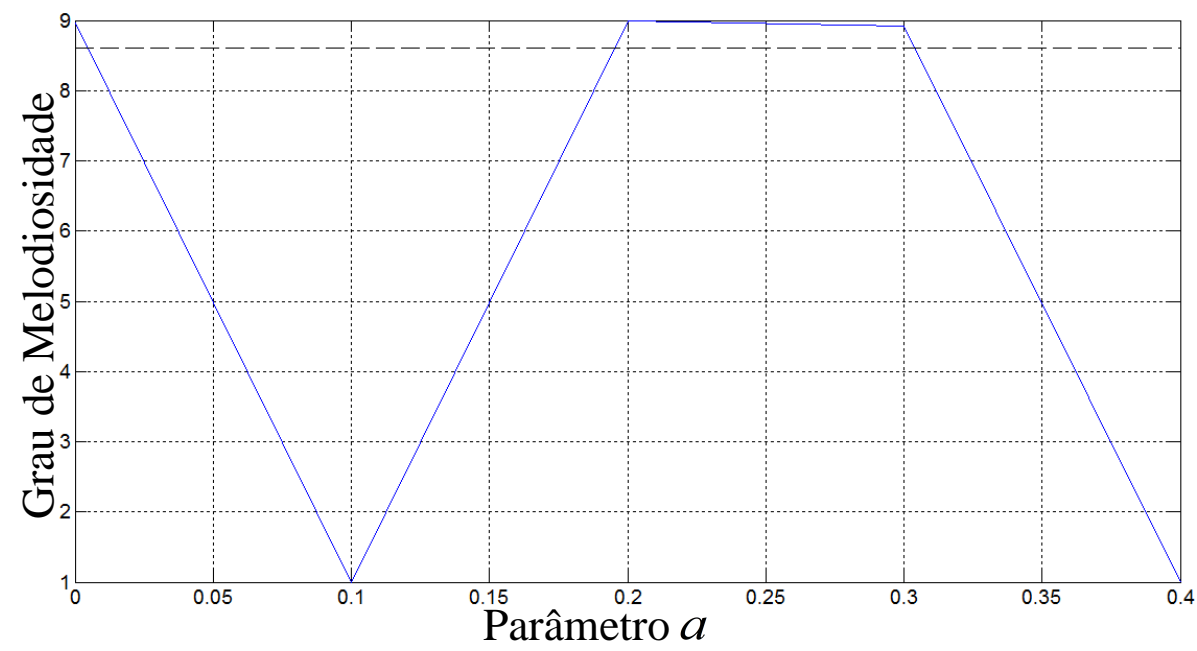

Figura 3.25: Grau de melodiosidade da melodia composta pela rede LSTM variando o parâmetro $a$ do mapa de Hénon.

A região entre 0.1 e 0.2 cobre quase toda a extensão do grau de melodiosidade, ou seja, de 1 até 9 . O controlador proporcional é aplicado com um valor de $k=0.01$, e o valor inicial do parâmetro $a$ é ajustado a 0.1 . O sistema composicional é executado para compor uma melodia com grau de melodiosidade igual a 5. A Fig. 3.26 mostra a evolução do parâmetro $a$, o qual atinge o valor de 5 depois de 572 iterações.

A melodia mostrada na Fig. 3.27 foi composta usando o sistema composicional completo, esta melodia tem grau de melodiosidade igual a 5 . 


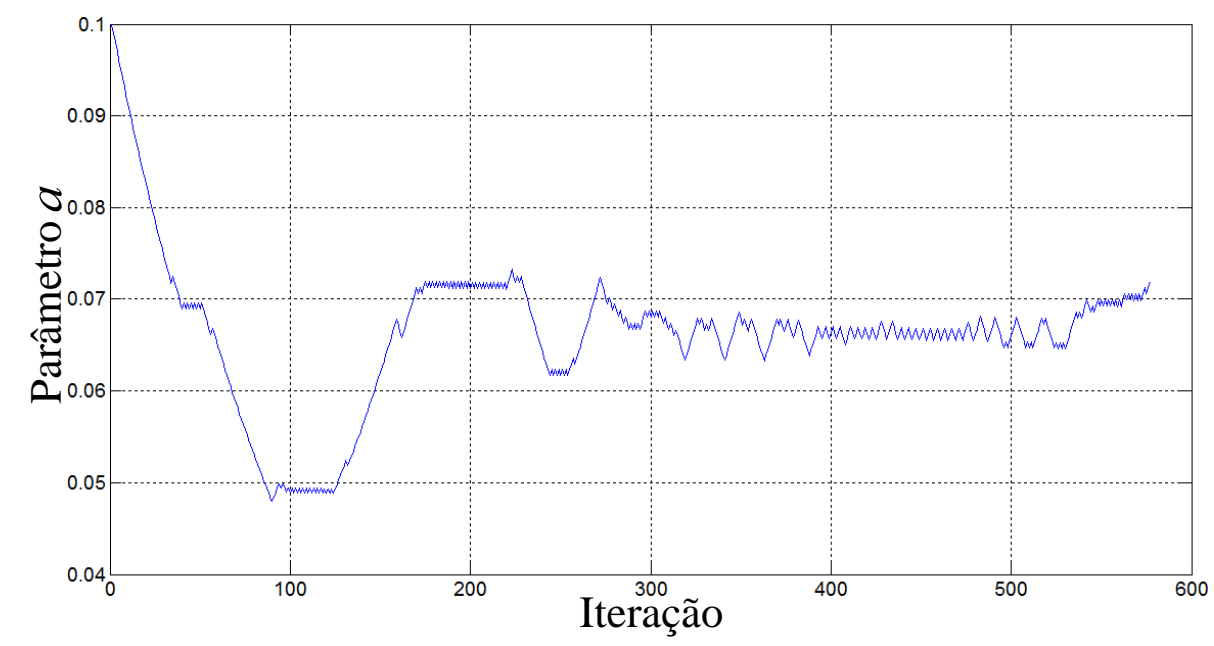

Figura 3.26: Evolução do parâmetro $a$ do mapa de Hénon até atingir o valor predefinido de melodiosidade igual a 5.

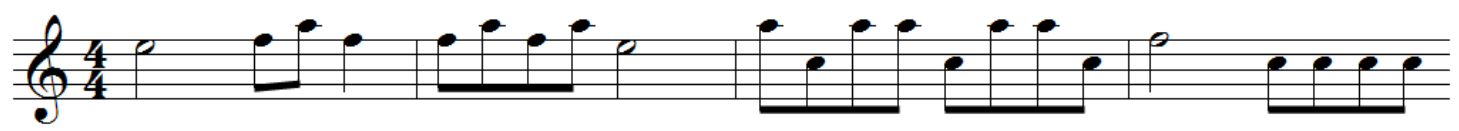

Figura 3.27: Melodia com grau de melodiosidade igual a 5 composta pelo modelo de composição baseado na rede LSTM com entrada de inspiração caótica.

\subsection{Considerações Finais}

Neste capítulo foram apresentados os três modelos desenvolvidos para a composição de estruturas melódicas. O primeiro modelo foi iniciado com o estudo do modelo de composição de melodias proposto por Liu et al. (2010), que gera uma rede complexa usando as notas de uma melodia conhecida, para posteriormente compor uma nova melodia aplicando uma caminhada sobre os nós da rede respeitando uns critérios para a seleção do próximo nó. É plausível saber de antemão que o novo material musical conservará as propriedades da melodia de origem ao não existirem mecanismos que mudem as conexões fixas da rede e as notas originais. Com base em tal estudo, e visando obter maior variabilidade na saída, no primeiro modelo de composição musical proposto foram usadas redes complexas predefinidas, isto é, redes complexas amplamente conhecidas e estudadas na teoria de redes, as quais apresentam características estéticas interessantes presentes na natureza que podem ser transferidas ao novo material musical composto pelo modelo. As redes predefinidas adotadas foram: regular, de pequeno mundo, aleatória de Erdős-Rényi e livre de escala. Na fase de geração da rede, cada nó está associado com uma nota de uma dada escala musical de entrada, enquanto as arestas são criadas conservando as regras de construção próprias a cada tipo de rede. As melo- 
dias são compostas desempenhando uma caminhada aleatória controlada por critérios.

Os resultados revelaram que a estética da melodia segundo o grau de melodiosidade depende não apenas do critério usado para a seleção das notas, mas também do tipo de rede e da escala musical de entrada. Baseado nesta premissa, o conjunto de escalas foi estendido o suficiente através do desenvolvimento de um sistema para a codificação e decodificação de escalas musicais, que, ademais, permitiu a busca automática de uma escala com propriedades adequadas para composição musical segundo duas medidas: grau de uniformidade e média da porcentagem de similaridade harmônica. Este método permite compor melodias interessantes e possibilita uma alta diversidade ao conservar as características topológicas das redes dentro da melodia. Tal é o caso das melodias de redes regulares que têm um comportamento previsível e musicalmente monótono, repetitivo e minimalista ${ }^{9}$; as melodias de pequeno mundo são de igual forma um pouco repetitivas, porém formadas por pequenos pulos a outros domínios da escala que diminui o efeito minimalista. Já a melodia aleatória de Erdős-Rényi é logicamente imprevisivel e cheia de intervalos grandes. Por fim, foi verificado que a propriedade livre de escala é transferida à nova melodia, aportando propriedades de recorrência e autosemelhança, características importantes que têm sido encontradas na música em diferentes estudos relacionados com a estética musical. As simulações computacionais mostraram que o modelo anterior é promissor para síntese de estruturas musicais pelo fato de prover diversidade diferenciada segundo o tipo de rede. No entanto, apesar do sucesso destes resultados, as redes predefinidas carecem de mecanismos de memória, o que dificulta a variabilidade. Portanto, o desenvolvimento do modelo de composição musical automática de melodias foi direcionado à exploração de redes neurais recorrentes em combinação com sistemas dinâmicos caóticos.

A segunda fase do problema de síntese iniciou com o estudo do modelo de composição de melodias baseado em redes neurais recorrentes e relevo de paisagens naturais proposto por Corrêa et al. (2008). Nesse modelo uma rede neural recorrente é treinada usando o algoritmo BPTT para aprender as características ou o estilo de uma melodia de entrada. Para tanto, foi incorporada uma melodia adicional e independente, chamada fonte de inspiração, proveniente do mapeamento do contorno de uma imagem geográfica que varia a similaridade entre a melodia de origem e a melodia de saída. As desvantagens deste método incluem: necessidade de criar um banco de dados de imagens, espaço de memória e tempo de processamento. Com o intuito de resolver essas desvantagens, o método para gerar a fonte de inspiração foi substituído

\footnotetext{
${ }^{9}$ Gênero musical de caráter repetitivo e estático
} 
pela adição de pequenos fragmentos de uma melodia caótica, uma vez que devido às características dos sistemas caóticos é possível obter infinitas variações na saída através de pequenas mudanças nos parâmetros do sistema e, consequentemente, obter muitas melodias com diferentes características e complexidade. Para estabelecer a melodia caótica foi usado o algoritmo proposto por Coca et al. (2010). Várias medidas foram usadas para quantificar as características da melodia composta pela rede, e vários testes foram conduzidos para encontrar a relação entre as características musicais da rede gerada e a quantidade de notas de inspiração. Foi observado que a variação do número de notas de inspiração afeta a complexidade da melodia de saída, sendo mais forte a influência do caos quanto maior for o número de notas de inspiração, obtendo assim uma melodia com maior variação, porém preservando as características da melodia original (Coca et al., 2011).

Baseada nos anteriores resultados, e sustentada na premissa de que no contexto de composição musical é usual e importante determinar a qualidade da melodia final, uma nova evolução do modelo anterior foi desempenhada. Inicialmente, o problema de desvanecimento do gradiente presente no algoritmo BPTT foi superado com a adoção da rede LSTM. O objetivo foi desenvolver um modelo de composição musical capaz de compor novas melodias com um valor predefinido em alguma medida subjetiva, neste caso foi escolhido o grau de melodiosidade. Os experimentos computacionais revelaram que existem algumas pequenas regiões onde há algum grau de relação proporcional entre um parâmetro do sistema e a complexidade da melodia caótica, e entre esta última e a melodiosidade da melodia de saída. Com esta informação foi possivel definir uma estratégia para controlar a melodiosidade da melodia de saída através de pequenas mudanças em um parâmetro do sistema caótico. Os resultados mostraram que o modelo é bastante promissor para sistemas de composição baseados na estética. Este foi o primeiro esforço para provar que é plausível controlar automaticamente características subjetivas de melodias sintéticas (Coca et al., 2013). 


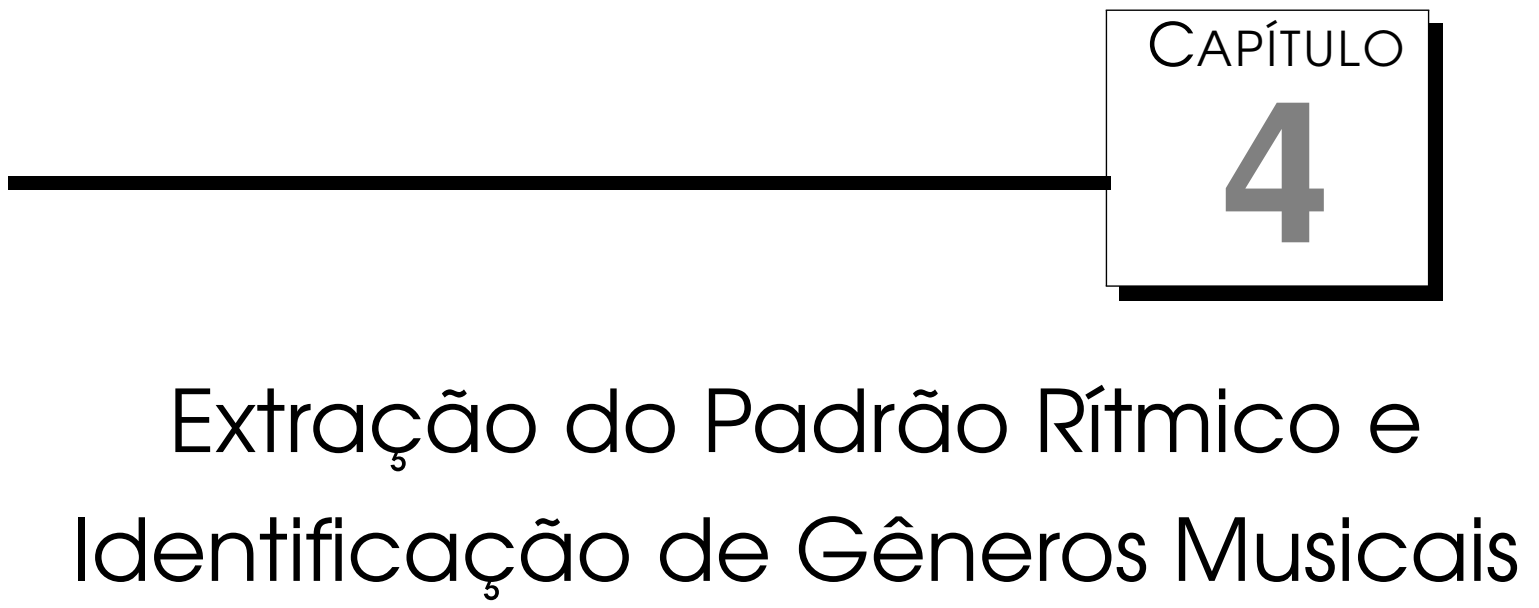

base rítmica de uma peça musical popular geralmente é composta por
elementos característicos que definem o gênero musical. Estes ele-
mentos são formados por padrões rítmicos, sendo os mais repetitivos os padrões principais do gênero, enquanto os menos frequentes correspondem a padrões fortuitos que cumprem uma função de transição, diversificação, introdução ou conclusão.

Neste capítulo é abordada a perspectiva de reconhecimento de padrões e de mineração com redes complexas na solução de tarefas do âmbito musical. Na Seção 4.1 é apresentado um método para a extração automática do padrão rítmico de uma canção popular e para a sumarização rítmica de um conjunto de canções do mesmo gênero e artista usando detecção de comunidades em redes complexas. Uma nova medida para quantificar a relevância das comunidades é usada para diferenciar os diferentes tipos de padrões rítmicos (Coca \& Zhao, 2014d). Diferentes disposições para criar as redes são comparadas e os resultados usando diferentes algoritmos de detecção são contrastados (Coca \& Zhao, 2014c).

Aproveitando o bom desempenho do método de extração proposto, na Seção 4.2 é apresentada uma nova metodologia para a identificação de gêneros musicais, a qual inclui uma fase de mineração através de medidas topológicas de redes complexas que é desempenhada para caracterizar unicamente os padrões principais de cada amostra (Coca \& Zhao, 2014b). 


\subsection{Sumarização e Extração do Padrão Rítmico}

O método de extração rítmica proposto pode ser usado para extrair qualquer tipo de padrão rítmico, tanto polifônico quanto monofônico ${ }^{1}$, usando dados simbólicos, e pode ser aplicado não apenas para uma amostra, mas também para um conjunto de amostras. O primeiro caso corresponde ao problema de extração rítmica simples, na qual para uma única música podem ser extraídos todos os padrões principais e fortuitos, já o segundo caso corresponde ao problema de sumarização que consiste em extrair o padrão mais representativo do conjunto entre todos os padrões principais de todas as amostras.

\subsubsection{Descrição do Modelo}

As etapas do modelo de extração rítmica são: seleção da informação rítmica do arquivo MIDI, depuração dos dados usando um método de quantização, separação e representação das células rítmicas (CRs), codificação dos vetores de representação, concatenação vertical das linhas de percussão, geração de um dígrafo com os códigos das células rítmicas, aplicação de detecção de comunidades e cálculo da medida de relevância, caminhada controlada sobre os nós da comunidade mais relevante, decodificação das células rítmicas dos nós resultantes da caminhada e geração do padrão em notação simbólica. A Fig. 4.1 mostra o diagrama de blocos do método, cada passo é explicado a seguir.

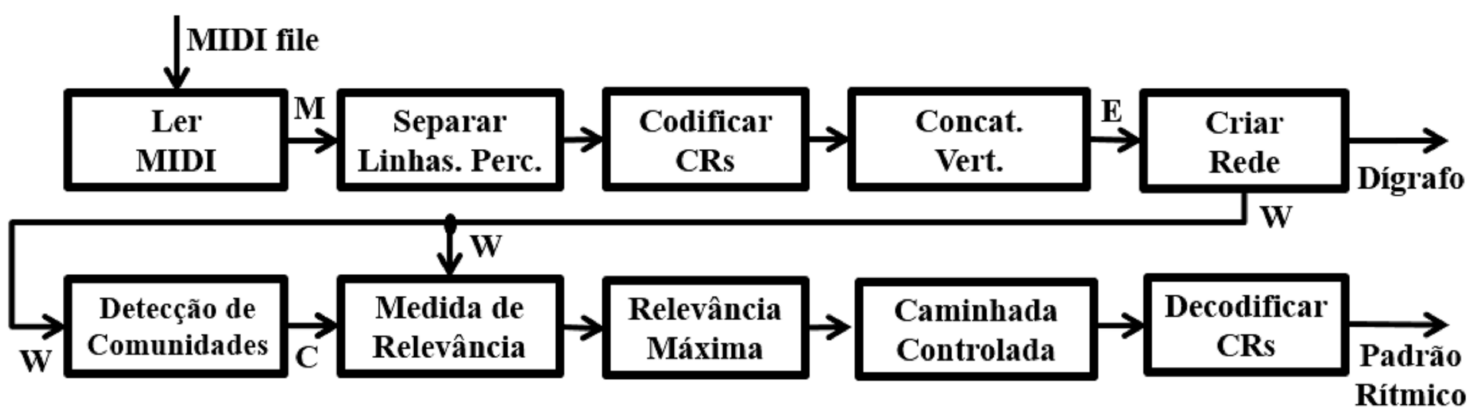

Figura 4.1: Diagrama de blocos do método proposto para a extração do padrão rítmico.

\section{Representação e Codificação de Células Rítmicas}

Uma figura rítmica $^{2} r$ (ou o seu silêncio equivalente) pode ser dividida em $n \in \mathbb{N}$ figuras de igual duração, isso é conhecido como a $n$-ésima divisão de uma figura rítmica. As figuras rítmicas podem ser unidas para gerar novas figuras usando dois tipos de operações: ligadura e ponto(s) de aumento

\footnotetext{
${ }^{1}$ A polifonia ocorre quando duas ou mais linhas musicais evoluem simultaneamente, enquanto na monofonia somente evolui uma

${ }^{2}$ Ver definição de termos musicais no Apêndice B
} 
(Lacerda, 1966). Seja $\delta\left(r_{1}, r_{2}, \ldots, r_{k}\right)$ o operador de ligadura o qual soma as durações das $k$ figuras que envolve, isto é: $\sum_{1}^{k} r_{i}$; e seja $\rho(r, b)$ o operador de ponto de aumento, o qual adiciona $b \geq 1$ vezes a metade acumulativa do seu valor, ou seja, $\sum_{1}^{b} \frac{r}{2^{2}}$. Uma Célula Rítmica (CR) é um conjunto de figuras rítmicas provenientes da $n$-ésima divisão da figura rítmica que ocupa o tempo de uma batida (também chamada unidade de tempo), onde duas ou mais subfiguras consecutivas podem ser alteradas mediante os operadores anteriores. Uma Célula Rítmica Primária (CRP) é a célula obtida da divisão natural da unidade de tempo, isto é, sem o uso dos operadores $\delta(\cdot)$ e $\rho(\cdot)$. Já uma Célula Rítmica Secundária (CRS) é uma CR derivada de uma CRP mediante o uso desses operadores entre um subconjunto de eventos consecutivos, tal CRP é chamada célula primária de origem, por exemplo, sabendo que $\delta(\downarrow, \downarrow)=\downarrow$ e $\delta(\downarrow, \downarrow)=\rho(\downarrow, 1)=\downarrow$., para a CRP da Fig. 4.2(a) são formadas as três CRSs da Fig. 4.2(b). Cabe ressaltar que nem todas as células rítmicas primárias podem gerar células secundárias (Coca \& Zhao, 2014c).

Tanto as CRPs quanto as CRSs são representadas em notação matemática mediante um vetor $\mathbf{v} \in \mathbb{N}$ de $1 \times n$, chamado aqui vetor de representação. As CRPs são representadas em notação binária, onde um " 1 " representa um onset $^{3}$ e um "O" um silêncio, por exemplo, o vetor de representação binário da CRP da Fig. 4.2(a) é $\left[\begin{array}{llll}0 & 1 & 1 & 1\end{array}\right]$, o que indica que a célula rítmica é composta de 4 figuras, sendo a primeira destas um silêncio, e as três restantes figuras de igual duração. Algumas das desvantagens dessa notação são a dificuldade no processamento de ritmos por computador (Liu \& Toussaint, 2012), e que por só considerar o início dos eventos e não a duração, produz confusão com outros conjuntos de figuras rítmicas, por exemplo, Ydd) compartilha o mesmo vetor binário do anterior exemplo.

As CRSs são representadas com a Notação de Durações Ponderadas ${ }^{4}$ (NDP) (Sethares, 2007) que foi primeiramente usada para a detecção automática da métrica musical (Brown, 1993). Esta notação é uma variação da notação cronotônica ${ }^{5}$ (Hofmann-Engl, 2003), onde a duração de cada figura é representada como o número de vezes que contém o mínimo valor rítmico (beat atômico) comum entre as figuras da sequência e repetido tantas vezes este valor. A NDP usa dentro do vetor os pesos das amplitudes ${ }^{6}$ na posição de onset e zeros nas outras posições, por exemplo, a primeira CRS da CRP de origem \% $\downarrow \downarrow)$ da Fig. 4.2(a) é \%॰), e o seu beat atômico é $\downarrow$ ), cujo valor é $1 / 2$, e · contém duas vezes o beat atômico e d uma, portanto, o vetor cronotônico da sequência é [0221] e o vetor em NDP é [0201]. Na Fig. 4.2(b) encontram-se

\footnotetext{
${ }^{3}$ Tempo inicial da ocorrência de um evento musical em unidades de batida ou em segundos

${ }^{4}$ Do inglês: Duration-weighted notation

${ }^{5}$ Do inglês: Chronotonic

${ }^{6}$ Do inglês: Weighted amplitude, termo usado por Brown (1993) para designar o beat atômico
} 
todos os vetores de representação das CRSs da CRP de origem da Fig. 4.2(a) (Coca \& Zhao, 2014c). Note-se que o vetor de representação é independente do valor das figuras, por consequência, o valor da unidade de tempo deve ser indicado. No caso anterior, a unidade de tempo é a semibreve ( $d$ valor 2$)$ que é dividida em 4 partes obtendo 4 valores de colcheia ( $\downarrow$ valor $1 / 2$ ). Na Tabela 4.1 é mostrada a notação matemática de todas as CRPs e as CRSs provenientes da quarta divisão, especificamente, a primeira coluna mostra o equivalente decimal $\left(\Delta_{p}\right)$ do vetor binário da segunda coluna, a segunda a Notação Binária (NB) das CRPs, a terceira a Combinatória das Ligaduras Possiveis (CLPs) de cada CRP, a quarta o vetor de NDP das CRSs e a última a ordem lexicográfica $\left(\Delta_{s}\right)$ dos números combinatórios da terceira coluna.

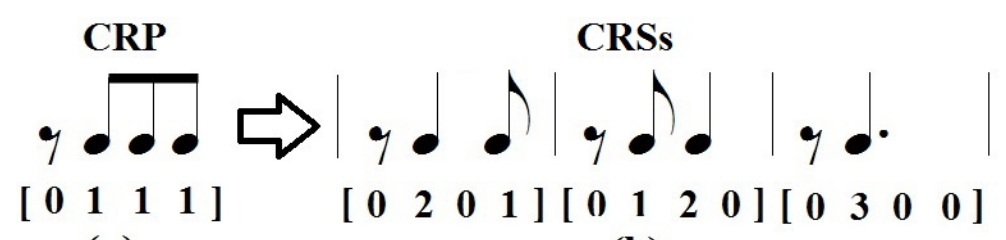

(a)

(b)

Figura 4.2: Vetor de representação de (a) uma Célula Rítmica Primária (CRP) e (b) as suas Células Rítmicas Secundárias (CRSs) com $n=4$.

\section{Codificação de Células Rítmicas}

O vetor de representação é uma forma simples e compreensível de representar grupos de eventos sonoros e não sonoros, no entanto, este é afetado pela variabilidade dimensional e, ademais, não facilita a identificação e descrição de estruturas rítmicas. Para superar essas limitações e facilitar a organização, ordenação, caracterização, manuseio computacional e construção de CRs, foi criado um sistema para a codificação de tal vetor (Coca \& Zhao, 2014d).

No processo de construção do vetor de representação é usado um algoritmo combinatório especial. Portanto, o código proposto deverá ser compatível com as características desse algoritmo, sendo a principal a conservação da ordem lexicográfica na organização dos objetos gerados, a qual é similar à ordem alfabética das palavras de um dicionário (Ruskey, 2003).

Uma CR pode ser codificada usando quatro cifras, cada uma com um significado específico. Esses valores são necessários para identificar qualquer célula rítmica e são dispostos no vetor $\mathbf{c}_{1 \times 4} \in \mathbb{N}$, chamado vetor de código, assim: $\mathbf{c}=\left[\begin{array}{cccc}n & \Delta_{p} & \Delta_{s} & \Delta_{b}\end{array}\right]$. A seguir são explicados os elementos do código:

1. $n$ : Indica o número de divisões da figura rítmica que foi dividida. Este valor é importante porque define o número máximo de elementos que deve ter o vetor de representação. 
Tabela 4.1: Notação Binária (NB) de todas as Células Rítmicas Primárias (CRPs) e o seu equivalente decimal $\Delta_{p}$, Combinatória das Ligaduras Possíveis (CLPs), Notação de Durações Ponderadas (NDP) e ordem lexicográfica $\left(\Delta_{s}\right)$ de todas as Células Rítmicas Secundárias (CRSs) com $n=4$.

\begin{tabular}{|c|c|c|c|c|}
\hline$\Delta_{p}$ & NB das PRCs & CLPs & NDP das CRSs & $\Delta_{s}$ \\
\hline 0 & 0000 & & & 0 \\
\hline 1 & 0001 & & & 0 \\
\hline 2 & 0010 & & & 0 \\
\hline 3 & 0011 & $\overline{1}$ & 0020 & 1 \\
\hline 4 & $\overline{0} \overline{1}-\overline{0}$ & & & $0^{-}$ \\
\hline 5 & 0101 & & & 0 \\
\hline 6 & $0 \overline{1} 10$ & $\overline{1}$ & $0 \overline{2} 0$ & 1 \\
\hline \multirow{3}{*}{7} & \multirow{3}{*}{$\begin{array}{lllll}0 & 1 & 1 & 1\end{array}$} & 10 & $0 \overline{2} 0_{1}^{-}$ & 1 \\
\hline & & 01 & 0120 & 2 \\
\hline & & 11 & 0300 & 3 \\
\hline 8 & $\overline{1} \bar{O}^{-} 0^{-} \overline{0}$ & & & $0^{-}$ \\
\hline 9 & 10001 & & & 0 \\
\hline$\overline{1} \overline{0}$ & 1010 & & & $0^{-}$ \\
\hline$\overline{1} \overline{1}$ & 101 & $\overline{1}$ & 1020 & 1 \\
\hline$\overline{1} \overline{2}$ & $1 \overline{1} 00$ & $\overline{1}$ & 2000 & - \\
\hline$\overline{1} \overline{3}$ & 1101 & $\overline{1}$ & 2001 & 1 \\
\hline \multirow{6}{*}{14} & \multirow{3}{*}{1110} & 10 & 2010 & $\overline{1}^{-}$ \\
\hline & & 01 & 1200 & 2 \\
\hline & & 11 & 3000 & 3 \\
\hline & \multirow{7}{*}{1111} & 100 & 2011 & 1 \\
\hline & & 010 & 1201 & 2 \\
\hline & & 001 & 1120 & 3 \\
\hline \multirow[t]{4}{*}{15} & & 110 & 3001 & 4 \\
\hline & & 101 & 2020 & 5 \\
\hline & & 011 & 0300 & 6 \\
\hline & & 111 & 4000 & 7 \\
\hline
\end{tabular}

2. $\Delta_{p}$ : Indica o valor decimal do vetor de representação binário da CRP de origem. Pode ter valores no intervalo $0 \leq \Delta_{p} \leq\left(2^{n}-1\right)$.

3. $\Delta_{s}$ : Este valor indica a posição lexicográfica do vetor de NDP da CRS dentro do total de CRSs possiveis da CRP de origem. Se o código for de uma CRP então $\Delta_{s}$ será igual a 0 . Pode ter valores no intervalo $0 \leq \Delta_{s} \leq$ $\left(2^{n-1}-1\right)$.

4. $\Delta_{b}$ : Indica o número de batidas que ocupa a célula rítmica. Sua inclusão dentro do vetor de código se justifica dado que duas células rítmicas podem ter os primeiros três valores do vetor de código iguais, porém ocupando uma quantidade diferente de batidas.

Na Tabela 4.2 são mostradas todas as células rítmicas resultantes da quarta divisão da mínima ( $d$, compasso de ${ }_{2}^{x}$ ) e os seus respectivos códigos. Conforme 
Tabela 4.2: Vetor de código das CRPs e CRSs da quarta divisão da figura de mínima (d).

\begin{tabular}{|c|c|c|c|c|}
\hline$\Delta_{p}$ & CRP & Código & CRS & Código \\
\hline$\overline{0}$ & & 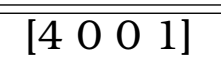 & \multirow{6}{*}{ ל. } & \\
\hline 1 & ?. & {$\left[\begin{array}{llll}4 & 1 & 0 & 1\end{array}\right]$} & & \\
\hline 2 & coly & {$\left[\begin{array}{llll}4 & 2 & 0 & 1\end{array}\right]$} & & \\
\hline 3 & 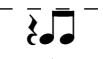 & {$\left[\begin{array}{llll}4 & \overline{3} & 0 & 1\end{array}\right]$} & & {$\left[\begin{array}{llll}4 & \overline{3} & 1 & 1\end{array}\right]$} \\
\hline 4 & $\bar{\varphi}$ & {$\left[\begin{array}{llll}4 & 4 & 0 & 1\end{array}\right]$} & & \\
\hline 5 & ydyd & {$\left[\begin{array}{llll}4 & 5 & 0 & 1\end{array}\right]$} & & \\
\hline 6 & & 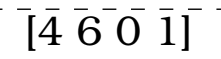 & $\bar{y}$ & {$\left[\begin{array}{lll}\overline{4} & \overline{6}^{-}{ }^{-} & \overline{1}\end{array}\right]$} \\
\hline \multirow{3}{*}{7} & \multirow{3}{*}{ 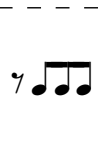 } & \multirow{3}{*}[\begin{array}{llll}{4}&{7}&{0}&{1}\end{array}]{} & & 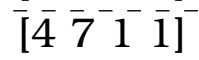 \\
\hline & & & 9d). & {$\left[\begin{array}{llll}4 & 7 & 2 & 1\end{array}\right]$} \\
\hline & & & & {$\left[\begin{array}{llll}4 & 7 & 3 & 1\end{array}\right]$} \\
\hline 8 & d) & 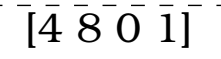 & & \\
\hline 9 & Dy9d & {$\left[\begin{array}{llll}4 & 9 & 0 & 1\end{array}\right]$} & & \\
\hline$\overline{1} 0$ & Dy $\delta_{y}$ & {$\left[\begin{array}{lllll}4 & 10 & 0 & 1\end{array}\right]$} & & \\
\hline$\overline{1} \overline{1}$ & $\sqrt{4}$ & {$\left[\begin{array}{lllll}4 & 1 & 1 & 0 & 1\end{array}\right]$} & $\delta$ & 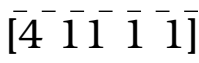 \\
\hline$\overline{1} \overline{2}$ & De & {$\left[\begin{array}{llll}4 & 12 & 0 & 1\end{array}\right]$} & dét & {$\left[\begin{array}{llll}4 & 12 & 1 & 1\end{array}\right]$} \\
\hline$\overline{1} \overline{3}$ & (.व\%) & {$\left[\begin{array}{llll}4 & 13 & 0 & 1\end{array}\right]$} & $\sqrt{y}$ & {$\left[\begin{array}{llll}4 & 13 & 1 & 1\end{array}\right]$} \\
\hline & & & & {$\left[\begin{array}{lllll}4 & 14 & 1 & 1\end{array}\right]$} \\
\hline 14 & •. & {$\left[\begin{array}{llll}4 & 14 & 0 & 1\end{array}\right]$} & d) $y$ & {$\left[\begin{array}{llll}4 & 14 & 2 & 1\end{array}\right]$} \\
\hline & & & d. & {$\left[\begin{array}{llll}4 & 14 & 3 & 1\end{array}\right]$} \\
\hline & & & J & {$\left[\begin{array}{llll}4 & 15 & 1 & 1\end{array}\right]$} \\
\hline & & & d)dD & {$\left[\begin{array}{llll}4 & 15 & 2 & 1\end{array}\right]$} \\
\hline & & & $\sqrt{6}$ & {$\left[\begin{array}{llll}4 & 15 & 3 & 1\end{array}\right]$} \\
\hline 15 & $\sqrt{.00}$ & {$\left[\begin{array}{llll}4 & 15 & 0 & 1\end{array}\right]$} & d.D) & {$\left[\begin{array}{llll}4 & 15 & 4 & 1\end{array}\right]$} \\
\hline & & & 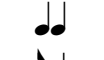 & {$\left[\begin{array}{llll}4 & 15 & 5 & 1\end{array}\right]$} \\
\hline & & & d). & {$\left[\begin{array}{llll}4 & 15 & 6 & 1\end{array}\right]$} \\
\hline & & & 1 & {$\left[\begin{array}{llll}4 & 15 & 7 & 1\end{array}\right]$} \\
\hline
\end{tabular}

a tabela, para o exemplo anterior, o código da CRP de Fig. 4.2(a) é $\left[\begin{array}{llll}4 & 7 & 0 & 1\end{array}\right]$ e o

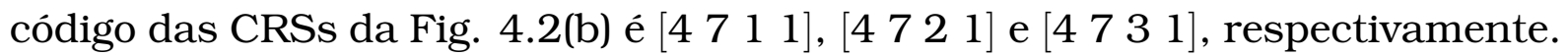

Algumas vantagens do vetor de código são:

1. Permite identificar qualquer tipo de CR de maneira fácil e única. Neste caso o código pode ser considerado como o endereço da CR;

2. Indica como construir qualquer $\mathrm{CR}$, uma vez que tem uma relação direta com o vetor de representação, o qual pode ser facilmente gerado usando um algoritmo combinatório especial (Ruskey, 2003);

3. Padroniza o vetor de representação, o qual sofre de dependência dimensional, a um vetor com tamanho fixo de quatro elementos;

4. Os elementos do código são descritivos, já que proporcionam informação sobre algumas características básicas da CR; 
5. Facilita a ordenação, a comparação e o manuseio entre CRs, pelo fato de preservar a ordem lexicográfica;

6. Envolve as figuras tanto sonoras quanto não sonoras, posto que considera também os silêncios tanto dentro quanto fora da batida.

No Apêndice A, Seção A.2, são descritos em detalhe os algoritmos de codificação e decodificação de células rítmicas que foram desenvolvidos.

\section{Criação de uma Rede Complexa Musical}

Uma rede pode ser criada para representar qualquer um dos elementos de uma peça musical, tais como: harmonia, estrutura, altura ou ritmo. Para este último, usualmente na literatura, a rede é criada usando Figuras Rítmicas Individuais (FRIs), onde um nó é uma figura rítmica e uma aresta é criada entre duas figuras rítmicas consecutivas (Liu et al., 2009; Corrêa et al., 2010; Coca et al., 2010). No entanto, este método tem várias lacunas que afetam a qualidade da representação dos dados mediante a rede, por exemplo: (1) os silêncios, caso forem considerados, não são discriminados entre silêncios de batida e silêncios dentro da batida. Estes dois tipos de silêncios são diferentes, uma vez que o primeiro forma uma CR e o segundo faz parte de uma $\mathrm{CR}$; (2) desconsiderar as figuras como pertencentes a um grupo produz uma perda da ordem e da hierarquia das figuras, propriedades que são conservadas na teoria musical. Por exemplo, no compasso de ${ }_{4}^{\times}$uma figura de colcheia (১) de início da batida é diferente a uma colcheia pós-batida e a uma colcheia do compasso ${ }_{8}^{\times}$, mesmo tendo igual duração; também uma semínima (.) proveniente da ligadura de duas colcheias pós-batida $(\delta . \delta . \delta=\delta$..$\delta)$ é diferente a uma semínima de batida; (3) as vantagens do sistema de codificação não são aproveitadas.

Visando resolver as lacunas anteriores, nesta tese é proposto o uso de CRs na criação da rede rítmica, onde um nó já não corresponde mais a uma figura ritmica individual, e sim ao grupo de figuras que formam uma CR. Na Tabela 4.3 são mostradas as diferenças entre usar dígrafos criados com FRIs e com CRs. Como exemplo, considere o fragmento rítmico com três frases da Fig. 4.3, onde as duas primeiras frases são repetidas algum número de vezes, enquanto a terceira somente é executada uma vez. Esta última cumpre com a função de ponte entre as outras duas. O uso de repetição de frases e pontes entre frases é frequentemente usado em música (Lacerda, 1966). Para o mesmo fragmento rítmico, na Fig. 4.4(a) e 4.4(b) é apresentado o dígrafo gerado com FRIs e com CRs, respectivamente. Comparando os dois dígrafos, é possivel enxergar que no primeiro existe uma perda de informação que diminui a qualidade da representação musical. 
Tabela 4.3: Diferenças entre os dígrafos criados com Figuras Rítmicas Individuais (FRIs) e com Células Rítmicas (CRs).

\begin{tabular}{|c|c|c|c|c|}
\hline Item & Ritmo & Diferenças & Dígrafo com FRIs & Dígrafo com CRs \\
\hline 1 & & & & \\
\hline 2 & & & & \\
\hline 3 & & & & \\
\hline 4 & & $\begin{array}{l}\text { Os silêncios são desconside- } \\
\text { rados }\end{array}$ & & \\
\hline 5 & $\mathbf{4}$ & $\begin{array}{l}\text { Silêncios de beat são diferen- } \\
\text { tes aos silêncios dentro do } \\
\text { beat }\end{array}$ & & \\
\hline 6 & & & & \\
\hline
\end{tabular}

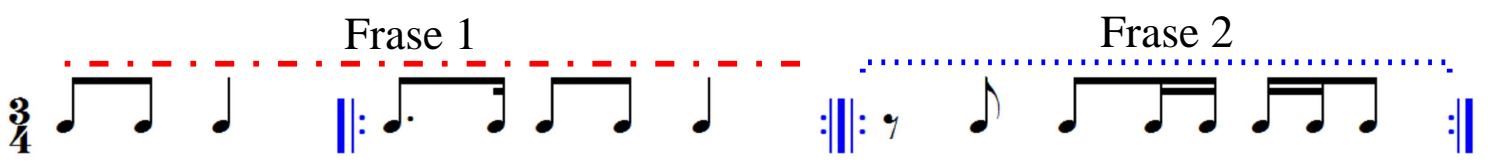

Frase 3

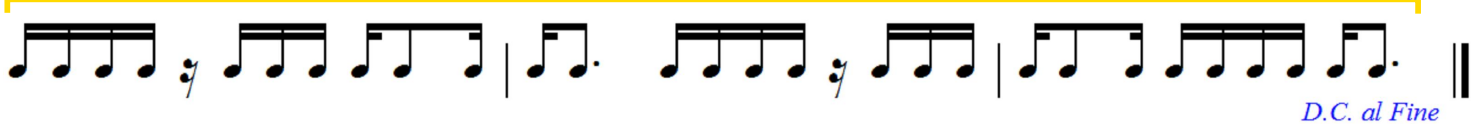

Figura 4.3: Fragmento rítmico com repetição de frases e uma ponte.

Por outro lado, uma peça musical pode ter uma ou mais linhas de percussão, portanto, para gerar a rede as linhas de percussão devem ser extraídas do arquivo MIDI e armazenadas em um vetor individual, para posteriormente, mediante o algoritmo codificador, serem extraídas e codificadas as CRs, e com estes códigos gerada a rede, onde os nós são os códigos e uma aresta é criada entre dois códigos consecutivos. Para gerar uma rede com duas ou mais linhas de percussão simultâneas duas opções são possíveis, a saber: concatenar os vetores de códigos horizontal ou verticalmente. Por exemplo, para três linhas, os códigos obtidos para cada linha são armazenados no vetor a, b e c, respectivamente. Seja $x \| y$ a aplicação do operador de concatenação \| sobre os elementos (ou vetores) $x$ e $y$, cujo resultado é $x y$. A concatenação vertical das linhas de percussão consiste em juntar os vetores com os códigos das CRs em um único vetor, um após o outro, assim: $\mathbf{D}=\mathbf{a}\|\mathbf{b}\| \mathbf{c}$, cujo resultado é $\mathrm{D}=\left[\begin{array}{lll}\mathbf{a} & \mathbf{b} & \mathbf{c}\end{array}\right]$. A concatenação horizontal consiste em colocar os três vetores em disposição matricial, um embaixo do outro, com o vetor da primeira linha no topo, para posteriormente concatenar os elementos das colunas da matriz resultante, formando um único vetor. Este processo é executado usando o operador de concatenação da seguinte maneira: $\mathbf{E}=\mathbf{a}^{\mathbf{T}}\left\|\mathbf{b}^{\mathbf{T}}\right\| \mathbf{c}^{\mathbf{T}}$, cujo resul- 


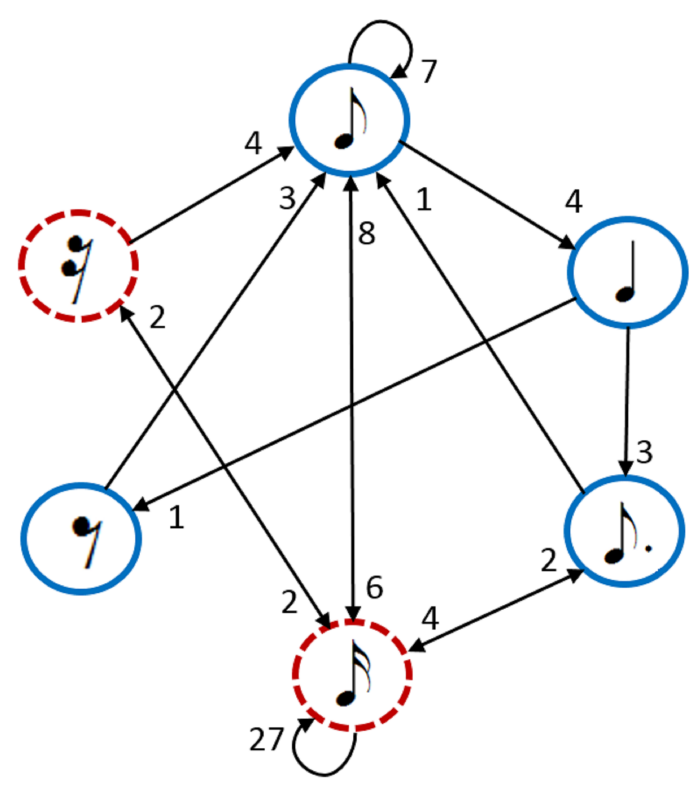

(a)

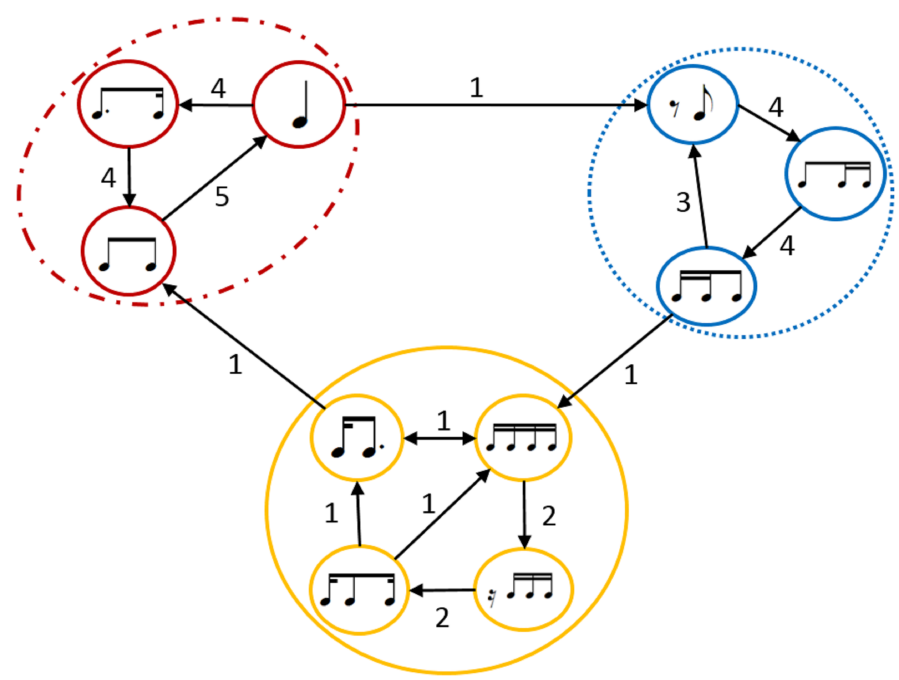

(b)

Figura 4.4: Dígrafos do fragmento rítmico da Fig. 4.3. (a) Usando Figuras Rítmicas Individuais (FRIs); (b) Usando CRs. As comunidades estão destacadas.

tado é:

$$
\mathbf{E}=\left[\begin{array}{c}
a_{1} \\
a_{2} \\
\vdots \\
a_{t}
\end{array}\right]\left\|\left[\begin{array}{c}
b_{1} \\
b_{2} \\
\vdots \\
b_{t}
\end{array}\right]\right\|\left[\begin{array}{c}
c_{1} \\
c_{2} \\
\vdots \\
c_{t}
\end{array}\right]=\left[\begin{array}{c}
a_{1} b_{1} c_{1} \\
a_{2} b_{2} c_{2} \\
\vdots \\
a_{t} b_{t} c_{t}
\end{array}\right]
$$

onde $t$ é o número total de CRs. Por fim, é criada a rede para o vetor $\mathbf{D}$ ou $\mathbf{E}$. Para um conjunto de canções a rede é criada concatenando horizontalmente os vetores de código de cada canção, isto é, o vetor resultante da concatenação vertical ou horizontal (vetor D ou E).

\section{Detecção de Comunidades}

As comunidades da rede musical criada com CRs estão relacionadas com os padrões rítmicos da peça musical. Para ilustrar melhor essa relação, considerese novamente o fragmento rítmico da Fig. 4.3, cujos dígrafos gerados com FRIs e com CRs são mostrados na Fig. 4.4(a) e 4.4(b), respectivamente. Para estes dois dígrafos as suas comunidades foram detectadas ${ }^{7}$ usando o algoritmo de otimização de modularidade, obtendo para o primeiro duas comunidades, enquanto para o segundo três comunidades, correspondendo cada uma a uma frase do fragmento rítmico. Isto posto, o uso de CRs consegue refletir com maior precisão a estrutura rítmica do fragmento dentro da estrutura topológica da rede.

\footnotetext{
${ }^{7}$ As comunidades detectadas estão destacadas nas figuras
} 
Por outro lado, conforme supracitado, a saída do algoritmo de detecção de comunidades não diz nada a respeito da função das comunidades dentro da rede, o que, desde o ponto de vista musical, significa que as três partes do fragmento acontecem com igual importância e caracterizam de igual forma o fragmento todo, o que não é verdade, dado que as três frases do fragmento têm uma função diferente dentro da estrutura musical, pois a primeira e a segunda são repetidas algumas vezes antes de chegarem na terceira que cumpre a função de transição entre as duas primeiras. Portanto, as duas primeiras frases caracterizam melhor o fragmento rítmico e dão uma ideia do seu gênero musical. Conforme o anterior, poder-se-ia decidir em apagar a terceira comunidade sem arriscar uma perda significativa de informação musical, o que poderia ser bastante útil quando se trabalha com redes de milhões de nós, quando se deseja filtrar os dados ou para obter uma melhor visualização da rede. Como consequência, uma medida para quantificar a importância dos dados originais dentro das comunidades detectadas que permita diferenciar os tipos de frases é necessária. Nota-se que a relevância das frases (comunidades) não está relacionada com o tipo e/ou a quantidade de CRs, mas com a força de coesão interna. A seguir é descrita a medida proposta para relacionar quantitativamente a importância das frases musicais dentro de um fragmento musical e as correspondentes comunidades detectadas.

\section{Medida de Relevância de Comunidades}

Uma nova medida de redes complexas foi criada com o objetivo de quantificar a relevância das comunidades da rede em termos da magnitude e da distribuição da força das arestas. A ideia principal é que a frequência de ocorrência dos dados que criaram a rede é refletida nos pesos das arestas e na sua distribuição intra-comunidade.

No tocante à magnitude dos pesos das arestas, a relevância inter e intracomunidade da rede com matriz de adjacência $\mathbf{W}$ e matriz de comunidades $\mathrm{C}$ é dada pela matriz $\mathbf{H}=\mathbf{B} / \operatorname{tr}(\mathbf{B})$, onde $\operatorname{tr}(\cdot)$ é o traço da matriz e $\mathbf{B}$ é uma matriz intermediária que contém a soma total dos pesos inter e intra-comunidade, a qual é calculada como: $\mathbf{B}=1 / 2\left[(\mathbf{W C})^{T} \mathbf{C}\right]$. Na matriz $\mathbf{H}$ o elemento $H_{i, j}$ indica a força total das conexões compartilhadas entre as comunidades $i \mathrm{e}$ $j$; em consequência a força total da comunidade $i$ é $H_{i, i}$. A matriz $\mathbf{H}$ indica a relevância parcial das comunidades, já que duas comunidades diferentes e de tamanhos distintos podem ter igual valor de relevância. Portanto, a distribuição dos pesos das arestas dentro da comunidade deve ser considerada. A medida de relevância segundo os pesos e a distribuição das forças é denotada 
como $\Lambda(\mathbf{C}) \in[0,1]$ e calculada como:

$$
\Lambda(\mathbf{C})=\frac{\mathbf{d}}{\sum_{0<i \leq k} d_{i}},
$$

em que d é um vetor intermediário que contém a quantificação da concentração do peso das arestas dentro das comunidades, e cujos elementos são calculados com: $d_{i}=\left[(\mathbf{W C})^{\mathrm{T}} \mathbf{C}\right]_{i i} /\left[(\mathbf{A C})^{\mathrm{T}} \mathbf{C}\right]_{i i}$ para $1 \leq i \leq k$, onde $\mathbf{A}$ é a respectiva matriz de adjacência binária. Um valor alto de relevância indica quanto a comunidade representa a rede toda, portanto, as comunidades menos relevantes podem ser ignoradas sem perda significativa de informação associada aos dados originais de entrada. Cabe ressaltar que a medida de relevância pode ser usada tanto para comunidades disjuntas quanto para sobrepostas.

Para ilustrar melhor o funcionamento desta medida, para o dígrafo da Fig. 4.4(b) foi calculada a matriz de relevância segundo o pesos das arestas, obtendo:

$$
\mathbf{H}=\left[\begin{array}{ccc}
0.40 & 0.03 & 0 \\
0 & 0.34 & 0.03 \\
0 & 0 & 0.25
\end{array}\right]
$$

Os valores obtidos demostram que a comunidade 1 e 2 concentram a maior parte dos pesos das arestas com um valor de 0.4 e 0.34 , respectivamente, enquanto a comunidade 3 concentra uma proporção menor, igual a 0.25. A relevância segundo a distribuição dos pesos das arestas $(\Lambda(\mathbf{C}))$ é: $\left[\begin{array}{ll}0.46 & 0.39\end{array}\right.$ 0.14]. Novamente, o resultado concorda com o esperado e enfatiza ainda mais a predominância das duas primeiras frases sobre a terceira.

Método Proposto para a Extração do Padrão Rítmico e Sumarização Rítmica

As comunidades com o maior valor de relevância correspondem aos padrões rítmicos principais e as menos relevantes com frases fortuitas ou de transição, tais como pontes, introdução ou coda...etc. Desta forma, os nós da comunidade mais importante são usados para criar o padrão principal da peça musical. Para construir o padrão rítmico uma caminhada entre os nós implicados deve ser efetuada, mas algumas regras devem ser estabelecidas, sendo estas: considerar (a) todos os nós; (b) todas as arestas; (c) o peso das arestas; e (d) a ordem do nó e o sentido das arestas devem ser respeitados.

$\mathrm{Na}$ tarefa de sumarização a comunidade mais relevante corresponde a todos os padrões rítmicos principais de cada amostra do conjunto de canções, portanto, fazendo uma caminhada sobre esta comunidade, muitos padrões são possíveis. Contudo, para extrair somente o padrão que sumariza o conjunto todo, os nós com o maior grau médio total intra-comunidade são seleci- 
onados e o padrão rítmico de sumarização é criado através de uma caminhada sobre esses nós respeitando as regras descritas acima.

\subsubsection{Simulações Computacionais}

Nesta seção é aplicado o método proposto para extrair o padrão rítmico de bateria de uma canção conhecida e para sumarizar ritmicamente um conjunto de canções do mesmo gênero e artista. Especificamente, o objetivo é determinar quais são as CRs que conformam o padrão rítmico principal da obra musical e o padrão que representa o gênero de um conjunto de canções, bem com a ordem de ocorrência das CRs dentro de cada padrão. Posteriormente, mediante o algoritmo decodificador descrito na Seção A.2 do Apêndice A, é gerada a matriz de notas ${ }^{8}$ do padrão principal e, consequentemente, o arquivo MIDI. Além disso, é determinada a influência do algoritmo de detecção de comunidades sobre a exatidão dos padrões extraídos e a melhor disposição para criar a rede.

A canção escolhida foi From me to you de The Beatles. Devido à natureza do objetivo apenas uma parte da obra é necessária, sendo esta a linha de percussão que é executada pela bateria. A partitura de bateria ${ }^{9}$ da canção From me to you é mostrada na Fig. 4.5. A estrutura percussiva executada pela bateria é composta por três linhas rítmicas que evoluem simultaneamente no tempo. A primeira linha, situada na parte superior, é a encarregada de executar os pratos e o hit-hat; a segunda, situada na parte do meio, executa os tons (esquerdo e direito); já a terceira, localizada na parte inferior, executa o bumbo.

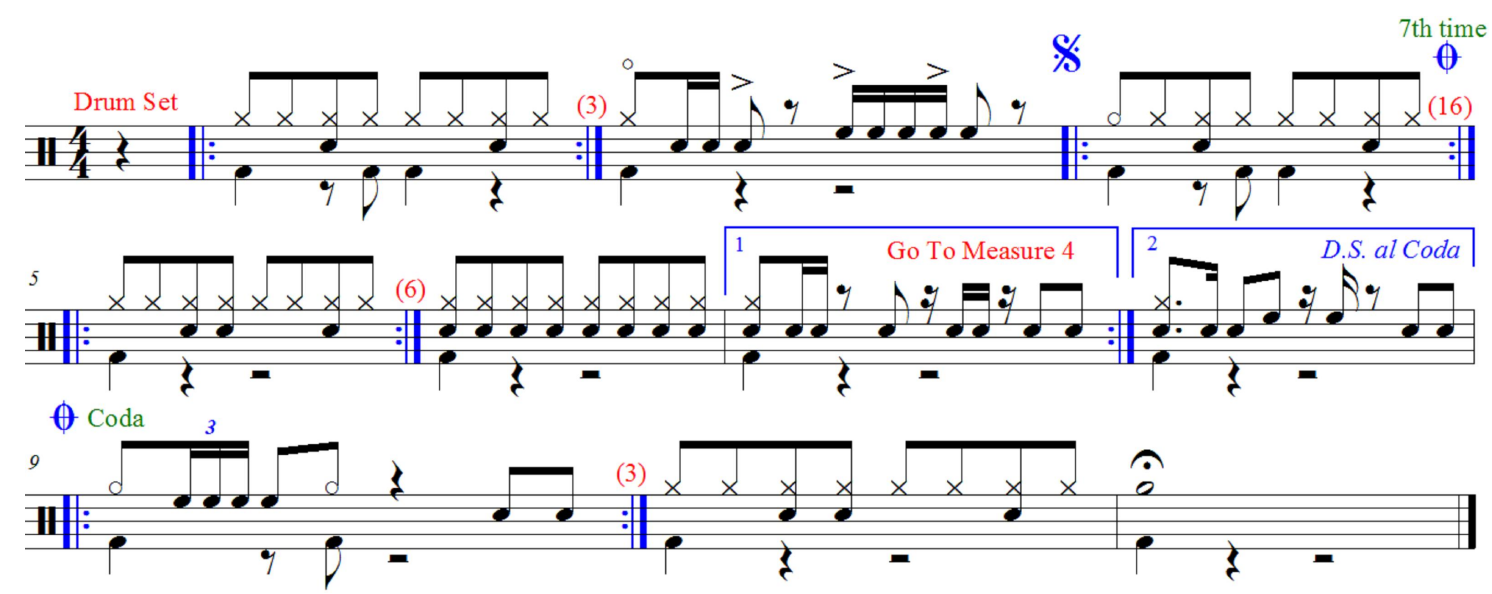

Figura 4.5: Partitura de bateria de From me to you de The Beatles.

Na Tabela 4.4 são listados os padrões e as pontes que compõem a canção,

\footnotetext{
${ }^{8}$ Matriz que contém a informação de todos os eventos musicais

${ }^{9}$ No Apêndice B, Seção B.3, é descrita a notação musical usada para a bateria
} 
bem como algumas características básicas: número dos compassos que ocupam, quantidade total de repetições, Extensão em Batidas (EB), Quantidade de CRs (QCRs) e ranking de relevância estimado segundo o número total de ocorrências dentro da obra toda $(\hat{\Lambda})$ (onde a primeira colocação tem a maior relevância estimada). Os padrões rítmicos extraídos serão comparados com a informação contida nessa tabela. A canção é composta por 3 partes e 4 pontes, a última ponte é a coda (ponte que leva ao fim). Vale destacar que a ponte 2 e 3 e a parte 3 têm características similares e podem ser agrupadas em uma única parte.

Tabela 4.4: Partes e pontes rítmicas da canção From me to you e algumas características básicas: Extensão em Batidas (EB), Quantidade de CRs (QCRs) e ranking de relevância estimado $(\hat{\Lambda})$.

\begin{tabular}{c|c|c|c|c|c}
\hline Tipo de frase & Compassos & Total de repetições & EB & QCRs & $\hat{\Lambda}$ \\
\hline \hline Parte 1 & 2 e 4 & $3+16+16+7=42$ & 4 & 3 & 1 \\
Ponte 1 & 3 & 1 & 4 & 3 & 5 \\
Parte 2 & 5 & $6+6+1=13$ & 4 & 4 & 2 \\
Ponte 2 & $6-7$ & 1 & 8 & 6 & 4 \\
Ponte 3 & $6-8$ & 1 & 8 & 5 & 4 \\
Parte 3 & 9 & 3 & 4 & 4 & 3 \\
Ponte 4 & 11 & 1 & 1 & 2 & 6 \\
\hline
\end{tabular}

Em (Corrêa et al., 2010) foi usado o dígrafo da linha de percussão de From me to you (Fig. 1(d) nesse artigo), como exemplo da etapa de geração do dígrafo para a extração dos atributos de um sistema de classificação de gêneros musicais. Esse dígrafo foi criado misturando as três linhas de percussão em uma só. Nesse dígrafo pode ser facilmente percebido que os dados usados para sua geração diferem dos encontrados na partitura, e que, ademais, há vários erros que dificultam a análise. Os erros desse dígrafo são: (1) os valores das figuras rítmicas são inexatos, pois não foi feita uma boa depuração dos dados provenientes do arquivo MIDI mediante um método de quantização ${ }^{10}$; (2) os silêncios foram desconsiderados; (3) as figuras rítmicas foram consideradas de forma individual e não como um grupo dentro da batida; (4) a mistura vertical elimina a informação de simultaneidade temporal das linhas percussivas, considerando os diferentes instrumentos que conformam a percussão como um só. Em (Corrêa, 2012) um novo esforço foi feito para tentar corrigir os problemas anteriores, porém apenas abrangendo simultaneamente o item (3) e (4). Na etapa de extração do ritmo, para cada pulsação foi usada a mediana das figuras dos instrumentos de percussão, com isso, a divisão por

\footnotetext{
${ }^{10}$ A duração e o início dos eventos no arquivo MIDI podem ter imprecisões causadas por recursos de imitação da interpretação ou por erros na gravação, dentre outras causas. O processo de corrigir esses valores com valores precisos em unidades de batida chama-se quantização
} 


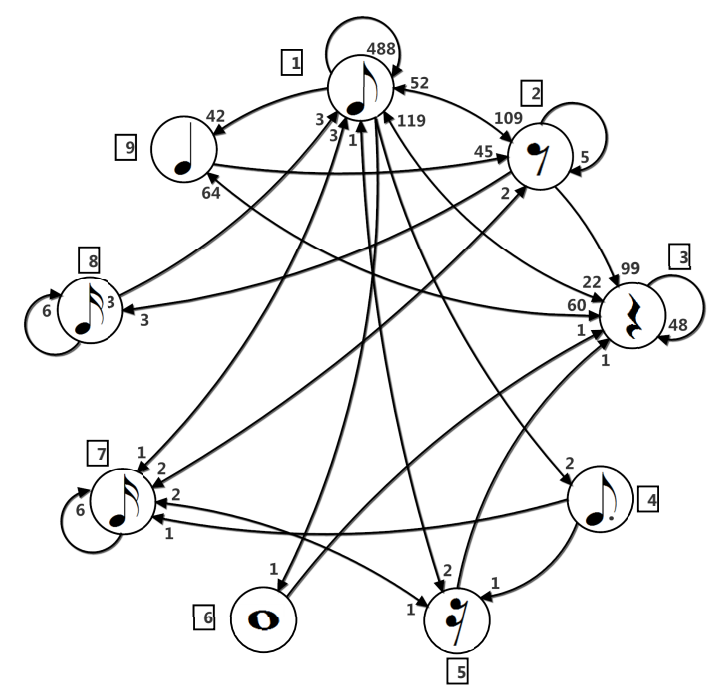

Figura 4.6: Dígrafo da percussão de From me to you usando FRIs e concatenação horizontal $\left(\mathbf{R}_{0}\right)$.

pulsações foi adotada, mas continuam os outros problemas e persiste uma perda considerável de informação musical.

Nesta tese todos esses problemas foram resolvidos. Primeiro, o arquivo MIDI foi depurado usando um método de quantização ${ }^{11}$. Os problema 2 e 3 foram simultaneamente resolvidos mediante o uso de células rítmicas. O último problema foi resolvido concatenando verticalmente os códigos das CRs das três linhas de percussão. Para propósitos de comparação, será contrastada a influência no resultado final de usar FRIs ou CRs, e de usar diferentes disposições das linhas de percussão na geração da rede, isto é, usar as linhas separadamente ou concatenadas vertical ou horizontalmente. O dígrafo da linha de percussão de From me to you usando FRIs, quantização e concatenação horizontal é denotado como $\mathbf{R}_{0}$ e é mostrado na Fig. 4.6. O dígrafo gerado para a linha superior, intermediária e inferior usando CRs é denotado como $\mathbf{R}_{1}, \mathbf{R}_{2}$ e $\mathbf{R}_{3}$, e é mostrado na Fig. 4.7(a), 4.7(b) e 4.7(c), respectivamente. A rede gerada usando CRs e concatenação horizontal e vertical é denotada como $\mathbf{R}_{4}$ e $\mathbf{R}_{5}$, e é mostrada na Fig. 4.8 e 4.9, respectivamente.

Visando particionar os dígrafos em comunidades para assim obter os padrões rítmicos, os algoritmos de detecção de comunidades disjuntas descritos na Seção 2.1.3 são aplicados para cada um dos dígrafos $\left(\mathbf{R}_{0}\right.$ a $\left.\mathbf{R}_{5}\right)$. As comunidades $^{12}$ obtidas com o algoritmo OM e de Louvain são mostradas, respectivamente, na Tabela 4.5 e Tabela 4.6. O algoritmo de Louvain foi aplicado usando o software Gephi (Bastian et al., 2009), e o resultado obtido para $\mathbf{R}_{5}$ é mostrado na Fig. 4.10.

Analisando os resultados obtidos com o algoritmo OM, as comunidades

\footnotetext{
11 Nesta tese também foi desenvolvido um método de quantização

12 Por questão de espaço, nas tabelas a palavra comunidade é abreviada assim: Com.
} 


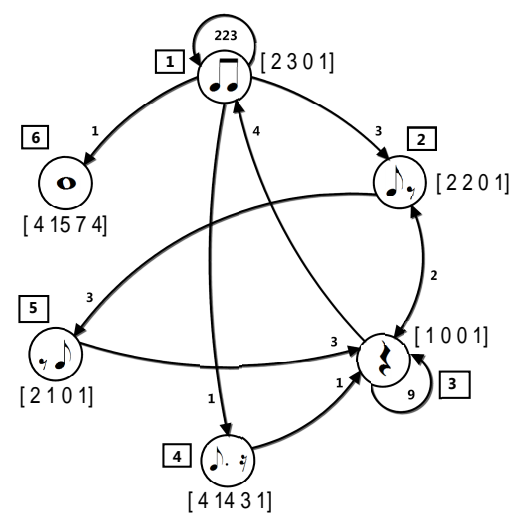

(a)

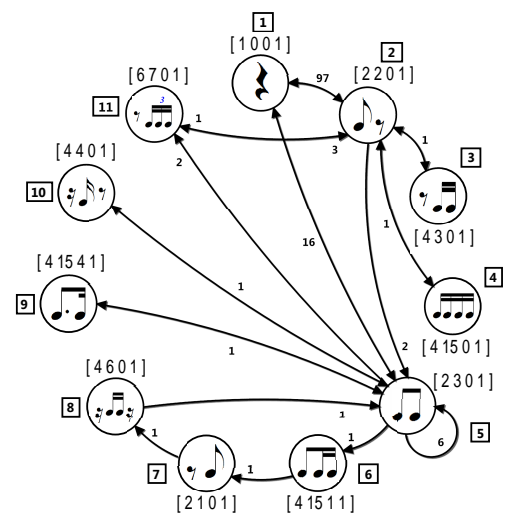

(b)

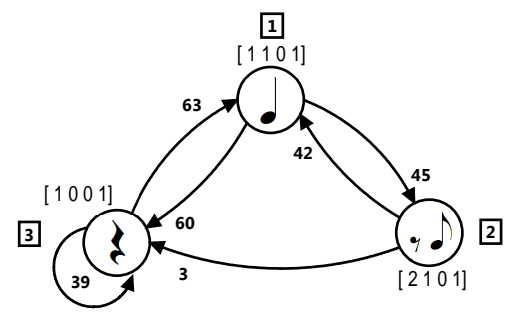

(c)

Figura 4.7: Dígrafos das linhas de percussão de From me to you. (a) Linha superior $\left(\mathbf{R}_{1}\right)$; (b) Linha intermediária $\left(\mathbf{R}_{2}\right)$; (c) Linha inferior $\left(\mathbf{R}_{3}\right)$.

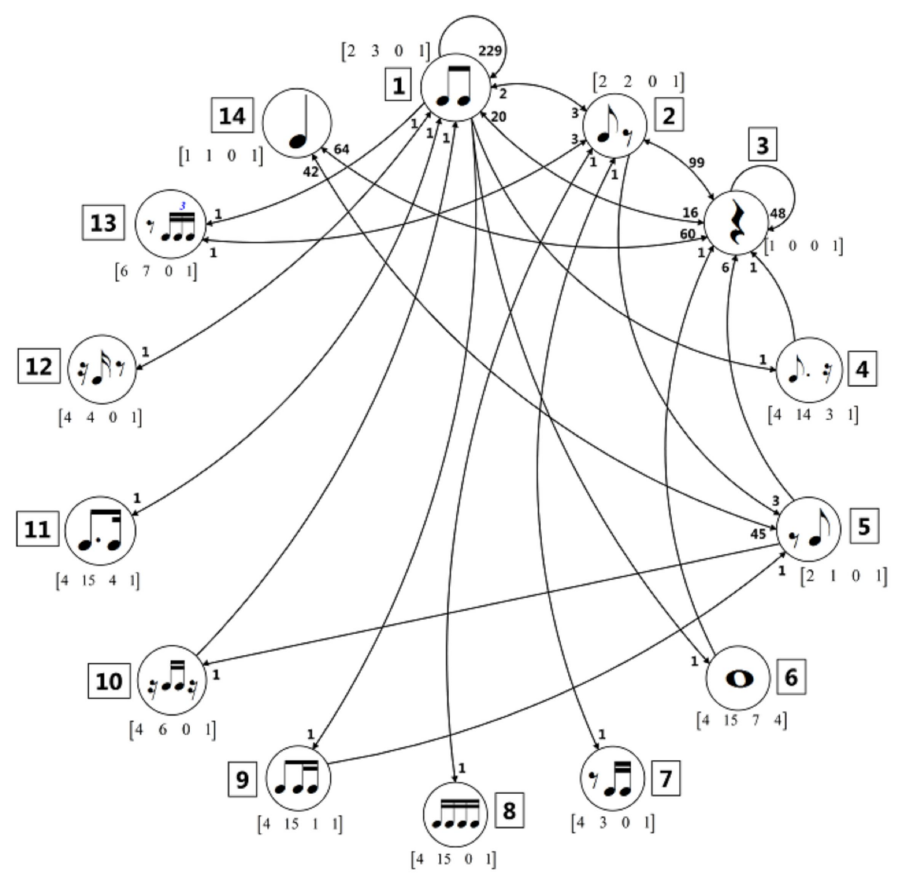

Figura 4.8: Dígrafo das três linhas de percussão de From me to you concatenadas horizontalmente $\left(\mathbf{R}_{4}\right)$.

Tabela 4.5: Comunidades detectadas com o algoritmo de otimicação de modularidade para os dígrafos $\mathbf{R}_{0}$ a $\mathbf{R}_{5}$.

\begin{tabular}{|c|c|c|c|c|c|c|}
\hline Com. & $\mathbf{R}_{0}$ & $\mathbf{R}_{1}$ & $\mathbf{R}_{2}$ & $\mathbf{R}_{3}$ & $\mathbf{R}_{4}$ & $\mathbf{R}_{5}$ \\
\hline 1 & 16 & 146 & 1234 & 12 & $\begin{array}{l}1469 \\
111213\end{array}$ & $\begin{array}{lll}1 & 23 \\
9 & 19\end{array}$ \\
\hline 2 & 239 & 235 & $\begin{array}{llll}5 & 6 & 7 & 8 \\
9 & 10 & 1 & 1\end{array}$ & 3 & $\begin{array}{llll}2 & 3 & 5 & 7 \\
8 & 10 & 14\end{array}$ & 456 \\
\hline $\begin{array}{l}3 \\
4\end{array}$ & $\begin{array}{l}457 \\
8\end{array}$ & & & & & $\begin{array}{llll}7 & 8 & 14 & \\
10 & 11 & 12 & 13 \\
15 & 16 & 17 & 18\end{array}$ \\
\hline
\end{tabular}




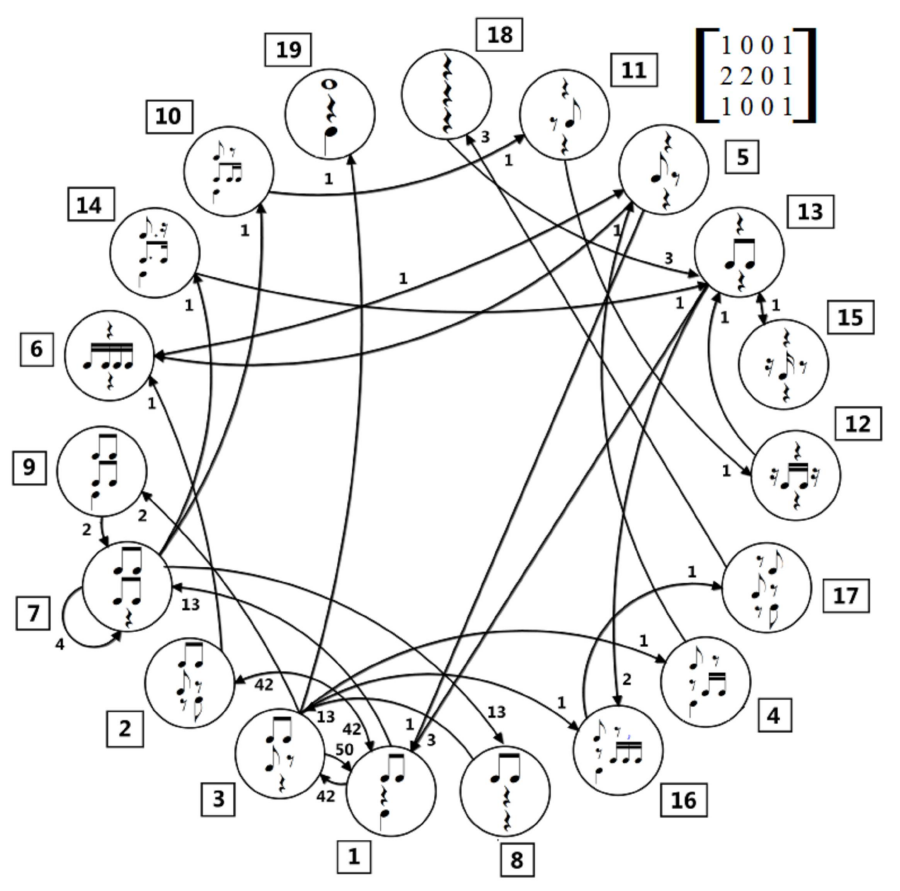

Figura 4.9: Dígrafo das três linhas de percussão de From me to you concatenadas verticalmente $\left(\mathbf{R}_{5}\right)$.

Tabela 4.6: Comunidades detectadas com o algoritmo de Louvain para os dígrafos $\mathbf{R}_{0}$ a $\mathbf{R}_{5}$.

\begin{tabular}{|c|c|c|c|c|c|c|}
\hline Com. & $\mathbf{R}_{0}$ & $\mathrm{R}_{1}$ & $\mathbf{R}_{2}$ & $\mathbf{R}_{3}$ & $\mathbf{R}_{4}$ & $\mathbf{R}_{5}$ \\
\hline 1 & 457 & 1346 & 7668 & 12 & 5991014 & 122319 \\
\hline 2 & 123 & 25 & 1234 & 3 & 12346 & 456 \\
\hline 3 & 689 & & 591011 & & 78111213 & 789 \\
\hline 4 & & & & & & $10 \quad 11 \quad 12$ \\
\hline & & & & & & $\begin{array}{lll}13 & 14 & 15 \\
16 & 17 & 18\end{array}$ \\
\hline
\end{tabular}
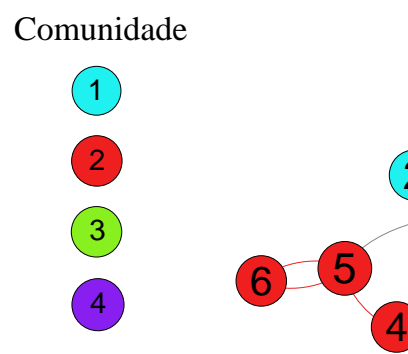

10

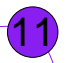

12

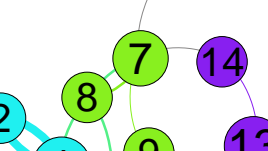

1315

4 316

19

Figura 4.10: Comunidades detectadas com o algoritmo de Louvain para o dígrafo $R_{5}$. 
Tabela 4.7: Relevância das comunidades detectadas com o algoritmo de otimização de modularidade para os dígrafos $R_{0}$ a $R_{5}$.

\begin{tabular}{c|c|c|c|c|c|c}
\hline Com. & $\Lambda\left(\mathbf{C}^{\left(\mathbf{R}_{0}\right)}\right)$ & $\Lambda\left(\mathbf{C}^{\left(\mathbf{R}_{1}\right)}\right)$ & $\Lambda\left(\mathbf{C}^{\left(\mathbf{R}_{2}\right)}\right)$ & $\boldsymbol{\Lambda}\left(\mathbf{C}^{\left(\mathbf{R}_{3}\right)}\right)$ & $\boldsymbol{\Lambda}\left(\mathbf{C}^{\left(\mathbf{R}_{4}\right)}\right)$ & $\boldsymbol{\Lambda}\left(\mathbf{C}^{\left(\mathbf{R}_{5}\right)}\right)$ \\
\hline \hline 1 & 0.80 & 0.95 & 0.95 & 0.53 & 0.44 & 0.77 \\
2 & 0.17 & 0.05 & 0.05 & 0.47 & 0.56 & 0.03 \\
3 & 0.01 & & & & & 0.16 \\
4 & 0.02 & & & & & 0.04
\end{tabular}

obtidas para $\mathbf{R}_{\mathbf{0}}$ são ao mesmo tempo distorcidas e ambíguas. Distorcidas porque a informação de dependência e ordem das figuras dentro da batida foi desconsiderada, e ambíguas devido à mistura das figuras rítmicas comuns entre as linhas, produto da concatenação vertical. De maneira semelhante, tem-se que as comunidades obtidas para os dígrafos das linhas individuais $\left(\mathbf{R}_{1}, \mathbf{R}_{2}\right.$ e $\left.\mathbf{R}_{3}\right)$ dão uma ideia imprecisa do padrão rítmico da canção, uma vez que mostram as CRs do padrão de forma fragmentada. De igual forma, as comunidades obtidas para o dígrafo $\mathbf{R}_{4}$ são ambíguas, uma vez que as CRs comuns entre duas ou mais linhas são representadas por um único nó. Entretanto, as comunidades obtidas para o dígrafo $R_{5}$ são mais consistentes com a estrutura real da canção, já que mostram a informação de dependência e ordem das figuras dentro de cada batida, bem como a relação existente entre as CRs das linhas durante a evolução da música. Uma análise semelhante pode ser feita para as comunidades detectadas com o algoritmo de Louvain.

Em seguida, com a matriz de comunidades devolvida pelos algoritmos é calculada a medida de relevância para os 6 dígrafos. Na Tabela 4.7 é mostrado o valor de relevância das comunidades detectadas com o algoritmo OM, e na Tabela 4.8 a relevância das comunidades encontradas com o algoritmo de Louvain. Nessas tabelas o valor de relevância das comunidades da rede $x$ é denotado como $\Lambda\left(\mathbf{C}^{\left(\mathbf{R}_{x}\right)}\right)$. Um valor de relevância alto indica quanto a comunidade representa melhor a rede toda, portanto, os nós que conformam as comunidades mais relevantes serão as CRs dos padrões principais da canção, e os nós das comunidades menos relevantes correspondem a pontes rítmicas. Quando comparados os valores de relevância das tabelas com a informação contida no dígrafo da Fig. 4.9 e na Tabela 4.4 é possivel enxergar que a rede $\mathbf{R}_{5}$ é mais consistente com a estrutura real da canção. Por tal razão, as seguintes análises serão efetuadas somente para esta rede.

Na Tabela 4.9 são listados os nós do dígrafo da Fig. 4.9 que formam as partes e pontes descritas na Tabela 4.4. Nota-se que existem algumas CRs compartilhadas por várias partes, a CR 1 entre as partes 1 e 3, a CR 7 entre as partes 3,4 e 5; e a CR 10 e 13 entre as partes 4 e 5.

Com relação às comunidades detectadas com Louvain, pode-se perceber que a comunidade 1 (nós $1,2,3,19$ ) corresponde ao padrão rítmico 1 (com ex- 
Tabela 4.8: Relevância das comunidades detectadas com o algoritmo Louvain para os dígrafos $R_{0}$ a $R_{5}$.

\begin{tabular}{c|c|c|c|c|c|c}
\hline Com. & $\Lambda\left(\mathbf{C}^{\left(\mathbf{R}_{0}\right)}\right)$ & $\Lambda\left(\mathbf{C}^{\left(\mathbf{R}_{1}\right)}\right)$ & $\Lambda\left(\mathbf{C}^{\left(\mathbf{R}_{2}\right)}\right)$ & $\Lambda\left(\mathbf{C}^{\left(\mathbf{R}_{3}\right)}\right)$ & $\Lambda\left(\mathbf{C}^{\left(\mathbf{R}_{4}\right)}\right)$ & $\Lambda\left(\mathbf{C}^{\left(\mathbf{R}_{5}\right)}\right)$ \\
\hline \hline 1 & 0.03 & 0.93 & 0.06 & 0.53 & 0.49 & 0.80 \\
2 & 0.97 & 0.07 & 0.94 & 0.47 & 0.51 & 0.02 \\
3 & & & & & & 0.14 \\
4 & & & & & & 0.04 \\
\hline
\end{tabular}

Tabela 4.9: Nós do dígrafo $\mathbf{R}_{5}$ que formam cada parte da canção From me to you.

\begin{tabular}{c|c|l|c}
\hline Parte & Tipo de frase & Nós & Total de nós \\
\hline \hline 1 & Padrão rítmico 1 & 123 & 3 \\
2 & Ponte 1 & 456 & 4 \\
3 & Padrão rítmico 2 & 1783 & 4 \\
4 & Ponte 2 & 9710111213 & 6 \\
5 & Ponte 3 & 107141315 & 5 \\
6 & Padrão rítmico 3 & 16171813 & 4 \\
7 & Ponte 4 (Fim) & 19 & 1 \\
\hline
\end{tabular}

ceção do nó 19$)^{13}$, a comunidade 3 (nós $7,8,9$ ) ao padrão 2 , a comunidade 2 (nós 4,5,6) à ponte 1 , e a comunidade 4 (nós $10,11,12,13,14,15,16,17,18$ ) às pontes 2,3 e ao padrão 3 . Com relação à relevância das comunidades detectadas com os dois algoritmos (OM e Louvain), o maior valor de relevância é da comunidade 1 com uma porcentagem de $77 \%$ e $80 \%$, respectivamente; e o segundo maior valor é da comunidade 3 com uma porcentagem de $16 \%$ e $14 \%$, respectivamente. As demais comunidades têm valor de relevância inferior a $10 \%$. Esses valores concordam com o ranking de relevância estimado $(\hat{\Lambda})$ da Tabela 4.4 .

Contudo, o resultado do algoritmo de Louvain parece ser melhor do que o do algoritmo OM. Isso pode ser testado comparando os padrões da Tabela 4.9 com as comunidades detectadas por ambos os algoritmos (Tabela $4.5 \mathrm{e}$ 4.6). Uma comparação objetiva é feita através das medidas de comparação de agrupamentos descritas na Seção 2.3.3. Na Fig. 4.11 é mostrado o valor de ARI e NMI para as comunidades detectadas com os dois algoritmos (OM e Louvain) para o dígrafo $R_{5}$ com relação às partições originais da Tabela 4.9, porém desconsiderando os nós comuns. É fácil perceber que os valores de ARI e NMI são maiores para as comunidades detectadas com o algoritmo de Louvain, portanto, o padrão rítmico será extraído usando esse resultado.

Por fim, para este exemplo, o padrão rítmico principal corresponde aos nós 1, 2, 3 e 19 do dígrafo da Fig. 4.9, cujos códigos são [2301;1001; 1101], [2301; 1001; 1101], [2301; 1001; 1101] e [2301; 1001; 1101], respectivamente. Para construir o padrão rítmico, pode ser visto no dígrafo que o nó 19 deve finalizar a

\footnotetext{
${ }^{13} \mathrm{O}$ nó 19 gera confusão ao algoritmo pelo fato de somente ter uma conexão de entrada
} 


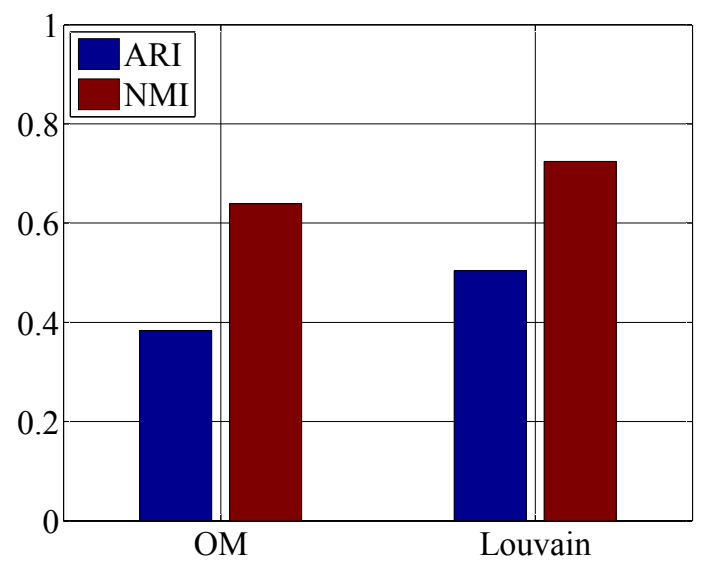

Figura 4.11: Métricas índice corrigido de Rand (ARI) e informação mútua normalizada (NMI) das comunidades detectadas pelo algoritmo de Otimização de Modularidade (OM) e de Louvain para $\mathbf{R}_{5}$.

sequência e que o único nó que pode dar início à sequência é o nó 1 , então conservando as regras é obtida a sequência: $1,2,1,3,1,2,1,3 \ldots .19$. Os códigos dos nós desta sequência são decodificados para obter a matriz de notas de cada CRs e, consequentemente, o arquivo MIDI. A partitura do padrão rítmico extraído é mostrada na Fig. 4.12. Note-se que o número de repetições das CRs 1,2 e 3 é igual a 42, o qual corresponde à soma das repetições do padrão dentro da partitura, porém, este valor é derivado dos pesos das arestas do dígrafo. Note-se também que, para a conexão entre os nós 3 e 1, oito pesos não foram considerados porque o seu uso restringe a continuidade da caminhada entre todos os nós, esta restrição é devido ao fato de que 2 conexões entre o nó 3 e 1 são geradas na transição do padrão 1 ao padrão 2, e 6 conexões são geradas dentro do padrão 2.

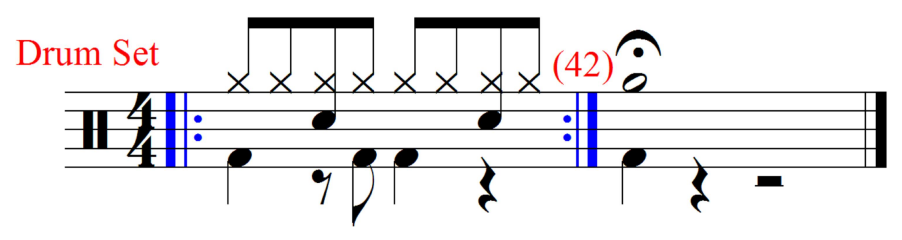

Figura 4.12: Partitura do padrão rítmico extraído do dígrafo $\mathbf{R}_{5}$.

Note-se ainda que, devido ao fato das comunidades detectadas serem disjuntas a identificação de CRs compartilhadas entre uma ou mais partes foi desconsiderada. Em outras palavras, os nós 1, 7, 10 e 13 pertencem a uma, e somente uma comunidade, fato que não é real segundo a estrutura da obra musical (ver Tabela 4.9). Portanto, o uso de um algoritmo para a detecção de comunidades sobrepostas é mais apropriado para este tipo de dígrafos. Na Tabela 4.10 são mostrados os nós das comunidades detectadas com o algoritmo BNMF e os respectivos valores de relevância. 
Tabela 4.10: Valores de relevância e comunidades detectadas com o algoritmo BNMF para o digrafo $\mathbf{R}_{5}$.

\begin{tabular}{c|l|c}
\hline Comunidade & \multicolumn{1}{|c|}{ Nós } & $\boldsymbol{\Lambda}\left(\mathbf{C}^{\left(\mathbf{R}_{5}\right)}\right)$ \\
\hline \hline 1 & $1,7,9,19$ & 0.20 \\
2 & $1,7,8,9,19$ & 0.62 \\
3 & $4,6,10,11,12,14,15,16,17,18,19$ & 0.12 \\
4 & $2,3,5,13,19$ & 0.06 \\
\hline
\end{tabular}

Na Fig. 4.13 é mostrado o valor de pertinência dos nós dentro das comunidades detectadas pelo algoritmo BNMF. Verifica-se que os nós 1,7,9 e 19 são comuns a várias comunidades, isso é esperado para o nó 1 e 7 , uma vez que, conforme supracitado, a CR 1 é usada pela parte 1 e 3 , e a CR 7 pelas partes 3, 4 e 5. Contudo, as comunidades detectadas pelo algoritmo BNMF não concordam totalmente com os valores esperados, apenas parcialmente com a identificação de nós comuns.

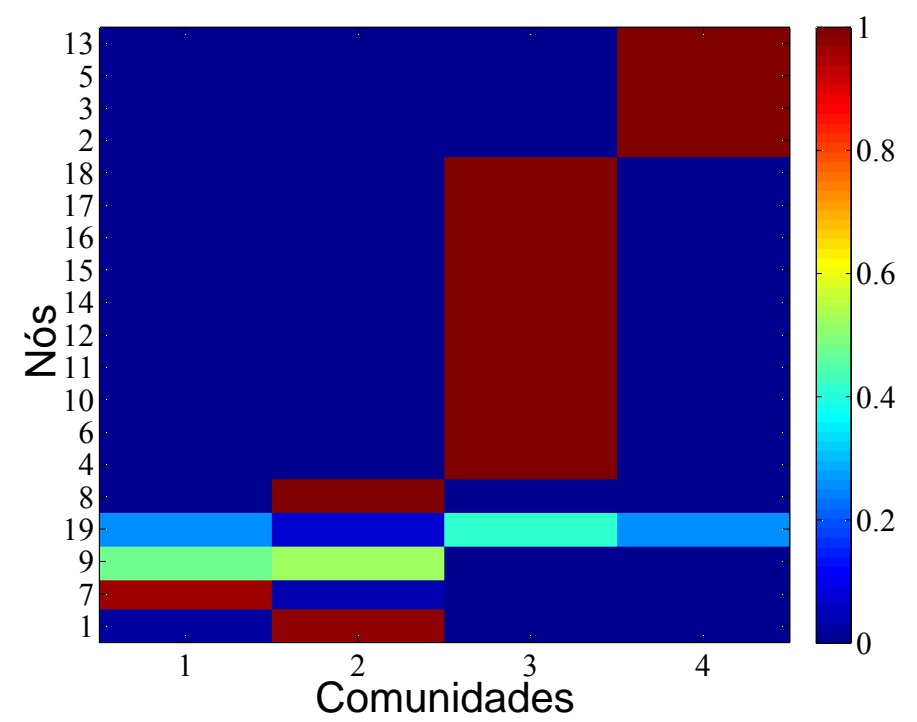

Figura 4.13: Valor de pertinência dos nós das comunidades detectadas pelo algoritmo BNMF.

A Fig. 4.14 mostra o valor de pertinência dos nós 1,7,9 e 19 dentro das 4 comunidades detectadas pelo algoritmo BNMF. No que diz respeito ao nó 1 , pode ser visto que sua pertinência é maior para a comunidade 2 , o que confirma que este nó está mais ligado aos nós 7 e 8, formando assim a parte 3 da Tabela 4.9. Com relação ao nó 7, o algoritmo indica que ele está mais ligado à comunidade 1 , formando assim uma porção da parte 4 da Tabela 4.9.

A Fig. 4.15 apresenta o valor do índice ômega e da informação mútua normalizada generalizada (GNMI) das comunidades detectadas para o dígrafo $\mathbf{R}_{5}$ com o algoritmo BNMF, calculados tendo como referência as partições originais da Tabela 4.9 e considerando os nós comuns. Estes valores são menores 


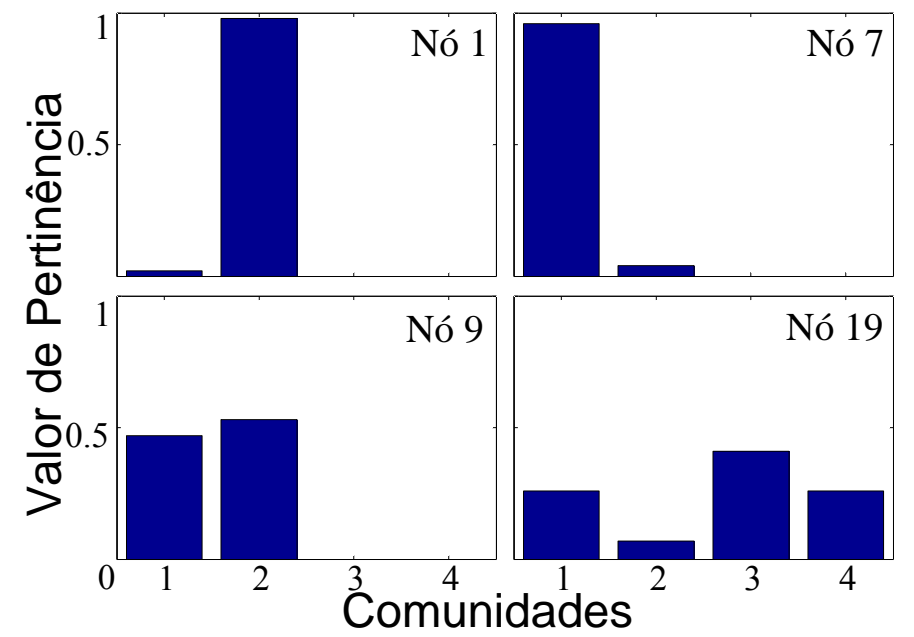

Figura 4.14: Valor de pertinência dos nós comuns entre as comunidades detectadas pelo algoritmo BNMF.

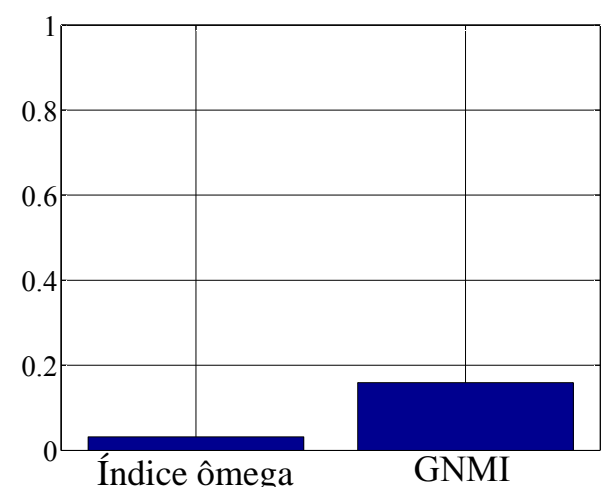

Figura 4.15: Índice ômega e informação mútua normalizada generalizada (GNMI) das comunidades detectadas para $\mathbf{R}_{5}$ com o algoritmo BNMF.

que os resultados obtidos com o algoritmo OM e de Louvain, o qual significa que o algoritmo BNMF é melhor para detectar nós comuns do que para detectar as comunidades em si mesmas.

O exemplo anterior serviu para ilustrar a utilidade do método proposto, no entanto, embora o método tenha sido aplicado a uma única amostra, ele pode ser usado para extrair o padrão rítmico, se houver, de qualquer música, de qualquer gênero e de qualquer artista. O método também foi aplicado para extrair o padrão principal das 20 canções mostradas na Tabela 4.12. Na Tabela 4.11 são apresentados os Nós da Comunidade Mais Relevantes (NCMR), o seu valor de relevância e a partitura do Padrão Rítmico de Bateria Extraído (PRBE). Note-se que quando diferentes canções compartilham o mesmo padrão, elas são separadas e agrupadas. O padrão principal dos grupos 4,7 e 8 tem duas variações, o padrão mostrado dentro do compasso e o padrão resultante de trocar a última $\mathrm{CR}$ pela $\mathrm{CR}$ após as duas barras, isto é, a CR do nó entre parênteses. 
Tabela 4.11: Nós das Comunidade Mais Relevantes (NCMR), valor de relevância e partitura do Padrão Rítmico de Bateria Extraído (PRBE) para as músicas da Tabela 4.12.

\begin{tabular}{|c|c|c|c|}
\hline No. Canção & NCMR & $\Lambda(\mathbf{C})$ & Partitura do PRBE \\
\hline 2 & $2,3,4$ & 0.75 & \\
\hline 3 & $2,3,4$ & 0.75 & \\
\hline 4 & $1,2,3$ & 0.77 & \\
\hline 6 & $2,6,7$ & 0.96 & \\
\hline 15 & $1,3,5$ & 0.99 & \\
\hline 18 & $6,7,8$ & 0.70 & \\
\hline$\overline{1}$ & $\overline{2}, \overline{3}$ & 0.99 & \\
\hline 5 & 1,2 & 0.94 & \\
\hline 7 & 1,2 & 1.00 & \\
\hline 11 & 1,2 & 0.90 & \\
\hline$\overline{8}$ & $1, \overline{2}, 3, \overline{4}$ & 0.92 & \\
\hline 12 & $3,4,5,6$ & 0.70 & \\
\hline 14 & $1,2,3,4$ & 0.91 & \\
\hline 16 & $1,2,3,4$ & 0.66 & \\
\hline 10 & $1, \overline{2}, 3, \overline{4}$ & 0.89 & \\
\hline 19 & $8,9,10,11,(12)$ & 0.67 & 亚乎? \\
\hline & & & $--\overline{\text { Drum }}$ \\
\hline 9 & 3,4 & 0.92 & \#㫣? ? \\
\hline & --------- & --- & Drum Set \\
\hline 13 & $2,3,4$ & 0.75 & 亚? \\
\hline & & & 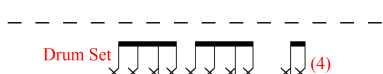 \\
\hline 17 & $2,3,(4)$ & 1.00 & 亚蕅? \\
\hline & & ---- & 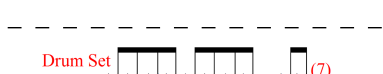 \\
\hline 20 & $1,2,3,4,(7)$ & 0.88 & 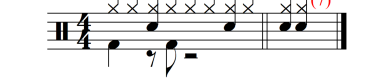 \\
\hline
\end{tabular}

Visando extrair o padrão rítmico que sumariza o gênero musical de um conjunto de canções gravadas por The Beatles ${ }^{14}$ (Beatles, 1993), foi gerada uma rede com as 20 músicas listadas na Tabela 4.12. A rede gerada, bem como as comunidades obtidas com o algoritmo de Louvain, é mostrada na Fig. 4.16 .

O vetor de relevância das comunidades obtidas com o algoritmo de Louvain para a rede formada pelas 20 canções da Tabela 4.12 é: $\left[\begin{array}{cccc}0.76 & 0.1 & 0.06 & 0.04\end{array}\right.$ 0.03]. A primeira comunidade tem o maior valor de relevância, portanto, será selecionada para gerar o padrão rítmico. Os nós com o maior grau total médio

\footnotetext{
14 Todas as músicas escritas por John Lennon e Paul McCartney, exceto as músicas: 13 por J. Lennon, P. McCartney, George Harrison e Richard Starkey; 1 por G. Harrison; 5 por Vonnie Morrison e Johnny Russell; 14 por Larry Williams; e 20 por Hal David, Burt Bacharach e Barney Williams
} 
Tabela 4.12: Conjunto de canções de The Beatles usadas para extração do padrão rítmico e sumarização rítmica.

\begin{tabular}{l|l}
\hline \multicolumn{2}{c}{ Nome da Canção } \\
\hline \hline 1. I Need You & 11. Do You Want to Know a Secret? \\
2. I'm Looking Through You & 12. Drive my car \\
3. I Want To Hold Your Hand & 13. Flying \\
4. From me to you & 14. Dizzy Miss Lizzy \\
5. Act Naturally & 15. I'll Be Back \\
6. If I Fell & 16. A Hard Day's Night \\
7. I Should Have Known Better & 17. Misery \\
8. I Call Your Name & 18. She Loves You \\
9. Can't Buy Me Love & 19. All I've Got To Do \\
10. All My Loving & 20. Baby It's You \\
\hline
\end{tabular}

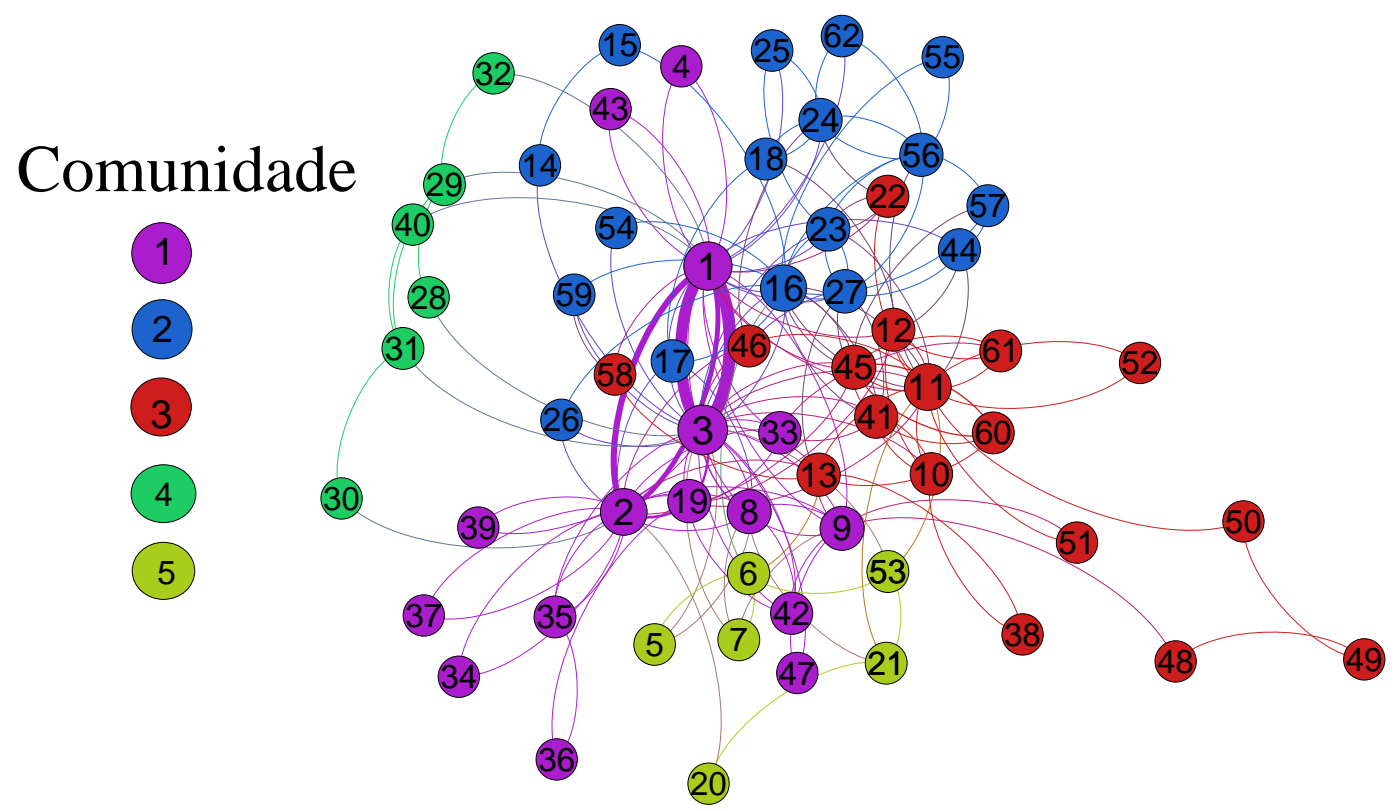

Figura 4.16: Comunidades detectadas com o algoritmo de Louvain para a rede formada pelas 20 canções da Tabela 4.12.

intra-comunidade são os nós 1,2 e 3, com grau médio $0.37,0.19$ e 0.30 , respectivamente. Aplicando a caminhada sobre estes nós e seguindo as regras supracitadas, é obtida a sequência de nós $1,2,1,3 \ldots$.Para esta sequência é aplicado o algoritmo decodificador e é obtido o padrão rítmico da Fig. 4.17. O padrão obtido sumariza ritmicamente o gênero musical do conjunto de canções, e este é um padrão típico do rock. É importante realçar que o padrão rítmico de sumarização extraído corresponde ao padrão do grupo 1 da Tabela 4.12, dado que esse grupo tem o maior número de músicas que compartilham o mesmo padrão. Isto posto, a sumarização realmente obtém o padrão principal mais comum entre todas as músicas do conjunto. 


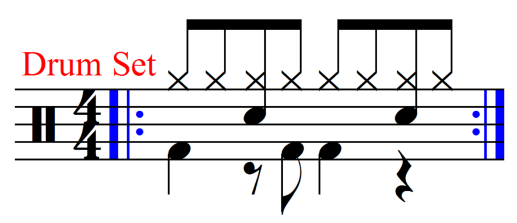

Figura 4.17: Padrão rítmico que sumariza o gênero musical do conjunto de canções de The Beatles listadas na Tabela 4.12.

\subsection{Identificação do Gênero Musical}

Nesta seção é apresentada uma nova metodologia para a identificação de gêneros musicais baseada em redes complexas. Seu fundamento e inspiração encontra-se nos bons resultados do método de extração de padrões rítmicos descritos na seção anterior (Coca \& Zhao, 2014d), e foi motivada pela metodologia de classificação de gêneros musicais publicada em (Corrêa et al., 2010). A ideia principal é que devido ao fato dos padrões rítmicos principais representarem melhor o gênero musical do que os padrões secundários, então, caracterizar unicamente a rede formada pelos padrões principais fará com que a informação mais discriminante do gênero musical fique concentrada no espaço de atributos.

\subsubsection{Descrição do Modelo}

Esta metodologia aproveita de maneira conjunta as vantagens da representação do ritmo mediante CRs, da medida de relevância de comunidades e das medidas topológicas de redes complexas. A adição de cada um desses três fatores é justificada a seguir:

1. Células ritmicas: O fundamento principal de usar CRs se deve ao fato do ritmo musical ser melhor representado com CRs do que com FRIs (Coca \& Zhao, 2014c). Além do mais, geralmente os gêneros musicais são caracterizados por padrões rítmicos preestabelecidos, que por sua vez, são formados por CRs predefinidas. Portanto, adotar a utilização de CRs é um recurso que vai em consonância com a natureza da música, ajudando a representar de uma maneira mais adequada e realista os grupos rítmicos que formam os padrões característicos do gênero musical.

2. Relevância de comunidades: Conforme descrito na Seção 4.1.1, pelo ao fato dos padrões secundários não caracterizarem bem um fragmento musical, e consequentemente o gênero, sua inclusão dentro da etapa de mineração poderia afetar a exatidão dos atributos e mascarar a informação própria do gênero, comprometendo o desempenho do reconhecimento. 
Em consequência, a depuração objetiva dos padrões rítmicos para conservar unicamente os padrões próprios do gênero, mostra-se como uma etapa preliminar importante. Antes da presente pesquisa, o problema recaía sobre como diferenciar esses dois tipos de padrões de maneira objetiva, porém, tendo em conta que um diferencial notável entre estes dois tipos de padrões é o número de ocorrências e tempo de permanência dentro do discurso rítmico, a medida de relevância foi desenvolvida para resolver tal problema. Portanto, sua inclusão dentro da metodologia de identificação é útil para depurar a rede e confinar a informação no espaço de atributos.

3. Medidas topológicas: A utilização de medidas topológicas na fase de mineração é devida ao fato delas extraírem melhor as características intrínsecas da rede, em oposição ao simples uso da matriz de adjacência. Além de tudo, ajudam também a reduzir a dimensionalidades do vetor de características.

A Fig. 4.18 apresenta o diagrama de blocos da metodologia proposta para a identificação de gêneros musicais, cujos passos são descritos a seguir.

No banco de dados, a base rítmica de cada amostra é armazenada em formato MIDI. Para cada instância são extraídas e codificadas as CRs usando o algoritmo da Seção A.1 do Apêndice A. Dependendo do gênero e da instrumentação usada, a base rítmica pode ter uma ou mais linha rítmicas. No diagrama de blocos, o número de linhas rítmicas é referenciado com $L$. Se a amostra tiver mais de uma linha $(L>1)$ será necessário aplicar a etapa de pré-processamento descrita na Seção 4.2.1. Em seguida, o dígrafo G é gerado seguindo os passos da Seção 4.1 .1 e as suas comunidades são detectadas e representadas com a matriz de comunidades C. Diante do exposto na Seção 4.1.2, a associação entre padrões e comunidades depende da exatidão do algoritmo de detecção, em consequência, nesta tese é recomendado usar o algoritmo de Louvain. Para diferenciar as comunidades, e consequentemente os padrões, a medida de relevância é aplicada. As comunidades com maior valor de relevância estão associadas com os padrões principais da música e, portanto, serão estas as únicas usadas na etapa de extração de atributos. Para tal, um limiar de relevância $\alpha$ deverá ser definido. Supondo que o dígrafo gerado tem $n$ nós e $k$ comunidades, i.e., $G=\left\{G_{1}, \ldots, G_{i-1}, G_{i}, \ldots G_{k}\right\}$, cujos valores de relevância ( $\Lambda$ ) são ordenados descendentemente, $\Lambda_{1} \geq \cdots \geq \Lambda_{i} \geq \cdots \geq \Lambda_{k}$, se o valor de relevância da comunidade $i$ for menor ao valor de relevância limiar $\alpha\left(\Lambda_{i}<\alpha\right)$, então os nós dos $G_{l}$ subdígrafos, com $i \leq l \leq k$, serão apagados do dígrafo original, obtendo o dígrafo depurado $\hat{G}=\left\{G_{1}, \ldots, G_{i-1}\right\}$, com $\hat{n}<n$ nós.

Conquanto, é factível que a quantidade e o comprimento dos padrões secundários seja variável, inclusive, até poderia não existir para uma dada 


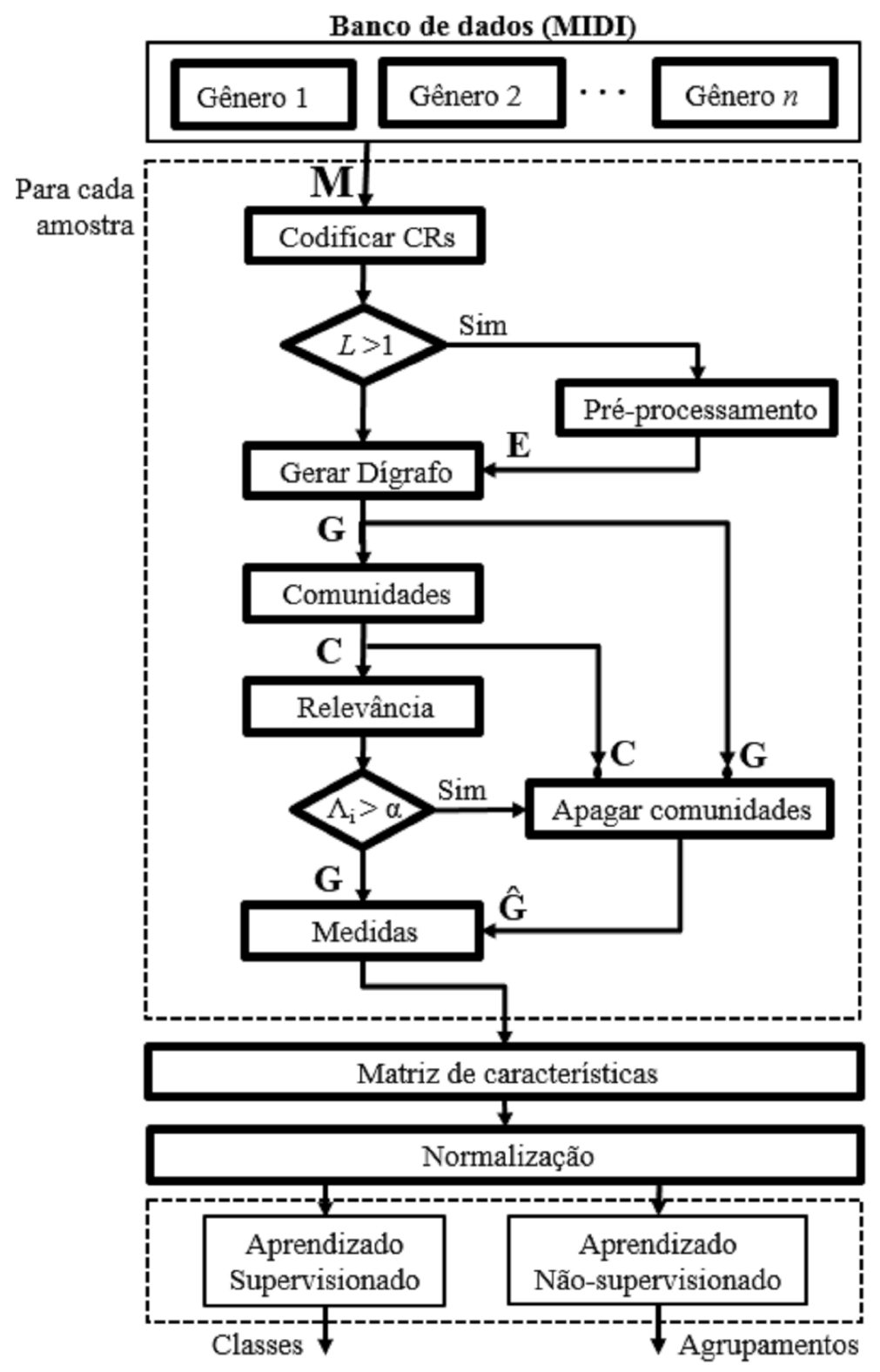

Figura 4.18: Diagrama de blocos da metodologia para a identificação de gêneros musicais baseada em redes complexas.

amostra. Dessa maneira, o valor do limiar de relevância deverá ser estimado empiricamente para cada banco de dados. O limiar $\alpha$ é um valor pequeno, e sua estimativa é feita sob a hipótese de que deve ser menor à metade do mínimo dos máximos (minimax) valores de relevância de todas as instâncias do banco de dados.

Por outro lado, devido ao fato dos dígrafos terem tamanhos diferentes, antes e depois de remoção de nós, o tamanho de todos os dígrafos deverá ser padronizado. Em (Corrêa et al., 2010) o tamanho dos dígrafos foi padronizado a um número fixo, igual a 18 nós, que corresponde à quantidade total de figuras rítmicas possiveis entre todas as amostras depois de excluir as menos frequentes. Contudo, nesta pesquisa tal padronização é realizada de forma 
sistemática e sem precisar excluir nenhuma figura rítmica dos padrões principais, além das já excluídas na etapa de depuração. O número de nós de padronização é igual à cardinalidade do conjunto de nós únicos do conjunto total de nós de todas as amostras. Este valor é importante para o cálculo das medidas topológicas globais que usam a média das medidas locais.

Na etapa de mineração para cada dígrafo depurado e redimensionado são calculadas as medidas topológicas descritas na Seção 2.1.1. Para evitar a influência da magnitude de uma ou várias medidas no processo de reconhecimento de padrões, a matriz de características é normalizada no intervalo $[0,1]$. Na etapa de reconhecimento de padrões são usadas duas abordagens de aprendizado: supervisionado e não supervisionado. Nesta tese a abordagem supervisionada é aplicada mediante o classificador Naive Bayes (Hand \& Yu, 2001) e a abordagem não supervisionada através do agrupamento hierárquico aglomerativo (Hastie et al., 2009).

\section{Descrição de Dados}

Com o intuito de contrastar a capacidade da metodologia proposta quanto ao seu funcionamento sobre sequências percussivas e não percussivas, dois bancos de dados foram usados. No primeiro contexto, foi usado um banco de dados com 180 amostras de três gêneros folclóricos da região andina colombiana: pasillo, bambuco e danza; e no segundo o banco de dados originalmente usado em (Corrêa et al., 2010) ${ }^{15}$, o qual é composto por sequências percussivas de bateria de quatro gêneros populares: blues, reggae, bossa nova e rock. A seguir são descritas algumas considerações preliminares importantes sobre os dois bancos de dados.

\section{Banco de Dados de Gêneros do Folclore Andino Colombiano}

Os gêneros do folclore musical da região andina colombiana que compõem este banco de dados são geralmente escritos para um formato de cordas típicas colombianas: bandola, tiple e violão; e podem ser meramente instrumentais ou vocais com acompanhamento instrumental. No entanto, também é possível encontrar peças escritas para outros tipos de formatos como piano e voz ou piano solo, e versões para piano de peças originalmente escritas para outro tipo de instrumentação (Morales, 1983). Na Tabela 4.13 são mostrados os padrões rítmicos predefinidos de cada gênero e algumas das suas variações.

O banco de dados foi criado usando exclusivamente obras originalmente escritas para piano ou versões adaptadas para piano ${ }^{16}$. Em concordância com

\footnotetext{
${ }^{15}$ Este banco de dados foi amavelmente emprestado pelos autores, os quais são possuidores dos direitos de autor

${ }^{16}$ Pelo fato de serem encontradas frequentemente músicas destes gêneros escritas ou adaptadas para piano
} 
Tabela 4.13: Padrões rítmicos e variações dos gêneros pasillo, bambuco e danza.

\begin{tabular}{|c|c|c|}
\hline Gênero & Padrão rítmico & Variações \\
\hline Pasillo & . Tydd & 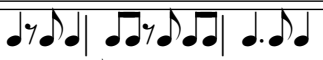 \\
\hline Bambuco & 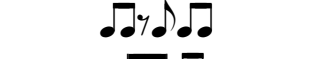 & dydd D. D. \\
\hline Danza & . .20 .0 & \\
\hline
\end{tabular}

o fundamento do método de extração rítmica exposto, somente a estrutura rítmica é necessária, a qual se refere exclusivamente à sequência de durações da base rítmica, que para o caso das canções folclóricas deste banco de dados é descrita pela parte inferior da partitura de piano, usualmente escrita para a mão esquerda. O piano, por se tratar de um instrumento com afinação definida, a estrutura rítmica deverá ser extraída excluindo as alturas e realizando uma redução nos seguintes casos:

1. Redução de acordes: A exclusão das alturas contempla qualquer número de notas que ocorram simultaneamente, isto é, intervalos e acordes também são reduzidos a um único valor de duração. Por exemplo, a Fig. 4.19(a) contém a redução dos compassos 5 e 6 da versão para piano do pasillo "Hacia el Calvario" de Carlos Vieco Ortíz (1900-1979). Este fragmento é formado por duas notas simples, dois acordes e dois intervalos.

2. Redução de retardos: Uma técnica da harmonia musical frequentemente usada consiste em suspender ou retardar a duração de uma ou mais notas (Lacerda, 1966). Nesta redução, para uma CR somente é considerada a duração até o começo do retardo, porque a partir deste é gerada uma simultaneidade de notas (intervalos ou acordes) dando lugar ao caso anterior. A Fig. 4.19(b) mostra a redução feita para os compassos 36 e 37 da danza para piano "Malvaloca" do compositor Luis A. Calvo (1882-1945), onde os baixos foram retardados.

3. Redução de ornamentos: Outro recurso usado na composição musical é o uso de ornamentos. Os ornamentos são notas adicionais de menor duração usadas para embelezar notas próprias do discurso melódico ou rítmico. Existem muito tipos de ornamentos, sendo o mais comum a apojatura, que é um conjunto de pequenas notas adicionadas antes do ataque da nota principal (Lacerda, 1966). Os ornamentos são usados em diversidade de instrumentos, e podem ser excluídos sem afetar significativamente o discurso musical. No exemplo da Fig. 4.19(c) é mostrada a exclusão da apojatura do compasso 22 da danza "Caricias del alma" do compositor Emilio Murillo Chapul (1880-1942).

Para ilustrar melhor o resultado da redução na extração da estrutura rítmica, além de mostrar como o padrão rítmico predefinido do gênero é refletido 


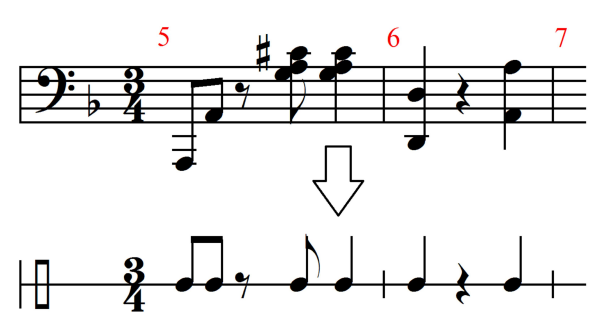

(a)

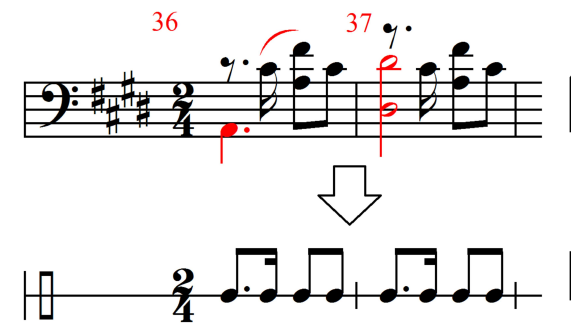

(b)

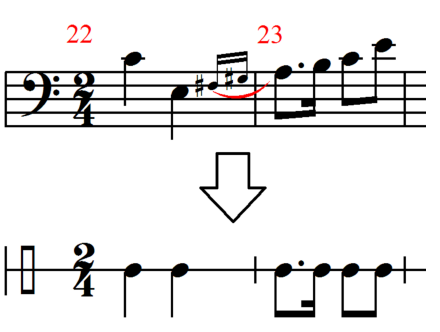

(c)

Figura 4.19: Reduções realizadas na extração da estrutura rítmica. (a) Redução de acordes; (b) Redução de retardos; (c) Redução de ornamentos.

no dígrafo quando gerado usando CRs, na Fig. 4.20 é mostrado o dígrafo obtido para uma amostra de cada um dos três gêneros musicais do banco de dados de músicas do folclore andino colombiano. O banco de dados é composto por 180 amostras, distribuídas assim: pasillo 61, bambuco 60 e danza ${ }^{17}$ 59. A Tabela C. 1 do Apêndice $\mathrm{C}$ apresenta os detalhes de cada amostra como: nome, compositor e gênero.

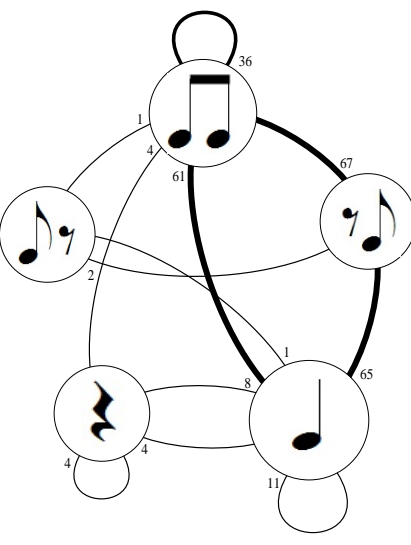

(a)

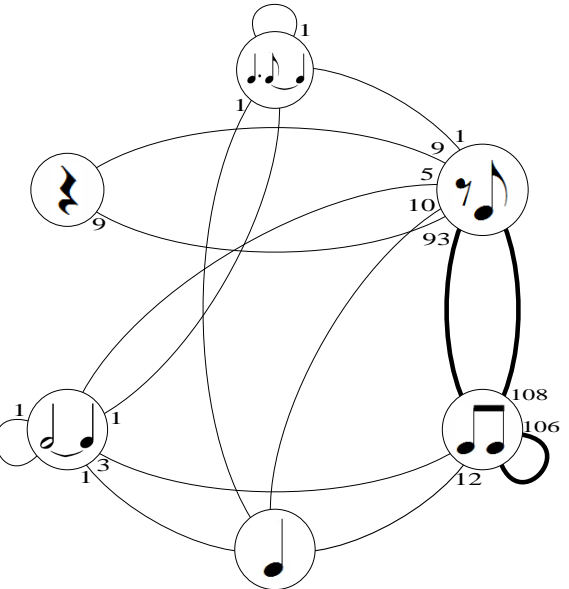

(b)

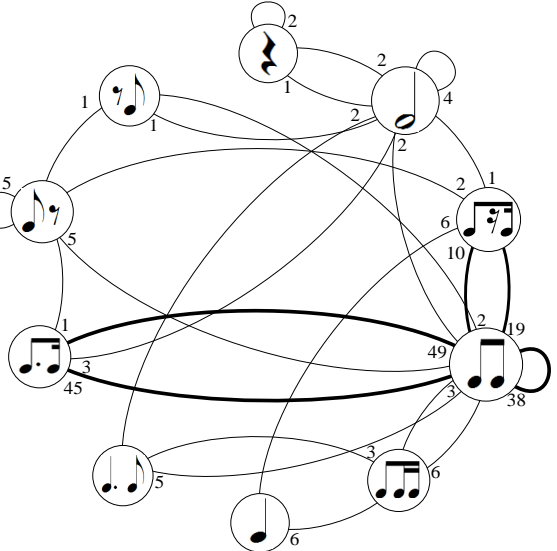

(c)

Figura 4.20: Exemplos de dígrafos da base de dados de três gêneros do folclore andino colombiano. (a) Pasillo - Hacia el calvario de Carlos Vieco; (b) Bambuco - Cuatro preguntas de Pedro Morales Pino; (c) Danza - Malvaloca de Luis A. Calvo.

\section{Banco de Dados de Gêneros Populares}

Este banco de dados é composto por 280 amostras de quatro gêneros populares, 70 amostras de cada gênero, sendo estes: blues, bossa nova, reggae e rock (Corrêa et al., 2010). Uma amostra deste banco de dados corresponde

17 Entre estes três gêneros a maior parte das músicas que podem ser encontradas corresponde ao gênero pasillo, enquanto para o gênero danza têm sido escritas poucas músicas, portanto o banco de dados foi criado conservando um equilíbrio entre o máximo número de músicas do gênero danza que foram encontradas e os outros gêneros 
à base percussiva da música, que para os gêneros blues, reggae e rock, é executada pela bateria. No processo de geração dos dígrafos as seguintes considerações preliminares devem ser consideradas.

1. Guantizar: O algoritmo codificador de CRs requer a pureza dos dados, uma vez que se forem usados dados não quantizados o algoritmo devolverá CRs diferentes das verdadeiras, o que alteraria a fidelidade da representação do ritmo e, consequentemente, a acurácia. Desta forma, uma etapa de quantização deve ser realizada para sincronizar os valores rítmicos. Alguns métodos para quantização podem ser encontrados em (Cemgil et al., 2000). Neste trabalho é usado um método baseado na diferença mínima entre os valores não quantizados e os valores exatos em unidades de batida. O método quantiza separadamente o vetor de onset e o vetor de durações. Desse modo, são necessários dois vetores de quantização, os quais contêm os valores exatos das posições onde devem ser aproximados os valores de entrada ${ }^{18}$.

2. Separar a matriz de notas de cada linha rítmica: A matriz de notas contém os valores rítmicos de todas as linhas de percussão da peça musical, por conseguinte, esta deve ser dividida em submatrizes, uma para cada linha rítmica. Esta divisão é feita sabendo que cada linha rítmica é executada por um instrumento particular, que por sua vez, é definido por um número MIDI. O instrumento predominante no banco de dados é a bateria, que é formada por vários instrumentos de percussão, portanto, criando várias linhas rítmicas. Nesta tese esses instrumentos são agrupados para formarem apenas três linhas rítmicas, no entanto, mais grupos podem ser usados dependendo dos requerimentos do objetivo. $\mathrm{Na}$ Tabela B. 2 os nomes e os números MIDI dos instrumentos que compõem em conjunto este instrumento, bem como os grupos de instrumentos designados em cada uma das três linhas, são apresentados ${ }^{19}$. É importante realçar que na fragmentação da matriz de notas pode acontecer que dois ou mais instrumentos do mesmo grupo sejam executados em uníssono. Isto afeta os passos seguintes e cria confusão na hora de extrair e codificar as CRs. Portanto, estas figuras devem ser apagadas da matriz de notas de cada grupo.

3. Preencher com códigos de silêncios de batida: Devido ao fato de algumas linhas começarem e/ou terminarem antes que outras, nesta etapa

\footnotetext{
${ }^{18}$ Nesta tese também foi desenvolvido um método para a estimação dos vetores de quantização

19 Neste banco de dados outros instrumentos de percussão podem ser encontrados em algumas músicas, geralmente em músicas de Bossa Nova, neste caso, esses instrumentos são adicionados em algum dos grupos estabelecidos na primeira coluna da Tabela B.2 segundo o seu timbre, posição dentro da partitura ou função dentro da base rítmica
} 


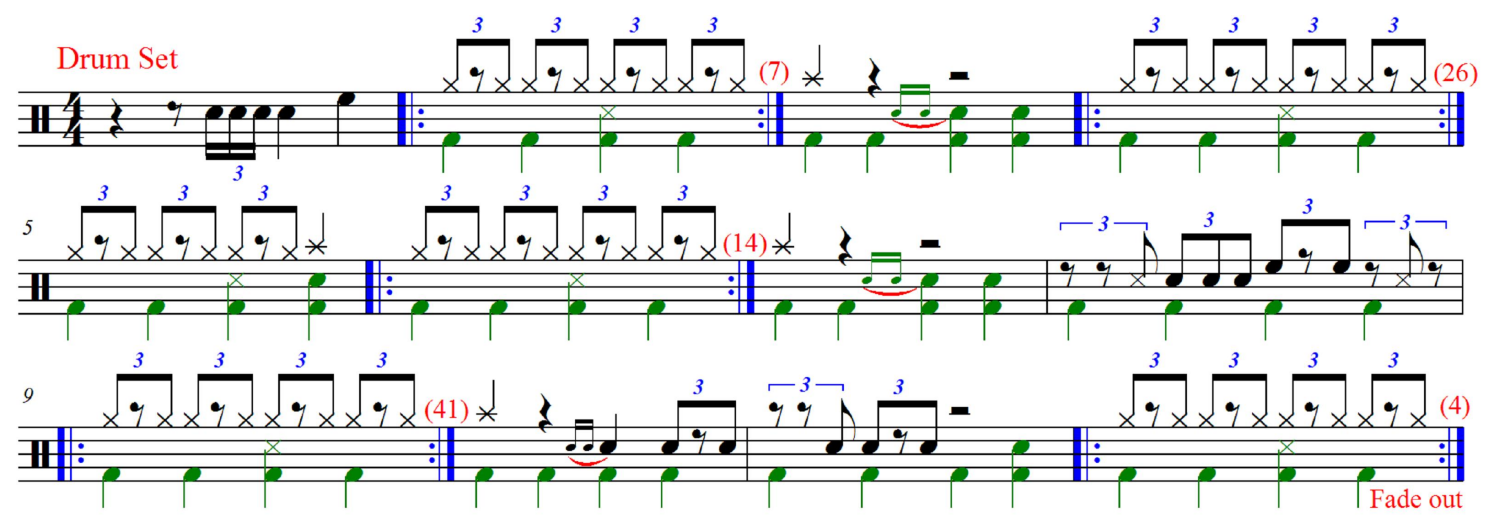

Figura 4.21: Partitura de bateria da canção Is This Love de Bob Marley.

devem ser preenchidos os vetores de códigos com códigos de silêncios de batida (igual a $\left[\begin{array}{llll}n & 0 & 0 & 1\end{array}\right]$ ), adicionados tantos códigos quanto forem necessários, de tal forma que todos os vetores tenham igual tamanho.

Para ilustrar melhor o resultado do pré-processamento efetuado na geração dos dígrafos usando sequências de bateria, na Fig. 4.21 é mostrada a partitura de bateria da canção Is This Love de Bob Marley e na Fig. 4.22(c) o seu respectivo dígrafo. Note-se que nos compassos 3 e 10 há uma apojatura que não foi considerada na geração do dígrafo. Além do mais, a Fig. 4.22 também apresenta o dígrafo obtido para uma amostra de cada um dos quatro gêneros musicais do banco de dados de músicas populares.

\subsubsection{Simulações Computacionais}

Com o intuito de comparar o efeito de incluir os três fatores (CRs, relevância e medidas topológicas) no desempenho da metodologia de identificação de gêneros musicais, são descritas as metodologias resultantes de adicionar estes três fatores de maneira individual e em conjunto, e comparadas duas destas. Na Tabela 4.14 são mostrados os 8 tipos de metodologias de identificação resultantes da ausência (0) ou presença (1) de cada um dos três parâmetros. As oito metodologias são nomeadas com a letra $\mathrm{C}$ e numeradas de 1 até 8 (chamado identificador, Id.), por exemplo, a metodologia proposta nesta tese é a C8, porque usa simultaneamente CRs, relevância de comunidades e medidas topológicas. A última coluna da tabela contém uma breve descrição de cada metodologia. Note-se que o uso da medida de relevância somente tem sentido quando forem usadas CRs. A razão principal disso é que as figuras rítmicas quando separadas do seu grupo criam uma ambiguidade devido ao fato de uma figura rítmica poder pertencer a várias CRs diferentes, e esta ambiguidade é refletida nas comunidades do dígrafo, dificultando a diferenciação dos diferentes tipos de padrões (Coca \& Zhao, 2014d). Em consequência, as 


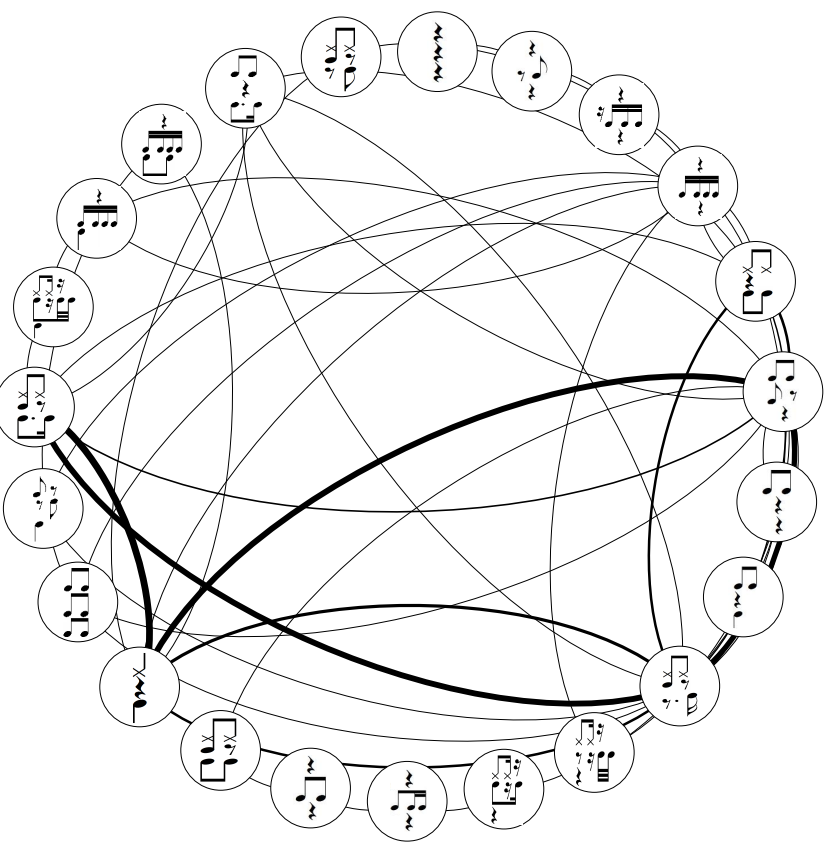

(a)

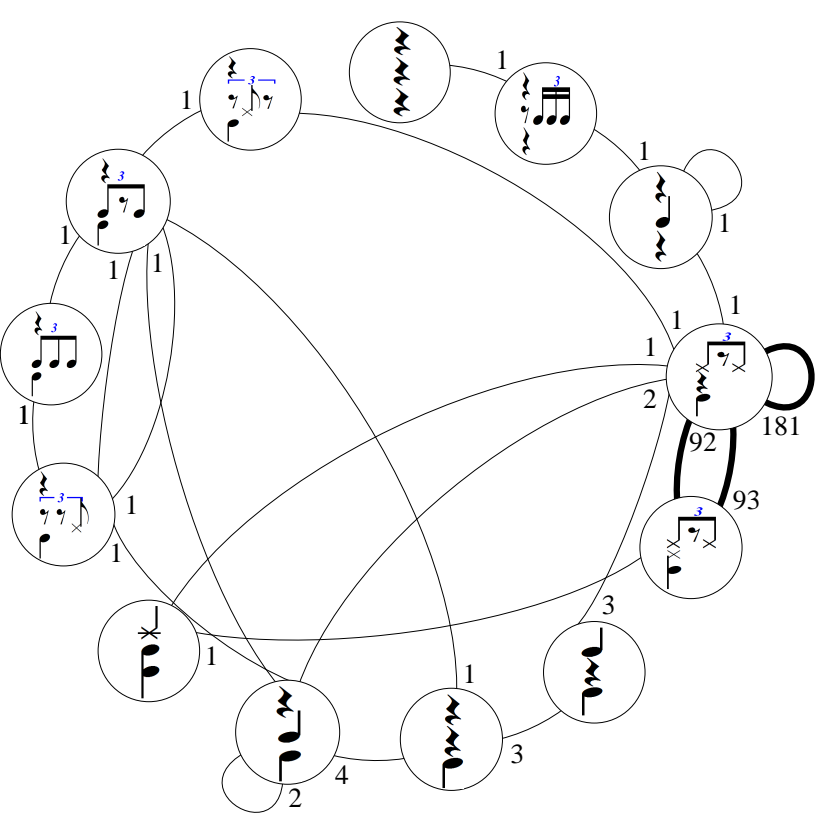

(c)

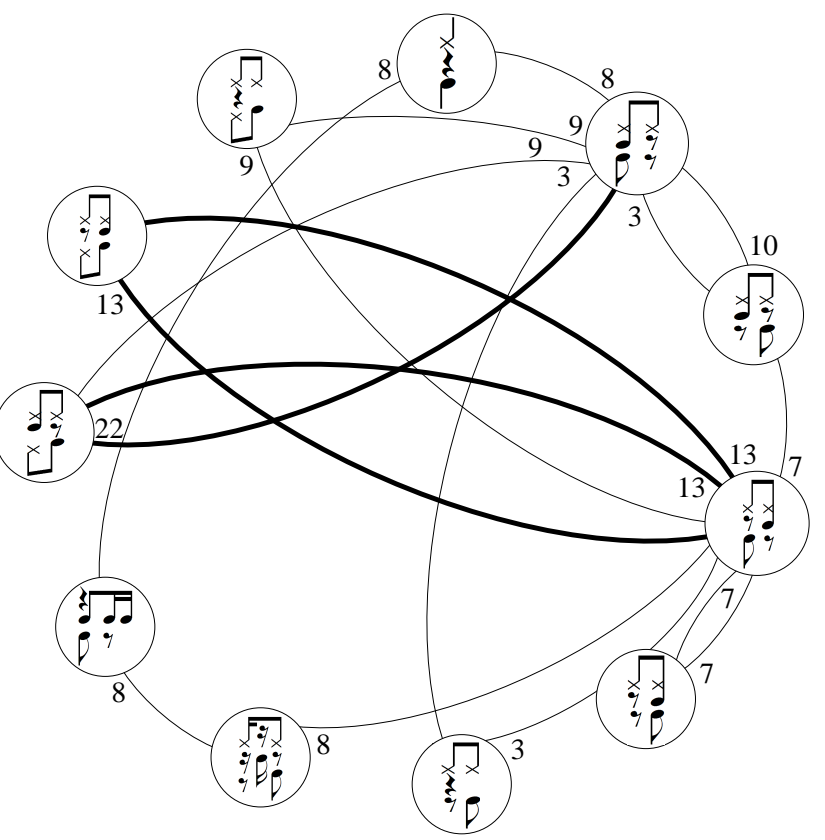

(b)

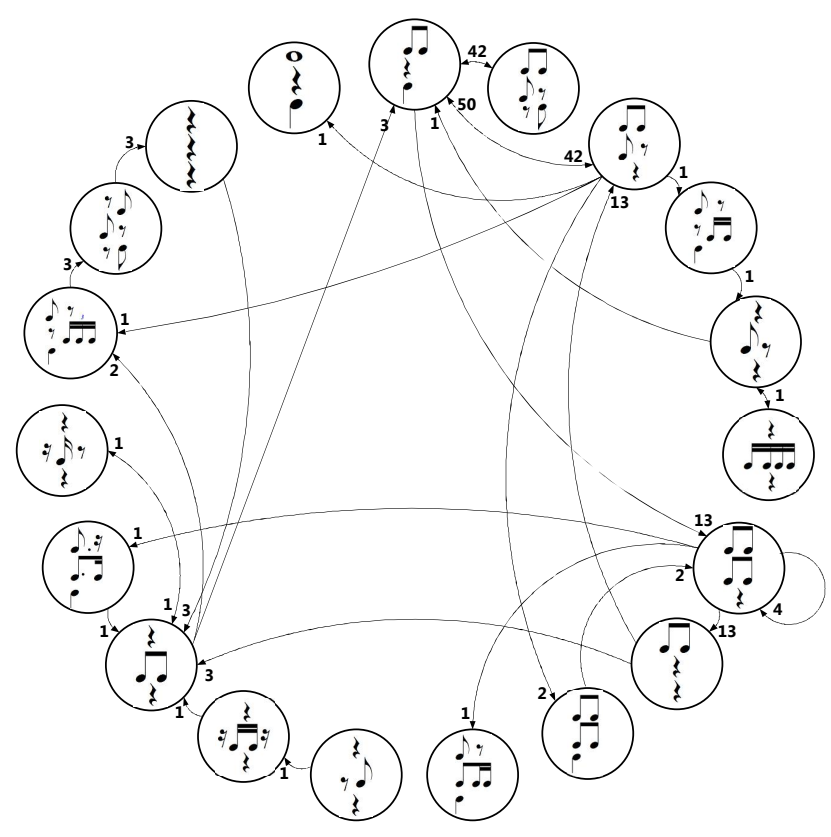

(d)

Figura 4.22: Dígrafos de exemplos do banco de dados de quatro gêneros populares. (a) Blues - The Thrill Is Gone de BB King; (b) Bossa Nova - Fotografia de Tom Jobim; (c) Reggae - Is This Love de Bob Marley; (d) Rock - From Me to You de The Beatles. 
Tabela 4.14: Metodologias para a identificação de gêneros musicais resultantes da ausência (0) ou presença (1) de CRs, relevância de comunidades e medidas topológicas de redes complexas.

\begin{tabular}{c|c|c|c|c}
\hline Id. & CRs & Relevância & Medidas & Descrição \\
\hline \hline C1 & 0 & 0 & 0 & Metodologia de (Corrêa et al., 2010) \\
C2 & 0 & 0 & 1 & C1 com medidas \\
\hline C5 & 0 & 1 & 0 & - \\
C4 & 0 & 1 & 1 & - \\
\hline C5 & 1 & 0 & 0 & C1 com CRs \\
C6 & 1 & 0 & 1 & C8 sem relevância \\
C7 & 1 & 1 & 0 & Metodidas \\
C8 & 1 & 1 & 1 & gia proposta nesta tese \\
\hline
\end{tabular}

metodologias de classificação C3 e C4 não serão estudadas.

A seguir são apresentados os resultados obtidos com os dois bancos de dados e usando as duas abordagens de aprendizado.

\section{Banco de dados 1: Gêneros com Base Rítmica não Percussiva}

A somatória total de CRs de todas as amostras é 1543, que ao todo formam um conjunto de 146 nós, então para todas as metodologias que usam CRs (C5 a C8), a matriz de adjacência de cada dígrafo é redimensionada a este último valor, obtendo uma matriz de adjacência de $146 \times 146$. As metodologias C5 e C7, ao não usarem medidas topológicas na etapa de mineração, o vetor de características é formado juntando todas as linhas da matriz de adjacência em uma linha só, obtendo para cada amostra um vetor de 21316 colunas (igual a $146^{2}$ ). Esta dimensão se faz impraticável na hora de aplicar PCA (matriz de atributos de $180 \times 21316$ ), paralisando totalmente o sistema, portanto, estas duas metodologias (C5 e C7) são também descartadas. Os dígrafos das metodologias que usam FRIs ( $\mathrm{C} 1$ e C2) foram de igual forma redimensionados a 32 nós, que é o número total de figuras únicas. Embora este valor seja aceitável para este banco de dados específico, ele cresce exponencialmente e poderia trazer uma consequência semelhante à da metodologia C5 e C7 quando usados bancos de dados com grande quantidade de FRIs diferentes. Portanto, nesta tese apenas serão comparadas as metodologias C6 e C8.

A Fig.4.23 apresenta o valor de máxima relevância de cada amostra, a linha sólida inferior é o mínimo desses valores (minimax), portanto, $\alpha=0.25$.

Para a etapa de mineração foram selecionadas as medidas topológicas mais adequadas para caracterizar o tipo de redes do banco de dados, portanto, para esta seleção foi considerado que as medidas devem caracterizar redes direcionadas, ponderadas, cíclicas e de pequeno porte, e que além de serem congruentes com as características anteriores, também devem ser globais. Em 


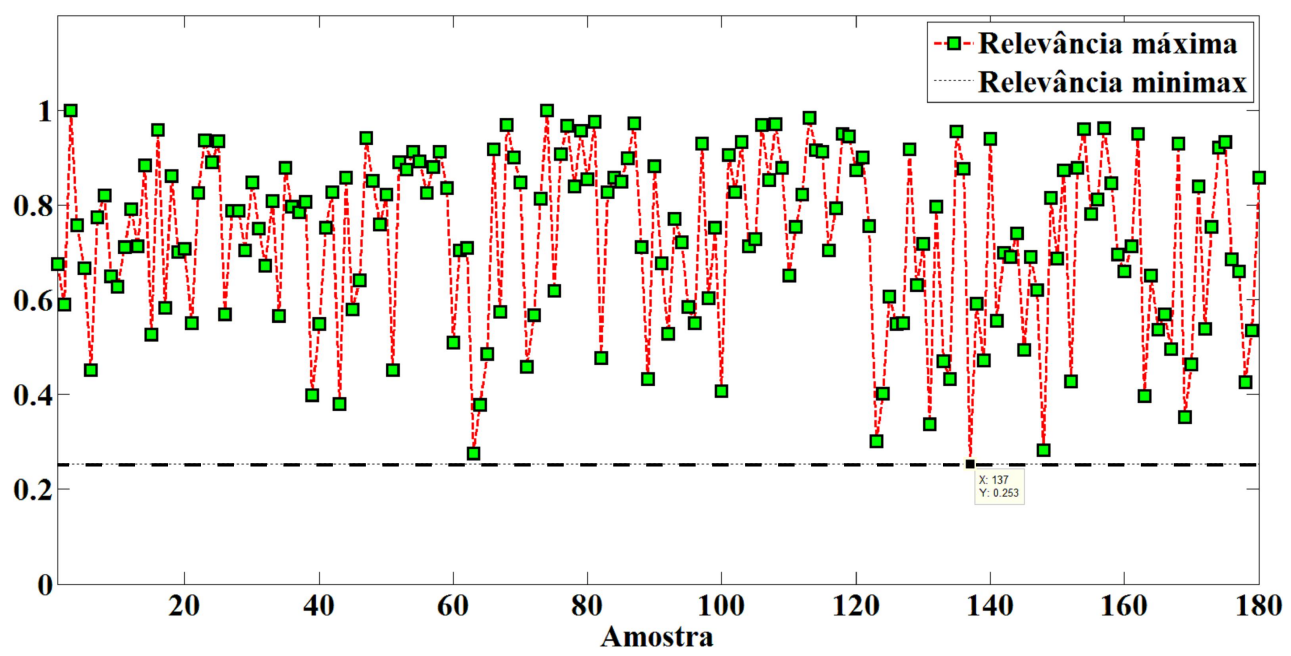

Figura 4.23: Máximo valor de relevância das amostras do banco de dados de músicas folclóricas.

concordância com estes critérios, foram escolhidas 14 medidas ${ }^{20}$ abrangendo as quatro categorias de medidas topológicas estudadas na Seção 2.1.1, obtendo os seguintes quatro conjuntos:

1. Conjunto (D): Contém 4 medidas de integração: índice de Wiener (IW), raio $(r)$, diâmetro $(\Delta)$ e média harmônica $(h)$;

2. Conjunto (G): Contém 4 medidas de segregação: média do coeficiente de aglomeração ponderado e direcionado $\left(\tilde{C}^{D}\right)$, coeficiente cíclico direcionado $(\Theta)$, reciprocidade $\left(r_{e}\right)$ e proporção de autoconexão $\left(p_{a}\right)$;

3. Conjunto (C): Contém 4 medidas de resiliência e medidas básicas: grau médio $(\bar{k})$, força média $(\bar{s})$, coeficiente de Pearson $(\rho)$ e expoente da lei de potência $(\gamma)$;

4. Conjunto (O): Contém 2 medida de centralidade: média do coeficiente de participação de entrada $\left(\mu\left(P^{i n}\right)\right)$ e de saída $\left(\mu\left(P^{o u t}\right)\right)$.

Com o intuito de reduzir possíveis redundâncias e visualizar os dados no espaço de atributos também foi aplicada PCA. A Fig. 4.24 apresenta os novos três componentes principais da metodologia C8, na Fig. 4.24(a) o primeiro

\footnotetext{
${ }^{20}$ Observações: a distância média $(\lambda)$ foi descartada porque não é apropriada para redes com nós isolados e a eficiência global $(E)$ por ser recíproca da média harmônica $(h)$, os coeficientes de Pearson da distribuição conjunta de graus direcionada (in/in,in/out,out/in,out/out) e o expoente da lei de potência do grau de entrada/saída foram descartados por não serem adequados para o tamanho da rede depurada, e os coeficientes de aglomeração direcionados segundo o tipo de triângulo porque nem sempre existem estes tipos de triângulos na redes, impedindo fazer um boa comparação. Outras medidas foram estudadas como o coeficiente clube de ricos e o índice de acoplamento (matching index), mas foram também descartadas por serem locais. Contudo, o coeficiente de participação é uma medida local, porém foi globalizada usando a média. A fração de autoconexão $\left(p_{a}\right)$, mesmo não sendo uma medida definida na literatura, foi considerada porque é uma característica presente nos padrões rítmicos estudados.
} 
componente contra o segundo, na Fig. 4.24(b) o primeiro contra o terceiro e na Fig. 4.24(c) a porcentagem de variância acumulada e explicada. Esta última aponta que são necessários apenas 6 componentes para atingir o $75 \%$ da variância explicada. Estas figuras também revelam que existe uma sobreposição da classe bambuco com as demais classes.

Visando determinar a combinação de características que produz a máxima acurácia, foi variado o limiar de relevância entre 0 e 0.25 e foi aplicada a metodologia C8 usando as 15 diferentes combinações de conjuntos de características e a técnica de reamostragem validação cruzada 10 -fold repetida 10 vezes. A Tabela 4.15 apresenta a porcentagem de acurácia inicial (acurácia em $\alpha=0$ ), a porcentagem de acurácia máxima ${ }^{21}$ (acurácia em $\hat{\alpha}$ ), o incremento de acurácia (coluna Dif.) e o número total de nós na acurácia máxima. Notese que a combinação CG não aumentou a acurácia, pelo contrário diminuiu a acurácia em $7.11 \%$.

A combinação de características que produz a maior acurácia é DGCO, na qual a acurácia em $\alpha=0$ passou de $65.72 \%$ com 146 nós para $69.11 \%$ com 139 nós em $\alpha=0.03$ (limiar ótimo $\hat{\alpha}$ ), obtendo um ganho de acurácia de $3.39 \%$ com um número menor de nós, ou seja, a dimensão do dígrafo diminuiu aproximadamente $4.8 \%$, enquanto a acurácia aumentou $5.15 \%$. Além do mais, o número de CRs passou de 1543 em $\alpha=0$ a 1476 em $\alpha=0.03$, ou seja foi necessária a exclusão de 67 CRs para aumentar a acurácia.

A Fig. 4.25 mostra o resultado das melhores combinações de conjuntos de características, o conjunto que produz a maior diferença (DGO)(Fig. 4.25(c)) e o que produz a maior acurácia (DGCO)(Fig. 4.25(d)), contrastadas com a evolução do número total de CRs (Fig. 4.25(a)) e o número total de nós (Fig. 4.25(b)). As barras nas figuras representam o desvio padrão.

Na Fig. 4.25(d) é possível enxergar que até o valor $\hat{\alpha}$ o número de nós diminui, mas a acurácia aumenta, e a partir deste ponto o número de nós continua diminuído junto com a acurácia. Isso acontece porque até antes do ponto $\hat{\alpha}$ as redes depuradas ainda contêm padrões secundários e, portanto, as redes ainda podem ser filtradas, mas no ponto $\hat{\alpha}$ as redes contêm maior proporção de padrões principais que concentram informação mais importante para discriminar o gênero e, consequentemente, influindo no aumento da acurácia. A partir do ponto $\hat{\alpha}$ a acurácia diminui porque o gênero musical é imperfeitamente representado nos dígrafos.

O resultado anterior sugere que as características que mais discriminam os gêneros encontram-se dentro dos quatro conjuntos de medidas, no entanto, com o intuito de encontrar as características exatas dentro de cada um desses conjuntos evitando a busca exaustiva ${ }^{22}$, foi aplicado o algoritmo de seleção

\footnotetext{
${ }^{21}$ Se não houver um incremento de acurácia será escolhido o valor mínimo

${ }^{22} \mathrm{O}$ total de combinações de características é $2^{14}-1=16383$
} 


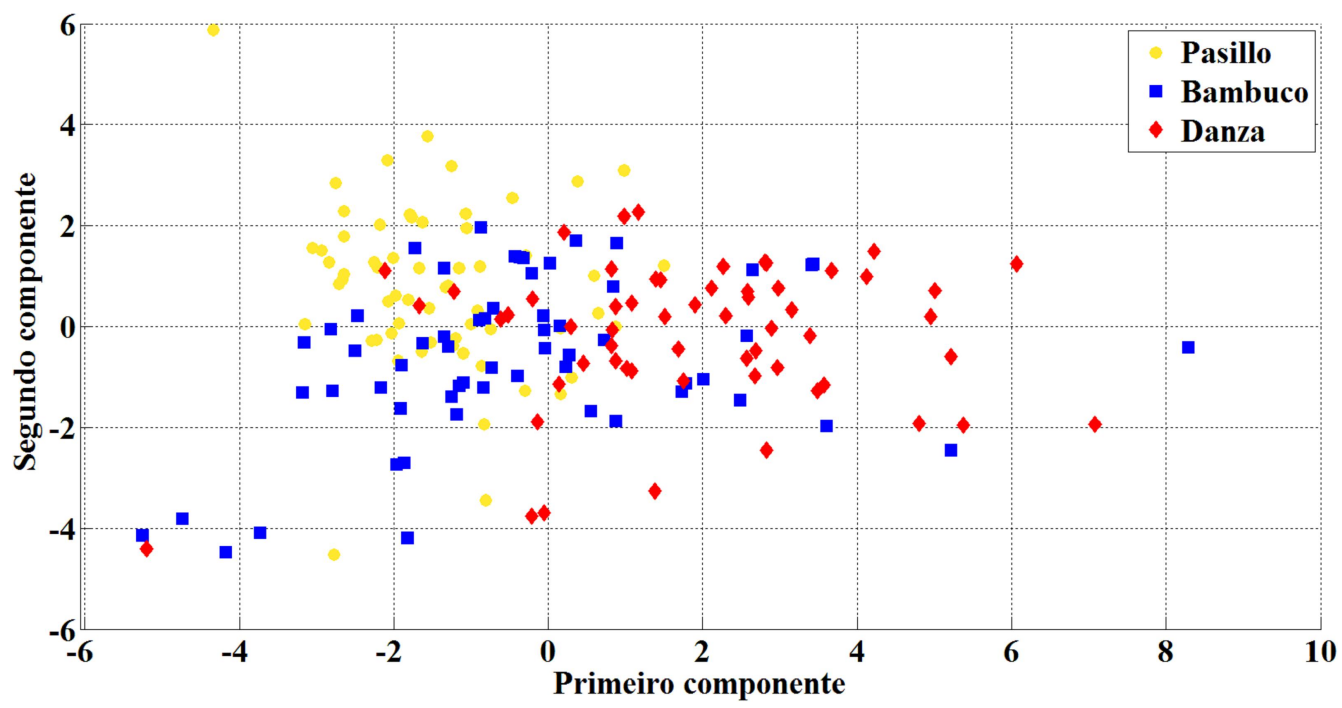

(a)

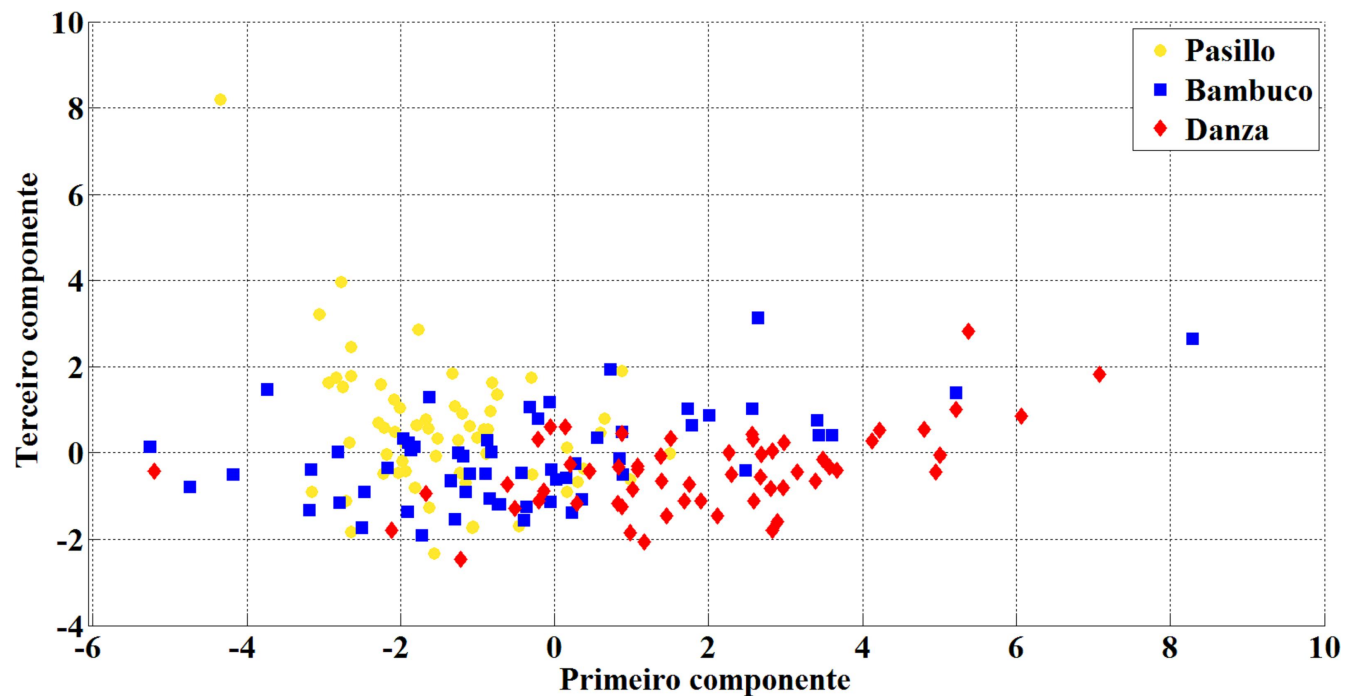

(b)

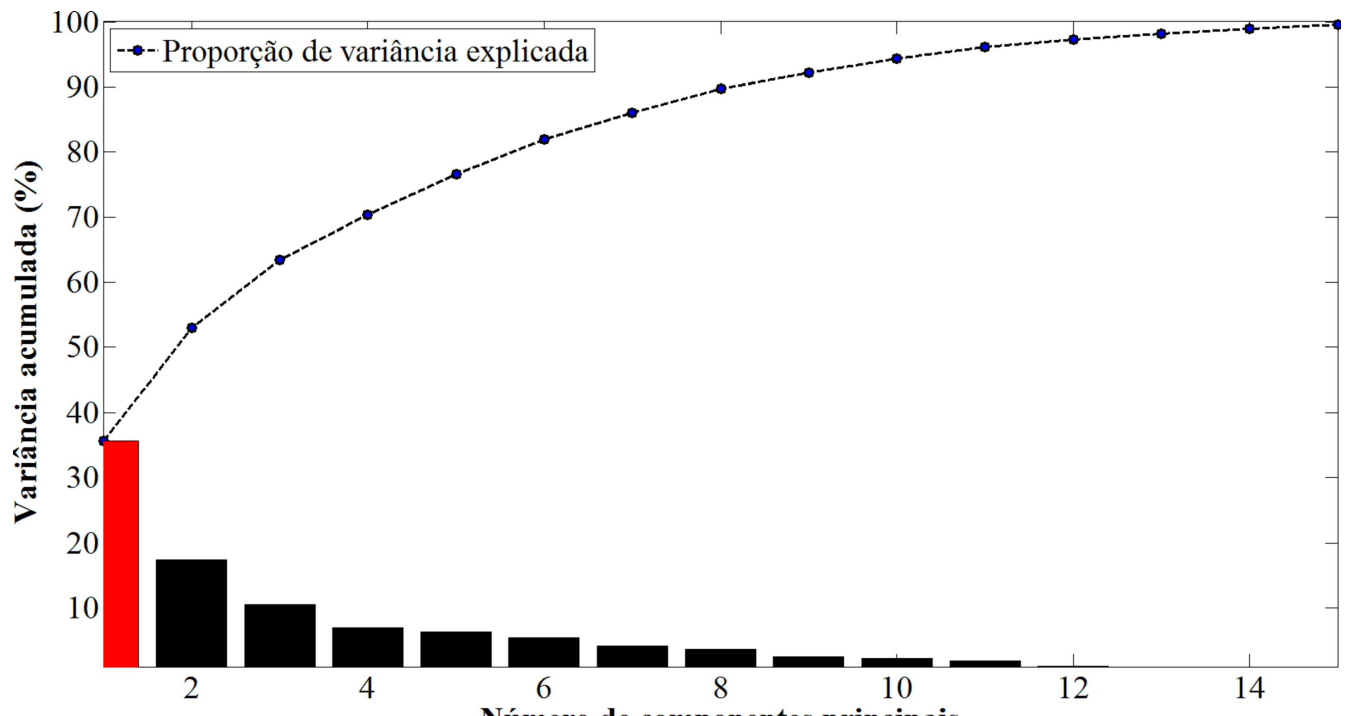

(c)

Figura 4.24: As novas três características obtidas com PCA para a metodologia C8. (a) primeira vs. segunda componente; (b) primeira vs. terceira componente; (c) porcentagem de variância acumulada e explicada. 


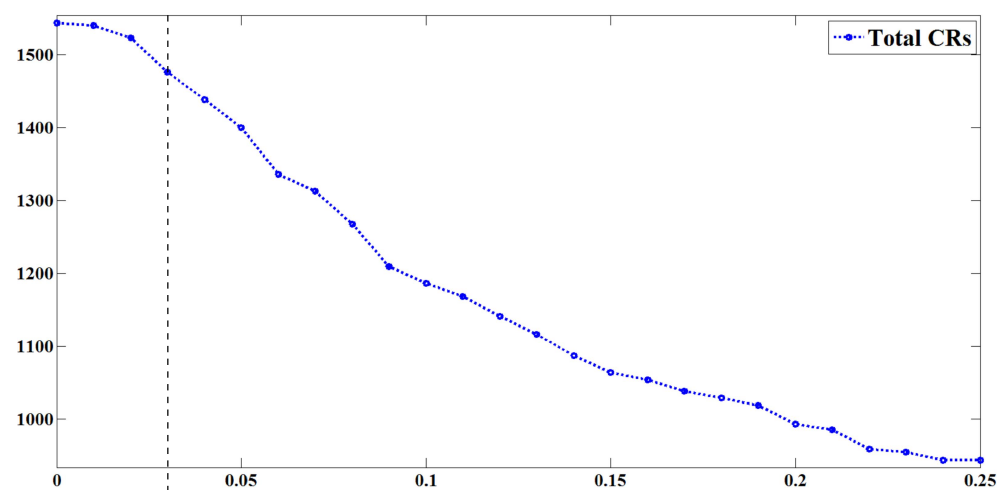

(a)

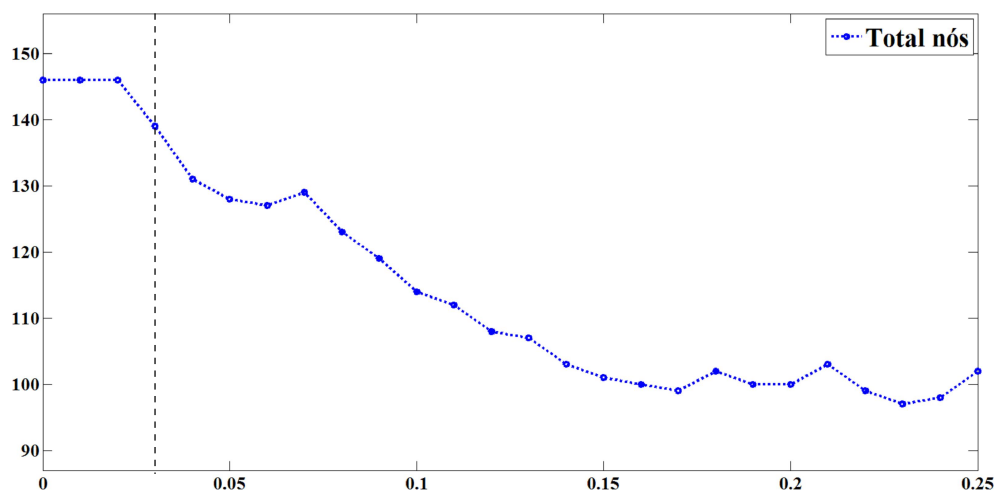

(b)

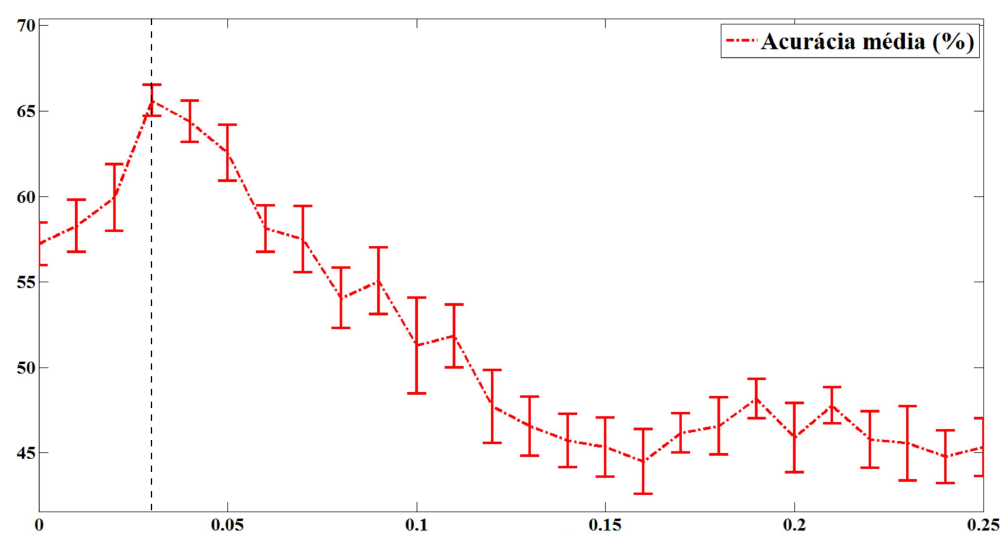

(c)

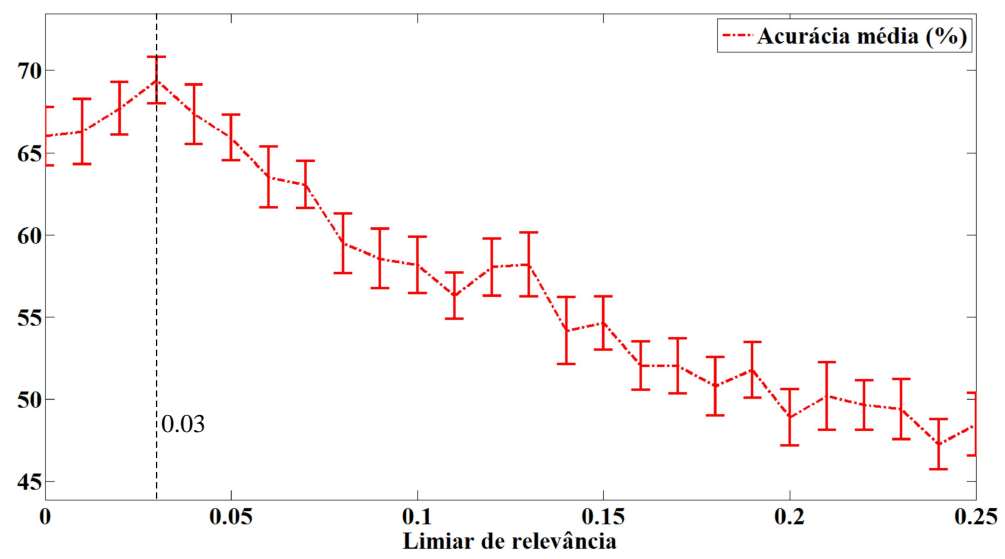

(d)

Figura 4.25: Evolução da rede e da acurácia quando variado o limiar de relevância na metodologia C8 usando o banco de dados de músicas folclóricas. (a) Número de CRs; (b) Número de nós; (c) Evolução da acurácia média usando o conjunto DGO; (d) Evolução da acurácia média usando o conjunto DGCO. 
Tabela 4.15: Porcentagem de acurácia inicial, máxima, diferença de acurácia (Dif.) e número de nós usando a metodologia C8, todas as combinações de conjuntos de características e o banco de dados de músicas folclóricas.

\begin{tabular}{c|c|c|c|c||c|c|c|c|c}
\hline \multirow{2}{*}{ Conj. } & \multicolumn{4}{|c||}{ Acurácia (\%) } & \multicolumn{4}{|c}{ Acurácia (\%) } \\
\cline { 2 - 4 } \cline { 6 - 9 } & Inicial & Máxima & Dif. & Nós & Conj. & Inicial & Máxima & Dif. & Nós \\
\hline \hline D & 51.44 & 55.16 & 3.71 & 139 & CO & 63.38 & 64.94 & 1.56 & 146 \\
C & 55.88 & 58.66 & 2.78 & 123 & GO & 58.16 & 61.83 & 3.67 & 131 \\
G & 55.05 & 56.22 & 1.17 & 146 & DCG & 60.61 & 64.33 & 3.72 & 139 \\
O & 50.72 & 53.05 & 2.33 & 114 & DCO & 65.16 & 67.72 & 2.56 & 139 \\
DC & 57.94 & 62.22 & 4.28 & 139 & DGO & 58.33 & 65.44 & 7.11 & 139 \\
DG & 52.66 & 58.72 & 6.06 & 139 & CGO & 63.16 & 65.44 & 2.28 & 139 \\
DO & 57.77 & 64.11 & 6.34 & 139 & DGCO & 65.72 & 69.11 & 3.39 & 139 \\
CG & 60.38 & 53.27 & -7.11 & 98 & & & & & \\
\hline
\end{tabular}

Tabela 4.16: Coeficiente kappa $(\kappa)$, variância de kappa (var $(\kappa)$ ) e porcentagem de acurácia (Ac.) usando resubstituição e validação cruzada 10-fold.

\begin{tabular}{c|ccc|ccc}
\hline \multirow{2}{*}{ Tipo de reamostragem } & \multicolumn{3}{|c|}{ C6 } & \multicolumn{3}{c}{ C8 } \\
\cline { 2 - 7 } & $\kappa$ & $\operatorname{var}(\kappa)$ & Ac. & $\kappa$ & $\operatorname{var}(\kappa)$ & Ac. \\
\hline \hline Resubstituição & 0.76 & 0.01 & $85 \%$ & 0.77 & 0.00 & $86 \%$ \\
Validação cruzada 10-folds & 0.49 & 0.03 & $66 \%$ & 0.55 & 0.03 & $70 \%$ \\
\hline
\end{tabular}

sequencial de características (SFS) usando validação cruzada 10-fold, fixando o limiar de relevância no valor ótimo de $(\alpha=0.03)$ e adotando como função critério a minimização do erro de classificação. O experimento foi repetido 1000 vezes e foi calculada a porcentagem de seleção de cada medida e a média e o desvio padrão do valor de critério de seleção, cujos resultados são mostrados na Fig. 4.26(a) e 4.26(b), respectivamente. As medidas que foram selecionadas mais do $50 \%$ das vezes são: raio $(r)$, diâmetro $(\Delta)$, coeficiente de aglomeração $\left(\tilde{C}^{D}\right)$, reciprocidade $r_{e}$ e média do coeficiente de participação de entrada $\left(\mu\left(P^{i n}\right)\right)$. Correspondendo estas a duas medidas de integração (conjunto D), duas medidas de segregação (conjunto C) e uma medida de centralidade (conjunto $\mathrm{O}$ ). Note-se que nenhuma medida de resiliência (conjunto $\mathrm{G}$ ) foi selecionada mais de $50 \%$ das vezes. A evolução da acurácia variando o limiar de relevância e usando o conjunto de características mais discriminativas é mostrada na Fig. 4.26(c). O resultado é similar ao obtido com o conjunto CDGO.

A Tabela 4.16 apresenta o coeficiente kappa $(\kappa)$, a variância de kappa $(\operatorname{var}(\kappa))$ e a porcentagem de acurácia (Ac.) das metodologias de análise (C6 e C8) usando as técnicas de reamostragem resubstituição e validação cruzada 10-fold repetida 10 vezes.

Entre as duas metodologias de análise os melhores resultados referentes ao coeficiente $\kappa$ e à porcentagem de acurácia são obtidos por C8. Quando comparados, em termos gerais, pode-se dizer que o desempenho melhorou 


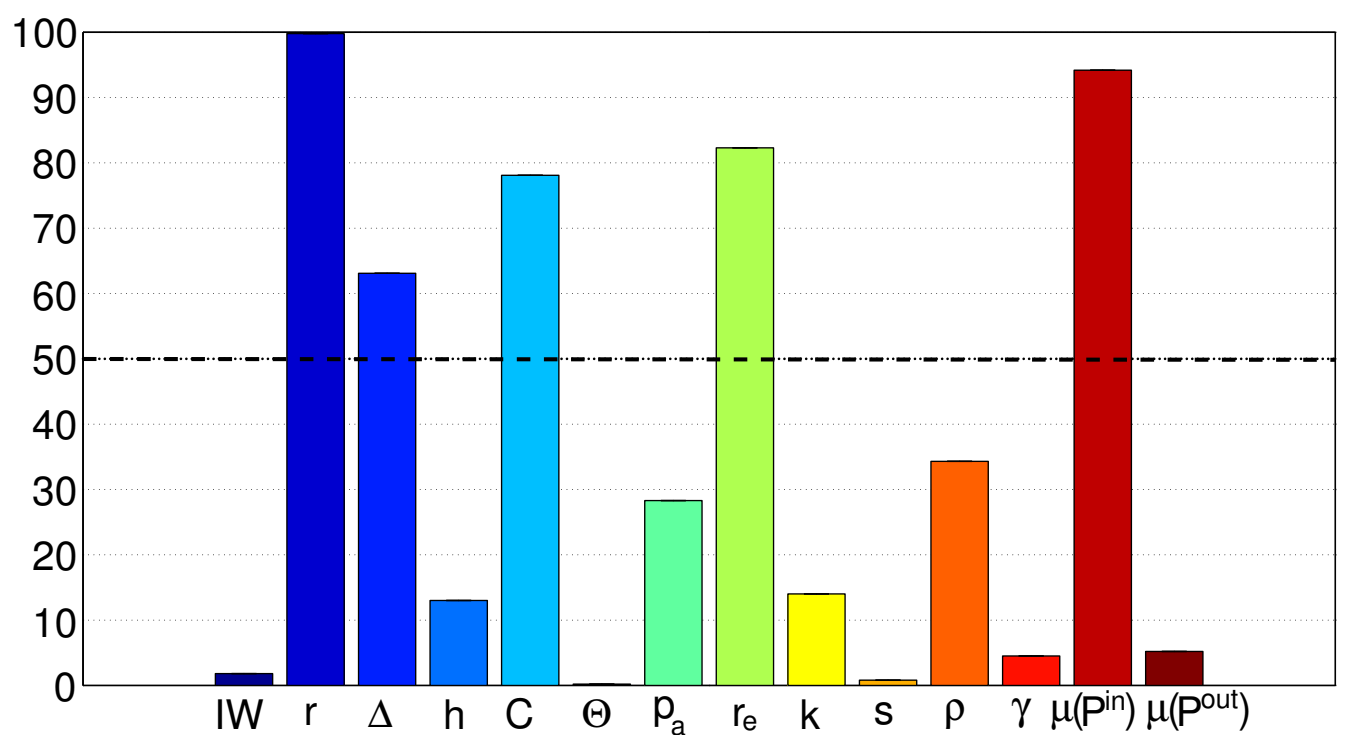

(a)

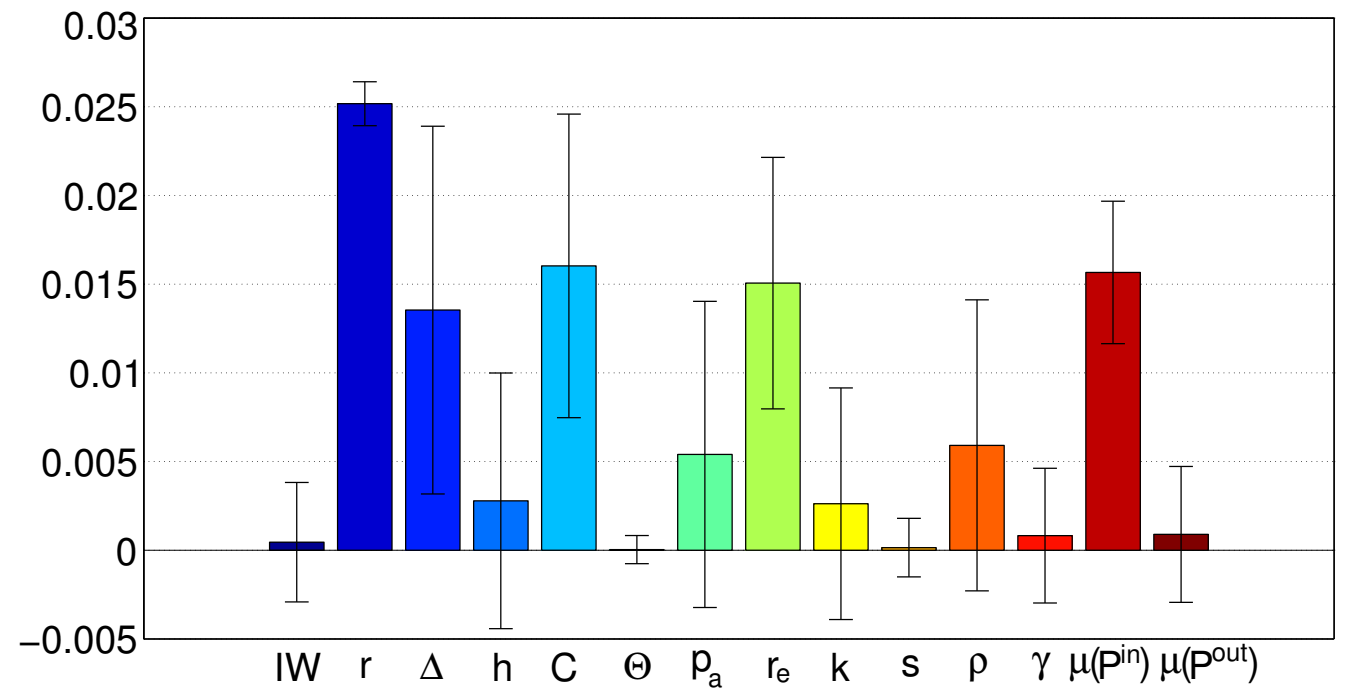

(b)

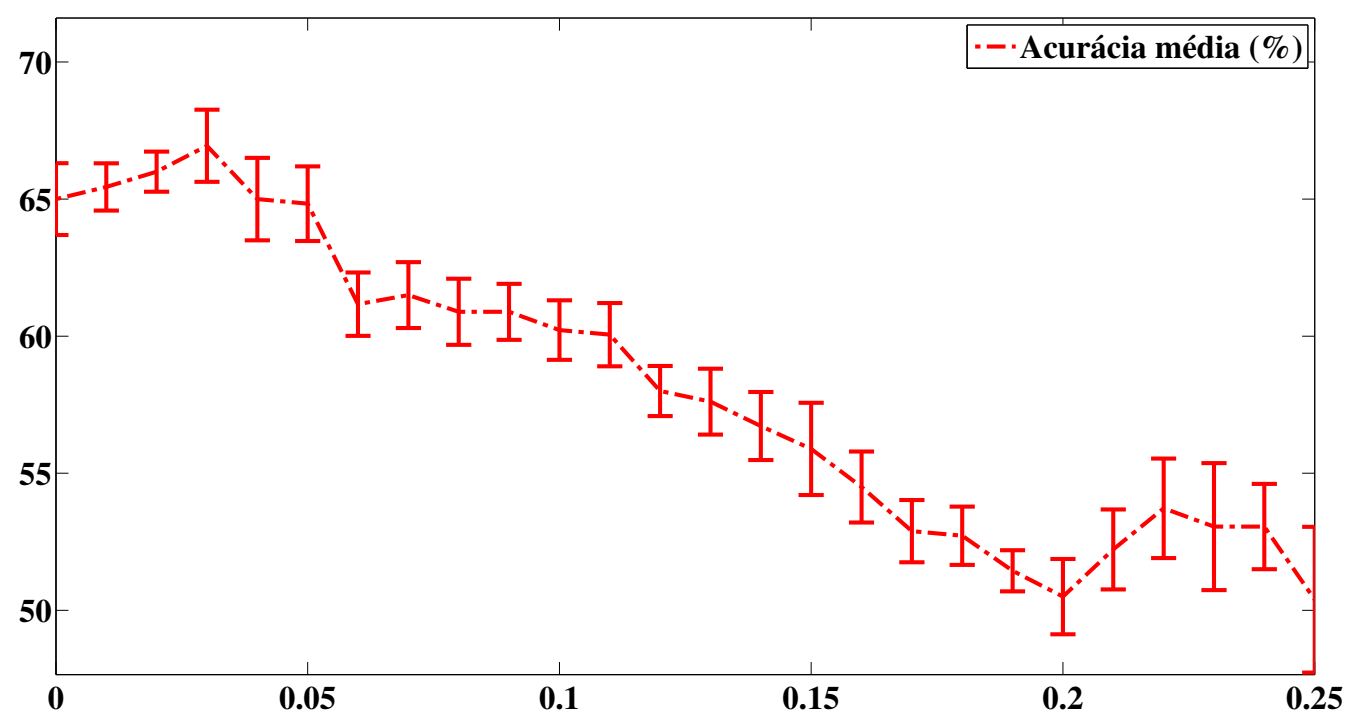

(c)

Figura 4.26: Resultado obtido com o algoritmo de seleção sequencial de características (SFS). (a) Porcentagem de seleção de cada medida; (b) Média e desvio do critério de seleção; (c) Evolução da acurácia média usando as características encontradas. 
Tabela 4.17: Coeficiente kappa $(\kappa)$, variância de kappa (var $(\kappa)$ ) e porcentagem de acurácia (Ac.) usando hold-out e variando a porcentagem de amostras do conjunto de treino entre $30 \%$ e $90 \%$.

\begin{tabular}{c|ccc|ccc}
\hline \multirow{2}{*}{ Hold-out } & \multicolumn{3}{|c|}{ C6 } & \multicolumn{3}{c}{ C8 } \\
\cline { 2 - 7 } & $\kappa$ & $\operatorname{var}(\kappa)$ & Ac. & $\kappa$ & $\operatorname{var}(\kappa)$ & Ac. \\
\hline \hline $30 \%-70 \%$ & 0.44 & 0.00 & $62 \%$ & 0.50 & 0.00 & $66 \%$ \\
$40 \%-60 \%$ & 0.43 & 0.00 & $62 \%$ & 0.57 & 0.00 & $71 \%$ \\
$50 \%-50 \%$ & 0.48 & 0.01 & $66 \%$ & 0.52 & 0.01 & $68 \%$ \\
$60 \%-40 \%$ & 0.44 & 0.01 & $63 \%$ & 0.58 & 0.01 & $72 \%$ \\
$70 \%-30 \%$ & 0.47 & 0.01 & $65 \%$ & 0.56 & 0.01 & $70 \%$ \\
$80 \%-20 \%$ & 0.50 & 0.01 & $67 \%$ & 0.75 & 0.01 & $83 \%$ \\
$90 \%-10 \%$ & 0.42 & 0.03 & $61 \%$ & 0.67 & 0.02 & $78 \%$ \\
\hline Média & 0.35 & 0.01 & $63.71 \%$ & 0.59 & 0.01 & $72.57 \%$ \\
Desvio & 0.11 & 0.01 & $2.29 \%$ & 0.09 & 0.01 & $5.94 \%$ \\
\hline
\end{tabular}

consideravelmente com o acréscimo dos três fatores juntos. Contudo, visando fazer uma comparação objetivamente, foi aplicado um teste de significância estatística para determinar a existência de uma diferença significativa em conformidade com o coeficiente $\kappa$. Os resultados obtidos usando hold-out e variando a porcentagem de amostras do conjunto de treino de $30 \%$ até $90 \%$ são detalhados na Tabela 4.17. Estes valores de $\kappa$ foram usados para testar a diferença de médias entre as duas metodologias $\left(H_{0}\right.$, hipótese nula da Eq. (2.69)).

A diferença de médias de $\kappa$ entre as duas metodologias foi testada usando a estatística t-student para o nível de significância 0.05 com 6 graus de liberdade (7 amostras de $\kappa$ ). Ao 95\% de significância o $T$ calculado (Eq. (2.70)) deve ser menor que -1.94. Como resultado, tem-se que o valor de $T$ calculado é igual a -4.33 , portanto a hipótese nula $H_{0}$ é rejeitada a este nível de significância, isto é, a média de $\kappa$ de C8 é estatisticamente maior que a de C6.

Os resultados do teste revelam que existe diferença significativa entre C8 e C6, portanto, o desempenho de C8 é significativamente melhorado pela presença da medida de relevância. Este fato explica a importância dos três fatores atuando de maneira conjunta. A matriz de confusão obtida com cada uma das metodologias de estudo usando resubstituição ${ }^{23}$ são ilustradas na Tabela 4.18. Estas matrizes revelam que a classe pasillo foi a classe com menos falsos negativos $(F N)$, enquanto a classe danza foi a classe com menos falsos positivos $(F P)$. No entanto, uma análise mais detalhada sobre o comportamento das metodologias é feita através de taxas de desempenho.

A Tabela 4.19 apresenta as taxas de desempenho, bem como a média e o desvio padrão de cada uma destas, resultantes da classificação usando cada uma das metodologia de estudo e a técnica de reamostragem resubstituição.

${ }^{23}$ Para incluir todas as amostras no conjunto de teste 
Tabela 4.18: Matriz de confusão das metodologias C6 e C8 usando resubstituição.

\begin{tabular}{c|ccc|ccc}
\hline & \multicolumn{3}{|c|}{ C6 } & \multicolumn{3}{c}{ C8 } \\
\cline { 2 - 7 } Classes & Pasillo Bambuco & Danza & Pasillo & Bambuco Danza \\
\hline \hline Pasillo & 60 & 12 & 3 & 60 & 11 & 4 \\
Bambuco & 0 & 39 & 2 & 0 & 43 & 4 \\
Danza & 1 & 9 & 54 & 1 & 6 & 51 \\
\hline
\end{tabular}

Tabela 4.19: Taxas de desempenho das duas metodologias de análise usando resubstituição.

\begin{tabular}{c|l|c|c|c|c|c}
\hline Metodologia & Classe & $S$ & $E$ & $P$ & $V P N$ & F-score \\
\hline \hline \multirow{5}{*}{ C6 } & Pasillo & 0.98 & 0.87 & 0.80 & 0.99 & 0.88 \\
& Bambuco & 0.65 & 0.98 & 0.95 & 0.85 & 0.77 \\
& Danza & 0.92 & 0.92 & 0.84 & 0.96 & 0.88 \\
\cline { 2 - 7 } & Média & 0.85 & 0.92 & 0.86 & 0.93 & 0.84 \\
& Desvío & 0.18 & 0.06 & 0.08 & 0.07 & 0.06 \\
\hline \hline \multirow{5}{*}{ C8 } & Pasillo & 0.98 & 0.87 & 0.80 & 0.99 & 0.88 \\
& Bambuco & 0.72 & 0.97 & 0.91 & 0.87 & 0.80 \\
& Danza & 0.86 & 0.94 & 0.88 & 0.93 & 0.87 \\
\cline { 2 - 7 } & Média & 0.85 & 0.93 & 0.86 & 0.93 & 0.85 \\
& Desvío & 0.13 & 0.05 & 0.06 & 0.06 & 0.04 \\
\hline
\end{tabular}

Segundo os valores de sensibilidade $(S)$, tem-se que em todas as metodologias a classe melhor identificada é o pasillo enquanto a pior identificada é o bambuco. Contudo, embora a classe pasillo é a classe melhor classificada também é a classe que mais contém falsos positivos $(F P)$, conforme sugerido pelos valores de precisão $(P)$. Com relação aos valores de especificidade $(E)$, as metodologias C6 e C8 têm comportamento similar dado que excluíram em maior proporção a classe bambuco. Com relação aos valores de F-score, as classes pasillo e bambuco são melhor classificadas e melhor excluídas das outras classes, com exceção da metodologia C6, que identifica e exclui corretamente em maior proporção a classe danza. No que diz respeito a $P$ e $V P N$, as duas metodologias têm comportamento semelhante. Por fim, tem-se que a metodologia C8 tem em média valores maiores em todas as taxas e a maioria destas com menor dispersão.

A abordagem de aprendizado não-supervisionado foi realizada através do agrupamento hierárquico aglomerativo. Visando atingir uma comparação equitativa a configuração do algoritmo de agrupamento foi conservada nas duas metodologias de análise. Para esta configuração foi adotada a distância cosseno (Eq. (2.58)) e estabelecido como método de agrupamento a ligação média (Eq. (2.61)). Para facilitar a comparação com os resultados da abordagem supervisionada, o número de grupos permaneceu igual ao número de classes, ou seja, 3 grupos. Para facilitar a análise dos dendrogramas, os agrupamentos 
Tabela 4.20: Tabela de contingência obtida com o agrupamento hierárquico aglomerativo e as duas metodologias de análise.

\begin{tabular}{|c|c|c|c|c|c|c|}
\hline & \multicolumn{3}{|c|}{ C6 } & \multicolumn{3}{|c|}{ C8 } \\
\hline & Pasill & $a m b$ & anza & Pasillc & imb & anza \\
\hline$\overline{\text { Gr. } 1}$ & 30 & $\overline{6}$ & 1 & 49 & 20 & 9 \\
\hline Gr. 2 & 26 & 32 & 11 & 8 & 25 & 9 \\
\hline Gr. 3 & 5 & 22 & 47 & 4 & 15 & 41 \\
\hline
\end{tabular}

são representados em cores, sendo agrupamento 1 em vermelho, agrupamento 2 em verde e agrupamento 3 em azul.

Devido à origem não supervisionada do agrupamento hierárquico, o resultado não é a classe de cada amostra e sim um vetor com grupos de amostras, isto é, a classe não é especificada, unicamente grupos de elementos, cujo número de referência não necessariamente está relacionado com o número da classe. Desta maneira, com o intuito de quantificar os resultados e realizar comparações, cada grupo é relacionado com uma classe, que é inferida a partir da quantidade de elementos de cada classe que foram atribuídos no mesmo grupo. Isso é feito partindo da informação prévia que se tem do ordenamento das classes dentro do banco de dados, uma vez que o índice das amostras está relacionada com a classe, conforme mostrado na Tabela C.1 do Apêndice C. A correspondência entre grupos e classes foi definida pela maior quantidade de objetos do grupo que pertencem a uma determinada classe, porém, se existir concorrência entre dois grupos diferentes pela mesma classe, o grupo com maior quantidade de elementos terá preferência e o grupo restante definirá sua classe de acordo com a segunda maior quantidade de elementos. Além disso, se um grupo só tiver elementos de uma classe, mesmo sendo uma quantidade pequena, este grupo dominará essa classe e os outros grupos deverão ser designados nas classes restantes, mesmo tendo uma quantidade maior de elementos da classe que foi fixada ao grupo com classe dominante única ${ }^{24}$. A tabela de contingência obtida para as duas metodologia é apresentada na Tabela 4.20, onde o agrupamento $i$ é denotado como Gr. $i$. Na Tabela 4.21 é apresentada a tabela de contingência de C8 incluindo os índices das amostras de cada agrupamento, com exceção das amostras da diagonal principal, pois, além de serem mais numerosas, com a informação apresentada ficam subentendidas. Na Fig. 4.27 é mostrado o dendrograma obtido para a metodologia C8.

Os valores de porcentagem de acurácia e de ARI foram calculados com os valores da tabela de contingência e são ilustrados no diagrama de barras da Fig. 4.28. Estes valores apoiam a conclusão sobre a predominância da meto-

\footnotetext{
${ }^{24}$ Um método para a correspondência automática entre grupos e classes foi desenvolvido aplicando um critério de maximização baseado em busca em profundidade
} 


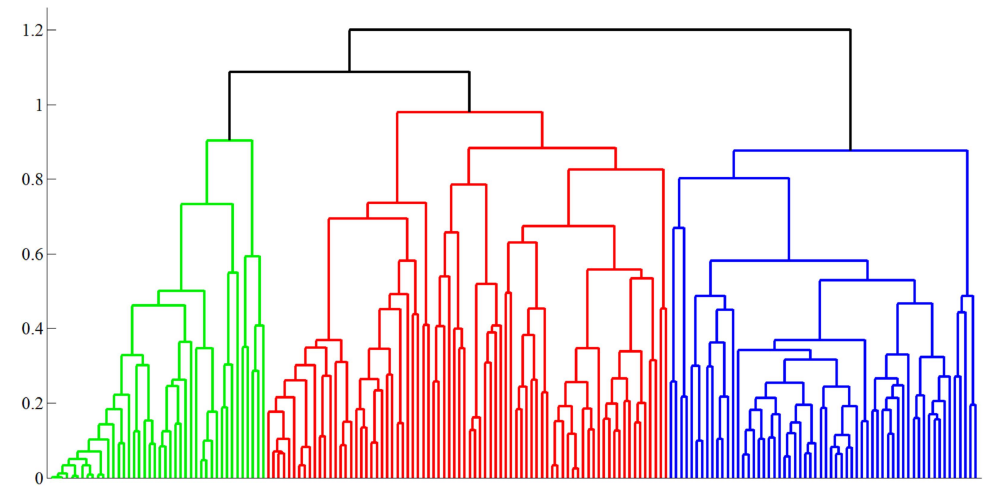

(a)

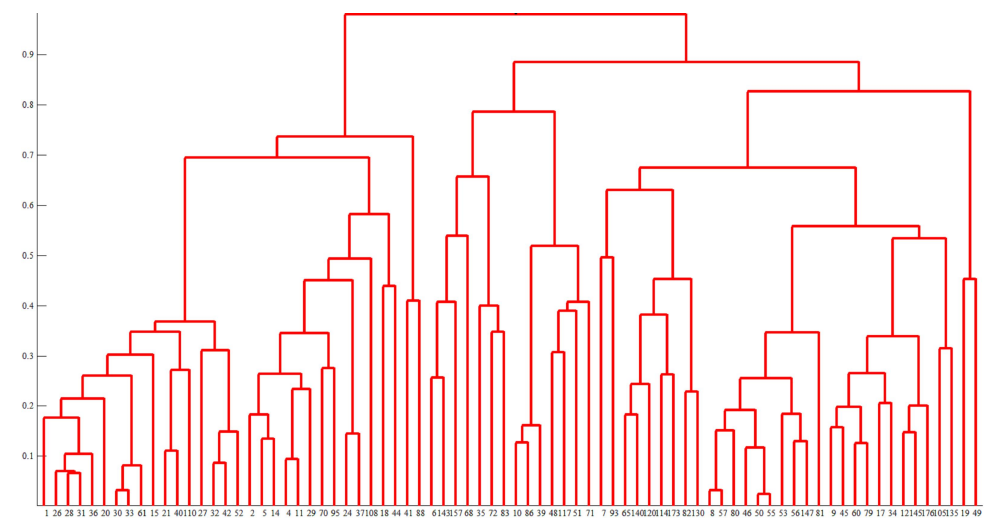

(b)

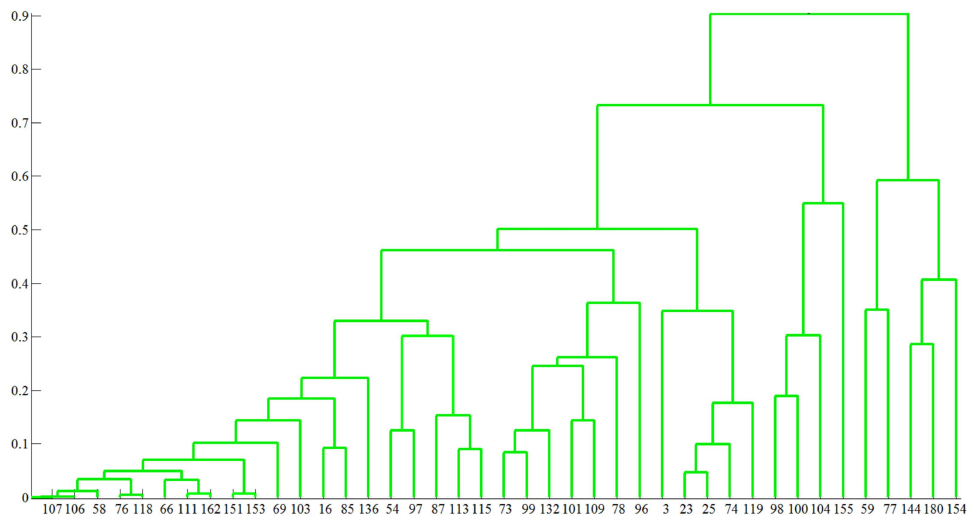

(c)

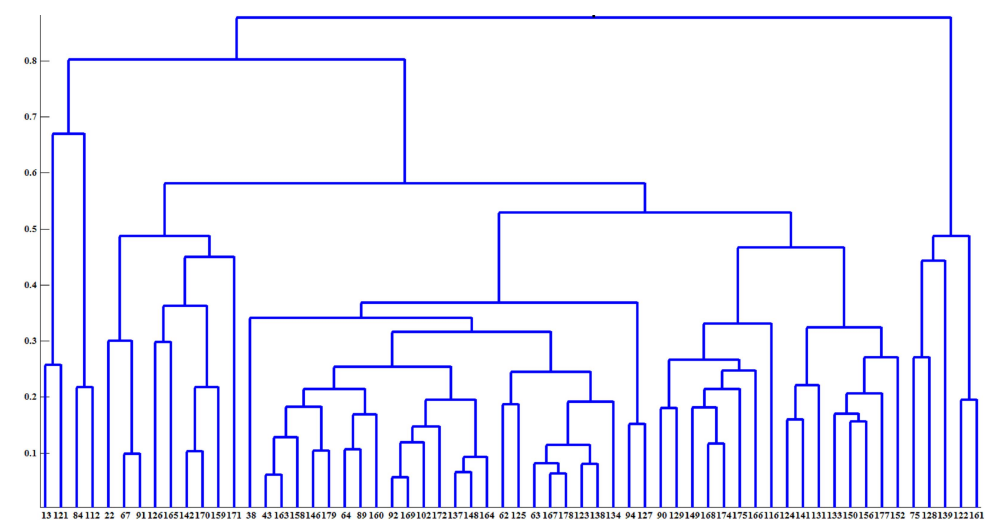

(d)

Figura 4.27: Dendrograma obtido com o agrupamento hierárquico aglomerativo usando a metodologia C8 e o banco de dados de músicas folclóricas. (a) Dendrograma completo; (b) Dendrograma do agrupamento 1; (c) Dendrograma do agrupamento 2; (d) Dendrograma do agrupamento 3. 
Tabela 4.21: Tabela de contingência com os índices das amostras dentro de cada agrupamento obtida com o algoritmo de agrupamento hierárquico aglomerativo, o banco de dados de músicas folclóricas e a metodologia C8.

\begin{tabular}{|c|c|c|c|}
\hline & Pasillo & Bambuco & Danza \\
\hline \multirow{3}{*}{ Gr. 1} & & $65,68,70-72,79-83,86$ & $130,135,140$ \\
\hline & & $88,93,95,105,108$ & $143,145,147$ \\
\hline & & $110,114,117,120$ & $157,173,176$ \\
\hline \multirow{3}{*}{ Gr. 2} & $\overline{3}, \overline{1} \overline{6}, \overline{2} \overline{3}$ & & $132,136,144$ \\
\hline & $25,47,54$ & & $151,153,154$ \\
\hline & 58,59 & & $155,162,180$ \\
\hline Gr. 3 & $13,22,38,43$ & $\begin{array}{l}62-64,67,75 \\
84,89-92,94 \\
102,112,116,121\end{array}$ & \\
\hline
\end{tabular}

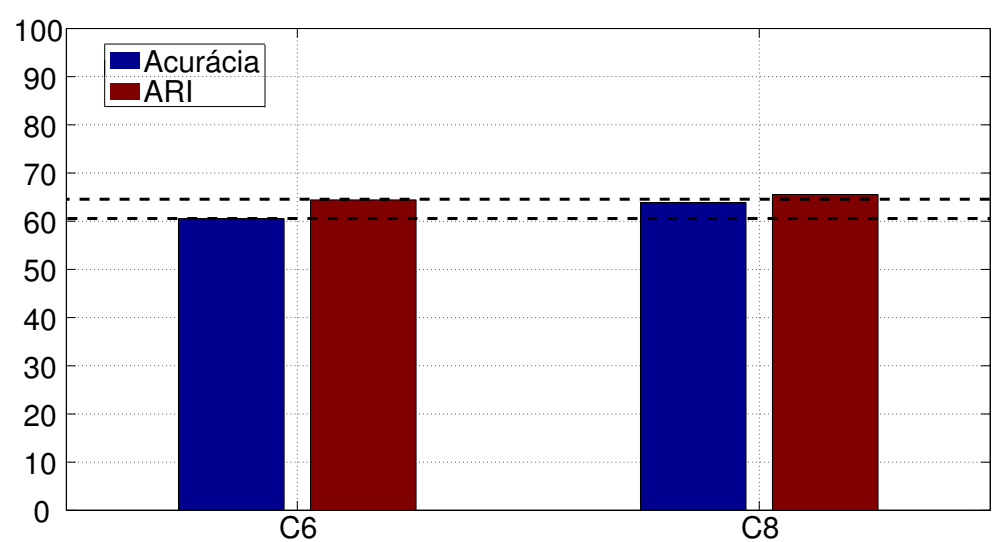

Figura 4.28: Acurácia total e ARI usando aprendizado não-supervisionado.

dologia C8. Conquanto, nas duas as metodologias a acurácia total foi reduzida na abordagem não-supervisionada, mas o ranking geral entre metodologias ficou estável.

Banco de dados 2: Gêneros com Base Rítmica Percussiva

Em concordância com as conclusões usando o banco de dados de músicas folclóricas, para este banco de dados apenas será usada a metodologia C8. Para todas as amostras o dígrafo foi gerado usando 3 linhas rítmicas. A Fig.4.29 apresenta o valor de máxima relevância de cada amostra, a linha pontilhada inferior é o mínimo desses valores (minimax), igual a 0.12.

Seguindo o procedimento similar ao usado para determinar a melhor combinação de características do banco de dados de musicas folclóricas, foi encontrado que a melhor combinação de grupos de características é novamente DGCO. A Fig. 4.30 mostra a evolução da acurácia, o número total de nós e o número de CRs, quando variado o limiar de relevância entre 0 e 0.12 e usado o melhor conjunto de características encontrado. Novamente o limiar de relevância ótimo ocorre em $\alpha=0.03$. 


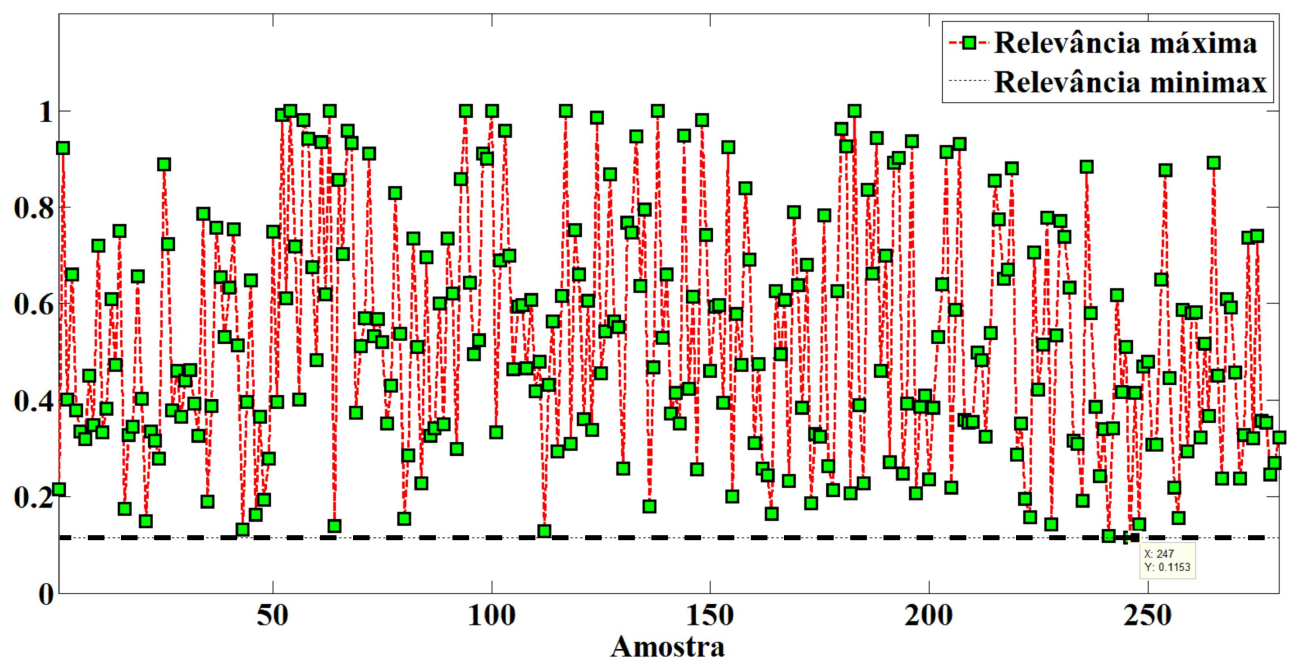

Figura 4.29: Máximo valor de relevância das amostras do banco de dados de músicas populares.

Tabela 4.22: Porcentagem de acurácia inicial e máxima, e diferença de acurácia absoluta (Dif.) e em porcentagem (Dif.(\%)) usando a metodologia C8, a combinação DCGO e o banco de dados de músicas populares.

\begin{tabular}{c|c|c|c|c}
\hline & Inicial $(\alpha=0)$ & Máxima $(\alpha=0.03)$ & Dif. & Dif.(\%) \\
\hline \hline CRs & 9029 & 5557 & -3472 & -38.45 \\
Nós & 3291 & 2040 & -1251 & -38.01 \\
Acurácia & 31 & 34 & +3 & 9.67 \\
\hline
\end{tabular}

A Tabela 4.22 resume os resultados obtidos na Fig. 4.30, sendo estes: total de CRs, total de nós e média da porcentagem de acurácia (Ac.) no estado de relevância inicial $(\alpha=0)$ e no estado ótimo $(\alpha=0.03)$. As duas últimas colunas mostram a diferença em valores absolutos (Dif.) e em porcentagem (Dif.(\%)) entre os valores das duas primeiras. No estado ótimo a acurácia aumentou $9.67 \%$, enquanto o número de CRs e o número de nós diminuíram aproximadamente $38 \%$. Usando resubstituição obteve-se um comportamento similar, no qual a acurácia passou de $35 \%$ a $42.5 \%$, portanto, a acurácia também foi incrementada com a presença dos três fatores. No entanto, a acurácia máxima obtida é menor à acurácia reportada em (Corrêa et al., 2010), o que pode ser explicado pelo fato do banco de dados ter amostras dentro de cada gênero que não seguem um padrão rítmico, pois não pertencem a um único gênero, e sim a diversidade de estilos e subgêneros.

O dendrograma obtido pelo agrupamento hierárquico para este banco de dados usando uma configuração igual à usada acima (distância cosseno e ligação média) e fixando o número de grupos ao número de classes, isto é, quatro grupos, é mostrado na Fig. 4.31. A tabela de contingência obtida é mostrada na Tabela 4.23, e a partir desses valores foi calculada a porcentagem de acurácia que é igual a $36.07 \%$ e ARI em porcentagem que é igual a $58.51 \%$. 


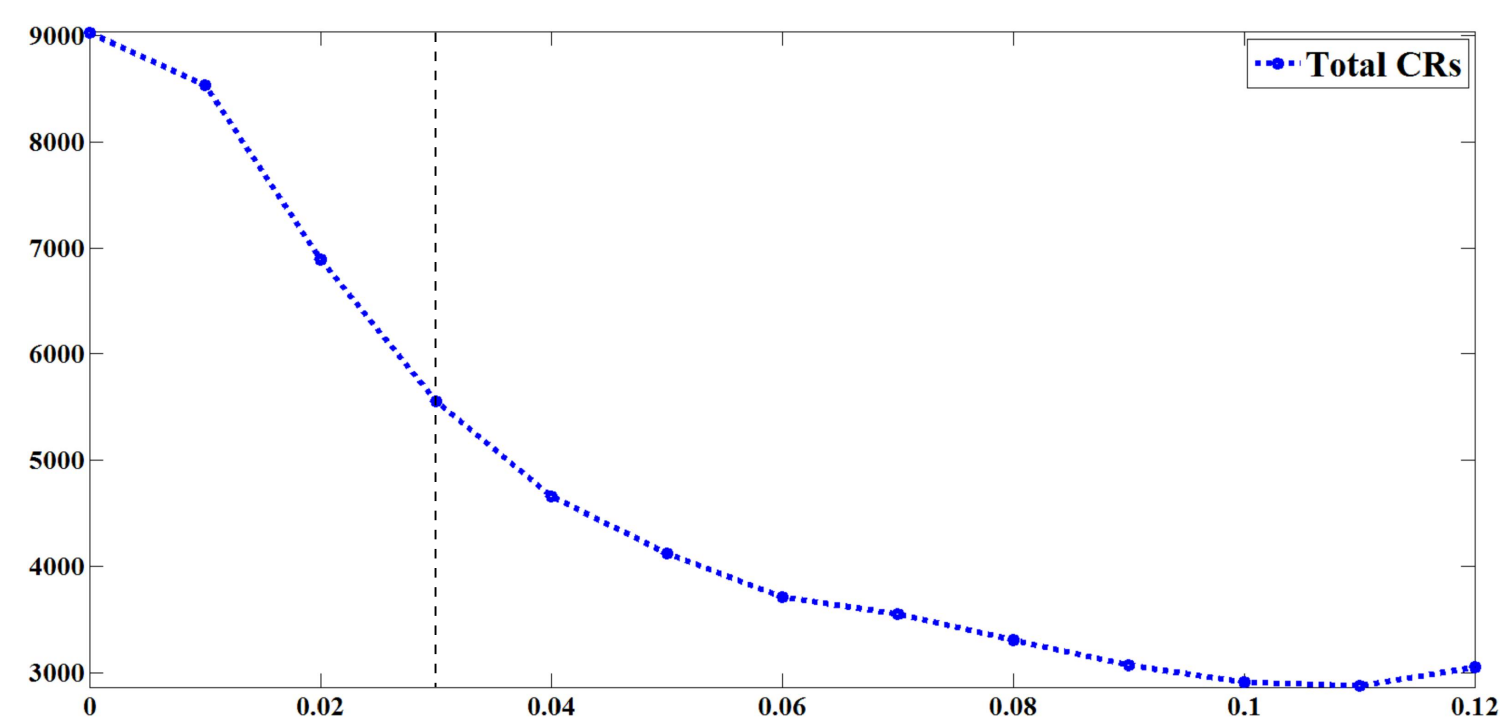

(a)

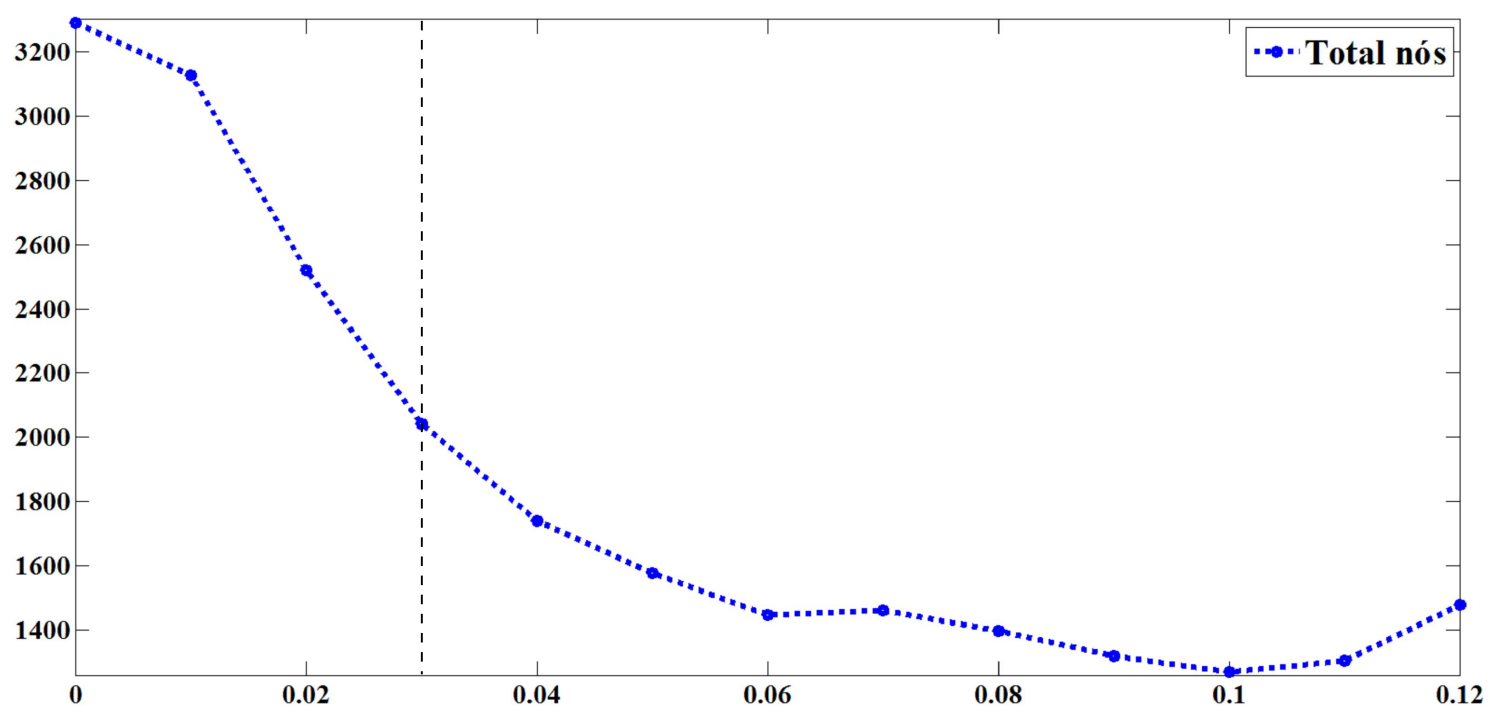

(b)

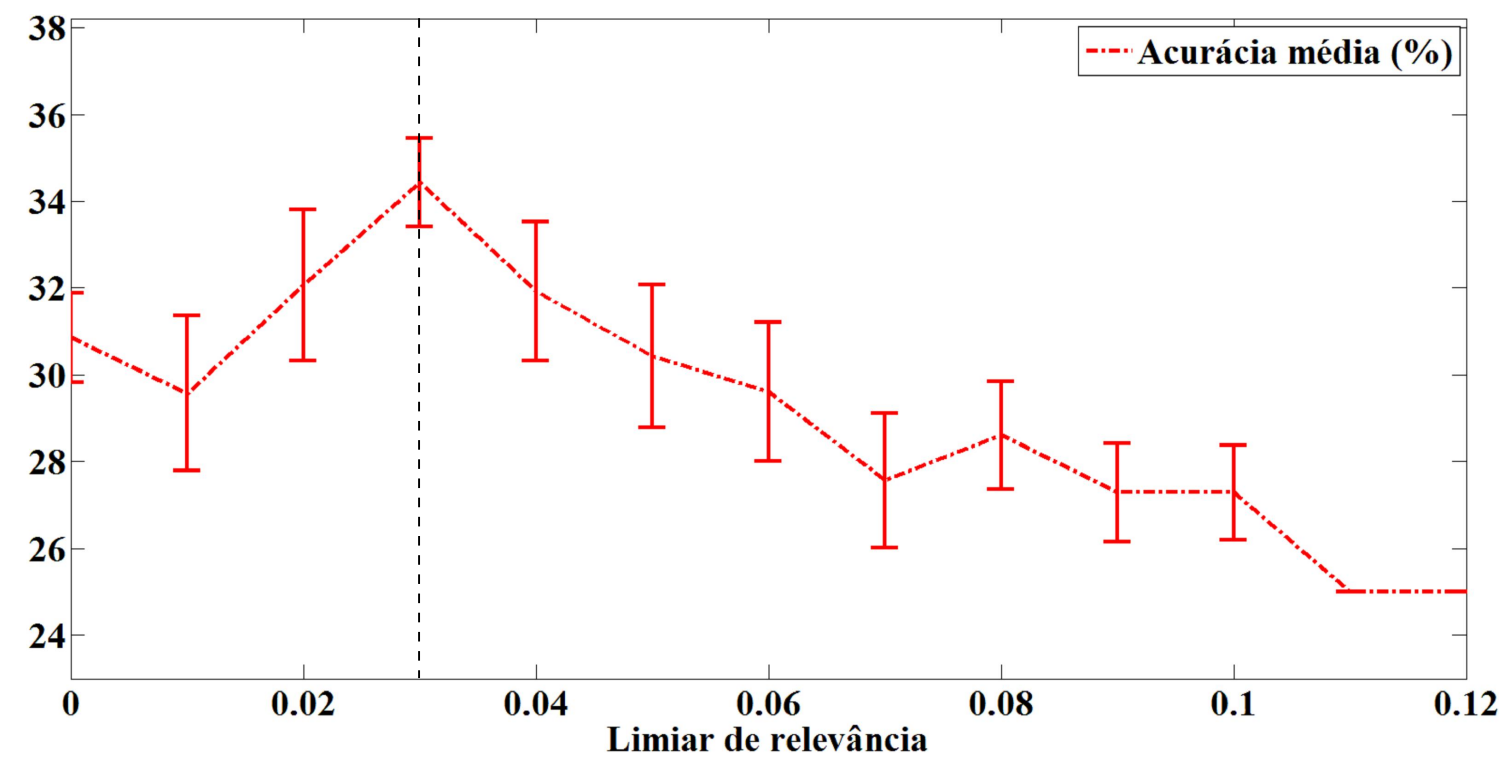

(c)

Figura 4.30: Evolução da rede e da acurácia quando variado o limiar de relevância na metodologia $\mathrm{C} 8$ usando o banco de dados de músicas populares. (a) Número de CRs; (b) Número de nós; (c) Evolução da acurácia média usando o conjunto DGCO. 


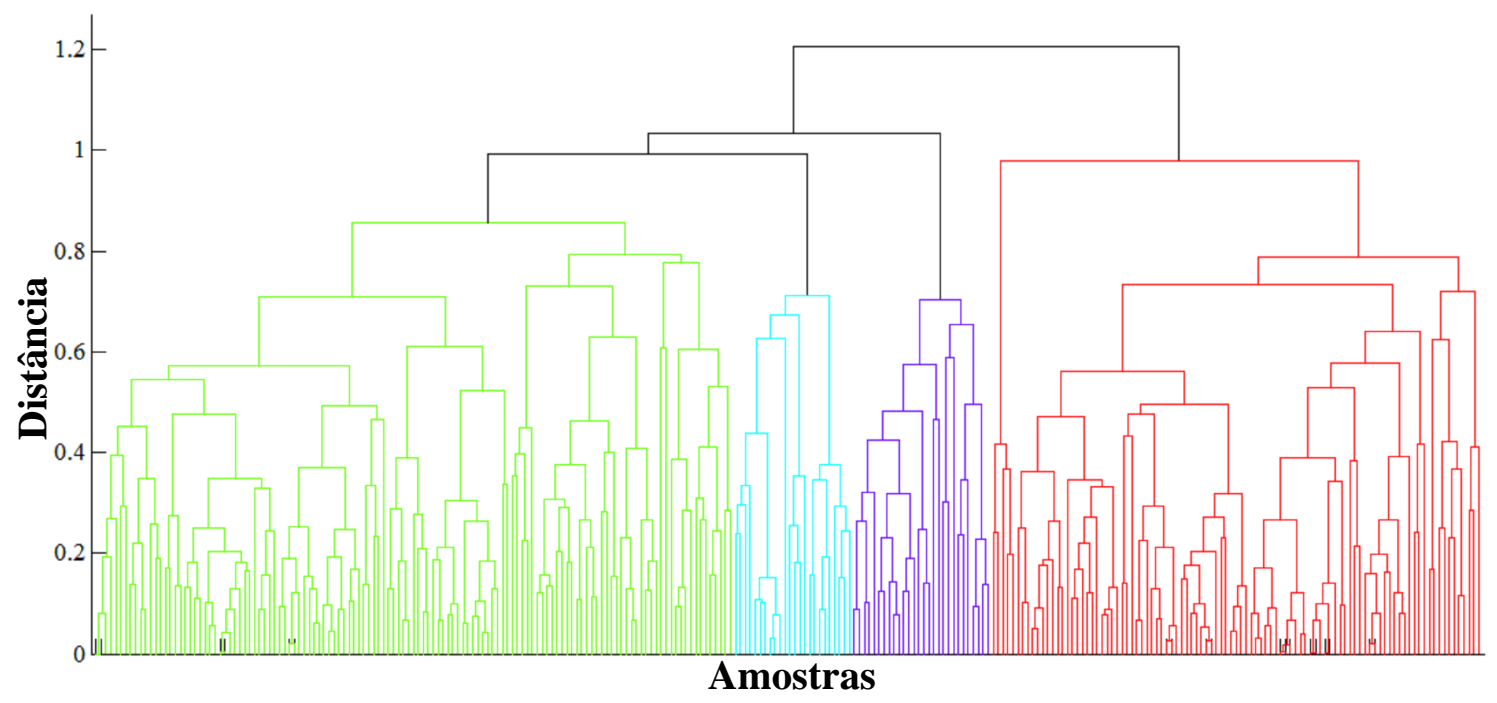

Figura 4.31: Dendrograma obtido com o agrupamento hierárquico aglomerativo usando a metodologia $\mathrm{C} 8$ e o banco de dados de músicas populares.

Tabela 4.23: Tabela de contingência obtida com o algoritmo de agrupamento hierárquico aglomerativo, o banco de dados de músicas populares e a metodologia C8.

\begin{tabular}{|c|c|c|c|c|}
\hline & \multicolumn{4}{|c|}{ Blues Reggae Bossa Nova Rock } \\
\hline Gr. 1 & 9 & 6 & 6 & 7 \\
\hline Gr. 2 & 22 & 39 & 18 & 20 \\
\hline Gr. 3 & 4 & 4 & 13 & 3 \\
\hline r. 4 & 35 & 21 & 33 & 40 \\
\hline
\end{tabular}

A acurácia obtida revela um valor semelhante ao obtido com a abordagem supervisionada.

\subsection{Considerações Finais}

Neste capítulo foi apresentado um método para a extração e sumarização de padrões rítmicos, e uma nova metodologia para a identificação de gêneros musicais. O método de extração se enquadra no contexto de extração de conhecimento musical através da detecção de comunidades em redes complexas, cobrindo desta forma a perspectiva de reconhecimento de padrões. A novidade do método é que é baseado em redes complexas e, por conseguinte, capaz de revelar topologias estruturais do ritmo (Coca \& Zhao, 2014d). Neste método a informação da duração das notas foi extraída e depurada com um método de quantização. O uso de Células Rítmicas (CRs) foi adotado para representar adequadamente o ritmo musical, e para superar a dependência dimensional do vetor de representação das CRs foi proposto um sistema de codificação. Técnicas de detecção de comunidades foram aplicadas para descobrir grupos 
de CRs e uma nova medida para caracterizar a relevância das comunidades detectadas foi proposta.

A detecção de comunidades foi realizada desde duas aproximações diferentes: detecção de comunidades disjuntas e sobrepostas. A aproximação com comunidades disjuntas foi desempenhada usando o algoritmo de otimização de modularidade e o algoritmo de Louvain. Para avaliar e contrastar o resultado foram adotadas duas medidas: índice corrigido de Rand e informação mútua normalizada. Valores maiores nestas medidas para o resultado obtido com o algoritmo de Louvain revelaram uma melhor extração rítmica, sugerindo assim que a qualidade do resultado depende também do algoritmo de detecção usado. Para a detecção de comunidades sobrepostas foi usado o algoritmo BNMF, que ajudou na identificação de CRs comuns entre padrões, de igual forma, medidas especiais para a avaliação de agrupamentos com sobreposição foram aplicadas: índice ômega e informação mútua normalizada generalizada. Os resultados revelaram que BNMF ajudou na identificação parcial das CRs comuns entre padrões, mas pouco na identificação dos padrões em si mesmos. Para diferenciar os tipos de padrões (primários e secundários) foi desenvolvida uma nova medida que quantifica a relevância das comunidades detectadas. O método foi testado usando a sequência de bateria de uma canção popular e, além do exemplo principal, o método também foi aplicado para um conjunto de 20 amostras.

A tarefa de sumarização foi executada para este mesmo conjunto, encontrando que o padrão de sumarização concorda com o padrão principal mais representativo entre todas as músicas. Os resultados demostraram que a representação do ritmo com CRs enriquece a informação rítmica, facilitando a extração do padrão rítmico de uma canção e a sumarização automática de um conjunto de músicas. O uso de CRs e da medida de relevância é interessante porque as CRs conseguem refletir a informação rítmica dentro das comunidades da rede com alta qualidade e a medida de relevância permite distinguir os tipos de padrões rítmicos (Coca \& Zhao, 2014d). Visando contrastar a influência da maneira de gerar a rede no resultado final, diferentes disposições das linhas de percussão foram usadas e os resultados foram comparados (Coca \& Zhao, 2014c). Estas disposições incluem usar as linhas separadamente ou misturadas mediante concatenação horizontal ou vertical, e usando CRs ou Figuras Rítmicas Individuais (FRIs). Em todos os casos, o uso de FRIs relevou uma perda de informação devido à ambiguidade ocasionada pela desconsideração da relação entre figuras rítmicas. Por outro lado, a extração rítmica com CRs e linhas separadas sugeriu uma melhor aproximação, mas o padrão rítmico foi fragmentado. A concatenação horizontal afetou a simultaneidade temporal ocasionando que CRs iguais, porém de diferentes linhas, formassem 
um mesmo nó. Finalmente, a concatenação vertical foi a mais consistente, facilitou a extração das CRs e manteve a integridade dos padrões rítmicos.

Em seguida, foi abordada a perspectiva de mineração com redes complexas e aplicada no tópico de aprendizado de máquina supervisionado e nãosupervisionado. Na Seção 4.2 foi apresentada uma nova metodologia para a identificação de gêneros musicais baseada na representação do ritmo musical com redes complexas. Esta nova metodologia incorpora três fatores ao processo de discriminação: células rítmicas, relevância de comunidades e medidas topológicas de redes. O primeiro fator proporcionou uma representação de alta qualidade, que considerou os silêncios, agrupou as figuras rítmicas adequadamente e permitiu a concatenação das linhas rítmicas de uma sequência de bateria conservando a evolução temporal da música. Com o segundo fator os padrões rítmicos do gênero da cada amostra foram destacados, apagando os padrões fortuitos e obtendo um dígrafo depurado que concentra as características mais importantes do gênero musical. A matriz de atributos foi gerada usando medidas topológicas de redes complexas, o que reduziu a dimensionalidade e facilitou a extração das características intrínsecas do dígrafo que estão relacionadas com o gênero musical. O uso destes três fatores em conjunto melhorou significativamente o desempenho e a acurácia de identificação, tanto na abordagem supervisionada quanto na não-supervisionada. Isso foi confirmado através de medidas de desempenho e de um teste de significância estatística sob a hipótese de diferença de médias de diferentes valores de kappa. Além disso, foi demonstrado que a metodologia proposta funciona tanto para gêneros com base rítmica percussiva quanto não percussiva. 


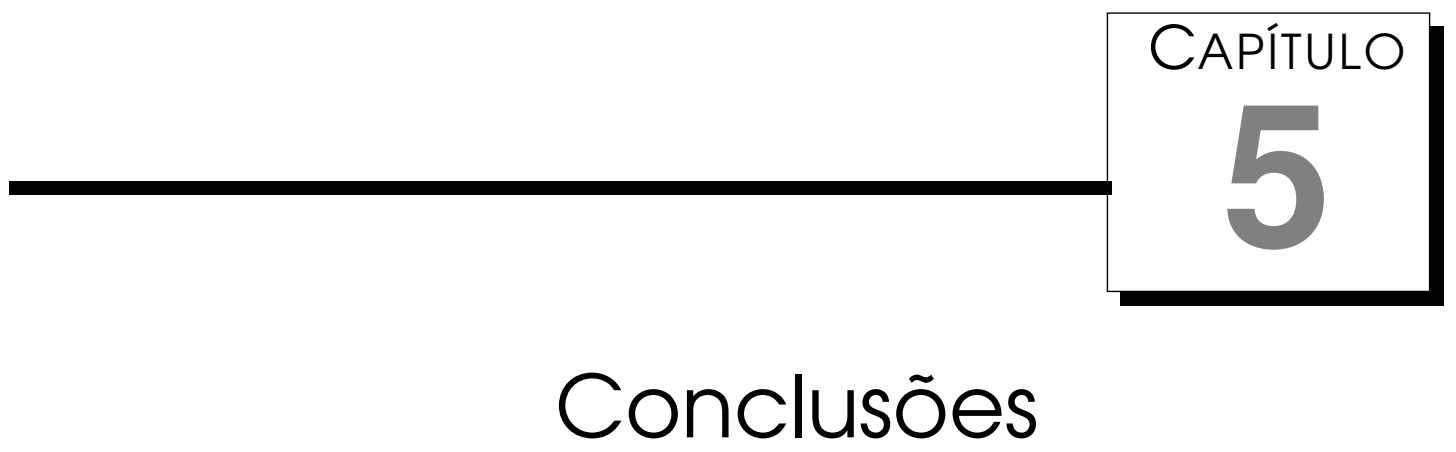

proveitando a versatilidade da teoria de redes complexas na represen-
tação e análise de sistemas complexos, nesta tese três abordagens de
aprendizado de máquina foram pesquisadas através do estudo dos seguintes problemas: sintese, reconhecimento de padrões e mineração de dados musicais. Com o intuito de criar novos modelos para a geração de estruturas musicais com características estéticas aceitáveis, o problema de síntese foi abordado a partir da preservação de características próprias de redes complexas predefinidas, que também estão presentes em redes reais e da natureza, como a lei de potência e do pequeno mundo. Na busca deste objetivo também foram exploradas as redes neurais recorrentes combinadas com sistemas dinâmicos caóticos. O problema de reconhecimento de padrões foi abordado com o estudo do ritmo musical, e concretizado com a criação de um modelo para a extração de padrões rítmicos, elementos importantes dentro do discurso musical que permitem caracterizar e discriminar o gênero. Os padrões rítmicos extraídos são categorizados em padrões principais e secundários. Aproveitando as vantagens do método de extração, uma nova metodologia para a discriminação de gêneros musicais foi desenvolvida, em cuja fase de mineração foram usadas medidas topológicas de redes complexas, porém aplicadas somente aos padrões principais, abordando dessa forma a terceira perspectiva, a de mineração.

Dentro das principais conclusões desta pesquisa podem ser destacadas:

- Os modelos de composição baseados na combinação de redes neurais recorrentes e sistemas caóticos revelaram que é possível controlar as características subjetivas de uma melodia, abrindo novas possibilidades 
para o desenvolvimento de algoritmos de composição que tenham como escopo a estética do resultado final.

- A seleção da notação matemática adequada para representar o ritmo mostrou-se como uma técnica preliminar fundamental na extração do padrão rítmico, revelando a importância que tem o estudo da melhor representação dos dados na solução de problemas de reconhecimento de padrões, e mostrando um novo caminho na busca de soluções com outros tipos de dados.

- A codificação de objetos musicais revelou-se como uma ferramenta importante que facilitou o manuseio computacional, e pode oferecer uma boa contribuição em problemas que precisem condensar, padronizar e identificar conjuntos de dados.

- A medida de relevância mostrou-se eficiente para diferenciar comunidades e, além de estender o leque de medidas topológicas de redes complexas, poderia oferecer uma boa contribuição em problemas de visualização, filtrado e sumarização de redes complexas.

- A metodologia de identificação de gêneros musicais é uma abordagem inovadora, que apresentou bom desempenho e mostrou ser uma promissora estratégia de reconhecimento de dados musicais, revelando que não só é suficiente o uso de técnicas avançadas de aprendizado, mas também uma boa representação e uma depuração seletiva dos dados. Propriedades que poderiam incentivar o aprimoramento de metodologias de classificação existentes ou o desenvolvimento de novas metodologias.

\subsection{Principais Contribuições}

As principais contribuições concebidas no decorrer desta pesquisa, com base nos desenvolvimentos realizados e descritos acima, bem como, nos resultados obtidos, são descritas a seguir:

1. Desenvolvimento de um novo modelo para a composição de melodias utilizando pela primeira vez redes complexas predefinidas, o qual inclui a seleção sistemática de uma escala com alta qualidade para composição e tem a capacidade de compor melodias que conservam as propriedades das redes, as transformando em atributos musicalmente interessantes.

2. Desenvolvimento de dois novos modelos para a composição de melodias usando redes neurais recorrentes com entrada de inspiração caótica, que permitem controlar a similaridade melódica e atingir um valor de referência preestabelecido de alguma medida subjetiva. 
3. Desenvolvimento de uma abordagem original para a codificação e decodificação de objetos musicais, especificamente, escalas e células rítmicas, que melhorou o manuseio computacional de estruturas musicais e o desempenho de aplicações baseadas em redes complexas.

4. Definição e aplicação de uma nova medida de redes complexas que quantifica a relevância das comunidades detectadas em termos da coesão da força intra-comunidade.

5. Abordagem inovadora para a extração de padrões rítmicos e para a sumarização rítmica de um conjunto, que produz resultados de alta qualidade.

6. Nova metodologia para a identificação de gêneros musicais baseada em redes complexas, a qual inclui as etapas de extração de padrões rítmicos, depuração da rede e mineração usando medidas topológicas.

7. Desenvolvimento de interfaces de software para composição de melodias usando os diferentes modelos propostos e obtenção do registro para a interface de composição de melodias caóticas (Coca \& Zhao, 2012).

\subsection{Trabalhos Futuros}

Embora os modelos desenvolvidos apresentem diversas características interessantes, novos desenvolvimentos poderão ser efetuados em trabalhos futuros. Alguns dos possiveis trabalhos futuros são sugeridos a seguir:

- Testar os modelos de composição baseados em redes neurais recorrentes usando diferentes tipos de sistemas dinâmicos caóticos na entrada de inspiração, tanto contínuos quanto discretos, e com diferente número de variáveis e parâmetros, com o intuito de determinar qual sistema é mais apropriado para compor melodias mais criativas sem perder a essência da melodia de treino. Para o modelo baseado na rede LSTM, testar com sistemas caóticos de três dimensões, onde a terceira variável seja designada para gerar as dinâmicas musicais. Também usar diferentes tipos de melodias de treino, de medidas subjetivas e/ou de sistemas dinâmicos, como fractais e osciladores. Estudar outras estratégias de controle e determinar a mais adequada, por exemplo, estudar o desempenho do modelo usando o controlador Proporcional Integral Derivativo (PID) ou, devido ao comportamento particular dos sistemas dinâmicos, uma estratégia para o controle do caos como o método OGY ${ }^{1}$, o método de controle

\footnotetext{
${ }^{1}$ Sigla de Ott, Grebogi e Yorke, o sobrenome dos autores.
} 
por indução ao ponto fixo $\left(\mathrm{FPIC}^{2}\right)$ ou o método de controle de realimentação por retardo de tempo (TDAS $\left.{ }^{3}\right)$.

- Desenvolver um sistema para a codificação de outros objetos musicais como acordes e forma musical, e estender o sistema de codificação de escalas a sistemas microtonais, isto é, sistemas com mais de 12 notas por oitava.

- Estudar a aplicabilidade do método de extração rítmico proposto em diversas tarefas, por exemplo, transcrição automática de música, detecção da fórmula de compasso, compressão de áudio, segmentação de obras musicais, composição automática e caracterização de gêneros musicais segundo o tipo de CRs, dentre outras.

- Estender a metodologia de identificação de gêneros musicais a tarefas adicionais como classificação multiclasse. Ademais, extrair, caracterizar e analisar os padrões rítmicos principais e secundários que sumarizam os gêneros musicais do conjunto de treino, visando determinar as CRs que melhor caracterizam os gêneros e a similaridade entre as CRs que os compõem.

- Aplicar os modelos desenvolvidos a outras tarefas baseadas em redes complexas, de tal forma que uma vez gerada a rede não seja mais necessário usar outro método antes de continuar com a tarefa principal, isto é, juntar diferentes modelos de MIR baseados em redes complexas tendo como vínculo comum a matriz de adjacência.

- Usar todos os métodos propostos nesta tese em um projeto de pesquisa maior, conhecido como ciência da canção de sucesso $\left(\mathrm{HSS}^{4}\right)$, que tem como objetivo caracterizar e predizer canções de grande sucesso comercial através da análise e mineração de bases de dados de históricos de vendas ou popularidade de canções. Nesta ousada pesquisa poderiam ser requeridas etapas de mineração, extração de padrões rítmicos, identificação de gêneros musicais e síntese musical, dentre outras. Portanto, os modelos propostos poderiam ser bastante úteis no desenvolvimento de pesquisas deste porte.

- Aplicar a medida de relevância para diferenciar e depurar redes geradas com outros tipos de dados, por exemplo, distinguir grupos esporádicos de amigos em uma rede social.

\footnotetext{
${ }^{2}$ Sigla de Fixed Point Induced Control

${ }^{3}$ Sigla de Time-Delayed Feedback

${ }^{4}$ Sigla de Hit Song Science
} 
APÊNDICE

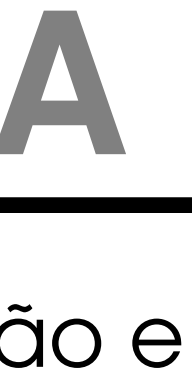

Algoritmos de Codificação e

Decodificação de Objetos Musicais

$\mathrm{N}$

este apêndice é apresentado o desenvolvimento dos algoritmos utilizados para a codificação e decodificação de objetos musicais, especificamente células rítmicas e escalas musicais. Os códigos das células rítmicas são usados para gerar dígrafos, obtendo uma melhor representação do ritmo que facilita a extração de informação musical útil em tarefas de mineração de dados e reconhecimento de padrões. Os códigos das escalas musicais são aplicados na busca de uma escala com características apropriadas para composição musical, a qual pode ser usada como fonte de material musical em um modelo de composição automática de melodias.

\section{A. 1 Células Rítmicas}

Neste seção é apresentado o desenvolvimento dos algoritmos para a codificação e decodificação de Células Rítmicas (CRs). A definição e forma de representação de uma $\mathrm{CR}$, bem como os elementos do vetor de código $\mathrm{c}_{1 \times 4}$ e a suas vantagens, são descritas na Seção 4.1.1. O codificador devolve o código de uma CR a partir do arquivo MIDI, enquanto o decodificador faz processo inverso. 


\section{A. 1.1 Algoritmo Codificador}

Do arquivo MIDI é extraída a matriz de notas ${ }^{1}$ usando uma função do toolbox MIDI de Matlab (Eerola \& Toiviainen, 2004). As entradas do algoritmo são: a matriz de notas $\mathrm{M}$, o número mínimo de divisões da unidade de tempo $n_{\text {min }}$, a unidade de tempo em beats $u_{c}$ de todos os fragmentos com mudança de unidade de tempo ${ }^{2}$ e a sua posição dentro de $\mathrm{M}$ (armazenada na matriz $\left.\mathbf{I}^{(u)}\right)$. A saída é o vetor de código $\mathbf{c}=\left[\begin{array}{llll}n & \Delta_{p} & \Delta_{s} & \Delta_{b}\end{array}\right]$. A matriz $\mathbf{M}$ deve ser previamente quantizada, pois tanto o codificador quanto o decodificador requerem a pureza dos dados para atingir a exatidão no resultado. Os dados de onset e de duração das figuras rítmicas, os quais estão contidos nas duas primeiras colunas da matriz de notas, são extraídos para cada CR e é obtido o vetor de código a partir da correspondente Notação de Durações Ponderadas (NDP) (Sethares, 2007).

\section{Fragmentação da Matriz do Ritmo Segundo a sua Unidade de Tempo $u_{c}$}

Do arquivo MIDI da obra musical é obtida a matriz de notas $\mathbf{M} \in \mathbb{R}_{+}^{m \times 7}$, onde $m$ é o número total de eventos musicais. Uma música pode ter diferentes fórmulas de compasso com igual ou diferente unidade de tempo. Neste último caso, é preciso separar da matriz de notas os valores rítmicos de cada fragmento que tem mudança de unidade de tempo. Para uma obra que tem $k$ fragmentos com mudança de unidade de tempo, as linhas da matriz $\mathbf{I}^{(u)}$ de dimensão $k \times 2$, contêm a informação das linhas de início e fim de cada fragmento dentro de M. A informação referente aos dados rítmicos (primeiras duas colunas de $\mathbf{M}$ ) do fragmento $k$ são separadas e armazenadas em uma nova matriz $\mathbf{R}$, chamada matriz do ritmo do fragmento $k$. A matriz $\mathbf{R}$ com dimensão $m_{k} \times 2$, onde o número de linhas $m_{k}$ é igual a $\left(I_{k, 2}^{(u)}-I_{k, 1}^{(u)}+1\right)$ e corresponde ao número de eventos do fragmento $k$, é ajustada para os seus dados começarem na primeira batida (batida 0), assim: $\tilde{\mathbf{R}}=\mathbf{R}-R_{1,1}$. Da matriz do ritmo são extraídos os dados de cada célula rítmica, mas para este propósito, primeiramente é necessário saber onde começa e termina cada CR dentro da matriz $\tilde{\mathbf{R}}$, e para tal fim, é calculado o seguinte vetor:

$$
\mathbf{b}=\left\lfloor\frac{\tilde{\mathbf{R}}_{1}}{u_{c}^{(k)}}\right\rfloor-\left\lceil\frac{\tilde{\mathbf{R}}_{1}+\tilde{\mathbf{R}}_{2}}{u_{c}^{(k)}}-\varepsilon\right\rceil,
$$

onde $\lfloor\cdot\rfloor$ e $\lceil\cdot\rceil$ são a função chão e teto, respectivamente; $u_{c}^{(k)}$ é a correspondente unidade de tempo da fórmula de compasso do fragmento $k \mathrm{e} \varepsilon$ um valor infinitesimal usado como limiar. Os índices das linhas com valor positivo do vetor

\footnotetext{
${ }^{1}$ As colunas da matriz de notas são: onset (em batidas), duração (em batidas), canal, altura, velocidade, onset (em segundos) e duração (em segundos).

${ }^{2}$ Por exemplo mudança de fórmula de compasso de ${ }_{4}^{x}$ a 8
} 
b são armazenados na matriz $\mathbf{I}^{(\mathbf{R})}$, que tem duas colunas e $t_{k}$ linhas, onde $t_{k}$ é o número de CRs do fragmento $k$. A segunda coluna de $\mathbf{I}^{(\mathbf{R})}$ é calculada como $I_{i, 2}^{(\mathbf{R})}=I_{i+1,1}^{(\mathbf{R})}-1, \quad 1 \leq i \leq\left(t_{k}-1\right)$.

Cada linha da matriz $\mathbf{I}^{(\mathbf{R})}$ contém o índice inicial e final das linhas de $\tilde{\mathbf{R}}$ onde começa e termina cada CR. Essa matriz serve para calcular o número de batidas em silêncio, o número de eventos de cada CR e para separar cada $\mathrm{CR}$ da matriz do ritmo. O número de figuras de cada $\mathrm{CR}$ é calculado como: $\mathbf{f}=\mathbf{I}_{2}^{(\mathbf{R})}-\mathbf{I}_{1}^{(\mathbf{R})}+1$, e o número de batidas em silêncio entre duas células rítmicas é calculado como: $\mathbf{s}=\left\lfloor\tilde{\mathbf{R}}_{\mathbf{I}_{1}^{(\mathbf{R})}}\right\rfloor-\left\lceil\tilde{\mathbf{R}}_{\mathbf{I}_{1}^{(\mathbf{R})}}+\tilde{\mathbf{R}}_{\mathbf{I}_{2}^{(\mathbf{R})}}\right\rceil$. Estes vetores são importantes porque ajudam a descrever melhor as características das CRs, podendo ser úteis em aplicações do codificador, por exemplo, em composição algorítmica.

\section{Obtenção do Vetor de Representação de uma CR}

Os dados da célula rítmica $t_{a}, t_{a} \leq t_{k}$, são separados da matriz do ritmo $\tilde{\mathbf{R}}$ usando a linha $t_{a}$ da matriz $\mathbf{I}^{(\mathbf{R})}$, e armazenados na matriz $\mathbf{A}$ de $m_{a} \times 2$, onde $m_{a}$ é o número de eventos da CR. O quarto elemento do vetor de código $\Delta_{b}$ (número de batidas que ocupa a $\mathrm{CR}$ ) é calculado da seguinte forma:

$$
\Delta_{b}=b^{\text {start }}-b^{\text {end }}=\left\lfloor\frac{A_{1,1}}{u_{c}^{(k)}}\right\rfloor-\left\lceil\frac{A_{m_{a}, 1}+A_{m_{a}, 2}}{u_{c}^{(k)}}\right\rceil,
$$

onde $b^{\text {start }} \mathrm{e} b^{\text {end }}$ é o índice da batida inicial e final que limita a CR, respectivamente. Em seguida, o valor estimado da amplitude ponderada ${ }^{3} \hat{u}_{t}$ é calculado como: $\hat{u}_{t}=u_{c} / n_{\min }$. Os valores $\hat{u}_{t}$ e $n_{\min }$ são provisórios já que dependem do tipo de célula rítmica. Para calcular os valores exatos de $u_{t}$ e $n$, os quais são necessários na formação do vetor de representação $\mathbf{v}$, primeiro é calculado o valor da figura de menor duração da célula, ou seja: $\omega=\min \left\{\mathbf{A}_{2}\right\}$ (note-se que $\omega \geq \hat{u}_{t}$ ). Os valores reais de $u_{t}$ e $n$ são calculados segundo as condições dadas na Eq. (A.3) e (A.4), respectivamente.

$$
\begin{gathered}
n=\left\{\begin{array}{cc}
n_{\min } & \operatorname{Se}\left(\omega=\hat{u}_{t}\right) \wedge\left(u_{c}=\Delta_{b}\right) \\
\Delta_{b} / \hat{u}_{t} & \operatorname{Se}\left(\omega>\hat{u}_{t}\right) \wedge\left(\omega \bmod \hat{u}_{t}=0\right) \\
\Delta_{b} / \omega & \text { caso contrário }
\end{array}\right. \\
u_{t}=\left\{\begin{array}{cc}
\omega & \operatorname{Se}\left(\omega<\hat{u}_{t}\right) \wedge\left(\hat{u}_{t} \bmod \omega=0\right) \\
\Delta_{b} / n & \operatorname{Se}\left(\omega>\hat{u}_{t}\right) \wedge\left(\omega \bmod \hat{u}_{t}=0\right) \\
\hat{u}_{t} & \text { caso contrário }
\end{array}\right.
\end{gathered}
$$

Com o valor real de $n$ é criado um vetor de zeros que conterá a NDP, isto é: $\mathbf{v}=\mathbf{0}_{1 \times n}$. Com $u_{t}$ é calculada a respectiva duração de cada figura rítmica em unidades de amplitude ponderada e a posição dentro do vetor de representação, assim: $\mathbf{p}=\left(\mathbf{A}_{1}-b^{\text {start }} / u_{t}\right)+1$ e $\mathbf{w}=\mathbf{A}_{1} / u_{t}$. Por fim, o vetor de NDP é obtido

\footnotetext{
${ }^{3}$ Do inglês: Weighted amplitude. Também chamado beat atômico
} 
da seguinte maneira: $v_{p_{j}}=w_{j}, \quad j=1,2, \ldots, m_{a}$.

\section{Função para o Cálculo do Vetor de Código}

O primeiro e o último elemento do vetor de código já são conhecidos ( $n$ e $\Delta_{b}$ ), então somente falta determinar a posição decimal da CRP $\left(\Delta_{p}\right)$ e a posição lexicográfica da CRS $\left(\Delta_{s}\right)$, para as quais, o cálculo será descrito a seguir.

Posição Decimal da Célula Rítmica Primaria $\Delta_{p}$ : Para o cálculo de $\Delta_{p}$ é usado o vetor de representação da CRP de origem. O vetor NDP pode ser de uma célula primária ou de uma secundária. Se o vetor $\mathbf{v}$ for binário então este representa a uma $\operatorname{CRP}\left(\mathbf{v}:=\mathbf{v}^{(p)}\right)$, caso contrário representa a uma CRS ( $\mathbf{v}:=$ $\mathbf{v}^{(s)}$ ). Em ambos os casos é necessário o vetor da CRP de origem. Caso o vetor de representação considerado for de uma CRP, o vetor de representação da CRP de origem é ele próprio e $\Delta_{p}$ é calculado apenas com a Eq. (A.5); caso contrário, é necessário calcular $\mathbf{v}^{(p)} \mathrm{de} \mathbf{v}:=\mathbf{v}^{(s)}$. Neste caso, primeiro é calculada a matriz $\mathbf{I}^{(q)}$ de dimensão $q \times 2$, onde $q$ é o número de figuras que foram ligadas, que contém o índice inicial e final do conjunto de ligaduras usadas para gerar $\mathbf{v}^{(s)}$ a partir de $\mathbf{v}:=\mathbf{v}^{(s)}$. Os índices iniciais, armazenados na primeira coluna do vetor $\mathbf{I}^{(q)}$, são os índices dos valores maiores a $1 \mathrm{de} \mathbf{v}^{(s)}$, e os índices finais são calculados da seguinte maneira: $\mathbf{I}_{2}^{(q)}=\mathbf{I}_{1}^{(q)}+\mathbf{v}_{\mathbf{I}_{1}^{(q)}}^{(s)}-1$. $\mathrm{O}$ vetor de representação da CRP de origem $\left(\mathbf{v}^{(p)}\right)$ é obtido preenchendo com 1 os elementos do vetor $\mathbf{v}^{(s)}$ entre os índices $\mathbf{I}_{1}^{(q)}$ e $\mathbf{I}_{2}^{(q)}$. O valor decimal da CRP de origem $\mathbf{v}^{(p)}$ é dado por:

$$
\Delta_{p}=\sum_{0<i \leq n}\left(\mathbf{v}_{i}^{(p)} \cdot 2^{n-i}\right)
$$

Posição Lexicográfica da Célula Rítmica Secundária $\left(\Delta_{s}\right)$ : A posição $\Delta_{s}$ de uma CRP sempre é 0 , portanto, não é necessário fazer cálculo algum e o vetor de código estará completo, porém, para uma CRS, $\Delta_{s}$ é calculado a partir de $\mathbf{v}:=\mathbf{v}^{(s)}$, conforme descrito a seguir.

O algoritmo 1, o qual é invocado como $\left[\mathbf{T}^{(\mathbf{B})}, \mathbf{I}^{(\mathbf{B})}\right]=\Phi\left(\mathbf{v}^{(p)}\right)$, devolve para um vetor binário $\mathbf{v}^{(p)}$, um vetor $\mathbf{T}^{(B)}$ com o tamanho dos blocos de 1's consecutivos (doravante simplesmente bloco) e uma matriz $\mathbf{I}^{(\mathbf{B})}$ com o índice inicial e final de cada bloco. Tanto $\mathbf{T}^{(B)}$ quanto $\mathbf{I}^{(\mathbf{B})}$ têm $l$ linhas, correspondendo ao número total de blocos.

Por outro lado, para as sequências compostas (vetores com mais de um bloco) o índice inicial e final de cada bloco deve ser escalado. O escalamento consiste em: tratar os índices como se fossem um bloco maior com todos os blocos concatenados, sobrepor os índices fronteira e deslocar o índice inicial 


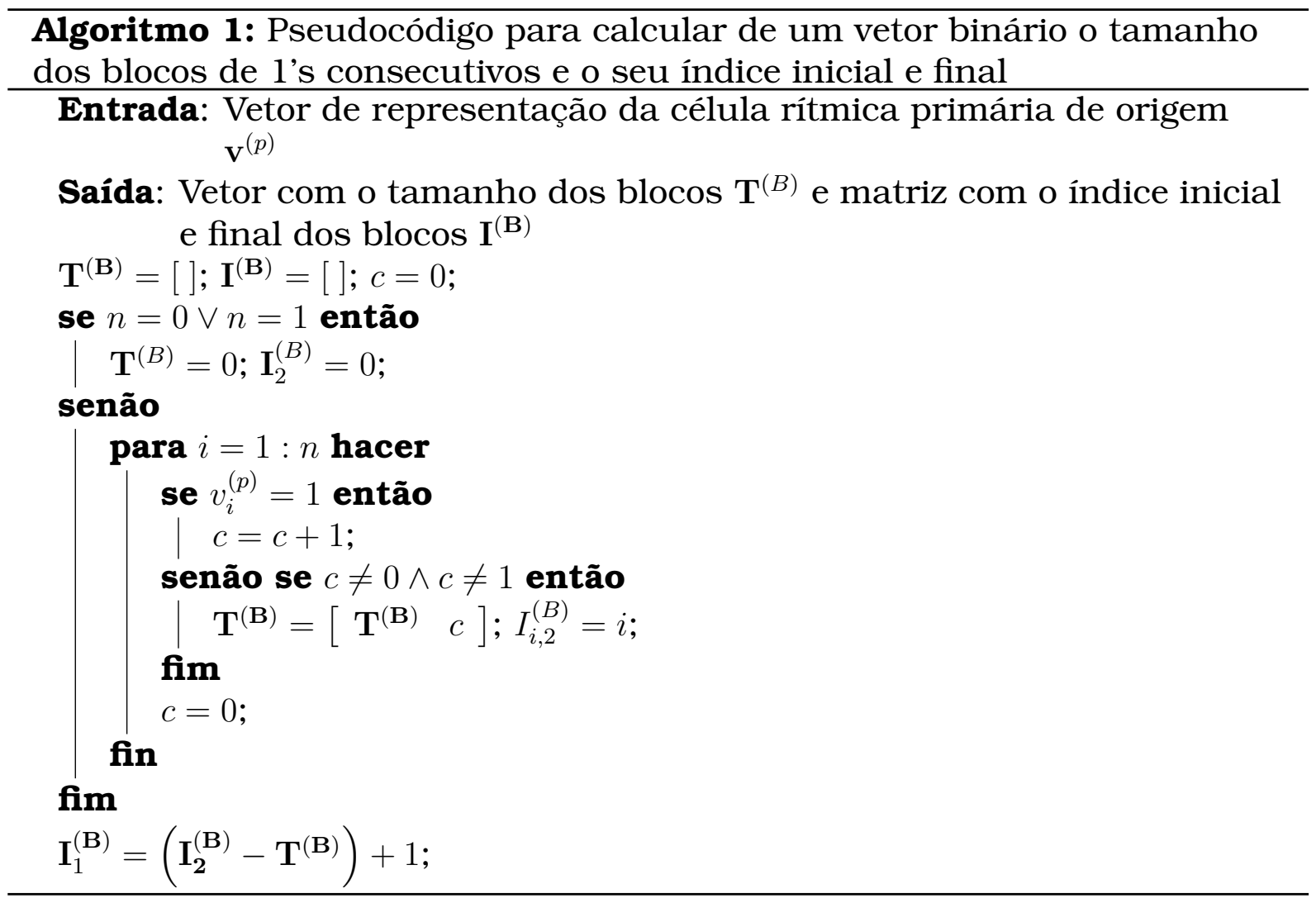

do primeiro bloco a 1. A matriz com os índices dos blocos escalados $\breve{\mathbf{I}}^{(B)}$ é dada por:

$$
\breve{\mathbf{I}}^{(\mathbf{B})}=\left\{\begin{array}{cc}
\mathbf{I}^{(\mathbf{B})}-I_{1,1}^{(\mathbf{B})}-1, & i=1 \\
\mathbf{I}^{(\mathbf{B})}-I_{i, 1}^{(\mathbf{B})}-\breve{I}_{i-1,2}^{(\mathbf{B})}, & 1<i \leq l
\end{array} .\right.
$$

O mapeamento anterior é referenciado como $\breve{\mathbf{I}}^{(\mathbf{B})}=\varphi\left(\mathbf{I}^{(\mathbf{B})}, j\right)$, pois ele será usado no próximo passo. As matrizes $\mathbf{I}^{(q)}$ e $\mathbf{I}^{(\mathbf{B})}$ são usadas para determinar o bloco pertencente a cada ligadura. Os índices das linhas de $\mathbf{I}^{(\mathbf{B})}$, cujos valores limitam os valores das linhas de $\mathbf{I}^{(q)}$, são armazenados em um vetor $\mathrm{g}$. A seguir, são escalados os índices das ligaduras dentro do seu bloco, assim: $\breve{\mathbf{I}}^{(q)}=\varphi\left(\mathbf{I}^{(q)}, g_{i}\right), \quad 1 \leq i \leq|\mathbf{g}|$. Por fim, são calculados $q$ vetores $\lambda$, os quais em conjunto contêm os números das ligaduras necessárias para criar o vetor de NDP da CRS a partir do respectivo vetor binário da CRP de origem, assim: $\lambda_{i}=\left[\begin{array}{llll}\breve{I}_{i, 1}^{(q)}+1 & \cdots & \breve{I}_{i, 2}^{(q)}-1 & \breve{I}_{i, 2}^{(q)}\end{array}\right]-1, \quad 0<i \leq q$. Os $q$ vetores $\lambda$ são concatenados em um novo vetor assim: $\gamma=\left[\begin{array}{llll}\lambda_{1} & \lambda_{2} & \cdots & \lambda_{q}\end{array}\right]$. O número máximo de possiveis ligaduras da CRP de origem é dado por: $l_{t}=\sum_{0<i \leq l}\left(T_{i}^{(B)}-1\right)$. Em seguida, são geradas as combinatórias de $l_{a}$ elementos tomados de $l_{t}$ e é testada a posição da combinação $\gamma$ dentro do total de combinatórias de $l_{a}$ elementos. As combinatórias são geradas com um algoritmo especial (Ruskey, 2003), representado aqui como $\Theta(\cdot)$, e guardadas na matriz $\Gamma$, assim: $\Gamma=\Theta\left(l_{t}, l_{a}\right)$. A 
posição lexicográfica de $\gamma$ dentro de $\Gamma$ é armazenada na variável $\sigma$. A posição lexicográfica absoluta da combinação $\gamma$ dentro do total de combinatórias corresponde ao último elemento do código procurado e é calculada como:

$$
\Delta_{s}=\sigma+\sum_{0<i \leq\left(l_{a}-1\right)}\left(\begin{array}{c}
l_{t} \\
i
\end{array}\right) .
$$

Note-se que o número total de possíveis CRSs de $\mathbf{v}^{(p)}$ é igual a: $2^{l_{t}}-1$. O diagrama de blocos do algoritmo codificador é mostrado na Fig. A.1.

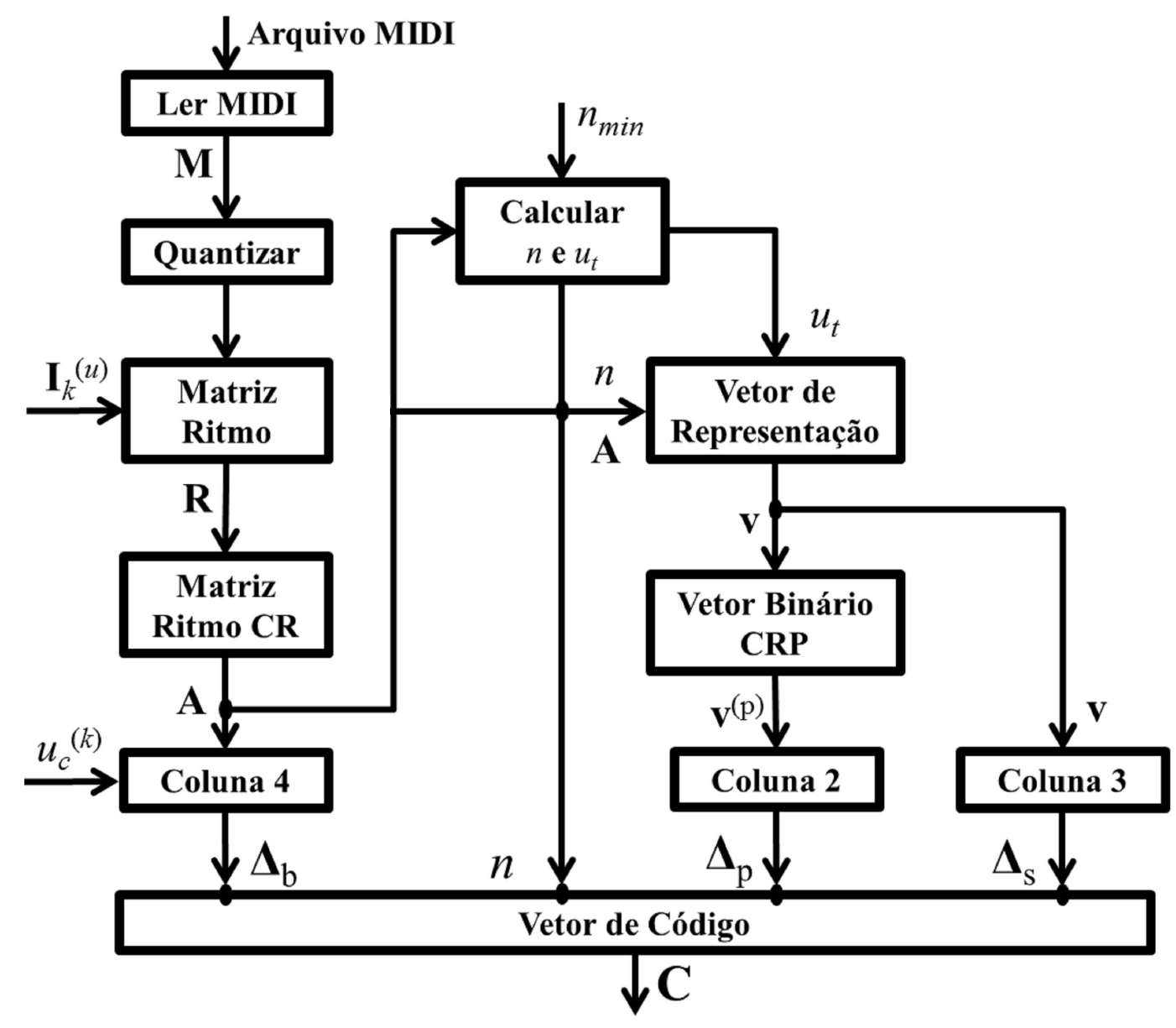

Figura A.1: Diagrama de blocos do codificador de células rítmicas.

\section{A. 1.2 Algoritmo Decodificador}

O algoritmo de decodificação faz o processo inverso do codificador, ou seja, devolve a matriz do ritmo A de uma CR a partir do seu vetor de código c.

Vetor de Representação da Célula Primaria de Origem

O primeiro passo consiste em obter o vetor de representação da CRP de origem $\left(\mathbf{v}^{(p)}\right)$ convertendo a posição decimal $\Delta_{p}$ em um binário de $n$ bits. Se o 
valor de $\Delta_{s}$ for 0 , trata-se de uma CRP e portanto o vetor de representação da CRP de origem é o vetor de representação da célula atual, neste caso, a matriz de notas é diretamente criada conforme mostrado na Seção A.1.2, porém, para uma CRS é necessário primeiro obter o seu vetor de representação em NDP. O número de ligaduras usadas para criar o vetor de NDP da CRS a partir do vetor binário da CRP de origem é dado por:

$$
l_{a}=\left\{\min \{j\} \mid \sum_{1}^{l_{t}}\left(\begin{array}{c}
l_{t} \\
j
\end{array}\right) \geq \Delta_{s} ; 0<j \leq l_{t}\right\} .
$$

A posição lexicográfica $\sigma$ da combinação de ligaduras $\gamma$ dentro das combinatórias de $l_{t}$ elementos tomados $l_{a}$ a $l_{a}$ é calculada usando a Eq. (A.7). Então, são geradas todas as combinatórias de ligaduras, isto é, $\Gamma=\Theta\left(l_{t}, l_{a}\right)$, para consequentemente selecionar a $\sigma$-ésima combinatória, assim: $\gamma=\Gamma_{\sigma}$. O próximo passo consiste em obter o índice inicial e final de todas as ligaduras de $\mathbf{v}^{(p)}$ usando o Algoritmo 1 e armazenando os índices escalados dentro de cada bloco dentro da matriz $\mathbf{I}^{(l)}$. A matriz $\mathbf{I}^{(l)}$ é requerida para obter os índices de cada ligadura de $\gamma$, estes índices são armazenados na matriz $\mathbf{I}^{(q)}$. Por facilidade, a matriz $\mathbf{I}^{(q)}$ é redimensionada a vetor, i.e., de dimensão $q \times 2$ a $1 \times 2 q$. O próximo passo é determinar a existência de ligaduras consecutivas dentro do mesmo bloco, e, se existirem, será necessário apagar os índices intermediários. Fazendo uso do Algoritmo 1, é determinado o conjunto de ligaduras consecutivas (blocos de valor $j$ ), obtendo $\left[\mathbf{T}^{(q, j)}, \mathbf{I}^{(q, j)}\right]=\Phi\left(\mathbf{I}^{(q)}-j\right.$ ), onde $j$ é uma variável percorrida na faixa $\min \left\{\mathbf{I}^{(q)}\right\} \leq j \leq \max \left\{\mathbf{I}^{(q)}\right\}$. Novamente o vetor de ligadura $\mathbf{I}^{(q)}$ é transformado em matriz. Por último, o vetor de representação da CR é gerado através dos índices inicial e final de entrada, somando os valores 1 de $\mathbf{v}^{(p)}$ entre os índices de cada linha de $\mathbf{I}^{(q)}$ e zerando os subsequente valores após a ligadura inicial.

\section{Gerar a Matriz do Ritmo}

O último passo consiste em obter a matriz de ritmo da célula a partir do vetor de representação v, como segue:

$$
\mathbf{A}=\left[\begin{array}{ll}
\mathbf{p}-1 & \mathbf{w}
\end{array}\right] \cdot\left(\Delta_{b} / n\right)
$$

onde $\mathrm{p}$ é um vetor com os índices dos elementos maiores que 1 do vetor $\mathbf{v} \mathrm{e}$ $\mathbf{w}=\mathbf{v}_{\mathbf{p}}$. Cabe ressaltar que a matriz do ritmo somente é calculada para uma $\mathrm{CR}$, para criar a matriz de notas para várias CRs as matrizes A devem ser consistentemente combinadas considerando a batida inicial de cada CR. $\mathrm{O}$ diagrama de blocos do algoritmo decodificador de CRs é mostrado na Fig. A.2. 


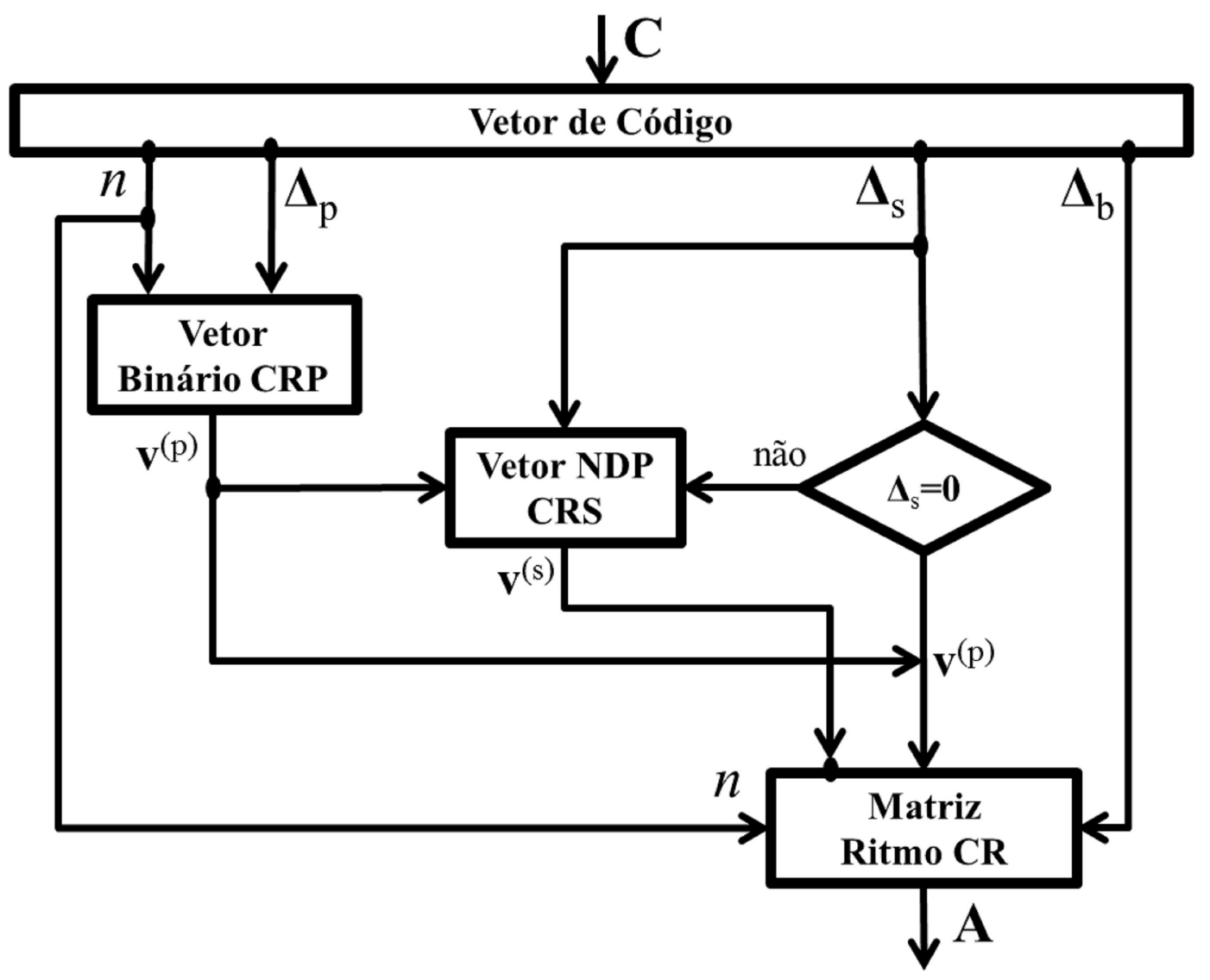

Figura A.2: Diagrama de blocos do decodificador de células rítmicas.

\section{A.2 Escalas Musicais}

Esta seção apresenta o desenvolvimento dos algoritmos para a codificação e decodificação de escalas musicais. Os elementos do código são descritos na Seção 3.1.1. O algoritmo codificador devolve o código da escala $\mathbf{c}_{1 \times 6}$ de um conjunto de tons musicais ou de valores MIDI, e o decodificador devolve os valores MIDI ou de frequência de uma escala segundo o código dado como entrada.

\section{A.2.1 Algoritmo Codificador}

Para uma escala de $n$ notas cujos tons encontram-se armazenados no vetor $\mathbf{e}_{1 \times(n+1)}$, o algoritmo codificador devolve o seu código $\mathbf{c}=\left[\begin{array}{llllll}t_{m} & n & g & \eta & m & \tau\end{array}\right]$. Cada um dos elementos do vetor de código, exceto $\tau$, são calculado a seguir. O codificador é composto por duas partes, a primeira valida se a estrutura da escala corresponde à estrutura de uma das escalas de análise e calcula os valores $t_{m}$ e $n$ (diagrama da Fig. A.4), e a segunda calcula os valores $g, \eta$ e $m$.

$\mathrm{O}$ vetor $\mathbf{e}_{1 \times(n+1)}$ contém todas as alturas da escala ordenadas ascendentemente (em valores MIDI ou tons) incluindo a oitava. O valor do primeiro elemento deste vetor corresponde à tônica $(\tau)$, com isso, o último valor do ve- 
tor de código é definido, isto é, $\tau=e_{1}$. No seguinte passo é calculado o vetor de intervalos entre notas sucessivas, assim: $I_{j}=\left|e_{j+1}-e_{j}\right|, \quad 1 \leq j \leq(n-1)$. Para este vetor é determinada a sua estrutura $u\left\{\hat{s}, \hat{t}, \hat{t}_{m}\right\}^{4}$, a qual deve ser validada antes de continuar.

Validação da Estrutura $u\left\{\hat{s}, \hat{t}, \hat{t}_{m}\right\}$

O primeiro passo de validação consiste em testar se $\hat{t}_{m} \in\{0,1, \ldots, 4\}$. Se for cumprida essa condição, então é testado se o valor de $\hat{n}=\hat{s}+\hat{t}+\hat{t}_{m}$ é adequado, ou seja, se $n_{\min } \leq \hat{n} \leq n_{\max }$, em que $n_{\min }$ e $n_{\min }$ são os limites de $n$ em função de $t_{m}$, os quais são definidos como:

$$
\begin{gathered}
n_{\min }=1 / 2 \cdot\left(12-t_{m}+\left(t_{m} \bmod 2\right)\right), \\
n_{\max }=12-2 t_{m} .
\end{gathered}
$$

A validação de $s$ e $t$ é definida de forma semelhante, isto é, é verificado se $s_{\min } \leq \hat{s} \leq s_{\max }$ e se $t_{\min } \leq \hat{t} \leq t_{\max }$. Os valores limite de $s, t$ e $n$ devem estar todos em função do parâmetro conhecido $t_{m}$. A equação para $s_{\min }=f\left(t_{m}\right) \mathrm{e}$ $s_{\max }=f\left(t_{m}\right)$ é, respectivamente:

$$
\begin{aligned}
& s_{\min }=t_{m} \bmod 2, \\
& s_{\max }=12-3 t_{m} .
\end{aligned}
$$

O valor de $t_{\min }$ é sempre 0 , e $t_{\max }=f\left(t_{m}\right)$ é definido como a metade da diferença entre $s_{\max }$ e $s_{\min }$, assim: $t_{\max }=\left(s_{\max }-s_{\min }\right) / 2$. Substituindo a Eq. (A.12) e (A.13) na definição anterior é obtido:

$$
t_{\max }=1 / 2 \cdot\left(12-3 t_{m}-\left(t_{m} \bmod 2\right)\right) .
$$

Se a validação de $\hat{s}$ e $\hat{t}$ forem bem-sucedidas, então é preciso validar se estes valores concordam com os valores teóricos, que são definidos em função dos parâmetros conhecidos $t_{m}$ e $n$. Usando as Eqs. (A.10) a (A.13), a expressão para $s=f\left(n, t_{m}\right)$ e $t=f\left(n, t_{m}\right)$ é, respectivamente:

$$
\begin{aligned}
& s=2 n-12+t_{m}, \\
& t=12-2 t_{m}-n .
\end{aligned}
$$

Se os valores teóricos ( $s$ e $t$ ) forem iguais aos valores de validação $(\hat{s}$ e $\hat{t}$ ) é

\footnotetext{
${ }^{4} \mathrm{O}$ símbolo $\wedge$ indica que os valores ainda não foram validados
} 
confirmado que os valores de $\mathbf{e}_{1 \times(n+1)}$ pertencem a uma das escalas de análise, podendo assim continuar com a segunda parte.

Cálculo de $g, \eta$ e $m$

Para calcular o número do grupo $g$ inicialmente é preciso calcular um vetor E com o número total de escalas primarias dentro de cada grupo e um vetor $\mathbf{M}$ com o número total de escalas secundárias (modos) geradas para cada escala primária E. O vetor $\mathrm{M}$ é calculado como:

$$
M_{i}=\frac{n}{d_{i}}, \quad i=1,2, \ldots,|\mathbf{d}|
$$

onde d é um vetor com os divisores do máximo divisor comum dos elementos de $u\left\{s, t, t_{m}\right\}$, sendo $d_{i}$ o $i$-ésimo divisor $\mathrm{e}|\mathbf{d}|$ a sua cardinalidade, igual ao número total de grupos. O vetor $\mathrm{E}$ é calculado a partir do seguinte sistema de duas equações com $|\mathbf{d}|$ incógnitas $^{5}$ :

$$
\begin{aligned}
\text { (1) } & =\sum_{1}^{|\mathbf{d}|} M_{i} \cdot E_{i} \\
\text { (2) } P C R & =\sum_{1}^{|\mathbf{d}|} E_{i}
\end{aligned},
$$

em que $P R$ é o número total de escalas secundárias, igual à somatória do número total de modos de cada escala primária, e $P C R$ é o número total de escalas primárias. O número total de escalas secundárias $P R$ é calculado assim:

$$
\begin{aligned}
P R_{s, t, t_{m}}^{n} & ={ }_{n} C_{(n-s)} \cdot{ }_{(n-s)} C_{t}, \\
& ={ }_{n} C_{(s+t)} \cdot{ }_{(s+t)} C_{s} .
\end{aligned}
$$

Para o caso de escalas formadas somente por intervalos $S$ e $T$, a seguinte versão simplificada pode ser usada: $P R_{s, t}^{n}={ }_{n} C_{s}={ }_{n} C_{t}$. O número total de escalas primárias $(P C R)$ é calculado usando a equação para o cálculo de permutações circulares com elementos repetidos ${ }^{6}$ (Ruskey \& Sawada, 1999), assim:

$$
P C R_{u_{j}}^{n}=\left\{\begin{array}{cc}
\frac{P R_{u_{j}}^{n}}{n}, & |\mathbf{d}|=1 \\
\frac{1}{n} \sum_{1}^{|\mathbf{d}|} \phi\left(d_{i}\right) \frac{\left(n / d_{i}\right) !}{\prod\left(u_{j} / d_{i}\right) !}, & \text { caso contrário }
\end{array},\right.
$$

onde $\phi(\cdot)$ é a função totiente de Euler (Goldberg et al., 1972) e $j$ é um índice usado para percorrer os elementos da estrutura $u\left\{s, t, t_{m}\right\}$. Quando o número

\footnotetext{
${ }^{5}$ Para as estruturas das escalas codificadas neste apêndice o máximo número de incógnitas é $3(|\mathbf{d}|=3)$

6 Também chamado em inglês como necklaces
} 
de divisores é igual a 2 a solução do sistema de Eqs. (A.18) é dada por:

$$
E_{i}=(-1)^{i} \frac{d_{1} \cdot d_{2} \cdot P C R-P R}{d_{\left(i-(-1)^{i}\right)}\left(d_{2}-d_{1}\right)}, \quad i=1,2 .
$$

Para o caso de três divisores o sistema é resolvido usando o método de Diofanto, obtendo a seguinte inequação para $E_{1}$ :

$$
\frac{P R-M_{2} \cdot P C R}{M_{1}-M_{2}}<E_{1}<\frac{P R-M_{3} \cdot P C R}{M_{1}-M_{3}} .
$$

Após encontrar uma solução inteira para $E_{1}$, o sistema é resolvido encontrando os valores para $E_{2}$ e $E_{3}$, da seguinte maneira:

$$
\begin{aligned}
& E_{2}=\frac{\left(P R-M_{3} \cdot P C R\right)-\left(M_{1}-M_{3}\right) E_{1}}{\left(M_{2}-M_{3}\right)}, \\
& E_{3}=\frac{\left(M_{2} \cdot P C R-P R\right)+E_{1}\left(M_{1}-M_{2}\right)}{\left(M_{2}-M_{3}\right)} .
\end{aligned}
$$

As permutações circulares com elementos repetidos de $n$ elementos com $k$ classes são geradas usando o algoritmo descrito em (Ruskey \& Sawada, 1999). O algoritmo é executado para os elementos da estrutura $u=\left\{s, t, t_{m}\right\}$, isto é, é invocado como $\mathbf{N}_{k}^{n}\left(s, t, t_{m}\right)$, onde o número total de elementos é $n=s+t+t_{m}$ e o número de classes é $k=3$. O conjunto obtido é armazenado na matriz $\mathbf{H}$, ou seja, $\mathbf{H}=\mathbf{N}_{k}^{n}\left(s, t, t_{m}\right)$. Um vetor $\mathbf{p}$ com o período de cada linha (escala primária) de $\mathbf{H}$ é calculado como segue:

$$
p_{j}=\left\{\alpha \mid \operatorname{Se} H_{j,(1: \alpha)}=H_{j,(i \alpha+1: i \alpha+\alpha)} \forall i \in[1 . . \beta]\right\},
$$

onde $\alpha$ varia entre $M_{1}$ e $M_{|\mathbf{d}|}, \beta$ é igual a $(n-\alpha) / m$ e $j$ é um índice percorrido entre 0 e $P C R$. Então, as linhas da matriz $\mathbf{H}$ são ordenadas descendentemente segundo o vetor de períodos. Seja $\phi(\cdot)$ uma função que devolve a posição exata de $\mathbf{I}$ dentro de $\mathbf{H}$ através do índice da linha $a$ e do número de deslocamentos $b$, operação definida como $[a, b]=\phi(\mathbf{H}, \mathbf{I})$; e seja $\delta(\mathbf{v}, k)$ uma função que devolve a posição dos elementos do vetor $\mathbf{v}$ que são iguais a $k$. Por fim, o número do grupo $g$ é igual a $\delta\left(\mathbf{E}, \mathbf{p}_{a}\right)$, e o número da escala $\eta$ dentro do grupo $g$ é igual a $\delta(\mathbf{w}, a)$, onde $\mathbf{w}$ é um vetor que contém os números das linhas da matriz que são iguais ao período na posição $a$, isto é: $\mathbf{w}=\delta\left(\mathbf{p}, p_{a}\right)$. Enfim, o número do modo $m$ corresponde ao número de deslocamentos $b(m=b)$. Na Tabela A.1 e A.2 são mostrados alguns valores usados pelo codificador.

\section{A.2.2 Algoritmo Decodificador}

Para uma escala cujo código $\mathbf{c}_{1 \times 6}$ é conhecido, o algoritmo decodificador devolve o vetor $\mathbf{e}_{1 \times n}$ que contém as alturas em valores MIDI ou o vetor $\mathbf{f}_{1 \times n}$ que 
Tabela A.1: Valores de algumas variáveis usadas pelo codificador de escalas quando aplicado a escalas com estrutura $u=\{s, t, 0\}$. Número de notas $(n)$, número de tons $(t)$, número de semitons $(s)$, grupo $(g)$, vetor com o total de escalas primárias $\mathrm{E}$, vetor com o total de escalas secundárias $\mathrm{M}$ e total de escalas secundárias $(P R)$.

\begin{tabular}{|c|c|c|c|c|c|c|}
\hline$n$ & $\bar{t}$ & $s$ & $g$ & $\bar{E}$ & $\mathbf{M}$ & $\overline{P R}$ \\
\hline$\overline{86}$ & $\overline{76}$ & $\overline{\mathbf{0}}$ & $\bar{~} \overline{11}$ & $\overline{11}$ & $\overline{11}$ & $\overline{11}$ \\
\hline 7 & 5 & 2 & 1 & 3 & 7 & 21 \\
\hline \multirow{3}{*}{8} & \multirow{3}{*}{4} & \multirow{3}{*}{4} & 1 & 8 & 8 & \multirow{3}{*}{70} \\
\hline & & & 2 & 1 & 4 & \\
\hline & & & 3 & 1 & 2 & \\
\hline \multirow[t]{2}{*}{9} & \multirow[t]{2}{*}{3} & \multirow[t]{2}{*}{6} & 1 & 9 & 9 & \multirow[t]{2}{*}{84} \\
\hline & & & 2 & 1 & 3 & \\
\hline \multirow[t]{2}{*}{10} & \multirow[t]{2}{*}{2} & \multirow[t]{2}{*}{8} & 1 & 4 & 10 & \multirow[t]{2}{*}{45} \\
\hline & & & 2 & 1 & 5 & \\
\hline 11 & $\mathbf{1}$ & 10 & 1 & 1 & 11 & 11 \\
\hline 12 & $\mathbf{0}$ & 12 & 1 & 1 & 1 & 1 \\
\hline \multicolumn{3}{|c|}{ Total } & & $\overline{31}$ & $\overline{611}$ & $2 \mathbf{2 3 3}$ \\
\hline
\end{tabular}

Tabela A.2: Valores de algumas variáveis usadas pelo codificador de escalas quando aplicado a escalas com estrutura $u=\left\{s, t, t_{m}\right\}$. Número de notas $(n)$, número de tons e meio $\left(t_{m}\right)$, número de tons $(t)$, número de semitons $(s)$, grupo $(g)$, vetor com o total de escalas primárias $\mathbf{E}$, vetor com o total de escalas secundárias $\mathrm{M}$ e total de escalas secundárias $(P R)$.

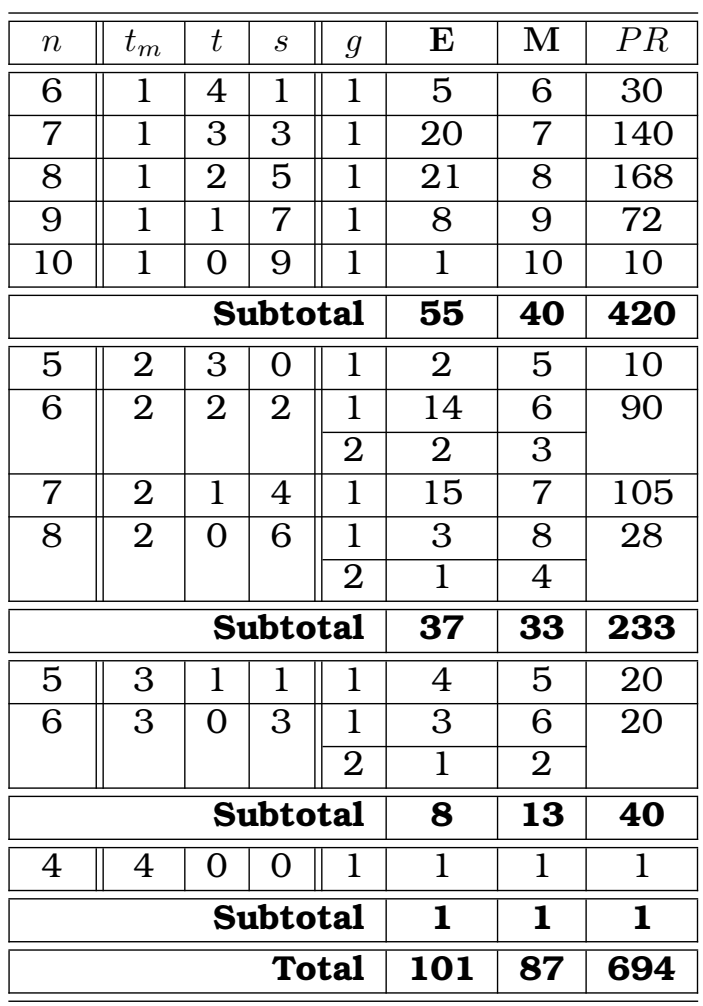

contém as alturas em valores de frequência. Inicialmente, todos os valores 


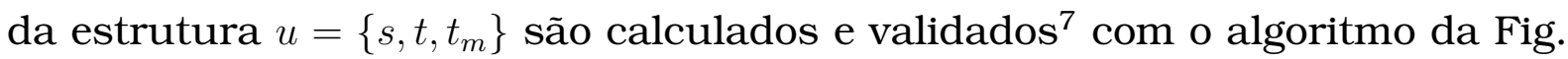
A.4. Com a estrutura validada é calculado o vetor com o total de escalas primarias E (Eq. (A.17)) e o vetor com o total de modos M (Eq. (A.24)). A estrutura completa $u=\left\{s, t, t_{m}\right\}$ é usada para gerar as permutações circulares com elementos repetidos, obtendo $\mathbf{H}=\mathbf{N}_{k}^{n}\left(s, t, t_{m}\right)$. As linhas da matriz $\mathbf{H}$ são ordenadas segundo o seu período p (calculado com a Eq. (A.25)). O vetor de intervalos I é separado da matriz $\mathbf{H}$ mediante a aplicação direta do seu índice, assim: $\mathbf{I}=\mathbf{H}_{\left(l_{1}^{g}+\eta-1\right)}$, onde $l_{1}^{g}$ é o índice inicial do grupo $g$ dentro da matriz $\mathbf{H}$, dado por:

$$
l_{1}^{g}=\left\{\begin{array}{cc}
1, & g=1 \\
\sum_{1 \leq i \leq(g-1)}^{g-1} E_{i}+1, & \text { caso contrário }
\end{array}\right.
$$

A partir do vetor de intervalos I a escala pode ser gerada em valores MIDI ou em valores de frequência. Estas duas opções são descritas a seguir.

\section{Escala em valores MIDI}

Seja $\rho(\mathbf{a}, i)$ um operador de rotação circular, o qual executa $i$ rotações circulares anti-horárias sobre um dado vetor a. Este operador é usado para obter o vetor de intervalos da escala secundária, deslocando o vetor da escala primária $m$ vezes, assim: $\overleftarrow{\mathbf{I}}^{(m)}=\rho(\mathbf{I}, m)$. Em seguida, é gerado o vetor $\mathbf{e}_{1 \times n}$ com os números MIDI da escala. O último valor do código $\tau=\mathbf{c}_{6}$ é a tônica (em valor MIDI), então $e_{1}=\tau$, e os demais elementos da escala são gerados da seguinte forma: $e_{i+1}=e_{i}+\overleftarrow{I}_{i}^{(m)}, 1 \leq i \leq n$. Para o caso do sistema 12-TET é possível converter a escala de valores MIDI em valores de frequência da seguinte maneira (Coca et al., 2010):

$$
f_{i}=440 \cdot 2^{\left(e_{i}-69\right) / 12}, \quad 0<i \leq n
$$

No entanto, para escalas temperadas microtonais, onde a notação musical é difícil e ainda não está totalmente definida (Gardner, 1990), essa conversão não é possivel, portanto, a conversão direta de I a valores de frequência é preferida.

\section{Escala em Valores de Frequência}

Inicialmente é calculado o vetor de pertinência binário $\mathrm{V}$ da escala $\xi$ de $n$ notas, onde um valor 1 na posição $V_{i}$ indica que a $i$-ésima nota da escala cromática $\Xi$ do sistema N-TET faz parte da escala $\xi$ e um valor 0 o caso contrário (Coca et al., 2010). O vetor de pertinência é inicializado com zeros,

\footnotetext{
${ }^{7}$ Para conferir que o código da escala é um código valido
} 
assim: $\mathbf{V}=0_{1 \times(N+1)}$. Além disso, dois novos vetores com dimensão $1 \times n$ são usados: $\Gamma$ e L. O vetor $\Gamma$ contém o número de deslocamentos necessários para passar do primeiro modo $m_{1}$ até o modo $m_{i}$, e é gerado como: $\boldsymbol{\Gamma}_{i+1}=\boldsymbol{\Gamma}_{i}+\mathbf{I}_{i}, \quad 1 \leq i \leq n$; e o vetor $\mathbf{L}$ contém a posição das notas da escala $\xi$ dentro da escala cromática $\Xi$, ou seja, os índices com valor igual a 1 do vetor de pertinência $\mathbf{V}$. Com o vetor de deslocamento $\Gamma$ é criado o vetor de índices L, assim: $\mathbf{L}=\boldsymbol{\Gamma}+1$. O vetor de pertinência da escala primária é determinado como: $\mathbf{V}\left(\Gamma_{\mathbf{L}_{i}}\right)=1,0<i \leq(n+1)$. O vetor de pertinência da escala secundária é obtido mediante o deslocamento do vetor de pertinência da escala primária um certo número de vezes até atingir o modo desejado, assim: $\overleftarrow{\mathbf{V}}^{(m)}=\rho\left(\mathbf{V}, \Gamma_{m}\right)$

A escala cromática igualmente temperada em razões de frequência é gerada como (Coca et al., 2010):

$$
s_{i}=2^{\lambda(i-1) / 6}, \quad 0<i \leq N^{(k)}+1
$$

em que $\lambda \in(0,0.5]$ é o fator de afinação da escala, igual ao inverso do número de divisões do tom $\Delta\left(\lambda=1 / \Delta\right.$, onde $\lambda=0.5$ para 12-TET); e $N^{(k)}$ é o número total de notas que conformam a escala cromática em $k$ oitavas segundo o fator de afinação, calculado como $6 k / \lambda$. O vetor $\overleftarrow{\mathrm{V}}^{(m)}$ é aplicado como um filtro sobre o vetor s, retendo somente os intervalos que pertencem à escala desejada e apagando os outros. O resultado desta operação é o vetor $\tilde{\text { s, da }}$ seguinte forma:

$$
\tilde{s}_{i}=\overleftarrow{V}_{i}^{(m)} \cdot s_{i}, \quad 0<i \leq N^{(k)}+1 .
$$

Por fim, o vetor r com $n$ elementos é obtido apagando as entradas com valor zero do vetor $\tilde{\mathbf{s}}$, como segue: $\mathbf{r}=\left\{\tilde{s}_{i} \mid \tilde{s}_{i} \neq 0, \forall i\right\}$. A frequência da tônica $f_{\tau, o}$ do tom $\tau$ na oitava $o$ é obtida como: $f_{\tau, o}=55 \cdot 2^{(\tau+12 o-10) / 12}$, e com esta é obtida a escala em valores de frequência da seguinte forma: $\mathbf{f}=f_{\tau, o} \cdot \mathbf{r}$.

A Fig. A.4 apresenta o diagrama em blocos do processo de validação da estrutura da escala $u=\left\{s, t, t_{m}\right\}$, o qual é usado pelo codificador e pelo decodificador. A Fig. A.3(a) e A.3(b) mostra o digrama de blocos do codificador e do decodificador, respectivamente. 


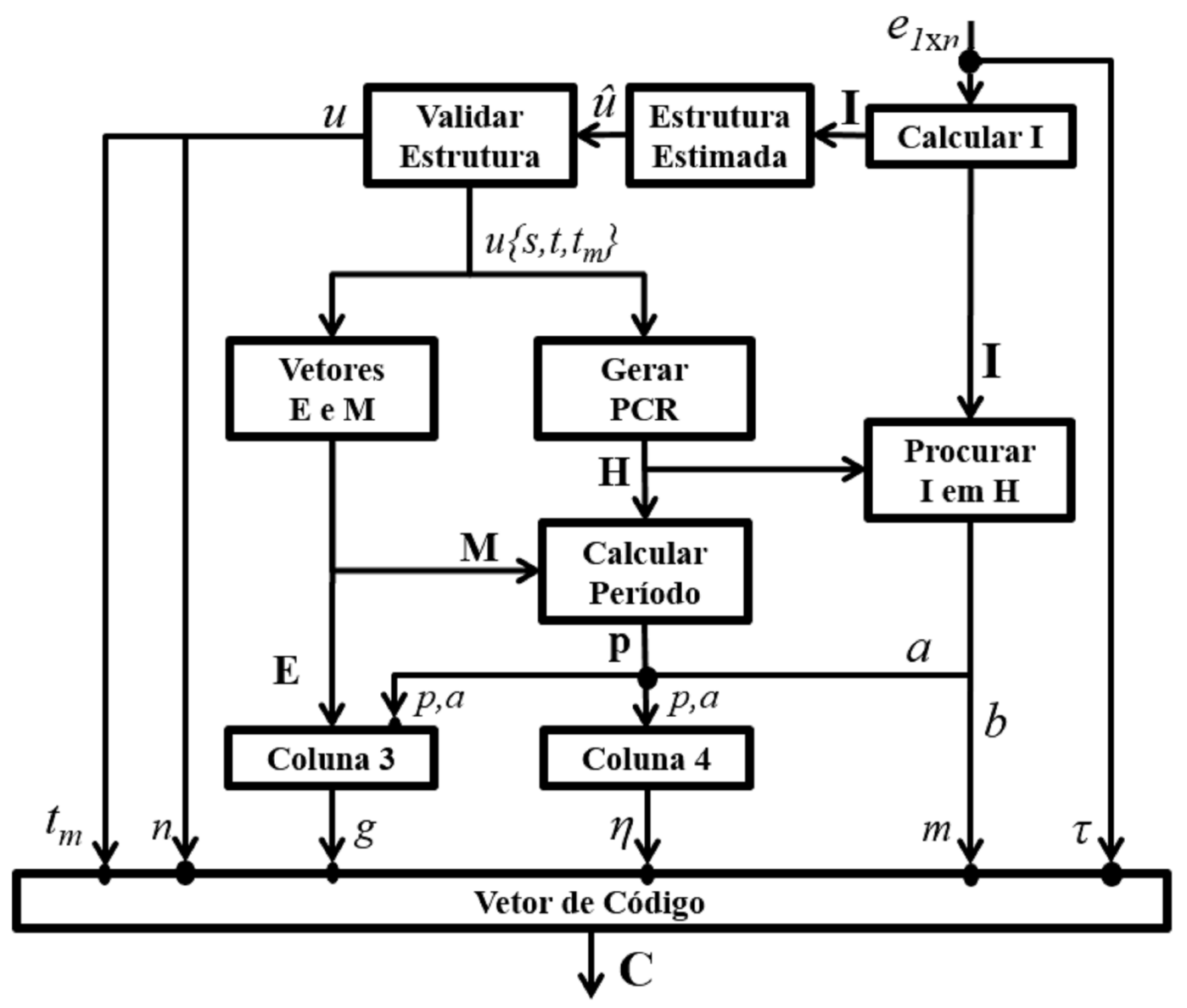

(a)

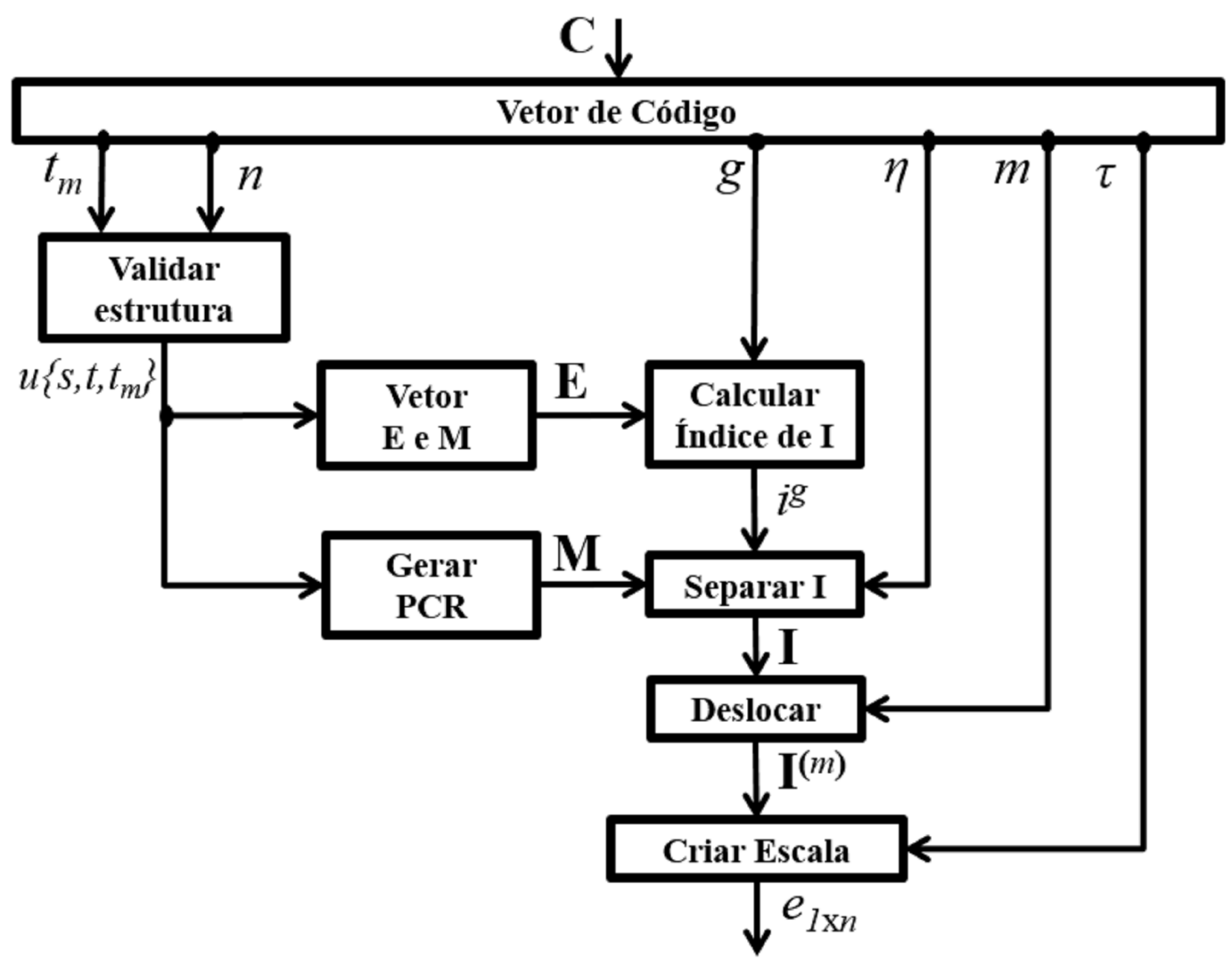

(b)

Figura A.3: Diagrama de blocos do algoritmo (a) codificador e (b) decodificador de células rítmicas. 


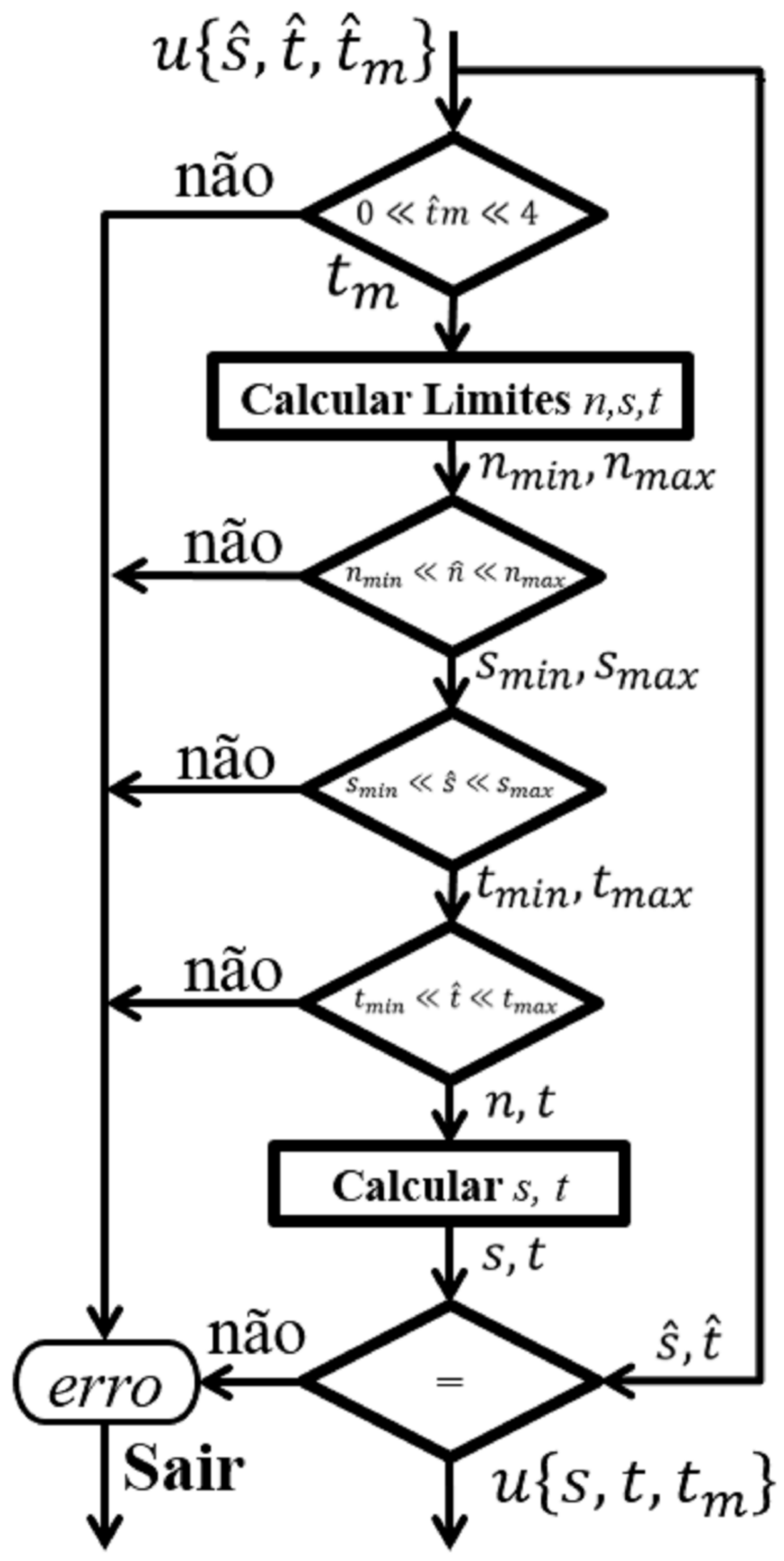

Figura A.4: Diagrama de blocos do algoritmo de validação da estrutura da escala. 


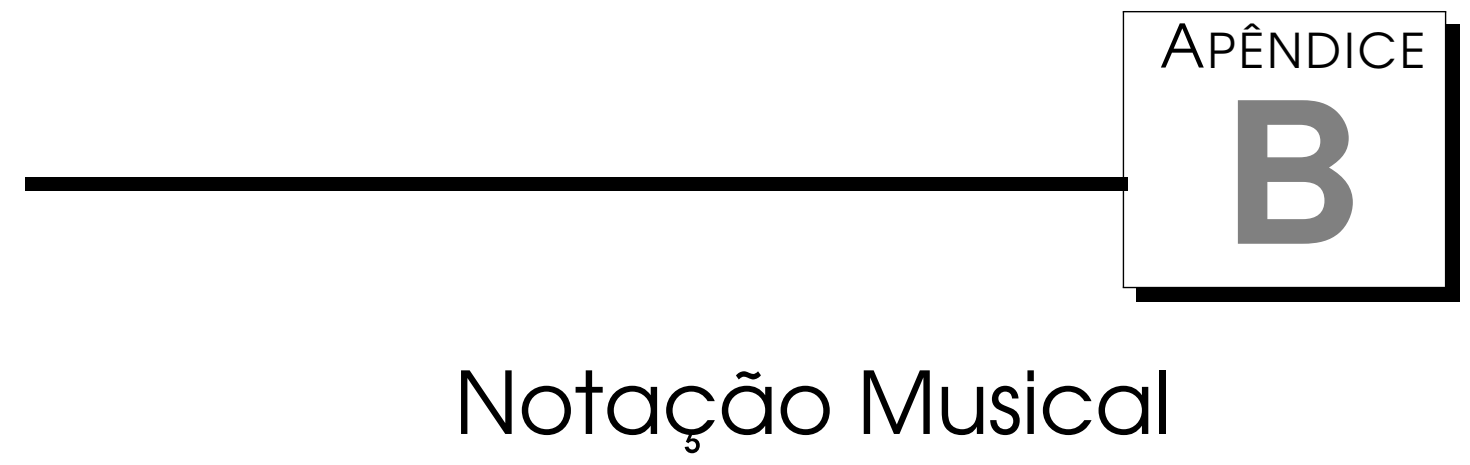

$\mathrm{N}$ este apêndice são definidos os conceitos básicos da teoria de notação musical necessários para a melhor compreensão de alguns aspectos abordados neste trabalho. A ênfase principal deste apêndice encontra-se na notação musical da altura e do ritmo, bem como na notação usada para a bateria.

\section{B. 1 Notação de Altura}

Na notação musical comum o elemento mais importante é o conjunto de cinco linhas horizontais e equidistantes denominado pentagrama ou pauta ${ }^{1}$, posto que sobre as linhas, e nos espaços incluídos entre elas, escreve-se a maior parte dos signos musicais. O pentagrama define duas dimensões importantes: temporal e tonal. A dimensão temporal define a distância cronológica ao longo do pentagrama e entre eventos sucessivos (horizontalmente), enquanto a dimensão tonal está relacionada com a frequência de oscilação das notas (verticalmente) (Lacerda, 1966). Na Fig. B.1(a) são mostradas as linhas e os espaços do pentagrama musical. Cada linha e cada espaço representam uma nota, as quais são organizadas de grave a agudo, isto é, as notas mais graves são escritas na parte inferior e as mais agudas na parte superior, sendo uma nota mais aguda que a sua sucessora e menos grave que a sua predecessora. As linhas de um pentagrama são numeradas de baixo ( $1^{\mathrm{a}}$ ) para cima (5⿳⺈⿴囗十一). Quando a cabeça de uma nota se situa acima da $5^{\underline{a}}$ linha ou abaixo da 1a é necessário usar pequenos segmentos, denominados linhas suplementa-

\footnotetext{
${ }^{1}$ Pautas com menos de cinco linhas também são possíveis
} 
res, que permitem visualizar a posição relativa da nota. Os pentagramas são normalmente divididos por barras verticais que dividem fragmentos temporais de igual duração, chamados compassos, e podem ser agrupados em sistemas mediante as barras de divisão ou por uma chaveta na parte esquerda dos pentagramas envolvidos. O uso da chaveta é necessário quando a extensão do instrumento superar a extensão do pentagrama (como o piano) ou quando for desejado agrupar vários pentagramas que evoluem simultaneamente no tempo. Os símbolos que compõem a notação musical são escritos sobre ou próximo dos pentagramas, e o seu significado ou valor é definido quase sempre pela sua posição. Os principais símbolos musicais que são escritos sobre as linhas são: notas, claves e pausas. As notas musicais representam a altura relativa dos sons de acordo com a sua posição vertical no pentagrama. Na notação padrão são usadas sete notas, as quais podem ser nomeadas usando a nomenclatura italiana ou a inglesa, sendo estas: Dó, Ré, Mi, Fá, Sol, Lá, Si na primeira nomenclatura e C, D, E, F, G, A, B na segunda (Lacerda, 1966). Uma nota colocada no pentagrama só tem nome definido quando for usado um símbolo no inicio do pentagrama que designa uma nota de referência, este símbolo é chamado clave e define o nome da nota musical de uma única linha, obedecendo as demais linhas e espaços ao nome das seguintes notas na sequencia estabelecida pela nomenclatura usada. Existem três claves, chamadas clave de Sol ( $)$, de Fá ( ๆ:) e de Dó ( $\mid 9$ ), as quais ao todo podem ocupar 9 posições no pentagrama, sendo as posições mais comuns a clave de Sol na $2^{\underline{a}}$ linha, a clave de Fá na $4^{\underline{a}}$ linha e a clave de Dó na $3^{\underline{a}}$ ou $4^{\underline{a}}$ linha. A clave de Dó refere-se sempre ao Dó central, Dó inferior da clave de Sol ou Dó superior da clave de Fá, independente da linha em que for escrito ( $1^{\mathbf{a}}$ até $5^{\underline{a}}$ ) (Lacerda, 1966).

Na sequência natural das notas do piano, entre cada par de notas sucessivas existe uma nota que está a meia unidade de distância entre as duas notas vizinhas, esta unidade de distância é chamada semitom (S), existindo, por tanto, um tom (T) completo entre duas notas da sequência, exceto entre Mi e Fá e entre Si e Dó, ou seja, a sequência de tons e semitons formada pela sequência natural das notas é T T S T T T S, onde o último semitom é formado entre a última nota e a nota inicial que é repetida para fechar o ciclo. A sequência natural das notas se conhece como escala diatônica maior e a distância entre duas notas em unidades de semitom como intervalo, sendo que um intervalo de oitava é aquele que abrange todas as notas da escala, isto é, 12 semitons. O nome dos intervalos e o respectivo número de semitons é mostrado na Tabela B.1. A nota que está a um semitom de distância entre duas notas da escala é alcançada através de um símbolo que altera a 
altura da nota que precede, chamado acidente. Os acidentes básicos ${ }^{2}$ são: sustenido $(\sharp)$, que eleva um semitom; bemol (b), que diminui um semitom; e bequadro $(\measuredangle)$, que anula qualquer alteração anterior. O nome da nova nota deriva do nome da nota alterada e do acidente usado, por exemplo, um sustenido antecedendo um Dó criará um Dó sustenido. Os acidentes apenas têm efeito dentro do mesmo compasso, portanto, se for necessário manter o efeito por mais de um compasso será necessário usar um grupo de acidentes que são dispostos no inicio do pentagrama e logo após a clave, o qual é chamado armadura de clave. A armadura de clave tem efeito ao longo do pentagrama todo, a não ser que o seu efeito seja anulado por um acidente (geralmente bequadro) ou por uma nova armadura de clave (Lacerda, 1966). A Fig. B.1(b) ilustra as armaduras de clave com sustenidos e bemóis.

As oitavas são numeradas tendo como referência o primeiro Lá após a clave de Sol, que é o Lá da quarta oitava (A4), e, portanto, pertencendo à quarta oitava, não existindo um limite inferior ou superior na numeração das oitavas além da resposta auditiva do ser humano. Normalmente os pianos modernos têm sete oitavas. A Fig. B.1(a) apresenta as linhas complementares, os números das linhas e espaços, as claves, os intervalos da escala diatônica maior, a posição das notas dentro do pentagrama e a denominação das notas nas duas nomenclaturas.

Uma escala é um conjunto ordenado de notas sucessivas e separadas por semitons e/ou tons. Se a escala só tiver semitons trata-se de uma escala cromática, caso contrário trata-se de uma escala diatônica. A escala cromática contém todas as notas possiveis dentro de uma oitava. A primeira nota da escala se chama tônica e participa na denominação da escala, por exemplo, a sequência natural das notas descrita acima é chamada escala diatônica de Dó maior. Quando uma escala for começada em uma nota diferente à tônica, porém conservando a sequência estabelecida, dá origem a uma escala derivada chamada modo. Uma escala tem tantos modos quantas notas tiver, portanto, a escala diatônica de Dó maior tem 7 modos, que são chamados modos gregos, os quais têm nome definido, a saber: jônio, dórico, frígio, lídio, mixolídio, eólio e lócrio. O modo eólio também é conhecido como escala diatônica menor. Se a estrutura de intervalos de uma escala for alterada pela adição ou subtração de um dado intervalo é obtida uma nova escala que conserva a mesma estrutura de intervalos, mas com uma nova sequência de notas, por exemplo, a escala diatônica maior começando em Sol (+ 7 semitons) se chama Sol maior (Lacerda, 1966). Esta operação é conhecida como transposição.

Um conjunto de notas executadas com uma duração definida, uma após a outra, e não importando a ordem dentro da sequência nem a unicidade dentro

\footnotetext{
${ }^{2}$ Outros acidentes são: o duplo sustenido $(\times)$ e o duplo bemol (bb), que eleva e diminui um tom, respectivamente.
} 
do conjunto forma uma melodia. Por sua vez, um conjunto de três ou mais notas da escala executado de maneira simultânea é chamado acorde, e o conjunto de acordes que acompanham uma melodia se conhece como harmonia, e justamente a parte da teoria musical que estuda e forma de encadear estes acordes recebe este mesmo nome. O conjunto de duas notas não é chamado de acorde e sim de intervalo. Se as notas que formam um intervalo ou acorde trocarem de posição formam um intervalo ou acorde invertido (Lacerda, 1966).

Por outro lado, um particular conjunto de frequências estudado pela física é a série harmônica. Nesta série, para uma dada frequência inicial, chamada frequência fundamental, a frequência dos demais sons (ou tons) da série são múltiplos da frequência fundamental, as quais coincidem com os valores das frequências fundamentais de algumas notas musicais, formando uma relação de intervalos definida com respeito à tônica e dando lugar à escala dos harmônicos, que é mostrada na Fig. B.2. Da série harmônica deriva o sistema de afinação natural, que é um sistema usado para dividir ou afinar a oitava, onde os intervalos são representados por números racionais com valores inteiros tão pequenos quanto possível, chamados razões de frequência e mostrados na Tabela B.1. Note que a razão de frequência está relacionada com os números das notas da escala dos harmônicos. Apesar deste sistema de afinação ser considerado natural, não consegue refletir iguais propriedades para todas as escalas, dado que é criado um desvio quando usada a transposição. Como solução a esse problema foi criada a escala temperada, que consiste em dividir a oitava em $N$ partes iguais (escala igualmente temperada de $N$ notas $\left.\left(N-\mathrm{TET}^{3}\right)\right)$ e, mesmo afetando a afinação ideal, esta afinação é preferida e amplamente usada na música ocidental, normalmente a escala 12-TET (Gardner, 1990).

Uma nota musical também pode ser expressa mediante o formato MIDI (Musical Instrument Digital Interface), que é um protocolo usado para a comunicação e transferência de dados entre instrumentos digitais. O formato MIDI contém toda a informação requerida sobre a evolução dos eventos musicais, como inicio, fim, intensidade, instrumentos...etc., portanto, considera-se como uma partitura digital. Este tipo de representação também é conhecido como representação simbólica. No que respeita às notas musicais, estas são descritas em termos de duração, intensidade e altura mediante números inteiros, em contraposição ao uso de valores de frequência. Por exemplo, os números MIDI de A0, A4 e C8 são 21, 69 e 108, respectivamente (Eerola \& Toiviainen, 2004).

\footnotetext{
${ }^{3}$ Sigla de Tone Equal Temperament
} 


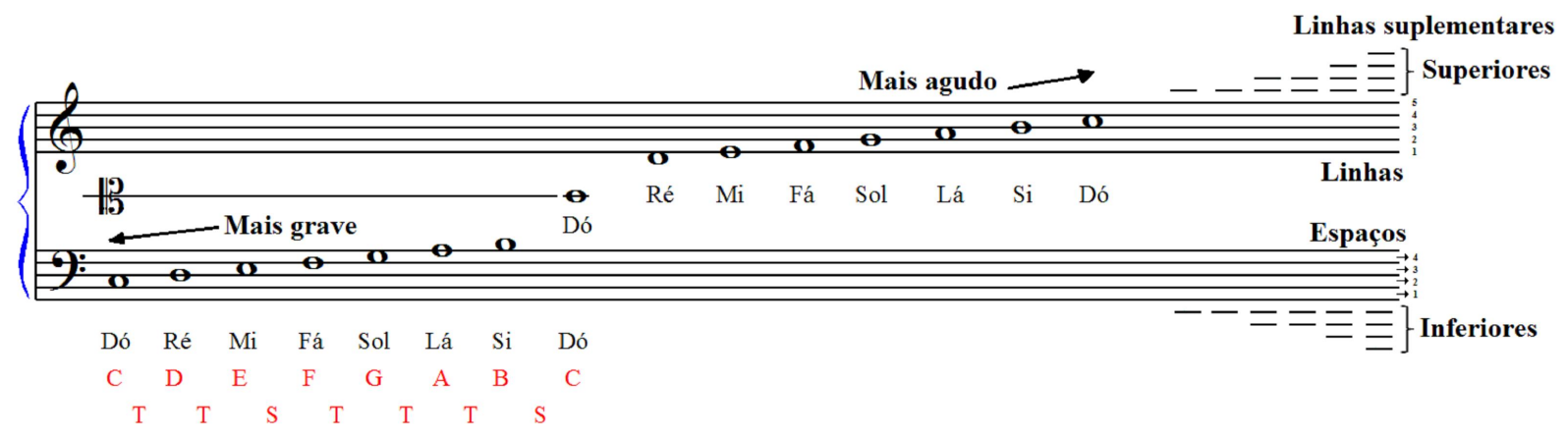

(a)

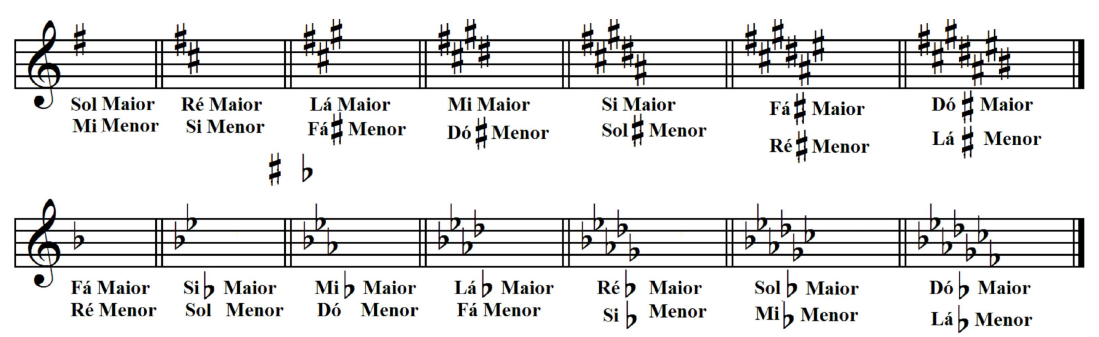

(b)

Figura B.1: Pentagrama musical incluindo (a) linhas, espaços, linhas suplementares, claves e as notas musicais com os seus respectivos intervalos e nomes; (b) Armaduras com sustenidos e bemóis.

\section{B.2 Notação de Duração}

As notas musicais além de terem uma altura relativa, também têm uma duração que é defina pela sua forma. As diferentes formas que pode ter uma nota se chamam figuras ritmicas, as quais têm um valor relativo binário que formam um sequência de durações, onde uma figura tem o dobro de duração da figura predecessora e a metade da sua sucessora. As figuras rítmicas básicas $^{4}$ de maior a menor duração são sete, a saber: semibreve (o), mínima (d),

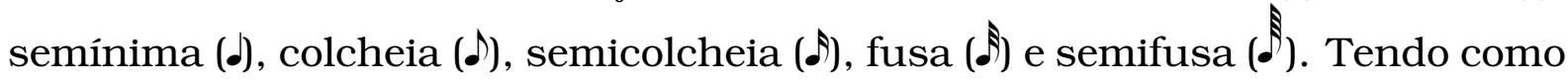
unidade de referência a semibreve, que tem valor de 1 , é formada a seguinte

${ }^{4}$ Outras figuras são breve $(\boxminus)$, com duração igual a duas semibreves; e quartifusa $\left(\bullet^{\circ}\right)$, que equivale à metade de uma semifusa.

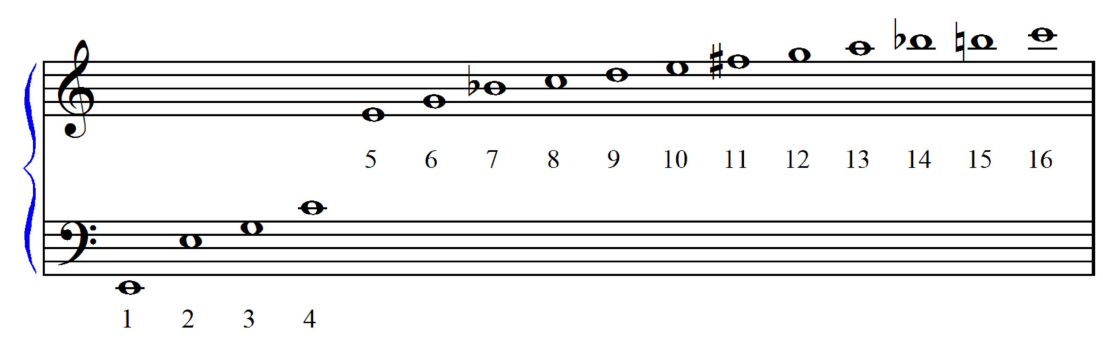

Figura B.2: Série dos harmônicos. 


\begin{tabular}{c||c|c|c|c|c|c|c}
\hline Intervalo & Uníssono & $2^{a}$ menor & $2^{a}$ maior & $3^{a}$ menor & $3^{a}$ maior & $4^{a}$ justa & $4^{a}$ aumentada \\
\hline \hline Semitons & 0 & 1 & 2 & 3 & 4 & 5 & 6 \\
R. freq. & $1: 1$ & $16: 15$ & $9: 8$ & $6: 5$ & $5: 4$ & $4: 3$ & $10: 7$ \\
\hline \hline Intervalo & $5^{a}$ justa & $6^{a}$ menor & $6^{a}$ maior & $7^{a}$ menor & $7^{a}$ maior & Oitava & \\
\hline \hline Semitons & 7 & 8 & 9 & 10 & 11 & 12 & \\
R. freq. & $3: 2$ & $8: 5$ & $5: 3$ & $9: 5$ & $15: 8$ & $2: 1$ & \\
\hline
\end{tabular}

Tabela B.1: Razões de frequência (R. freq.) dos intervalos da serie harmônica.

sequência de durações $1,1 / 2,1 / 4,1 / 8,1 / 16,1 / 32$ e 1/64. Durações diferentes podem ser obtidas com signos de aumentação ou de prolongamento, sendo estes o ponto, a ligadura e a fermata. O ponto de aumento (.) adiciona a metade da duração da figura envolvida, por exemplo: $d .=d+\downarrow$ e $\mathfrak{c}=\xi+y$. Além disso, uma figura pode ter um ou mais pontos de aumentos, onde cada ponto adicional afeta de igual forma a duração da figura de forma acumulativa. A ligadura ( $($ ) é uma linha curva que soma a duração das duas figuras que a limitam, por exemplo $d \cdot=d$. A fermata é um semicírculo $(\curvearrowright$ ) que quando colocado acima ou embaixo de uma figura da licença ao interprete de aumentar a duração segundo o seu critério. Uma peça musical é dividida em pulsos periódicos (batidas) de duração relativa que agrupam figuras rítmicas de menor duração. A figura que preenche a duração de uma batida se chama unidade de tempo e a que preenche a duração de um compasso unidade de compasso (Lacerda, 1966).

Dado que a divisão binária só produz durações potências de dois, para durações de divisões diferentes se deve usar um símbolo adicional, que é um número que quando colocado acima de um conjunto de figuras de igual duração, estas atingem a duração da figura maior mais próxima à duração total das figuras envolvidas, em outras palavras, a duração de cada figura envolvida é igual à duração resultante de dividir a figura maior mais próxima tantas vezes o número que foi escrito. Esta subdivisão se chama quiáltera. As quiálteras mais comuns são: tercina, quintina e sextina, que dividem a figura em três, cinco e seis partes iguais, respectivamente (Lacerda, 1966).

Os eventos silenciosos com duração equivalente à figuras rítmicas são conhecidos como pausas. As pausas obedecem às mesmas regras das figuras rítmicas, mas usam símbolos diferentes. Na Fig. B.3 são mostrados os valores e os símbolos das figuras rítmicas e das pausas. Cabe ressaltar que o símbolo da pausa de semibreve e da mínima, mesmo sendo igual, o primeiro é colocado embaixo de uma linha, enquanto o segundo é disposto acima de uma linha. No pentagrama padrão de cinco linhas a pausa de semibreve é colocada embaixo da $4^{\text {a }}$ linha, enquanto a de mínima sobre a $3^{\text {a }}$ linha (Lacerda, 1966).

A duração de um compasso é definida pela fórmula de compasso, que é uma fração colocada após a clave, onde o numerador indica o número de tempos que ocupa o compasso e o denominador o valor de cada tempo, tendo 
Nome

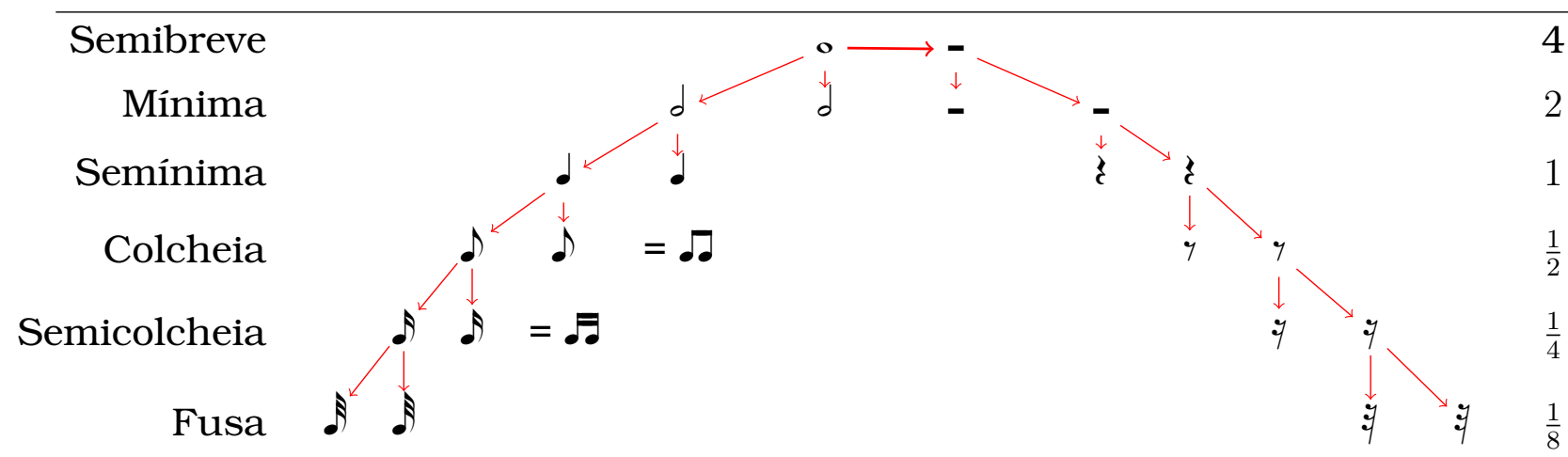

Figura B.3: Nomes, símbolos e valores das figuras rítmicas e das pausas.

como unidade de referência a semibreve (valor 1), por exemplo: ${ }_{4}^{2}, \frac{3}{4}, \frac{4}{4}, \frac{2}{2}, \frac{3}{8}$, 8 ,...etc. As fórmulas de compasso mais comuns são abreviadas mediante uma letra, assim: $\mathbf{c}={ }_{4}^{4}$ e $\mathbf{c}=\frac{2}{2}$.

\section{B.3 Notação de Bateria}

A bateria é um conjunto de instrumentos de percussão de dois tipos: tambores e pratos, que são percutidos por um único músico mediante um par de baquetas. Na Fig. B.4 são mostrados os instrumentos que formam a bateria e na Tabela B.2 o seu respectivo nome, estes são relacionados através do identificador (Id.) da coluna 2. Na quarta coluna é mostrado o número MIDI dos instrumentos de uma bateria padrão (4 pratos, 1 chimbal, 1 caixa, 2 toms, 1 surdo e 1 bumbo), no entanto, também podem ser usados instrumentos adicionais, cujo número MIDI é apresentado na quinta coluna. A notação musical usada para a bateria segue as mesmas regras da notação comum, porém as linhas já não estão mais relacionadas com uma nota musical e sim com um instrumento da bateria que, ademais de ser diferenciado pela posição no pentagrama, também pode ser diferenciado pela forma da cabeça da figura rítmica. Na Fig. B.5 é apresentada a notação musical básica da bateria, onde a notação de cada instrumento está relacionada com o nome, o valor MIDI e a forma física através do identificador (Id.).

Nesta tese os instrumentos são separados em subgrupos segundo a família e a posição dentro do pentagrama musical, conforme mostrado na primeira coluna da Tabela B.2. Está divisão serve para separar as linhas rítmicas que geram os dígrafos. 
Tabela B.2: Instrumentos musicais que compõem a bateria e os seus respectivos nomes e números MIDI.

\begin{tabular}{|c|c|c|c|c|}
\hline \multirow{3}{*}{ Grupo } & \multirow{3}{*}{ Id. } & \multirow{3}{*}{ Nome } & Padrão & Auxiliar \\
\hline & & & 1 & 2 \\
\hline & & & No. MIDI & No. MIDI \\
\hline \multirow{8}{*}{1} & $\overline{\mathrm{A}}$ & Prato de condução & 51 & 59 \\
\hline & B & Prato de condução cúpula & 53 & \\
\hline & $\mathrm{C}$ & Prato de efeito & 55 & \\
\hline & $\mathrm{D}$ & Prato Chinês & 52 & \\
\hline & $\mathrm{E}$ & Prato de ataque & 49 & 57 \\
\hline & $\mathrm{F}$ & Chimbal aberto & 46 & \\
\hline & $\mathrm{G}$ & Chimbal fechado & 42 & \\
\hline & $\overline{\mathrm{H}}^{-}$ & Caixa aro & $\overline{3} \overline{7}$ & \\
\hline \multirow{4}{*}{2} & I & Caixa & 38 & 40 \\
\hline & $\mathrm{J}$ & Tom-tom médio menor & 48 & 50 \\
\hline & $\mathrm{K}$ & Tom-tom médio maior & 47 & 45 \\
\hline & $\mathrm{L}$ & Surdo & 43 & 41 \\
\hline \multirow[t]{2}{*}{3} & $\overline{\mathrm{M}}^{-}$ & Chìmbal pedàl & $\overline{4} \overline{4}$ & \\
\hline & $\mathrm{N}$ & Bumbo & 36 & 35 \\
\hline
\end{tabular}

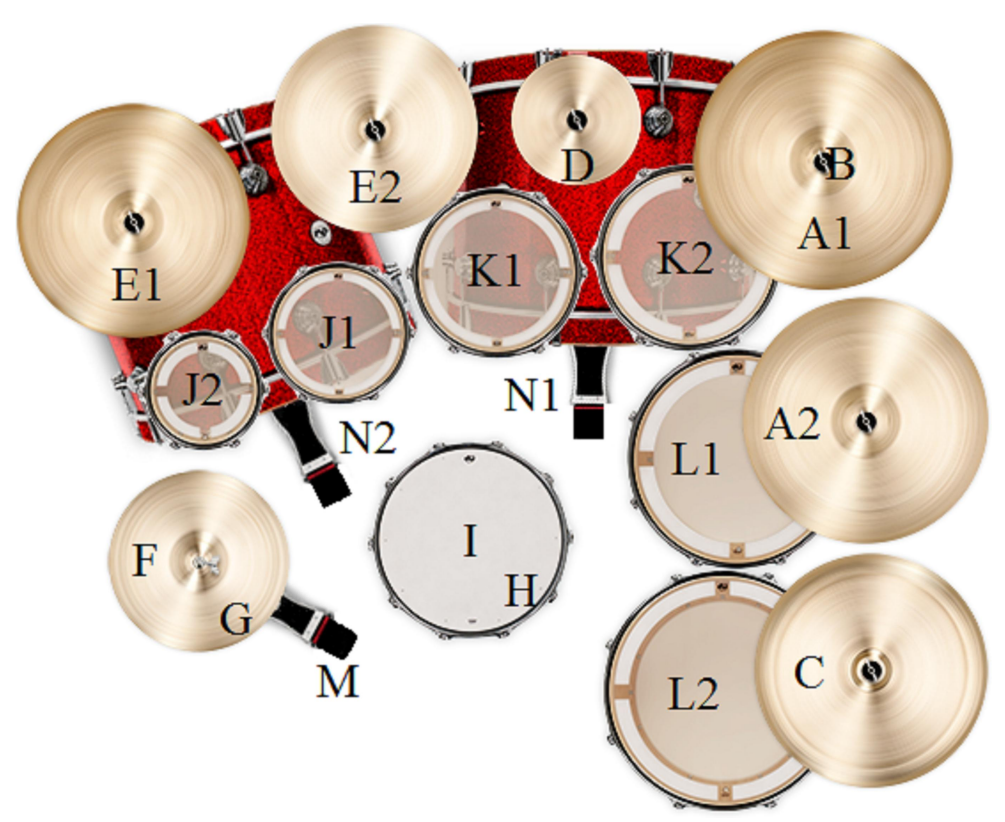

Figura B.4: Instrumentos musicais que compõem a bateria. O identificador (Id.) relaciona o instrumento com o nome e o número MIDI da Tabela B.2.

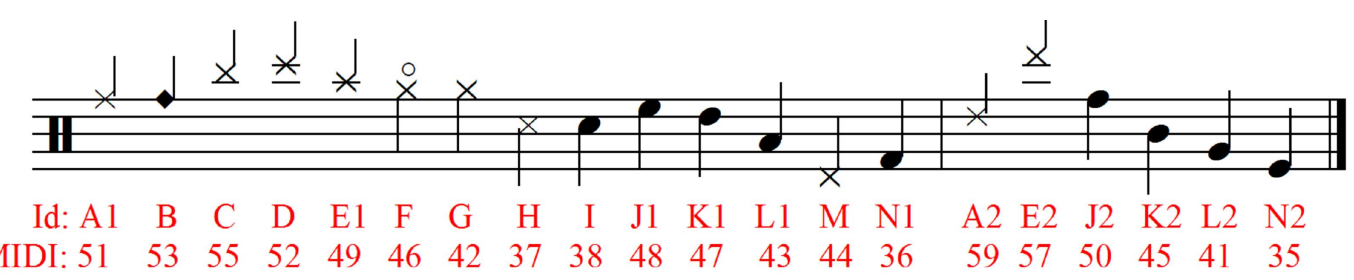

Figura B.5: Notação musical dos instrumentos que compõem a bateria. O identificador (Id.) relaciona a notação do instrumento com o nome e o número MIDI da Tabela B.2 
APÊNDICE

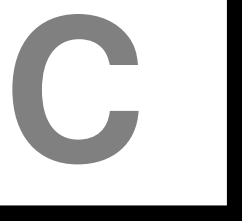

\section{Lista de Amostras do Banco de Dados de Músicas Folclóricas}

Neste apêndice é apresentada a lista das amostras que formam o banco de dados de três gêneros folclóricos da região andina colombiana. Este banco de dados foi usado para testar a funcionalidade da metodologia de identificação de gêneros musicais proposta nesta tese quando aplicada sobre estruturas rítmicas não percussivas. Os gêneros do banco de dados são: pasillo, bambuco e danza; e contém ao todo 180 amostras, sendo 61, 60 e 59 amostras em cada classe, respectivamente. Na seguinte tabela é descrito o nome e o compositor das amostras de cada gênero.

Tabela C.1: Lista de amostras do banco de dados de três gêneros da região andina colombiana: Pasillo, Bambuco e Danza.

Obras musicais - Pasillo

\begin{tabular}{|c|c|c|c|}
\hline 1. & 1. Adolfo Mejía - Pasillo No. 1 Bm & 32. & 32. José A. Morales - Titiribí \\
\hline 2. & 2. Adolfo Mejía - Pasillo No. $2 \mathrm{Cm}$ & 33. & 33. José A. Morales - Tristes alegría \\
\hline 3. & 3. Alberto Castillo - Rondinella & 34. & 34. José A. Morales - Viejo Tiplecito \\
\hline 4. & 4. Aurelio Vásquez Pedreros - No lo creas & 35. & 35. Leonardo Gómez Silva - Lejanías \\
\hline 5. & 5. Carlos Escamilla (el ciego) - Brisas del salto & 36. & 36. Leonardo Gómez Silva - Río de oro \\
\hline 6. & 6. Carlos Escamilla (el ciego) - Colón & 37. & 37. Luis A. Calvo - Arroyito \\
\hline 7. & 7. Carlos Escamilla (el ciego) - El Combeima & 38. & 38. Luis A. Calvo - Emmita \\
\hline 8. & 8. Carlos Escamilla (el ciego) - Huracán & 39. & 39. Luis A. Calvo - Entusiasmo \\
\hline 9 . & 9. Carlos Escamilla (el ciego) - Inspiración & 40. & 40. Luis A. Calvo - La Chata \\
\hline 10. & 10. Carlos Escamilla (el ciego) - Nené & 41. & 41. Luis A. Calvo - Noel \\
\hline 11. & 11. Carlos Escamilla (el ciego) - Refajo & 42. & 42. Luis A. Calvo - Tolimense \\
\hline 12. & 12. Carlos Vieco Ortiz - Adiós casita & 43. & 43. Luis Uribe Bueno - El Cucarrón \\
\hline 13. & 13. Carlos Vieco Ortiz - Atardecer & 44. & 44. Nicolás Torres - Rocío \\
\hline 14. & 14. Carlos Vieco Ortiz - Hacia el calvario & 45. & 45. Pedro Morales Pino - Ausencia \\
\hline 15. & 15. Carlos Vieco Ortiz - Patasdilo & 46. & 46. Pedro Morales Pino - El Calavera \\
\hline 16. & 16. Carlos Vieco Ortiz - Tierra labrantía & 47. & 47. Pedro Morales Pino - El rayo X \\
\hline 17. & 17. Carlos Vieco Ortiz - Violento & 48. & 48. Pedro Morales Pino - Íntimo \\
\hline
\end{tabular}


Obras musicais - Pasillo

\begin{tabular}{|c|c|c|c|}
\hline 18. & 18. Emilio Murillo - Don Quijote & 49. & 49. Pedro Morales Pino - Iris \\
\hline 19. & 19. Fulgencio García - Bohemio & 50. & 50. Pedro Morales Pino - Latigazo \\
\hline 20. & 20. Fulgencio García - Coqueteos & 51. & 51. Pedro Morales Pino - Lejanía \\
\hline 21. & 21. Gustavo Gómez Ardila - Aires de mi tierra & 52. & 52. Pedro Morales Pino - Paulina \\
\hline 22. & 22. Ismael Posada Posada - Ecos del desierto & 53. & 53. Pedro Morales Pino - Pepe \\
\hline 23. & 23. Ismael Posada Posada - El hogar & 54. & 54. Pedro Morales Pino - Pierrot \\
\hline 24. & 24. Jamir Mauricio Moreno E. - Añoranza & 55. & 55. Pedro Morales Pino - Recordando \\
\hline 25. & 25. Jorge Villamil - Me llevaras en ti & 56. & 56. Pedro Morales Pino - Reflejos \\
\hline 26. & 26. José A. Morales - Camino de pozo azul & 57. & 57. Pedro Morales Pino - Rumor \\
\hline 27. & 27. José A. Morales - Don Berna & 58. & 58. Pedro Morales Pino - Saltarín \\
\hline 28. & 28. José A. Morales - Granito de oro & 59. & 59. Pedro Morales Pino - Volutas \\
\hline 29. & 29. José A. Morales - Los gamines de Yolanda & 60. & 60. Ricardo Acevedo Bernal - Sabanero \\
\hline 30. & 30. José A. Morales - Michín & 61. & 61. Sebastián Solari - Río Cali \\
\hline 31. & 31. José A. Morales - Rocas Lindas & & \\
\hline \multicolumn{4}{|c|}{ Obras musicais - Bambuco } \\
\hline 62. & 1. Adolfo Mejía - Bambuco No. 1 & 92. & 31. Gerardo Betancourt - Kata \\
\hline 63. & 2. Adolfo Mejía - Bambuco No. 2 & 93. & 32. Gerardo Betancourt - Liberación Emergente \\
\hline 64. & 3. Alex Pastrana - Mi bambuquito & 94. & 33. Gerardo Betancourt - Marcel \\
\hline 65. & 4. Elias M. Soto - Las brisas del pamplonita & 95. & 34. Gerardo Betancourt - Mi pueblo \\
\hline 66. & 5. Gregorio García F. - El calentano & 96. & 35. Gerardo Betancourt - Notas al viento \\
\hline 67. & 6. Guillermo Calderón - Mi país & 97. & 36. Gerardo Betancourt - Olvido \\
\hline 68. & 7. Anónimo - Palo negro & 98. & 37. Gerardo Betancourt - Suite para clarinete \\
\hline 69. & 8. Antonio M. Valencia - Bambuco en el tiempo del ruido & 99. & 38. Gerardo Betancourt - Tus ojos \\
\hline 70. & 9. Bolivar de Calisto - El muro & 100. & 39. Gerardo Betancourt - Bambuco No.2 \\
\hline 71. & 10. Carlos Escamilla (el ciego) - Año nuevo & 101. & 40. Germán Dario Pérez - Ancestros \\
\hline 72. & 11. Carlos Vieco Ortiz - Brisas de Santa Elena & 102. & 41. Germán Darío Pérez - Minimito \\
\hline 73. & 12. Carlos Vieco Ortiz - Montañero & 103. & 42. Jamir Mauricio Moreno - Bambuqueando \\
\hline 74. & 13. Emilio Murillo - Chipre & 104. & 43. Jorge Camargo Spolidore - Chatica linda \\
\hline 75. & 14. Emilio Murillo - Claveles & 105. & 44. José A. Morales - María Antonia \\
\hline 76. & 15. Emilio Murillo - Coplas del terruño & 106. & 45. José A. Morales - Pior es nada \\
\hline 77. & 16. Emilio Murillo - El guatecano & 107. & 46. José A. Morales - Tese queto \\
\hline 78. & 17. Emilio Murillo - El trapiche & 108. & 47. Leonardo Gómez Silva - Mi tierruca \\
\hline 79. & 18. Emilio Murillo - El vaquero & 109. & 48. Luis A. Calvo - El republicano \\
\hline 80. & 19. Emilio Murillo - El vespertino & 110. & 49. Luis A. Calvo - Ricaurte \\
\hline 81. & 20. Emilio Murillo - Pandereta & 111. & 50. Luis A. Calvo - Yerbecita de mi huerto \\
\hline 82. & 21. Emilio Murillo - Pisahuevos & 112. & 51. Malciades Garavito - San Pedro en el Espinal \\
\hline 83. & 22. Emilio Murillo - Risa triste & 113. & 52. Pedro Morales Pino - Lejos de ti \\
\hline 84. & 23. Emilio Murillo - Rumichaca & 114. & 53. Pedro Morales Pino - Cuatro preguntas \\
\hline 85. & 24. Emilio Sierra - Ontabas & 115. & 55. Pedro Morales Pino - Fusagasugueno \\
\hline 86. & 25. Francisco Cristancho Camargo - Bochica & 116. & 56. Pedro Morales Pino - Nunca mía serás \\
\hline 87. & 26. Francisco Cristancho Camargo - Pa' que me miro & 117. & 57. Pedro Morales Pino - Tierramia \\
\hline 88. & 27. Francisco Cristancho Camargo - Bachue & 118. & 58. Pedro Morales Pino - Trigueña \\
\hline 89. & 28. Fulgencio García - Sobre el humo & 119. & 59. Pedro Morales Pino - Trigueñita \\
\hline 90. & 29. Gerardo Betancourt - Aires de Pericongo & 120. & 60. Pedro Morales Pino - Ya vez \\
\hline 91. & 30. Gerardo Betancourt - Bambuco en mi menor & 121. & 60. Rafael Godoy - Soy Colombiano \\
\hline \multicolumn{4}{|c|}{ Obras musicais - Danza } \\
\hline 122. & 1. Adolfo Mejía - Pincho & 152. & 31. Luis A. Calvo - La presentida \\
\hline 123. & 2. Adolfo Mejía - Trini & 153. & 32. Luis A. Calvo - Livia \\
\hline 124. & 3. Carlos Vieco Ortiz - María Eugenia & 154. & 33. Luis A. Calvo - Madeja de luna \\
\hline 125. & 4. Emilio Murillo - Así es tu amor & 155. & 34. Luis A. Calvo - Malvaloca \\
\hline 126. & 5. Emilio Murillo - Caricias del alma & 156. & 35. Luis A. Calvo - María Elena \\
\hline 127. & 6. Emilio Murillo - Danza apasionada & 157. & 36. Luis A. Calvo - Perla del Ruiz \\
\hline 128. & 7. Emilio Murillo - Danza No. 1 & 158. & 37. Luis A. Calvo - Rubia espiga \\
\hline 129. & 8. Emilio Murillo - Danza No. 2 & 159. & 38. Luis A. Calvo (Arr.) - Cocotero \\
\hline 130. & 9. Emilio Murillo - Fronda Lirios & 160. & 39. Luis A. Calvo y N. Lievano - Pasionata \\
\hline 131. & 10. Emilio Murillo - Fugitiva & 161. & 40. Luis Dueñas Perilla - Negrita \\
\hline 132. & 11. Emilio Murillo - La cabaña & 162. & 41. Oscar Orlando Santafé - Danza bárbara \\
\hline 133. & 12. Emilio Murillo - Matchicha bogotana No. 1 & 163. & 42. Pedro Morales Pino - Andina \\
\hline 134. & 13. Emilio Murillo - Matchicha bogotana No. 2 & 164. & 43. Pedro Morales Pino - Aura \\
\hline 135. & 14. Emilio Murillo - Muchachita linda & 165. & 44. Pedro Morales Pino - Auras del Ruiz \\
\hline 136. & 15. Emilio Murillo - Para ti & 166. & 45. Pedro Morales Pino - Blanca \\
\hline 137. & 16. Emilio Murillo - Quereme & 167. & 46. Pedro Morales Pino - Cautiva \\
\hline 138. & 17. Ismael Posada Posada - Flores negras & 168. & 47. Pedro Morales Pino - Danza No. 5 \\
\hline 139. & 18. Jamir Mauricio Moreno - Mi cabaña & 169. & 48. Pedro Morales Pino - Danza No. 6 \\
\hline 140. & 19. José A. Morales - Bucarelia & 170. & 49. Pedro Morales Pino - Danza No. 7 \\
\hline 141. & 20. José A. Morales - Luz Alba & 171. & 50. Pedro Morales Pino - Encanto de verte \\
\hline 142. & 21. José A. Morales - Marielena & 172. & 51. Pedro Morales Pino - Genta \\
\hline 143. & 22. José A. Morales - Marta la presentida & 173. & 52. Pedro Morales Pino - Lira colombiana \\
\hline 144. & 23. Luis A. Calvo - Adiós a Bogotá & 174. & 53. Pedro Morales Pino - Lola \\
\hline 145. & 24. Luis A. Calvo - Aire de fuera & 175. & 54. Pedro Morales Pino - María Luisa \\
\hline 146. & 25. Luis A. Calvo - Añoranza & 176. & 55. Pedro Morales Pino - Ojos negros \\
\hline 147. & 26. Luis A. Calvo - Betty & 177. & 56. Pedro Morales Pino - Onda fugaz \\
\hline 148. & 27. Luis A. Calvo - Carmiña & 178. & 57. Pedro Morales Pino - Penumbra \\
\hline 149. & 28. Luis A. Calvo - Coralito & 179. & 58. Pedro Morales Pino - Retorno \\
\hline 150. & 29. Luis A. Calvo - Emilia II & 180. & 59. Pedro Morales Pino - Sara \\
\hline 151. & 30. Luis A. Calvo - Gacela & & \\
\hline
\end{tabular}




\section{Referências Bibliográficas}

Abeßer, J., H. Lukashevich, \& P. Bräuer (2012). Classification of music genres based on repetitive basslines. Journal of New Music Research 41(3), 239257.

Abeßer, J., H. Lukashevich, C. Dittmar, P. Bräuer, \& P. Karuse (2010). Rulebased classification of musical genres from a global cultural background. In Proc. International Symposium on Computer Music Modeling and Retrieval (CMMR), pp. 317-336.

Akhtaruzzaman, M., M. Rashid, \& M. Ashrafuzzaman (2008). Mathematical and geometrical analysis and representation of north indian musical rhythms based on multi polygonal model. In Proc. International Conference on Signal Processing Systems (ICSPS), pp. 493-497.

Albert, R. \& A. Barabási (2002). Statistical mechanics of complex networks. Review of Modern Physics 74(1), 47-97.

Albert, R., H. Jeong, \& A. Barabási (1999). Internet: Diameter of the world wide web. Nature 401(6749), 130-131.

Alpaydin, E. (2004). Introduction to machine learning. MIT Press.

Angulo, F. (2004). Análisis de sistemas de control no lineales. Universidade Nacional da Colômbia.

Attakitmongcol, K., R. Chinvetkitvanit, \& S. Sujitjorn (2004). Characterization of traditional thai musical scale. WSEAS Trans. on Acoustics and Music 1, 90-95.

Backesa, A., D. Casanovab, \& O. Martinez (2013). Texture analysis and classification: A complex network-based approach. Information Sciences 219(10), 168-180. 
Barabási, A. \& R. Albert (1999). Emergence in scaling in random networks. Science 286(5439), 509-512.

Bastian, M., S. Heymann, \& M. Jacomy (2009). Gephi: An open source software for exploring and manipulating networks. In Proc. International AAAI Conference on Web and Social Media (ICWSM).

Beatles, T. (1993). The Beatles: Complete Scores-Full Transcriptions From the Original Recordings-Every Song Written \& Recorded By the Beatles (2 ${ }^{\mathrm{a}}$ ed.). Hal Leonard, Wi.

Bickerman, G., S. Bosley, P. Swire, \& R. Keller (2010). Learning to create jazz melodies using deep belief nets. In Proc. International Conference On Computational Creativity (ICCC), pp. 228-237.

Blondel, V., J.-L. Guillaume, R. Lambiotte, \& E. Lefebvre (2008). Fast unfolding of communities in large networks. Journal of Statistical Mechanics, P10008.

Boccaletti, S., V. Latorab, Y. Morenod, M. Chavezf, \& D. Hwanga (2006). Complex networks: Structure and dynamics. Physics Reports 424(4-5), 175-308.

Bornholdt, S. \& H. Schuster (2003). Handbook of graphs and networks: From the genome to the internet. Wiley- $\mathrm{VCH}$.

Brandes, U. \& T. Erlebach (2005). Network Analysis - Methodological Foundations. Springer.

Brown, J. (1993). Determination of the meter of musical scores by autocorrelation. J. Acoustical Society of America 94(4), 1953-1957.

Brusic, V. \& J. Zeleznikow (1999). Knowledge discovery and data mining in biological databases. The Knowledge Engineering Review Archive 14(3), 257277.

Buldúl, J., P. Cano, M. Koppenberger, J. Almendral, \& S. Boccaletti (2007). The complex network of musical tastes. New Journal of Physics 9(172), 115.

Cemgil, A., P. Desain, \& H. Kappen (2000). Rhythm Quantization for Transcription. Computer Music Journal 24(2), 60-76.

Chen, C. \& R. Miikkulainen (2001). Creating melodies with evolving recurrent neural networks. In Proc. Internacional Joint Conference on Neural Networks (IJCNN), pp. 2241-2246. 
Coca, A. (2009). Composición automática de estructuras musicales mediante sistemas dinámicos caóticos y bifurcaciones. Dissertação de mestrado em engenheria - Área automação industrial, Universidade Nacional da Colômbia, Sede Manizales.

Coca, A., D. Corrêa, \& L. Zhao (2013). Computer-aided music composition with LSTM neural network and chaotic inspiration. In Proc. International Joint Conference on Neural Networks (IJCNN), pp. 270-276.

Coca, A., G. Olivar, \& L. Zhao (2009). Controlling chaotic melodies. In Proc. Encuentro Nacional de Investigación en Posgrados (ENIP).

Coca, A., G. Olivar, \& L. Zhao (2010). Characterizing chaotic melodies in automatic music composition. Chaos - An Interdisciplinary Journal 20(3), 033125.

Coca, A., F. Roseli, \& L. Zhao (2011). Generation of composed musical structures through recurrent neural networks based on chaotic inspiration. In Proc. International Joint Conference on Neural Networks (IJCNN), pp. 3220-3226.

Coca, A. \& L. Zhao (2012). Compositor de melodias caóticas. Registro de software. Número do registro: 018120039473. Instituição de registro: INPI - Instituto Nacional da Propriedade Industrial, Brasil.

Coca, A. \& L. Zhao (2014a). Encoding and decoding of musical scales: Application in musical composition with complex networks. Artigo pronto para submissão.

Coca, A. \& L. Zhao (2014b). Musical genre recognition via relevance of communities of complex networks. Artigo submetido para ACM Transactions on Knowledge Discovery from Data.

Coca, A. \& L. Zhao (2014c). Musical rhythmic pattern extraction using relevance of communities in networks. Artigo submetido para Information Sciences.

Coca, A. \& L. Zhao (2014d). Rhythmic pattern extraction by community detection in complex networks. In Proc. The Brazilian Conference on Intelligent Systems (BRACIS), pp. 306-401.

Collier, W. \& T. Hubbard (1994). Musical scales and evaluations of happiness and awkwardness: Effects of pitch, direction, and scale mode. American Journal of psychology 114(3), 335-375.

Conklin, C. (2009). Melody classification using patterns. In Proc. International Workshop on Machine Learning and Music (MML), pp. 37-41. 
Corrêa, D. (2012). Inteligência artificial aplicada à análise de gêneros musicais. Tese de Doutorado, Universidade de São Paulo (USP), Brasil.

Corrêa, D., A. Levada, \& L. Costa (2011). Finding community structure in music genres networks. In Proc. International Society of Music Information Retrieval Conference (ISMIR), pp. 447-452.

Corrêa, D. \& J. Saito (2007). Aplicação de redes neurais para auxílio nas composições musicais utilizando compassos como primitivas e inspiração em relevos naturais. In Proc. Brazilian Symposium on Computer Music (BSCM), pp. 239-242.

Corrêa, D., J. Saito, \& S. Abib (2008). Composing music with BPTT and LSTM networks: Comparing learning and generalization aspects. In Proc. International Conference on Computational Science and Engineering (CSE), pp. 95100 .

Corrêa, D., J. Saito, \& L. Costa (2010). Musical genres: Beating to the rhythms of different drums. New Journal of Physics 12, 053030.

Costa, L., F. Rodrigues, G. Travieso, \& P. Villas (2005). Characterization of complex networks: A survey of measurements. Advances in Physics 56(1), 167-242.

Dabby, D. (1995). Musical variations from a chaotic mapping. Tese de Doutorado, Massachusetts Institute of Technology, Estados Unidos.

Deyi, L., C. Guisheng, \& C. Baohua (2005). Advanced Data Mining and Applications, Volume 3584 of Lecture Notes in Computer Science, Chapter Complex Networks and Networked Data Mining, pp. 10-12.

Duncan, A. (1991). Combinatorial music theory. Journal of the Audio Engineering Society 39(6), 427-448.

Eck, D. (2012). Machine learning and knowledge discovery in databases, Volume 7523 of Lecture Notes in Computer Science, Chapter Machine learning methods for music discovery and recommendation, pp. 4.

Eck, D. \& J. Schmidhuber (2002). Finding temporal structure in music: Blues improvisation with LSTM recurrent networks. In Proc. IEEE Workshop, Networks for Signal Processing XII, pp. 747-756.

Eerola, A. (2000). Expectancy-based model of melodic complexity. In Proc. International Conference on Music Perception and Cognition (ICMPC).

Eerola, T. \& P. Toiviainen (2004). MIDI Toolbox: MATLAB Tools for Music Research. Jyväskylä, Finland: University of Jyväskylä. 
Erdős, P. \& A. Rényi (1959). On random graphs I. Publicationes Mathematicae Debrecen 6, 290-297.

Euler, L. (1739). Tentamen Novae Theoriae Musicae Ex Certissismis Harmoniae Principiis Dilucide Expositae. Saint Petersburg Academy.

Fagiolo, G. (2007). Clustering in complex directed networks. Physical Review E 76(2), 026107.

Faloutsos, M., P. Faloutsos, \& C. Faloutsos (1999). On power-law relationship of the internet topology. ACM SIGCOMM 29, 251-260.

Fawcett, T. (2006). An introduction to ROC analysis. Pattern Recognition Letters 27(8), 861-874.

Forte, A. (1997). The Structure of Atonal Music. Yale University Press.

Fortunato, S. (2010). Community detection in graphs. Physics Reports 486(35), 75-174.

Franklin, J. (2006). Recurrent neural networks for music computation. Journal on Computing 18(3), 321-338.

Fripertinger, H. (1999). Enumeration and construction in music theory. In Proc. Diderot Forum on Mathematics and Music, pp. 179-204.

Galván, I. (2004). Redes de Neuronas Artificiales Un Enfoque Práctico. Pearsons.

Gardner, R. (1990). 20th-Century Microtonal Notation: Contributions to the Study of Music and Dance. Praeger.

Garlaschelli, D. \& M. Loffredo (2004). Patterns of link reciprocity in directed networks. Physical Review Letters 93, 268701.

Gers, F. (2001). Long Short-Term Memory in Recurrent Neural Networks. Tese de Doutorado, École Polytechnique Fédérale de Lausanne EPFL, Suíça.

Gill, K. \& D. Purves (2009). A biological rationale for musical scales. Plos One 4(12), e8144.

Goldberg, K., M. Newman, \& E. Haynsworth (1972). Handbook of Mathematical Functions with Formulas, Graphs, and Mathematical Tables, Chapter The Euler Totient Function, pp. 826. Dover publications.

Good, P. (2006). Resampling Methods - A Practical Guide to Data Analysis (3 ${ }^{\text {a }}$ ed.). Birkhäuser. 
Guimerà, R. \& L. Amaral (2005). Functional cartography of complex metabolic networks. Nature 433(7028), 895-900.

Hand, D. \& K. Yu (2001). Idiot's Bayes - not so stupid after all? International Statistical Review 69(3), 385-399.

Hastie, T., R. Tibshirani, \& J. Friedman (2009). The Elements of Statistical Learning: Data Mining, Inference, and Prediction ( $2^{\mathrm{a}}$ ed.). Springer.

Hatonen, K., M. Klemettinen, H. Mannila, P. Ronkainen, \& H. Toivonen (1996). Knowledge discovery from telecommunication network alarm databases. In Proc. International Conference on Data Engineering (ICDE), pp. 115-122.

Haykin, S. (1999). Neural Networks A Comprehensive Foundation. Springer.

Hochreiter, S., Y. Bengio, P. Frasconi, \& J. Schmidhuber (2001). A Field Guide to Dynamical Recurrent Neural Networks, Chapter Gradient flow in recurrent nets: The difficulty of learning long-term dependencies. IEEE Press.

Hofmann-Engl, L. (2003). Atomic notation and melodic similarity. Proc. Computer Music Modelling and Retrieval (CMMR).

Hofmann-Engl, L. (2005). An evaluation of melodic similarity models. Chameleon group online publication.

Hogg, R. \& A. Craig (1978). Introduction to Mathematical Statistics (4th ed.). Macmillan.

Hoover, A. \& K. Stanley (2009). Exploiting functional relationships in musical composition. Connection Science Special Issue on Music, Brain and Cognition 21(2), 227-251.

Hsu, J.-Y. (2009). Transnational ethnic networks. International Encyclopedia of Human Geography, 383-387.

Ibarra, H. (2001). Social networks and gender. International Encyclopedia of the Social and Behavioral Sciences, 14384-14388.

Itzkovitz, S., N. Kashtan, R. Levitt, et al. (2006). Recurring harmonic walks and network motifs in western music. Advances in Complex Systems 9(1-2), 121-132.

Jain, A., M. Murty, \& P. Flynn (1999). Data clustering: A review. ACM Computing Surveys 31(3), 264-323.

Jain, A. \& D. Zongker (1997). Feature selection: Evaluation, application, and small sample performance. IEEE Transactions on Pattern Analysis and Machine Intelligence 19, 153-158. 
Karydis, I., A. Nanopoulos, \& Y. Manolopoulos (2006). Symbolic musical genre classification based on repeating patterns. In Proc. ACM Workshop on Audio and Music Computing Multimedia (AMCMM), pp. 53-58.

Keith, M. (1991). Combinatorial Music Theory: Adventures in Musical Combinatorics. Vinculum Pr.

Kim, B. \& W. Yeo (2013). Probabilistic prediction of rhythmic characteristics in markov chain-based melodic sequences. In Proc. International Computer Music Conference (ICMC).

Kim, H. \& J. Kim (2005). Cyclic topology in complex networks. Physical Review E 72(3), 036109.

Kotsifakos, A., E. Kotsifakos, P. Papapetrou, \& V. Athitsos (2013). Genre classification of symbolic music with SMBGT. In Proc. International Conference on PErvasive Technologies Related to Assistive Environments (PETRA), Number 44 , pp. 1-44.

Lacerda, O. (1966). Compendio de teoria elementar da música (3ª ed.). Ricordi Brasileira.

Landis, J. \& G. Koch (1977). The measurement of observer agreement for categorical data. Biometrics 33(1), 159-174.

Levitin, D., P. Chordia, \& V. Menon (2012). Musical rhythm spectra from Bach to Joplin obey a 1/f power law. In Proc. National Academy of Sciences (NAS), Volume 109, pp. 3716-3720.

Lewis, J. (1991). Music and Connectionism, Chapter Creation by Refinement and the Problem of Algorithmic Music Composition, pp. 212-228. MIT Press.

Lima, D., M. Medeiros, M. Henriques, et al. (2004). The complex network of the brazilian popular music. Physica A 332, 559-565.

Lin, C., N. Liu, Y. Wu, \& A. Chen (2004). Database systems for advanced applications, Volume 2973 of Lecture Notes in Computer Science, Chapter Music classification using significant repeating patterns, pp. 506-518. Springer.

Liu, X., C. Tse, \& M. Small (2009). Composing music with complex networks. In Proc. International Conference on Complex Sciences: Theory and Applications (COMPLEX), pp. 2196-2205.

Liu, X., C. Tse, \& M. Small (2010). Complex network structure of musical compositions: Algorithmic generation of appealing music. Physica A 389(1), 126-132. 
Liu, Y. \& G. Toussaint (2012). Mathematical notation, representation, and visualization of musical rhythm: A comparative perspective. International Journal of Machine Learning and Computing 2(3), 261-265.

Lucy, C. (1994). Pitch, Pi, and Other Musical Paradoxes: A Practical Guide To Natural Microtonality. Lucy Scale Developments.

Makhtar, M., D. Neagu, \& M. Ridley (2011). Intelligent Data Engineering and Automated Learning - IDEAL, Volume 6936, Chapter Comparing Multi-class Classifiers: On the Similarity of Confusion Matrices for Predictive Toxicology Applications, pp. 252-261. Springer.

Markovica, D. \& C. Grosa (2014). Power laws and self-organized criticality in theory and nature. Physics Reports 536(2), 41-74.

McCormack, J., P. Mcllwain, A. Lane, \& A. Dorin (2007). Generative composition with nodal. In Proc. Workshop on Music and Artificial Life (part of ECAL), pp. 1-13.

McDaid, A., D. Greene, \& N. Hurley (2011). Normalized Mutual Information to evaluate overlapping community finding algorithms. CoRR abs/1110.2515.

McKay, C., J. Burgoyne, J. Hockman, J. Smith, G. Vigliensoni, \& I. Fujinaga (2010). Evaluating the genre classification performance of lyrical features relative to audio, symbolic and cultural features. In Proc. International Society for Music Information Retrieval Conference (ISMIR), pp. 213-218.

Metz, J., R. Calvo, E., M. Seno, R. Romero, \& L. Zhao (2007). Redes complexas: Conceitos e aplicações. Reporte técnico, Instituto de Ciências Matemáticas e de Computação ICMC, Universidade de São Paulo (USP), Brasil.

Mitchell, T. (1997). Machine Learning (1 ${ }^{\mathrm{a}}$ ed.). McGraw-Hill.

Montoya, J. \& R. Solé (2002). Small world patterns in food webs. Journal of Theoretical Biololgy 214(3), 405-412.

Morales, G. (1983). Compendio general de folklore colombiano (4⿳亠丷⿵冂丶 ed.), Volume 112. Fondo de Promoción de la Cultura del Banco Popular.

Mozer, M. (1994). Neural network music composition by prediction: Exploring the benefits of psychoacoustic constraints and multiscale processing. Connection Science 6(2-3), 247-280.

Murray, G., G. Carenini, \& R. Ng (2012). Using the omega index for evaluating abstractive community detection. In Proc. Workshop on Evaluation Metrics and System Comparison for Automatic Summarization, pp. 10-18. 
Newman, M. (2003a). Fast algorithm for detecting community structure in networks. Physical Review E 69, 066133.

Newman, M. (2003b). The structure and function of complex networks. SIAM Review 45(2), 167-256.

Newman, M. (2006). Modularity and communty structure in networks. Proceedings of the National Academy of Sciences 103(23), 8577-8582.

Newman, M. \& M. Girvan (2004). Finding and evaluating community structure in networks. Physical Review E 69(2), 026113.

Oliwa, T. \& M. Wagner (2008). Composing music with neural networks and probabilistic finite-state machines. In Proc. EvoWorkshops, Volume 4974 of Lecture Notes in Computer Science, pp. 503-508.

Pearlmutter, B. (1995). Gradient calculations for dynamic recurrent neural networks: A survey. IEEE Transactions on Neural Network 6(5), 1212-1228.

Peeters, G. (2005). Rhythm classification using spectral rhythm patterns. In Proc. International Society of Music Information Retrieval Conference (ISMIR), pp. 644-647.

Psorakis, I., S. Roberts, \& M. Ebden (2011). Overlapping community detection using Bayesian Nonnegative Matrix Factorization. Physical Review E 83(6), 066114.

Qian, L., L. Lie, C. Weare, \& F. Seide (2010). Music rhythm characterization with application to workout-mix generation. In Proc. IEEE International Conference on Acoustics Speech and Signal Processing (ICASSP), pp. 69-72.

Rás, Z. \& A. Wieczorkowska (Eds.) (2010). Advances in music information retrieval advances in music information retrieval, Volume 274 of Studies in Computational Intelligence. Springer.

Read, R. (1997). Combinatorial problems in the theory of music. Discrete Mathematics 167/168, 543-551.

Ritter, T., I. Wilkinsonb, \& W. Johnstonc (2004). Managing in complex business networks. Industrial Marketing Management 33(3), 175-183.

Roddick, F. J. \& P. Fule (2003). Exploratory medical knowledge discovery: Experiences and issues. SIGKDD Exploration 5, 94-99.

Rubinov, M. \& O. Sporns (2010). Complex network measures of brain connectivity: Uses and interpretations. NeuroImage 52(3), 1059-1069. 
Ruskey, F. (2003). Combinatorial Generation. University of Victoria.

Ruskey, F. \& J. Sawada (1999). An efficient algorithm for generating necklaces with fixed density. SIAM J. Computing 29(2), 671-684.

Santos, J. \& M. Embrechts (2009). Artificial Neural Networks - ICANN 2, Lecture Notes in Computer Science, Volume 5769, Chapter On the Use of the Adjusted Rand Index as a Metric for Evaluating Supervised Classification, pp. 175-184. Springer.

Schaffrath, H. (1995). The Essen folksong collection in kern format [computer database]. CA: Center for Computer Assisted Research in the Humanities.

Schuller, T. \& H. Theisens (2010). International Encyclopedia of Education, Chapter Networks and communities of knowledge, pp. 100-105. Elsevier.

Scott, J. (2000). Social network analysis: A handbook (2ª ed.). Sage.

Sethares, W. (2007). Rhythm and transforms. Springer.

Simonton, D. (1984). Melodic structure and note transition probabilities: A content analysis of 15618 classical themes. Psychology of Music 12, 3-16.

Simsekli, U. (2010). Automatic music genre classification using bass lines. In Proc. International Conference on Pattern Recognition (ICPR), pp. 4137-4140.

Sporns, O. (2002). Network analysis, complexity, and brain function. Complexity 8(1), 56-60.

Squartini, T., F. Picciolo, F. Ruzzenenti, \& D. Garlaschelli (2012). Reciprocity of weighted networks. CoRR abs/1208.4208.

Strogatz, S. (1994). Nonlinear Dynamics And Chaos: With Applications To Physics, Biology, Chemistry, And Engineering (Studies in Nonlinearity) (2 $2^{\underline{a}}$ ed.). Westview Press.

Strogatz, S. (2001). Exploring complex networks. Nature 410(6825), 268-276.

Sturm, B. (2012). A survey of evaluation in music genre recognition. In Proc. International Workshop on Adaptive Multimedia Retrieval (AMR), pp. 1-41.

Tabak, B., M. Takami, J. Rocha, \& D. Cajueiro (2011). Directed clustering coefficient as a measure of systemic risk in complex banking networks. Working Papers Series 249, Central Bank of Brazil, Research Department.

Teitelbaum, T., P. Balenzuela, P. Cano, \& J. Buldú (2008). Community structures and role detection in music networks. Chaos 043105, 1-7. 
Todd, P. (1989). A connectionist approach to algorithmic composition. Computer Music Journal 13(4), 173-194.

Tzanetakis, G. \& P. Cook (2002). Musical genre classification of audio signals. IEEE Transactions on speech and audio processing 10(5), 293-302.

Vasco, M. (2007). Combinatória de sons. Dissertação de mestrado, Universidade do Porto.

Verbeurgt, K., M. Fayer, \& M. Dinolfo (2004). A hybrid neural-markov approach for learning to compose music by example. In Proc. Canadian Conference on AI, Volume 3060 of Lecture Notes in Computer Science, pp. 480-484.

Vinh, N., J. E, \& J. Bailey (2010). Information theoretic measures for clusterings comparison: Variants, properties, normalization and correction for chance. Journal of Machine Learning Research 11, 2837-2854.

Völkel, T., J. Abeßer, C. Dittmar, \& H. Großmann (2010). Automatic genre classification of latin music using characteristic rhythmic patterns. In Proc. Audio Mostly Conference: A Conference on Interaction with Sound, pp. 1-16.

Wang, N. \& D. Wei (2014). From view of complex network: Fractal dimension of music notation. In Proc. Control and Decision Conference (CCDC), pp. 36473650.

Wasserman, S. \& F. Katherine (1994). Social Network Analysis: Methods and Applications. Cambridge University Press.

Watts, D. \& S. Strogatz (1998). Collective dynamics of small-world networks. Nature (393), 440-442.

Wiggins, S. (2003). Introduction to applied nonlinear dynamical systems and chaos (2 $2^{\mathrm{a}}$ ed.). Springer-Verlag.

Wormald, N. (1999). Models of random regular graphs. Surveys in Combinatorics 267, 239-298.

Xie, J., S. Kelley, \& B. Szymanski (2013). Overlapping community detection in networks: The state of the art and comparative study. ACM Computing Surveys 45(4), 43:1-35.

Yang, C., C. Tse, \& X. Liu (2009). Analyzing and composing music from motifs. In Proc. International Symposium on Nonlinear Theory and Its Applications (NOLTA), pp. 1-4.

Zanin, M., D. Papo, J. González, et al. (2013). Knowledge discovery in spectral data by means of complex networks. Metabolites 3(1), 155-167. 